\title{
Cochrane
}

Cochrane Database of Systematic Reviews

\section{School feeding for improving the physical and psychosocial health of disadvantaged students (Review)}

Kristjansson B, Petticrew M, MacDonald B, Krasevec J, Janzen L, Greenhalgh T, Wells GA, MacGowan J, Farmer AP, Shea B, Mayhew A, Tugwell P, Welch V

Kristjansson B, Petticrew M, MacDonald B, Krasevec J, Janzen L, Greenhalgh T, Wells GA, MacGowan J, Farmer AP, Shea B, Mayhew A, Tugwell P, Welch V.

School feeding for improving the physical and psychosocial health of disadvantaged students.

Cochrane Database of Systematic Reviews 2007, Issue 1. Art. No.: CD004676.

DOI: 10.1002/14651858.CD004676.pub2.

www.cochranelibrary.com 
TABLE OF CONTENTS

HEADER . . . . . . . . . . . . . . . . . . . . . . . . . . . . . . . . . . . . . . . . . . . . . . . . . . . . . .

ABSTRACT . . . . . . . . . . . . . . . . . . . . . . . . . . . . . . . . . . . . . . . . . . . . . . . . . . . .

PLAIN LANGUAGE SUMMARY . . . . . . . . . . . . . . . . . . . . . . . . . . . . . . . . . . . . . . . . . . .

BACKGROUND . . . . . . . . . . . . . . . . . . . . . . . . . . . . . . . . . . . . . 2

OBJECTIVES . . . . . . . . . . . . . . . . . . . . . . . . . . . . . . . . . . . . . . . . . . . . . . . . . . . . .

METHODS . . . . . . . . . . . . . . . . . . . . . . . . . . . . . . . . . . . . . . . . . . . .

RESULTS . . . . . . . . . . . . . . . . . . . . . . . . . . . . . . . . . . . . . . . . . . . . . . . . . .

DISCUSSION . . . . . . . . . . . . . . . . . . . . . . . . . . . . . . . . . . . . . . . . . . . . . . . . . .

AUTHORS' CONCLUSIONS . . . . . . . . . . . . . . . . . . . . . . . . . . . . . . . . . . . . . . . .

ACKNOWLEDGEMENTS . . . . . . . . . . . . . . . . . . . . . . . . . . . . . . . . . . . . . . . . . . . . . .

REFERENCES . . . . . . . . . . . . . . . . . . . . . . . . . . . . . . . . . . . . . . . . . . . . . .

CHARACTERISTICS OF STUDIES . . . . . . . . . . . . . . . . . . . . . . . . . . . . . . . . . . . . . . . .

DATA AND ANALYSES . . . . . . . . . . . . . . . . . . . . . . . . . . . . . . . . . . . . . . . . . 62

Analysis 1.1. Comparison 1 Developing country: School meal vs control. RCT, Outcome 1 Weight gain kg. . . . 67

Analysis 1.2. Comparison 1 Developing country: School meal vs control. RCT, Outcome 2 Height gain (cm). . . . . 68

Analysis 1.3. Comparison 1 Developing country: School meal vs control. RCT, Outcome 3 Weight for age: z-scores. 68

Analysis 1.4. Comparison 1 Developing country: School meal vs control. RCT, Outcome 4 Height for age: z-scores. 69

Analysis 1.14. Comparison 1 Developing country: School meal vs control. RCT, Outcome 14 MUAC. . . . . . 69

Analysis 1.21. Comparison 1 Developing country: School meal vs control. RCT, Outcome 21 Mid-upper arm muscle area. . . . . . . . . . . . . . . . . . . . . . . . . . . . . . . . . . . . 70

Analysis 1.22. Comparison 1 Developing country: School meal vs control. RCT, Outcome 22 Mid upper arm fat area. 70

Analysis 1.23. Comparison 1 Developing country: School meal vs control. RCT, Outcome 23 weight for height gain. 71

Analysis 2.1. Comparison 2 Developing country RCT: Subgroup analysis: meals vs control, Outcome 1 Undernourished vs adequately nourished: Weight gain in $\mathrm{kg}$. . . . . . . . . . . . . . . . . . . . . . . . . 71

Analysis 2.2. Comparison 2 Developing country RCT: Subgroup analysis: meals vs control, Outcome 2 Undernourished versus adequately nourished, height in $\mathrm{cm}$.

Analysis 2.3. Comparison 2 Developing country RCT: Subgroup analysis: meals vs control, Outcome 3 Age subgroup analysis: weight gain in $\mathrm{kg}$.

Analysis 2.4. Comparison 2 Developing country RCT: Subgroup analysis: meals vs control, Outcome 4 Age subgroup analysis: height gain $(\mathrm{cm})$.

Analysis 3.1. Comparison 3 Developing country: School meal vs control. CBA, Outcome 1 Weight gain kg-adjusted ICC 0.025 .

Analysis 3.2. Comparison 3 Developing country: School meal vs control. CBA, Outcome 2 Math change overall icc .15.

Analysis 3.3. Comparison 3 Developing country: School meal vs control. CBA, Outcome 3 Math change by nutritional status, icc 0.15 .

Analysis 3.5. Comparison 3 Developing country: School meal vs control. CBA, Outcome 5 Height gain (cm)- adjusted ICC $=0.016$.

Analysis 3.9. Comparison 3 Developing country: School meal vs control. CBA, Outcome 9 subgroup analysis weight by sex.

Analysis 3.10. Comparison 3 Developing country: School meal vs control. CBA, Outcome 10 Subgroup analysis: height by sex. . . . . . . . . . . . . . . . . . . . . . . . . . . . . . . . . . . . . .

Analysis 3.11. Comparison 3 Developing country: School meal vs control. CBA, Outcome 11 Subgroup by age: weight gain in $\mathrm{kg}$ - Agarwal adjusted.

Analysis 3.12. Comparison 3 Developing country: School meal vs control. CBA, Outcome 12 Subgroup by age: height gain in $\mathrm{cm}$ - Agarwal adjusted.

Analysis 3.13. Comparison 3 Developing country: School meal vs control. CBA, Outcome 13 Full scale IQ (total): adjusted-ICC 0.15. . . . . . . . . . . . . . . . . . . . . . . . . . . . . . . . . . . . . . . . . . .

Analysis 3.21. Comparison 3 Developing country: School meal vs control. CBA, Outcome 21 Full scale IQ (separated): cluster size as in analysis: icc $=.15$.

Analysis 3.24. Comparison 3 Developing country: School meal vs control. CBA, Outcome 24 Performance IQ (separated): numbers as in analysis: ICC $=0.15$. 
Analysis 3.26. Comparison 3 Developing country: School meal vs control. CBA, Outcome 26 Performance IQ (total): adjusted-ICC 0.15 . . . . . . . . . . . . . . . . . . . . . . . . . . . . . . . . .

Analysis 3.28. Comparison 3 Developing country: School meal vs control. CBA, Outcome 28 Verbal IQ (separated): cluster size as in analysis: $\mathrm{ICC}=0.15$.

Analysis 3.29. Comparison 3 Developing country: School meal vs control. CBA, Outcome 29 Verbal IQ (total): adjustedICC 0.15 .

Analysis 3.36. Comparison 3 Developing country: School meal vs control. CBA, Outcome 36 Percent weight for age: ICC= .025 .

Analysis 3.40. Comparison 3 Developing country: School meal vs control. CBA, Outcome 40 Percent height for age: ICC= 0.016 .

Analysis 3.44. Comparison 3 Developing country: School meal vs control. CBA, Outcome 44 Change in reading: ICC= .15 .

Analysis 3.47. Comparison 3 Developing country: School meal vs control. CBA, Outcome 47 change in spelling: ICC= .15 .

Analysis 3.56. Comparison 3 Developing country: School meal vs control. CBA, Outcome 56 change in attendance: icc $=$ .15 .

Analysis 3.57. Comparison 3 Developing country: School meal vs control. CBA, Outcome 57 End of study: attendance: icc $=.15$.

Analysis 4.2. Comparison 4 developed country: school meal versus control: CBA, Outcome 2 Weight gain: Corry-Mann alone.

Analysis 4.7. Comparison 4 developed country: school meal versus control: CBA, Outcome 7 Height gain in cm. adjusted ICC $=0.016$.

Analysis 5.1. Comparison 5 Developed country: School meal vs control RCT, Outcome 1 change in height.

Analysis 5.2. Comparison 5 Developed country: School meal vs control RCT, Outcome 2 Subgroup analysis: height by sex.

Analysis 5.3. Comparison 5 Developed country: School meal vs control RCT, Outcome 3 change in weight $(\mathrm{kg})$.

Analysis 5.4. Comparison 5 Developed country: School meal vs control RCT, Outcome 4 Subgroup analysis: weight by sex. . . . . . . . . . . . . . . . . . . . . . . . . . . . . . . . . .

Analysis 10.5. Comparison 10 Developing country: School meal vs control. RCT- Sensitivity, Outcome 5 Weight gain kgsensitivity ICC 0.01 .

Analysis 10.6. Comparison 10 Developing country: School meal vs control. RCT- Sensitivity, Outcome 6 Weight gain kgsensitivity ICC 0.05 .

Analysis 10.7. Comparison 10 Developing country: School meal vs control. RCT- Sensitivity, Outcome 7 Weight gain kg-

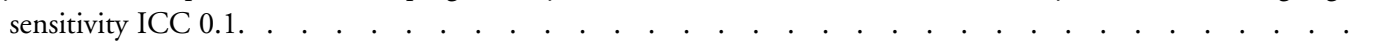

Analysis 10.9. Comparison 10 Developing country: School meal vs control. RCT- Sensitivity, Outcome 9 Height gain $(\mathrm{cm})$, sensitivity ICC 0.01 .

Analysis 10.10. Comparison 10 Developing country: School meal vs control. RCT- Sensitivity, Outcome 10 Height gain $(\mathrm{cm})$, sensitivity ICC 0.05 .

Analysis 10.11. Comparison 10 Developing country: School meal vs control. RCT- Sensitivity, Outcome 11 Height gain $(\mathrm{cm})$, sensitivity ICC 0.1 .

Analysis 11.1. Comparison 11 Developing country: School meal vs control. CBA - Sensitivity, Outcome 1 Math change overall icc.1.

Analysis 11.2. Comparison 11 Developing country: School meal vs control. CBA - Sensitivity, Outcome 2 Weight gain kgsensitivity ICC 0.01 .

Analysis 11.3. Comparison 11 Developing country: School meal vs control. CBA - Sensitivity, Outcome 3 Weight gain kg-

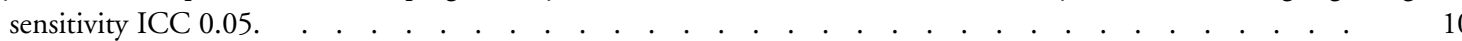

Analysis 11.4. Comparison 11 Developing country: School meal vs control. CBA - Sensitivity, Outcome 4 Weight gain kg-

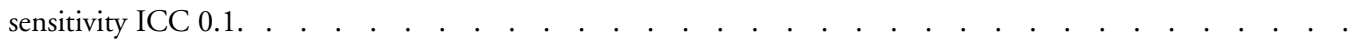

Analysis 11.5. Comparison 11 Developing country: School meal vs control. CBA - Sensitivity, Outcome 5 Math change overall icc .2. . . . . . . . . . . . . . . . . . . . . . . . . . . . . . . . . . . .

Analysis 11.6. Comparison 11 Developing country: School meal vs control. CBA - Sensitivity, Outcome 6 Height gain (cm)- sensitivity ICC 0.01 . 
Analysis 11.7. Comparison 11 Developing country: School meal vs control. CBA - Sensitivity, Outcome 7 Height gain (cm)- sensitivity ICC 0.05 .

Analysis 11.8. Comparison 11 Developing country: School meal vs control. CBA - Sensitivity, Outcome 8 Height gain

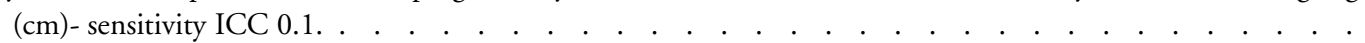

Analysis 11.11. Comparison 11 Developing country: School meal vs control. CBA - Sensitivity, Outcome 11 Percent height for age: icc $=0.05$

Analysis 11.12. Comparison 11 Developing country: School meal vs control. CBA - Sensitivity, Outcome 12 Percent height

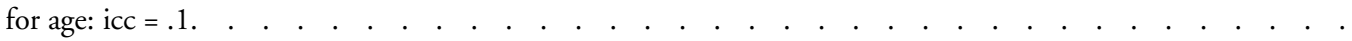

Analysis 11.14. Comparison 11 Developing country: School meal vs control. CBA - Sensitivity, Outcome 14 Full scale IQ (total)- sensitivity 0.1 . . . . . . . . . . . . . . . . . . . . . . . . . . . . . . . . . . . . . . . . . . . . . . . 108

Analysis 11.16. Comparison 11 Developing country: School meal vs control. CBA - Sensitivity, Outcome 16 Math (change) by nutritional status: cluster size as in analysis Sensitivity ICC=0.2 . . . . . . . . . . . . . . . . . . . 108

Analysis 11.17. Comparison 11 Developing country: School meal vs control. CBA - Sensitivity, Outcome 17 Math (change) by nutritional status: cluster size as in analysis Sensitivity ICC=0.1. . . . . . . . . . . . . . . . . . .

Analysis 11.18. Comparison 11 Developing country: School meal vs control. CBA - Sensitivity, Outcome 18 Full scale IQ (total)- sensitivity 0.20 .

Analysis 11.20. Comparison 11 Developing country: School meal vs control. CBA - Sensitivity, Outcome 20 Full scale IQ (end study): sensitivity cluster size as in analysis ICC $=0.1$.

Analysis 11.22. Comparison 11 Developing country: School meal vs control. CBA - Sensitivity, Outcome 22 Full scale IQ (end study): sensitivity cluster size as in analysis: ICC $=0.2$.

Analysis 11.23. Comparison 11 Developing country: School meal vs control. CBA - Sensitivity, Outcome 23 Performance

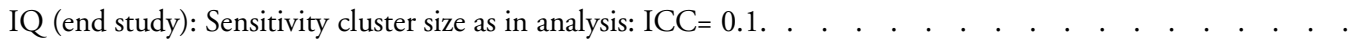

Analysis 11.25. Comparison 11 Developing country: School meal vs control. CBA - Sensitivity, Outcome 25 Performance

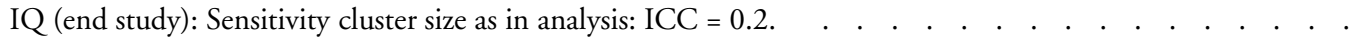

Analysis 11.27. Comparison 11 Developing country: School meal vs control. CBA - Sensitivity, Outcome 27 Verbal IQ (end study): Sensitivity cluster size as in analyses: $\mathrm{ICC}=0.1$. $\quad . \quad$. . . . . . . . . . . . . . . . . . . . . .

Analysis 11.29. Comparison 11 Developing country: School meal vs control. CBA - Sensitivity, Outcome 29 Verbal IQ

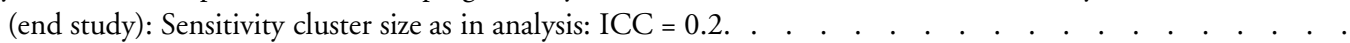

Analysis 11.30. Comparison 11 Developing country: School meal vs control. CBA - Sensitivity, Outcome 30 Percentage standard weight. Sensitivity $=0.01$.

Analysis 11.32. Comparison 11 Developing country: School meal vs control. CBA - Sensitivity, Outcome 32 Percent weight for age: Sensitivity ICC $=0.05$.

Analysis 11.33. Comparison 11 Developing country: School meal vs control. CBA - Sensitivity, Outcome 33 Percent weight for age: Sensitivity ICC $=0.1$.

Analysis 11.36. Comparison 11 Developing country: School meal vs control. CBA - Sensitivity, Outcome 36 Verbal IQ (total): sensitivity-0.10. . . . . . . . . . . . . . . . . . . . . . . . . . . . . . . . . . . . . .

Analysis 11.37. Comparison 11 Developing country: School meal vs control. CBA - Sensitivity, Outcome 37 Verbal IQ (total): sensitivity-0.20.

Analysis 11.38. Comparison 11 Developing country: School meal vs control. CBA - Sensitivity, Outcome 38 Performance IQ (total): sensitivity-0.10.

Analysis 11.39. Comparison 11 Developing country: School meal vs control. CBA - Sensitivity, Outcome 39 Percentage standard height. Sensitivity $=.01$.

Analysis 11.41. Comparison 11 Developing country: School meal vs control. CBA - Sensitivity, Outcome 41 Performance IQ (total): sensitivity-0.20. . . . . . . . . . . . . . . . . . . . . . . . . . . . . . . . . . . . .

Analysis 11.45. Comparison 11 Developing country: School meal vs control. CBA - Sensitivity, Outcome 45 change in

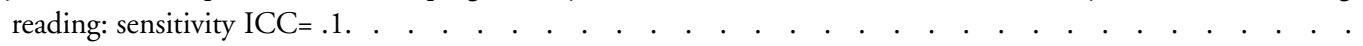

Analysis 11.46. Comparison 11 Developing country: School meal vs control. CBA - Sensitivity, Outcome 46 change in

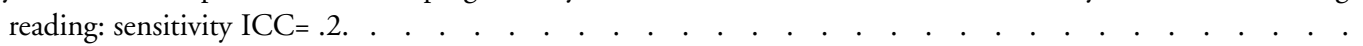

Analysis 11.50. Comparison 11 Developing country: School meal vs control. CBA - Sensitivity, Outcome 50 change in

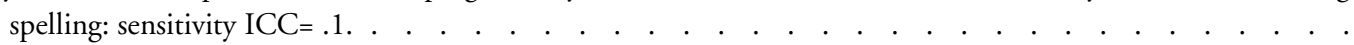

Analysis 11.52. Comparison 11 Developing country: School meal vs control. CBA - Sensitivity, Outcome 52 change in

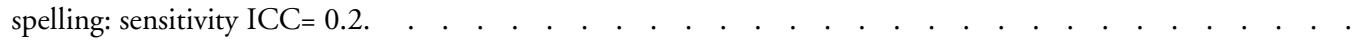


Analysis 11.58. Comparison 11 Developing country: School meal vs control. CBA - Sensitivity, Outcome 58 Change in attendance: sensitivity $=.10$. .

Analysis 11.59. Comparison 11 Developing country: School meal vs control. CBA - Sensitivity, Outcome 59 change in attendance: sensitivity $=.20$. . . . . . . . . . . . . . . . . . . . . . . . . . . . . . . . . . . . . . . .

Analysis 11.60. Comparison 11 Developing country: School meal vs control. CBA - Sensitivity, Outcome 60 End of study

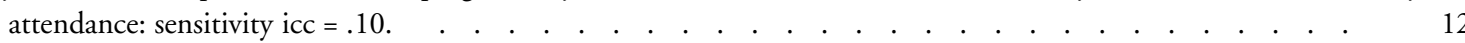

Analysis 11.61. Comparison 11 Developing country: School meal vs control. CBA - Sensitivity, Outcome 61 End of study

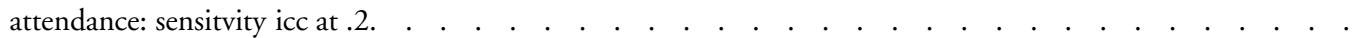

Analysis 11.62. Comparison 11 Developing country: School meal vs control. CBA - Sensitivity, Outcome 62 Change in Attendace: Sensitivity $=.05$.

Analysis 12.3. Comparison 12 Developed country: school meal versus control: CBA - Sensitivity, Outcome 3 Weight gain in $\mathrm{kg}$ - sensitivity icc=0.01. Leighton 1929 used for Orr. . . . . . . . . . . . . . . . . . . . . . . . .

Analysis 12.4. Comparison 12 Developed country: school meal versus control: CBA - Sensitivity, Outcome 4 Weight gain in kg.- sensitivity icc=0.05. Leighton used for Orr. . . . . . . . . . . . . . . . . . . . . . . . . . .

Analysis 12.5. Comparison 12 Developed country: school meal versus control: CBA - Sensitivity, Outcome 5 Weight gain in $\mathrm{kg}$. - sensitivity ICC=0.1. Leighton used for Orr. . . . . . . . . . . . . . . . . . . . . . . . . . .

Analysis 12.7. Comparison 12 Developed country: school meal versus control: CBA - Sensitivity, Outcome 7 Height gain in $\mathrm{cm}$. adjusted ICC $=0.016$. . . . . . . . . . . . . . . . . . . . . . . . . . . . . . . . . . . . . . .

Analysis 12.8. Comparison 12 Developed country: school meal versus control: CBA - Sensitivity, Outcome 8 Height gain in cm. sensitivity $\mathrm{ICC}=0.01$. . . . . . . . . . . . . . . . . . . . . . . . . . . . . . . . . . . . . . . . . . . .

Analysis 12.9. Comparison 12 Developed country: school meal versus control: CBA - Sensitivity, Outcome 9 Height gain in $\mathrm{cm}$. sensitivity $\mathrm{ICC}=0.05$. . . . . . . . . . . . . . . . . . . . . . . . . . . . . . . . . . . . . . . . .

Analysis 12.10. Comparison 12 Developed country: school meal versus control: CBA - Sensitivity, Outcome 10 Height gain in $\mathrm{cm}$. sensitivity ICC $=0.1$.

Analysis 12.12. Comparison 12 Developed country: school meal versus control: CBA - Sensitivity, Outcome 12 Height gain in cm. Leighton used for Orr. Sensitivity $0.01 . \quad$. . . . . . . . . . . . . . . . . . . . . . . . . . . . .

Analysis 12.13. Comparison 12 Developed country: school meal versus control: CBA - Sensitivity, Outcome 13 Height gain in cm. Sensitivity ICC = 0.05. Leighton used for Orr. $\quad . \quad$. . . . . . . . . . . . . . . . . . . . . . .

Analysis 12.14. Comparison 12 Developed country: school meal versus control: CBA - Sensitivity, Outcome 14 Height gain in cm. Sensitivity ICC = .1. Leighton used for Orr. . . . . . . . . . . . . . . . . . . . .

ADDITIONAL TABLES . . . . . . . . . . . . . . . . . . . . . . . . . . . . . . . . . . . . . 133

WHAT'S NEW . . . . . . . . . . . . . . . . . . . . . . . . . . . . . . . . . . . . . 137

HISTORY . . . . . . . . . . . . . . . . . . . . . . . . . . . . . . . . . . . . . . . . 138

CONTRIBUTIONS OF AUTHORS . . . . . . . . . . . . . . . . . . . . . . . . . . . . . . . . . . . 138

DECLARATIONS OF INTEREST . . . . . . . . . . . . . . . . . . . . . . . . . . . . . . . . . 139

SOURCES OF SUPPORT . . . . . . . . . . . . . . . . . . . . . . . . . . . . . . . . . . . . . . . . . . . 139

NOTES . . . . . . . . . . . . . . . . . . . . . . . . . . . . . . . . . . . . . . . . 139

INDEX TERMS . . . . . . . . . . . . . . . . . . . . . . . . . . . . . . . . . . . . . . . . . . . .

School feeding for improving the physical and psychosocial health of disadvantaged students (Review) 


\section{[Intervention Review]}

\section{School feeding for improving the physical and psychosocial health of disadvantaged students}

Betsy Kristjansson ${ }^{1}$, Mark Petticrew ${ }^{2}$, Barbara MacDonald ${ }^{3}$, Julia Krasevec ${ }^{3}$, Laura Janzen ${ }^{4}$, Trish Greenhalgh ${ }^{5}$, George A Wells ${ }^{6}$, Jessie MacGowan ${ }^{7}$, Anna P Farmer ${ }^{8}$, Beverley Shea ${ }^{7}$, Alain Mayhew ${ }^{7}$, Peter Tugwell ${ }^{9}$, Vivian Welch ${ }^{9}$

${ }^{1}$ School of Psychology, Faculty of Social Sciences, University of Ottawa, Ottawa, Canada. ${ }^{2}$ PEHRU, London School of Hygiene and Tropical Medicine, London, UK. ${ }^{3} \mathrm{C} / \mathrm{O}$ Cochrane Developmental, Psychosocial and Learning Problems Group, Bristol, UK. ${ }^{4}$ Department of Psychology \& Division of Haematology/Oncology, The Hospital for Sick Children, Toronto, Canada. ${ }^{5}$ Primary Care and Population Sciences, University College London, London, UK. ${ }^{6}$ Cardiovascular Research Reference Centre, University of Ottawa Heart Institute, Ottawa, Canada. ${ }^{7}$ Institute of Population Health, University of Ottawa, Ottawa, Canada. ${ }^{8}$ Department of Agricultural, Food and Nutritional Science and The Centre for Health Promotion Studies, University of Alberta, Edmonton, Canada. ${ }^{9}$ Centre for Global Health, Institute of Population Health, University of Ottawa, Ottawa, Canada

Contact address: Betsy Kristjansson, School of Psychology, Faculty of Social Sciences, University of Ottawa, Room 407C, Montpetit Hall, 125 University, Ottawa, Ontario, K1N 6N5, Canada. kristjan@uottawa.ca.

Editorial group: Cochrane Developmental, Psychosocial and Learning Problems Group.

Publication status and date: Edited (no change to conclusions), published in Issue 1, 2009.

Review content assessed as up-to-date: 30 April 2006.

Citation: Kristjansson B, Petticrew M, MacDonald B, Krasevec J, Janzen L, Greenhalgh T, Wells GA, MacGowan J, Farmer AP, Shea B, Mayhew A, Tugwell P, Welch V. School feeding for improving the physical and psychosocial health of disadvantaged students. Cochrane Database of Systematic Reviews 2007, Issue 1. Art. No.: CD004676. DOI: 10.1002/14651858.CD004676.pub2.

Copyright (C) 2009 The Cochrane Collaboration. Published by John Wiley \& Sons, Ltd.

\section{A B S T R A C T}

\section{Background}

Early malnutrition and/or micronutrient deficiencies can adversely affect physical, mental, and social aspects of child health. School feeding programs are designed to improve attendance, achievement, growth, and other health outcomes.

\section{Objectives}

The main objective was to determine the effectiveness of school feeding programs in improving physical and psychosocial health for disadvantaged school pupils .

\section{Search methods}

We searched a number of databases including CENTRAL (2006 Issue 2), MEDLINE (1966 to May 2006), EMBASE (1980 to May 2006), PsycINFO (1980 to May 2006) and CINAHL (1982 to May 2006). Grey literature sources were also searched. Reference lists of included studies and key journals were handsearched and we also contacted selected experts in the field.

\section{Selection criteria}

Data from randomized controlled trials (RCTs), non-randomised controlled clinical trials (CCTs), controlled before and after studies (CBAs), and interrupted time series studies (ITSs) were included. Feeding had to be done in school; the majority of participants had to be socio-economically disadvantaged.

School feeding for improving the physical and psychosocial health of disadvantaged students (Review)

Copyright $\odot 2009$ The Cochrane Collaboration. Published by John Wiley \& Sons, Ltd. 


\section{Data collection and analysis}

Two reviewers assessed all searches and retrieved studies. Data extraction was done by one of four reviewers and reviewed by a second. Two reviewers independently rated quality. If sufficient data were available, they were synthesized using random effects meta-analysis, adjusting for clustering if needed. Analyses were performed separately for RCTs and CBAs and for higher and lower income countries.

\section{Main results}

We included 18 studies. For weight, in the RCTs and CBAs from Lower Income Countries, experimental group children gained an average of $0.39 \mathrm{~kg}$ (95\% C.I: 0.11 to 0.67$)$ over an average of 19 months and $0.71 \mathrm{~kg}$ (95\% C.I.: 0.48 to 0.95$)$ over 11.3 months respectively. Results for weight were mixed in higher income countries. For height, results were mixed; height gain was greater for younger children. Attendance in lower income countries was higher in experimental groups than in controls; our results show an average increase of 4 to 6 days a year. Math gains were consistently higher for experimental groups in lower income countries; in CBAs, the Standardized Mean Difference was 0.66 (95\% C.I. = 0.13 to 1.18). In short-term studies, small improvements in some cognitive tasks were found.

\section{Authors' conclusions}

School meals may have some small benefits for disadvantaged children. We recommend further well-designed studies on the effectiveness of school meals be undertaken, that results should be reported according to socio-economic status, and that researchers gather robust data on both processes and carefully chosen outcomes.

\section{PLAIN LANGUAGE SUMMARY}

\section{School feeding for improving the physical and psychosocial health of disadvantaged schoolchildren}

Early malnutrition and/or micronutrient deficiencies can negatively affect many aspects of child health and development. School feeding programs are designed to provide food to hungry children and to improve their physical, mental and psychosocial health. This is the first systematic review on the topic of school feeding. Eighteen studies were included in this review; nine were performed in higher income countries and nine in lower income countries. In the highest quality studies (randomized controlled trials (RCTs) from low income countries, children who were fed at school gained an average of $0.39 \mathrm{~kg}$ more than controls over 19 months; in lower quality studies (controlled before and after trials (CBAs)), the difference in gain was $0.71 \mathrm{~kg}$ over 11.3 months. Children who were fed at school attended school more frequently than those in control groups; this finding translated to an average increase of 4 to 6 days a year per child. For educational and cognitive outcomes, children who were fed at school gained more than controls on math achievement, and on some short-term cognitive tasks. Results from higher income countries were mixed, but generally positive. For height, results from lower income countries were mixed; in RCTs, differences in gains were important only for younger children, but results from the CBAs were large and significant overall. Results for height from high Income countries were mixed, but generally positive. School meals may have small physical and psychosocial benefits for disadvantaged pupils. We recommend that further well-designed studies on the effectiveness of school meals be undertaken, that results should be reported according to the socio-economic status of the children who take part in them, and that researchers gather robust data on outcomes that directly reflect effects on physical, social, and psychological health.

\section{B A C K G R O U N D}

\section{Description of the condition}

The world has entered the new millennium inheriting an impressive legacy in health from the 20th century. Life expectancy in most countries has reached a new high and infant mortality a new low (PHAC 1999). However, these averages obscure the fact that health is unevenly and unfairly distributed according to socio-economic position; health and longevity are highest for 
the richest, and decrease steadily with decreasing income (PHAC 1999; Wilkins 1983; Wilkinson 1996). These social gradients in health, or socio-economic inequalities in health, are pervasive in all countries of the world (Diderichsen 2001) and are evident in most diseases, injuries, and health behaviours (Marchand 1998). Health inequalities have been defined as "the virtually universal phenomenon of variation in health indicators ... associated with socio-economic status" (Last 1995); inequalities may also be seen between different sexes or geographic groups. Health inequalities require three components for calculation: a valid measure of health status, a measure of social position or status, and a statistical method for summarizing the magnitude of the health differences between people in different social positions. Health inequities 'are unfair and remediable inequalities' (Tan-Torres 2001; Peter 2001). Thus, health inequalities are measurable, while health inequities require a value judgment.

\section{The rationale for school feeding programs}

According to Wynn (Wynn 1987) socio-economic differences in nutrition may be one of the most important factors causing socio-economic differences in health and mortality. Global estimates suggest that, in the period 2000-2002, over 852 million people across the world were undernourished (FAO 2004). Many of these were children. Most of these were in developing countries, but even in the United States, more than 3 million children experienced 'food insecurity with hunger' in the period between 1998 and 2000 (Sullivan 2002). Early malnutrition and/or micronutrient deficiencies can adversely affect physical, mental, and social aspects of child health. Effects on physical health may include underweight, stunted growth, lowered immunity, and mortality. Early malnutrition and/or micronutrient deficiencies have been linked to poorer cognitive functioning (Scrimshaw 1998; Worobey 1999; Leslie 1990). Short-term hunger can adversely affect attention and interest (Wilson 1983, cited in Levinger 1996; Read 1973). Overnight and morning fasting (e.g. skipping breakfast) has been shown to adversely affect performance on cognitive tasks, particularly for children who are nutritionally at risk (Pollitt 1995).

\section{Description of the intervention}

School feeding programs may help to ameliorate some of these problems. The goals of school feeding programs differ, but often include relieving short-term hunger (Allen 2001), improving micronutrient status (Allen 2001), growth (Allen 2001; Levinger 1986), cognition (Levinger 1986) and academic performance (Allen 2001; Levinger 1986) in both higher and lower-income countries. Worldwide, 115 million primary school aged children were 'out of school' in 2001/2002; most were from developing countries (UNESCO 2005) Therefore, in developing countries, school feeding also aims to increase school attendance and enrolment (Allen 2001, Levinger 1986) and to encourage students to stay in school longer. Agricultural and community development may be secondary outcomes in developing countries if locally grown food is used (Sanchez 2005).

However, there is some controversy over the effectiveness of school feeding programs. According to the World Food Program "Research and experience show that when food is provided at school, hunger is immediately alleviated, and school attendance often doubles within one year" (WFB 2005a). However, experts at a School Feeding/Food for Education Stakeholders meeting in 2000 concluded that there is little evidence for nutritional benefits of school feeding and that school feeding only enhances learning when other improvements in school quality are made (World Bank n.d.). Macintyre argued that school feeding programs address a symptom, rather than the root causes of hunger and that they may be stigmatizing (McIntyre 1992).

One important concern in school feeding studies is that, in poor families, the home diet may be reduced for children who are receiving food at school: this is termed 'substitution'. For example, a survey on school feeding in Malawi showed that $77 \%$ of children reported that they get less food at home when they receive school meals. This is substantiated by caregivers; $82 \%$ of caregivers reported that substitution was occurring. When there is extra food, it is used to benefit other household members, particularly children (Galloway 2006).

\section{Why it is important to do this review}

\section{Rationale for this review}

Many countries have school feeding programs. For example, in 2004 the World Food Program alone had school feeding programs in 72 countries, covering 16.6 million school children (WFP 2005b). A great deal of money is invested in these programs. Yet, to date there has been no formal systematic review of the effectiveness of school feeding programs across the world. It is therefore important to learn whether or not this is an effective and costeffective intervention for improving the health, nutritional status, school enrolment and school performance of disadvantaged children.

The purpose of this review is to assess the effectiveness of school meal programs for improving the health of socio-economically disadvantaged children. Another purpose is to study their effectiveness in terms of equity: are they benefiting those children who are more disadvantaged children at least as much as those who are more advantaged?

\section{Previous non-systematic reviews}


We have thus far been unable to identify an existing systematic review on the effectiveness of school feeding programs. However, we have identified some non-systematic reviews of school feeding programs (Grantham-McGregor 05; Levinger 1986; Pollitt 1978; Pollitt 1995; Walker 1986; Papamandjaris 2000), and reviews of supplementary feeding programs for children (Beaton 1982; Beaton 1993; Dickie 1982).

Some conclusions from these reviews are that: 1) the largest effects of feeding in early childhood on growth are likely to be found between the ages of 6 and 24 or 36 months, 2) growth may not be as important as other outcomes such as improved physical and psychological health (Beaton 1993), 3) the brain is sensitive to short-term lack of nutrients and that this may be particularly problematic for children who are undernourished (Pollitt 1995), 4) morning feeding might produce emotional benefits, enhance ability to work (Pollitt 1978), lead to 'transient' improvements in cognition (Grantham-McGregor 05) and improve classroom behaviour (Papamandjaris 2000) if classrooms are well set up (Grantham-McGregor 05), 5) school-feeding programs may increase attendance (Pollitt 1995), particularly in rural low income schools in developing countries (Levinger 1986), 6) many studies covered in the early reviews were poorly done (Pollitt 1978, Levinger 1986), 7) outside factors such as home environment seemed to have at least as much effect as school feeding; greater improvement might be achieved if both diet and the environments in which children lived and learned were improved, (Levinger 1986) and,8) evidence is mixed (Pollitt 1995).

Although the above reviews provided valuable information, they fail to give us a comprehensive picture of the effectiveness of school feeding across the globe. All were limited in their scope: some to just a few countries, most to either developing or industrialized countries, others to one feeding time (e.g. morning), and others to just a few outcomes. Furthermore, none were systematic reviews. Thus, standard methods were not used; details on search strategies, inclusion and exclusion criteria, number of studies found and considered, and quality of studies was not formally assessed. Importantly, little formal synthesis has been done.

\section{O B JECT IVES}

1. To determine the effectiveness of school feeding programs in improving physical and psychosocial health outcomes for low income school children.

2. To compare the effectiveness of school feeding programmes for socio-economically disadvantaged children and advantaged children.

3. To understand the process by which school feeding programs achieve (or fail to achieve) an impact on growth, cognitive development, and school performance.

\section{METHODS}

\section{Criteria for considering studies for this review}

\section{Types of studies}

Randomized controlled trials (RCTs), non-randomized controlled clinical trials (CCTs), interrupted time series (ITS), and controlled before and after studies (CBAs) were included. Control groups could be either "no-treatment" controls (lunch or breakfast at home or no feeding/fortification) or placebo controls (e.g. low energy glucose syrup at school). Other study designs were excluded.

\section{Types of participants}

Children and adolescents, in any country, aged 5 to 19 , who attended primary or high school. Note that this age range represents a change from the published protocol, which was focused solely on elementary school children. In the review, elementary and high school children were both included due to the dearth of studies on high school students.

Based on the 2004 World Bank List of Economies (World Bank 2005), countries were classified into two groups: 1) Low and Lower Middle Income Countries (LMIC) and 2) Higher income countries (Upper-Middle and Higher-income countries). Inclusion and exclusion criteria were somewhat different for these two groups. These criteria represent a modification of the published protocol; this was necessary in order to be more precise.

\section{Lower Income countries}

\subsection{Included:}

Those studies in which children were classified as 'predominantly disadvantaged' by one or more of the following criteria: 1) Living in a rural area or village; 2) Living in an urban area and described as socio-economically disadvantaged (e.g. poor or low-income) or from poor areas (e.g. slums); 3) if statistics were presented showing that $30 \%$ of more of the children in the sample were underweight, or stunted (nutritionist judgement) or that the average weight, height, and Body Mass Index (BMI) were low (nutritionist judgement) and 4) studies were implicitly or explicitly aimed at disadvantaged children, and indicators of disadvantage were provided in the paper.

\subsection{Excluded:}

Studies were excluded if: 1) children were from urban areas only with a large proportion of high socio-economic status (SES) children and results could not be broken out by SES or other proxy 
variables; or 2) where information was insufficient to allow us to judge the extent of disadvantage.

\section{Higher-income countries}

\subsection{Included:}

Those in which children were classified as disadvantaged by the following criteria: 1) they were from areas described as economically marginalized or disadvantaged (e.g. Low income area, ghetto, social housing projects, from mining communities); 2) they were described as low SES (e.g. working class) 3) more than half were from lower SES groups (including unemployed parents); 4) they were described as marginalized or "at-risk" due to social circumstances.

We also included studies in which some children were advantaged but results could be broken down by SES or baseline nutritional status.

\subsection{Excluded:}

1) Students were described as being from middle or high SES backgrounds only, 2) students were from mixed high and low SES and results were not broken down by SES or 3) information was insufficient to allow us to judge disadvantage.

\section{Types of interventions}

Included: Meals (breakfast or lunch) or snacks (including milk) administered in a school setting. If a study included two or more experimental groups given different types of meals, we chose the meals with the highest energy and/or protein content for data extraction and analysis.

Excluded interventions: micronutrient supplementation or fortification of existing meals, stand-alone nutrition education in schools or at home, obesity prevention programs, breastfeeding programs, food stamps, modifications to school meals to change nutrient content, community kitchens, food banks, and feeding centres.

Because of the increasing emphasis on reducing obesity in higherincome countries, programs built around school meals in these countries increasingly aim to enhance the nutritional content of children's diets by increasing availability and access to low-fat choices, fruits, and vegetables (Coleman 2005; Luepker 1996). However, the focus of this review is not on changing content of school meals, but rather on studying the effect of provision of food to children. Thus, these types of interventions are not part of this review.

\section{Types of outcome measures}

We extracted data on changes in the intervention group relative to the control/comparison group.

Physical health outcomes included nutritional status (anthropometry, bone mineral density, bone mineral content, micronutrient status, and haemoglobin, and hematocrit). Both hemoglobin and hematocrit are indices of anaemia, a condition in which the blood cannot carry enough oxygen, and most often due to iron deficiency.

Psychological health outcomes included educational outcomes (e.g., school achievement in math, reading, or spelling, school enrolment, school attendance) and other tests of cognition such as intelligence test scores, psychomotor and mental development, attention, memory, reasoning, verbal fluency, vocabulary, on-task behaviour.

Behavioural outcomes included on-task behaviour, attention problems, and behaviour problems.

Adverse outcomes included stigmatisation, dependency, disruptive behaviour at school, and obesity or excessive weight loss.

Excluded outcomes: Reduction of dental caries, increased nutritional knowledge, and intermediate physical health outcomes such as reduction of hunger and nutrient intake.

\section{Search methods for identification of studies}

\section{Electronic searches}

The search was performed by JM on the following electronic databases:

Cochrane CENTRAL Register of Controlled Trials (2006 ISSUE

2) via the OVID interface

MEDLINE (1966 to May 2006) via the OVID interface

EMBASE (1980 to May 2006) via the OVID interface

ADOLEC - Literature on adolescent health (To May 2006) - via Virtual Health Library interface

AMED (Allied and complementary medicine) (1985-May 2006) via the OVID interface

CAB Health (1973-May 2006) via the Silver Platter interface CINAHL (1982 to May 2006) via the OVID interface Current Contents (to May 2006) via the OVID interface Dissertation Abstracts (1981 to May 2006) via the OVID interface EBM Review (searched in May 2006) via the OVID interface ERIC (1966 to May 2006) via the OVID interface PsycINFO (1980 to May 2006) via the OVID interface Food and Agriculture Organization Corporate Document Repository (http://www.apps.fao.org)

Food Poverty Projects database (http://www.sustainweb.org/ povdb_index.asp) (to May 2006)

Graylit Network (http://graylit.osti.gov/) (to May 2006)

Grey Literature New York Academy of Medicine (http:// www.nyam.org/library/grey.shtml) (to May 2006) 
HMIS (Health Management Information Consortium),

Healthstar (1985 to May 2006) via the OVID interface

Healthpromis (http://healthpromis.hda-online.org.uk/) (to May 2006)

LILACS database - Latin American and Caribbean Health Sciences Literature (to May 2006) - via Virtual Health Library interface

MEDCARIB - Caribbean Health Sciences Literature (to May 2006) - via Virtual Health Library interface

PAHO - PAHO HQ Library Catalog (To May 2006) - via Virtual Health Library interface

Premedline (2002 to May 2006), EBM Reviews (to May 2006) via the OVID interface

SIGLE - System for Grey literature in Europe (1980 -May 2006) via the Silverplatter interface

Sociofile (1980 to May 2006) via the OVID interface

C2-SPECTR (Social, Psychological, Educational and Crimino-

logical Trials Register - http://128.91.199.101/) (to May 2006)

Search Strategy in MEDLINE:

1. Milk.sh,tw.

2. (feeding or school-feeding or meal\$ or snack\$).tw.

3. (breakfast or break fast or lunch or mid-day or mid day or dinner or supper).tw.

4. Or/1-35. Exp Schools/

6. (school\$ or school-based or kindergarten or preschool or pre-

school or daycare or day care).tw.

7.5 or 6

8. 4 and 7

9. Breastfeeding/ or (breastfeed\$ or breast feed\$).tw.

10. 8 not 9

11. Exp Child Nutrition/

12. Bone density/ or bone densit\$.tw.

13. Exp growth/

14. Body mass index/

15. Nutritional status/ or nutrition\$.tw.

16. (growth or bone mass or weight or height).tw.

17. Dietary services/ or diet/

18. Food services/

19. Hunger.sh,tw.

20. Food, Fortified/ or (fortification or fortified).tw.

21. (iron or iodine).tw,sh.

22. Dietary Supplements/ or (Dietary Supplement $\$$ or nutritional Supplement\$ or food Supplement\$).tw.

23. Exp Vitamin A/

24. Or/11-23

25. 10 and 24

The strategy was amended where necessary to search the other databases listed. An RCT filter was not used as we were also looking for CBA and ITS. No language restrictions were applied.

\section{Searching other resources}

\section{Handsearching}

We handsearched the electronic versions of the American Journal of Clinical Nutrition, Journal of Nutrition, European Journal of Clinical Nutrition, Nutrition Reviews, and Social Sciences and Medicine from the beginning of 1998 through to May 2006; Public Health Nutrition was handsearched from the beginning of 1999 to 2006. References of included articles and relevant reviews (Levinger 1986; Pollitt 1978; Pollitt 1995) were scanned for eligible studies. The annotated Bibliography "School Feeding Works" (WFB 2005a) was also scanned for relevant studies.

\section{Personal contacts}

People and or organizations focusing on nutrition, hunger, and international development were contacted by email to identify relevant studies on school feeding programs that we may have missed; these include Arlene Mitchell and Francisco Espejo of the WFP 2005b Food Program School Feeding Team, UNICEF, Ms. Catherine Bertini of the United Nations System Standing Committee on Nutrition (SCN), Dr. Ernesto Pollitt, and Dr. Susan Walker.

\section{Data collection and analysis}

\section{Data Abstraction}

The abstracts and titles of articles retrieved by the electronic and hand searches were independently assessed for eligibility by two reviewers (EK and VR) and/or one reviewer (EK) and one research assistant (CB), according to the inclusion criteria above.

Full copies of all those deemed potentially eligible by one of the reviewers were retrieved for closer examination. Two reviewers (EK and VR) determined whether or not they met eligibility criteria. We sought the advice of BM, JK and TG when we needed input on whether or not the children were disadvantaged. We sought the input of MP in cases where CBAs had inappropriate controls. We developed our data abstraction forms a priori based on the data collection forms from the Effective Practice and Organization of Care (EPOC) review group (EPOC 2002). They were modified to capture specific items of data needed for this review. These forms were pilot-tested with four included studies to ensure clarity, completeness and ease of use. Data were extracted by one of four reviewers and checked by another reviewer who had not done the original extraction. We extracted data on study design, description of the intervention (including process), details on participants (including age, sex, number in each group), length of intervention, definition of poor/low income, other socio-demographic variables, including place of residence, race/ethnicity, age, and nutritional status, critical appraisal (see below), physical, cognitive, and behavioural outcomes. We had planned to extract data on cost-effectiveness, but found none. Where possible, we 
recorded effects by socio-economic position. JK or BM reviewed the included studies, summarizing data on nutritional content, percent of the Recommended Dietary Allowance (RDA) for energy the meal provided.

\section{Process evaluation}

In order to identify possible confounders, data on a number of process elements were extracted. Our list was chosen to represent factor that could impact on effectiveness. It included:

1. Intensity of approach (percentage of RDA for energy and whether low or high)

2. Type of feeding and time of day food given

3. Settings (e.g. Where is food given- type of school, given in classroom, lunchroom)

4. Provider delivering intervention (was it peer supervised, teacher supervised, supervised by lunchroom staff, volunteers?)

5. Monitoring intake

6. Compliance

7. Quality/acceptability of food given

8. Duration of intervention

9. Substitution

A 2.3. Detail on the Process evaluation

Contemporary research practice recommends process evaluation alongside empirical trials of complex interventions so as to identify how the intervention was implemented in practice, the mechanism by which it achieved its impact, and any local contextual issues that may have influenced outcome (Campbell 2000; Calnan 2003). Process evaluation can also be undertaken as part of a systematic review, by extracting, analysing and synthesising any data from the included studies that may help explain mechanism(s) of action and/or heterogeneity of outcomes. Thus, when a complex social intervention appears to have had a significant effect in one trial but no effect (or a negative effect) in another, an analysis of the link between the context (as described in the paper), intervention and outcome aims to generate further hypotheses about the circumstances in which this intervention might be more or less successful. To this end, TG reviewed all papers included in the final review in order to identify information on process elements that may have helped to explain the process by which each intervention achieved (or failed to achieve) an impact in each primary study. Descriptive data were extracted from the papers on historical context, local political and economic climate, funding source, extent of involvement and partnership with local researchers, sampling (e.g. how 'disadvantage' was defined and measured), methodological detail of the implementation (e.g. level of supervision during the supplemented meal), context in which growth measurements and psychometric testing were undertaken, and so on. These data were tabulated in an Excel spreadsheet and used alongside the quantitative findings to help generate the various process hypotheses that are included in the methods, results, and discussion. The process evaluation was particularly helpful in the current review as we lacked sufficient data for meta-regression.

\section{I. Energy content}

One important process element was energy content, which was assessed by the nutritionists (BM and JK). Only energy was considered as many studies only provided the average kilocalorie content of the meal/snack, but did not provide sufficient detail regarding the food to estimate other nutrients.

\subsubsection{Rules used in calculating energy content:}

1. When the total kilocalories or \% Recommended Daily Allowance (RDA) of energy were provided in the text of the study, this figure was used. When the amount of kilocalories were not provided but the descriptions of food were sufficient (quantity and type of food), the kilocalorie content of the meal/snack was estimated using the United States Department of Agriculture (USDA) nutrient data file.

2. When meals/snacks with different kilocalorie contents were provided on different days (Powell 1983), a weighted average was taken (e.g. if a meal with $400 \mathrm{kcals}$ was provided 3 days a week and a meal with $600 \mathrm{kcals}$ was provided 2 days a week, then the weighted average of 480 kilocalories was used.

3. When the number of days on which different meals/snacks were given on was not specified (Agarwal 1989) or when the energy content was different in year 1 than year 2 of the study (Neumann 2003), a straight average was used for the energy content.

2.2.2. Calculating \% RDA for energy

The \% RDA for energy was calculated by dividing the given or estimated average kilocalorie content of the meal/snack by the RDA for the age/sex specific target group in each study (SCN 1989). When the intervention group of a study was comprised of various age and sex groups, and outcomes were given for the entire group only, a weighted average for the RDA was used to calculate the $\%$ RDA. In addition, as a check, the $\%$ RDA was calculated for each age and sex group for which there was a corresponding RDA by dividing the total kilocalories provided by the meal/snack by the age and sex specific RDA. Energy intensity was considered as a continuous variable. However, for purposes of helping to interpret the data, interventions will also be characterized as having two levels of energy content: low (interventions providing $<15 \%$ of the RDA for energy) and higher (interventions providing $15 \%$ or more of the RDA for energy).

Due to lack of information, we were unable to calculate energy content for three studies (Bro 1994, Bro 1996, Shemilt 2004).

After data abstraction was completed, tables of included and excluded studies were developed.

\section{Data extraction and analysis}

Results were analysed separately for lower and higher-income countries because the settings and populations are so different it would be misleading to combine them. 


\section{I Continuous data. RCTs, CCTs, and CBAs}

To perform meta-analyses of continuous data, we input data on means, standard deviations, and the number of participants for each outcome in the two groups. It is important to note that, in all cases, these means and standard deviations were unadjusted for confounders; however, they were adjusted for clustering when needed. We used mean and standard deviation for change in the meta-analyses in all but one case (Agarwal 1989). In this case, we used end-of-study results for intelligence because we could not find an appropriate Rho (correlations between beginning and endof-study in the control group).

In cases where standard deviations and/or standard deviations for change were not published, and the study was published $<30$ years ago (after 1976), we wrote to the authors requesting this information. Susan Walker provided us with means and standard deviations for change, and with before and after correlations in the control group for the Powell 1998 study; data from the Powell 1983 study was unavailable. For Du 2004, Zhang Qian provided change data for weight and height, corrected for clustering (Zhang 2006). We received no reply from Agarwal and Paige concerning their respective studies (Agarwal 1989, Paige 1976).

Change data

Data on change was either taken directly or calculated from other information presented in the papers for the following studies: Bailey (Bailey 1962), Baker (Baker 1980 ( boys)), Corry-Mann (Corry-Mann 1926), and Devadas (Devadas1979: 5-6). Susan Walker provided data on change and on correlations between the beginning and end-of study for the Powell 1998 study (Walker 2004). These correlations were used in calculating standard deviations for change for the Agarwal (Agarwal 1989) and Powell 1983 studies, using standard deviation from baseline and end of study according to the methods described in section 8.5.2.10 of the Cochrane Handbook. In cases where data were not meta-analyzed, regression analyses, multilevel analyses, or Analyses of Variance were selected as providing the better estimate of effect, because: a) multilevel analyses accounted for clustering or because b) other ANOVAs and regressions provided results for change.

\subsection{Interrupted time series}

We used the average of before and after session presented in the two ITS studies (Bro 1994, Bro 1996).

We did not have any discrete outcomes in our meta-analyses.

\subsection{Skewness}

Except for Shemilt 2004's trail-making test (Shemilt 2004), skewness was not indicated in any of the studies included in this review. For all papers except Corry-Mann 1926, summary statistics were provided rather than the original raw data and we were thus unable to check the raw data for skewness. Furthermore, because change scores were used in most analyses, we were unable to do the rough check described in Section 8.5.2.11 of the Cochrane Handbook (Higgins 2005).

\subsection{Data synthesis}

We conducted meta-analysis using a random effects model. Weighted mean differences were calculated unless otherwise stated. We conducted separate analyses for each outcome across: 1) Lower income countries vs. Higher-income country, and 2) Different study designs (i.e. ITS, RCT and CBA). A clinical psychologist (LJ) commented on the clinical relevance of the psychological outcomes.

\subsection{Methods of analysis for studies with potential unit of analysis errors}

Studies which allocated by school or class could have unit of analysis errors if they did not adjust for between-cluster correlation. Therefore, we reviewed each primary study to determine whether or not clustering was part of the study design. If it was, we then determined whether or not the analyses adjusted for clustering. If analyses were adjusted in the primary study, we used them.

3.6.1. Methods used to correct for design effect in clustered trials or CBAs that were not adjusted for clustering:

1. When the pooled estimate used was an SMD (because of varying metrics), the method outlined in section 8.11.2.4 of the Cochrane Handbook (Higgins 2005) was used exactly as described to inflate the standard error. First, we calculated the unadjusted SMD and 95\% confidence interval. The unadjusted SMD was entered as the effect estimate in the generic inverse variance method, then we inflated the standard error of the effect estimate by multiplying by the square root of the variance inflation factor, calculated as: $(1+(\mathrm{m}-1)$ multiplied by (ICC), where $\mathrm{m}$ is the average cluster size. The standard error was calculated at the confidence interval divided by 3.92 .

2. When the pooled estimate was the WMD approach, we used the Variance Inflation Factor (VIF) to adjust the standard deviations in the treatment and control groups separately. These standard deviations were then used in the meta-analysis, and so are incorporated in the standard error of the mean difference and the weighting procedures. The result of this is equivalent to the method outlined in the Cochrane Handbook (following the SMD approach) when the variance inflation factors are the same in the treatment and control groups.

This approach was used because there is a real possibility that the cluster sizes differ between the treatment and control groups and therefore the VIF, which depends on cluster size, would be different. Therefore, the adjustment for variance inflation would differ between the treatment and control groups. As far as we know, the Cochrane Handbook does not provide for this eventuality. However it is necessary to take account of this difference in VIFs (see, for example, Agarwal in our review (Agarwal 1989)). 


\subsubsection{Calculating the Variance Inflation factor}

a. First we calculated cluster size. When numbers of participants in each analysis were provided, these numbers were divided by the number of clusters to calculate cluster size. Otherwise, we used the number of participants provided in the methods sections of the primary studies and divided that by the number of clusters. b. Then, we found appropriate Intra-Cluster Correlations (ICCs). For weight and height for Agarwal 1989, Bailey 1962, Du 2004, and Powell 1983, we used the ICCs published in Du's 2005 letter to the editor; (Du 2005). Thus we used ICCs of 0.025 and 0.016 for weight and height respectively. Sensitivity analyses were conducted with ICCs of $.01, .05$, and .10 for both weight and height. We conducted further sensitivity analyses for each outcome to assess how large the ICC needed to be to change the results. Varying the ICC to these extreme values did not change the statistical significance of any of the pooled results.

For math, reading, spelling, attendance and intelligence outcomes in Agarwal (Agarwal 1989 - boys) and/or the Powell (Powell 1983) studies, we used ICCs of 0.15 , with sensitivity analyses at 0.10 and 0.20 . This was based on recommendations from the Schochet report (Schochet 2005) for math and reading.

c. Then, for experimental and control groups separately, we calculated the VIF as follows:

$(1+(\mathrm{m}-1)$ multiplied by (ICC), where $\mathrm{m}$ is the average cluster size (Ukoumunne 1999). We then multiplied the original standard deviation by the square root of the VIF for experimental and control groups separately. These adjusted standard deviations were then entered into the RevMan data tables.

\subsection{Subgroup analyses}

3.7.1 Equity question. We had planned to perform subgroup analyses by socio-economic status as well as baseline nutritional status. However, none of the included studies presented tables stratified by SES (although two did briefly describe results by SES). Two studies presented results stratified by baseline nutritional status (Powell 1998 (A), Agarwal 1989), this was used in a subgroup analysis as a proxy for SES. Meta-regression was used to test for an interaction between baseline nutritional status and height and weight.

3.7.2 Age

Because growth rates may vary by age, we conducted a subgroup analysis across age groups for weight and height. We also planned to do subgroup analyses by age for cognition, as it is possible that the effectiveness of school meals in changing cognitive outcomes may vary according to age. However, our data were not sufficient to do this.

3.7.3 Sex

We also conducted subgroup analyses by sex, and reviewed each study to determine whether or not they reported interactions between sex and outcomes.

\subsection{Potential effect modifiers}

We carefully examined several of the process elements listed above: high/low energy, compliance, substitution, and duration of the intervention. Study quality may also impact on findings; studies of lower quality often show higher effect sizes than those of higher quality. For example, biased outcome assessment is possible in situations where those who assess the outcome variables are not blinded to study group (i.e., intervention or control).

To better understand the influence of potential effect modifiers, we tabulated effects for each study sorting them by type of study, blinding versus unclear blinding, date of study, and high versus low energy ( Table 1, Table 2).

\subsection{Presentation of raw and absolute differences}

Since absolute and relative differences convey different information, and both are needed to make an informed decision (Hembroff 2004) we calculated both absolute and relative differences between intervention and control conditions. The absolute difference in change from baseline was calculated by the Review Manager analysis as the difference in change from baseline between the school meal and control groups. We calculated the relative $\%$ change as the difference in change divided by the baseline of the control group of the most representative study. Because height and weight both increase over time, we also calculated the $\%$ change relative to the rate of change as the difference in change scores (over the study periods) divided by the control group rate of change over the same time period (using a weighted average of the rate of change in all studies, using the same weights as the Review Manager analysis).

\subsection{Heterogeneity}

Where meta-analysis was conducted, we assessed heterogeneity using the steps below.

1) Common sense (e.g. Are the interventions, participants or outcomes so different that they cannot be combined?)

2) $I^{2}$ measure for heterogeneity (Higgins 2003)

3) The Chi-Square test for heterogeneity.

3.11. Assessment of publication bias

There were too few studies in meta-analyses to evaluate the risk of publication bias by means of funnel plots (Egger 1997). As the best protection from publication bias is a robust search strategy, we made strenuous efforts to locate unpublished and grey literature.

\section{RES U L T S}

\section{Description of studies}


See: Characteristics of included studies; Characteristics of excluded studies.

\section{Results of the search}

After initial screening of titles and abstracts, we retrieved 400 potentially useful articles. Reviewers agreed that 30 studies were potentially relevant and of the appropriate design. Each was read in full. Of these, 18 studies met inclusion criteria; 12 were excluded. The 18 papers included 45 separate comparison groups (see Table of Characteristics of Included Studies).

\section{Included studies}

\section{Study design}

The 18 included studies comprised seven randomized controlled trials (RCTs), nine controlled before and after studies (CBAs), and two interrupted time series (ITS). Details of included studies are contained in the Characteristics of Included studies).

\begin{abstract}
Allocation/clustering
Clustering was an issue in nine studies; these were all allocated by school or class. Of these nine, three (Jacoby 1996; Neumann 2003; Shemilt 2004) adjusted for clustering in their analyses. We adjusted for clustering in five (Agarwal 1989 - boys; Bailey 1962; Du 2004; Orr 1928 - 13 yrs; Powell 1983). We were unable to adjust for clustering in one study (Chandler 1995) and therefore reported unadjusted Analysis of Variance results. Clustering was not an issue in the other nine studies (Baker 1980 ( boys), Bro 1994; Bro 1996; Corry-Mann 1926; Devadas1979: 5-6; Lieberman 1976; Paige 1976; Powell 1998 (A); Tisdall 1951). In five of the studies, students were allocated by individual and in four one experimental and one control school were allocated or we chose one experimental group to compare to another.
\end{abstract}

\section{Inclusion in meta-analyses}

Eight studies were not included in any of the meta-analyses. In five of these (Bro (Bro 1994; Bro 1996)); Lieberman (Lieberman 1976); Paige (Paige 1976), and Tisdall (Tisdall 1951)), standard deviations were unavailable. We report Analysis of Variance results from Jacoby (Jacoby 1996) and regression analyses from Shemilt (Shemilt 2004) as these analyses corrected for clustering. The Powell 1998 study (Powell 1998 (A)) and the Kenya study (Neumann 2003) were both included in meta-analyses for weight and height, but for psychosocial outcomes, we used results of multilevel regression. Similarly, the Orr study (Orr 1928 - 13 yrs) was included in meta-analyses for height, but lacked appropriate data for weight.

\section{Location}

Nine studies were from Lower Income Countries; five of the seven RCTs and four of the eight CBAs. Of the nine studies performed in higher-income countries; two of these were RCTs, six were CBAs, and two were Interrupted Time Series (see also Characteristics of Included Studies).

\section{Participants}

Children participating in studies included within this review ranged in age from 5 to 19 years; most studies included primary school children. Details on age, sex, and socio-economic characteristics of children in each study can be found in the 'Characteristics of Included Studies' table.

\section{Description of the interventions}

\section{Lower income countries}

Five programs provided meals: four provided breakfast and one provided lunch. The remaining four programs provided snacks/ milk. Energy provided ranged from 195 to $730 \mathrm{kcal}$ and protein provided ranged from 10-27 grams per day. Three studies (Bailey 1962; Du 2004; Neumann 2003) provided less than $<15 \%$ of RDA for energy, at $8-10 \%$ of the RDA for energy, $10 \%$ of the RDA for energy and $13 \%$ of the RDA for energy, respectively.

Five studies in lower-income countries provided no intervention to children in control groups; these children may have had meals at home, or had no meals. In four studies, children in the control group were given a very low energy snack (e.g. quarter of an orange), drink (e.g. syrup) or iron pill; the three Jamaican studies (Chandler 1995; Powell 1983; Powell 1998 (A)), did this to control for the effects of benevolent attention. In one study (Bailey 1962) boys in the control group were given iron tablets.

\section{Higher-Income Countries}

Five of the feeding programs involved meals: four breakfasts and one lunch, and four involved snacks/milk. Energy content of seven studies ranged from 126 to $705 \mathrm{kcal}$ and the amount of protein provided ranged from 3 to 26 grams.

\section{Outcomes}

\section{Physical outcomes}

Weight gain in $\mathrm{kg}$ and height gain in cm (11 studies), change in weight and height-for-age z-score or percent height and weightfor-age (three studies), change in mid-upper arm muscle area (one study), change in mid upper arm fat area (one study), change in 
Bone Mineral Density, Bone Area and Bone Content (one study), and change in haemoglobin (two studies), hematocrit (one study), and in other biochemical indices (two studies).

\section{Psychosocial outcomes included educational and cognitive test outcomes}

Educational outcomes comprised: change in school attendance (five studies), change in achievement in arithmetic (four studies), reading (two studies), spelling (two studies). Change in cognitive test outcomes included: end-of-study general intelligence (one study), change in Raven's Progressive Matrices score (one study), change in performance on Trail Making Test (Part A) (one study), sparse reports on 'mental tests' or achievement (three studies), and short-term change in cognitive tasks (two studies). Although we had planned to include school enrolment, we could not find any studies on enrolment that met our criteria.

\section{Behavioural outcomes}

Change in playground activity was considered in one study, change in hyperactivity (one study), behavioural conduct (two studies), and in on-task behaviour (two studies).

Adverse outcomes were not reported by any studies in this review.

\section{Excluded studies}

Twelve studies that met study design criteria (e.g. RCT, CCT, CBA and ITS), but that did not meet other criteria are presented in the Table of Excluded Studies. Among the 12 excluded studies, six were excluded because the interventions and/or outcomes were not relevant for our study, three were excluded because they were not in a school setting, 2 were excluded because the description of SES was not complete enough for us to make a judgement on SES and one was excluded because some control areas were replaced between baseline assessment and follow-up.

\section{Risk of bias in included studies}

Our quality criteria were modified from the EPOC checklist (EPOC 2002). The purpose of quality ratings was not to give an overall score, but rather to provide a descriptive overview of the methodological robustness of the included studies. Details are below and in Table 3.

\section{Criteria used}

\section{I.I. Criteria for RCTs}

We considered allocation concealment, comparability of groups on physical and/or psychological measures at baseline, reliable primary outcome measures, protection against contamination, blinded assessment of primary outcomes, co-intervention, and loss to follow-up. For each of these criteria, a rating of adequate (criteria met), unclear, or inadequate (criteria not met) was given. We also used the Jadad Scale (Jadad 1996). For the purposes of this review, we report on individual elements of the Jadad scale rather than on an overall score. For each of the Jadad criteria, a score of 1 (for met) or 0 (for not met) was given. One of the elements in the Jadad scale is double blinding, but it is important to note that double blinding is not always possible in a school meals situation.

\section{I.2. Criteria for CBAs}

In assessing methodological quality of the CBAs, we considered equivalence of baseline measurement of physical/psychological outcomes across groups, reliable primary outcome measures, protection against contamination, blinded assessment of primary outcomes, co-intervention, and loss to follow-up. For each of these criteria, a rating of adequate (criteria met), unclear, or inadequate (criteria not met) was given.

\section{I.3 Criteria for ITS}

In assessing methodological quality of the ITS designs, we considered protection against secular changes (including intervention independent of other changes, appropriate data analysis, and reason for number of pre and post points given), protection against detection bias (including intervention unlikely to affect data collection and blinded assessment), reliability of the outcome measures, and completeness of the data set. Each aspect of these criteria is described in more detail in Figure One. For each of these criteria, a rating of adequate (criteria 'met'), 'unclear', or 'inadequate' (criteria not met) was given.

\section{Detailed methods for rating}

Two reviewers (EK and BS) independently rated each aspect of study quality (EK and VR rated Shemilt). Disagreements were resolved at a consensus meeting. A nutritionist (JK) and a registered dietician (AF) assessed the reliability of anthropometric measurements and equivalence of baseline anthropometric measures across experimental and control groups. A registered clinical psychologist (LJ) assessed the reliability of psychological measures and the equivalence of baseline psychological measures across groups. An internal medicine specialist (PT) assessed the quality of haemoglobin, hematocrit, and bone mineral density measurements. Table 4 and Table 5 provide details on baseline equivalence of physical and psychological outcomes.

\section{Results of Quality Rating}

The results of the quality assessment of the included studies are listed in the Table of Included Studies and a complete summary 
can be seen in Table 3. Results from the Jadad Criteria and the EPOC criteria are presented separately below.

\section{I. Jadad criteria}

2.1.1. DESCRIBED AS RANDOMIZED. All seven RCTs were described as randomized.

2.1.2. DOUBLE BLINDING. Double-blinding was not done in any of the studies.

2.1.3. DESCRIPTION OF WITHDRAWALS AND DROPOUTS. Five RCTs provided descriptions of withdrawals and dropouts, two did not provide this description.

2.1.4. DESCRIPTION OF METHOD OF RANDOMIZATION. None of the studies described their method of randomization.

2.1.5. DESCRIPTION OF METHOD OF DOUBLE-BLINDING. This was not given for any of the studies.

\subsection{EPOC criteria}

2.2.1. RELIABLE OUTCOME MEASUREMENTS. Five studies were rated as adequate for all, seven studies were rated as unclear for all, five studies were rated as mixed adequate and unclear, and one study was rated as inadequate.

2.2.2. EQUIVALENCE OF BASELINE MEASURES. Seven studies were rated as adequate for all, five were rated as unclear for all, two studies were rated as mixed adequate and unclear, one was rated mixed inadequate and adequate, and three were not applicable.

2.2.3. PROTECTION AGAINST CONTAMINATION. Nine ratings of adequate were given, five were unclear, two were inadequate, and two were not applicable.

2.2.4. BLINDING OF OUTCOME ASSESSMENT. Blinding of outcome assessment was generally poor; six were rated adequate, nine were unclear, two were inadequate, and one was mixed inadequate and unclear.

2.2.5. CO-INTERVENTION. Co-intervention was almost always unclear; we gave fifteen ratings of unclear, one of adequate, and two were rated not applicable.

2.2.6. LOSS TO FOLLOW-UP. Loss to follow-up was rated adequate for seven of the studies, unclear for seven, inadequate for two, and not applicable for two.

2.2.7. ALLOCATIONCONCEALMENT (RCTs only). Allocation concealment was rated as unclear for all 7 of the RCTs.

\section{Effects of interventions}

\section{A. Physical Outcomes}

\section{Al. Weight gain}

\section{A1.1 Lower income countries: RCTs.}

Three RCTs (Du 2004; Neumann 2003; Powell 1998 (A)) were included in a meta-analysis for weight. There was some heterogeneity (Chi-square $=3.49, \mathrm{df}=2, \mathrm{p}=0.18, \mathrm{I}$-squared $=41.1 \%$ ). Children who were fed at school gained an average of $0.39 \mathrm{~kg}$ more than those who were not supplemented (95\% confidence interval 0.11 to 0.67 ) (Analysis 1.1 ); this is significant. Sensitivity analyses with ICCs at $0.01,0.05$, and 0.10 made little difference. This absolute difference of $0.39 \mathrm{~kg}$ represented a $1.2 \%$ difference relative to baseline and $12 \%$ relative to the control rate of weight gain. Study duration ranged from 7 to 24 months. Taking 19 months as the average study duration, this works out to a gain of $0.25 \mathrm{~kg}$ a year.

\section{A1.2. Lower Income Countries: CBAs.}

Three CBAs in lower income countries (Agarwal 1989 - boys, Bailey 1962; Devadas 1979: 5-6) were included in meta-analyses for weight. These CBAs were heterogeneous (Chi-square $=15.8$, $\mathrm{df}=5, \mathrm{p}=0.007, \mathrm{I}$-square $=68.3 \%)$. A statistically significant difference was found between supplemented and non-supplemented groups; on average, intervention groups gained $0.71 \mathrm{~kg}$ more than the control groups ( $95 \%$ confidence interval 0.48 to 0.95 ) (Analysis 3.1). Sensitivity analyses with ICCs of 0.01, 0.05, and 0.10 made little difference. This absolute difference in weight of $0.71 \mathrm{~kg}$ represented a $3.9 \%$ difference relative to baseline weight and a $44 \%$ difference relative to the control rate of weight gain. Study durations ranged from 10 to 12 months, for an average of 11.3 months. This works out to an average gain of 0.75 kilograms a year.

\section{A1.3. Higher Income Countries: RCTs.}

Only one RCT in higher income countries assessed weight gain (Baker 1980 ( boys)). Our analyses in REVMAN show no statistically significant differences in weight gain between children who received school milk and those who did not (WMD $(\mathrm{kg})=0.13$ (95\% confidence interval, -0.23 to 0.49 ) (Analysis 5.3).

\section{A1.4. Higher Income Countries: CBAs.}

Four CBAs in higher-income countries assessed changes in weight. In the year long Corry-Mann study (Corry-Mann 1926), boys who received milk gained an average of $1.42 \mathrm{~kg}$ more than controls (95\% C.I $=1.19$, 1.65) (Analysis 4.2) over 12 months. For the 7 month long Orr (Orr 1928) study, compared to controls, 5-yearold, 8 year olds, and 13 year olds who received milk gained from 0.18 to 0.44 more, eight-year-old children gained from $0.01 \mathrm{~kg}$ to $0.54 \mathrm{~kg}$ and 13 -year-old children gained from $0.28 \mathrm{~kg}$ to $0.38 \mathrm{~kg}$ more. In Paige 1976, the average weight increment for children who received the fortified drink was $0.5 \mathrm{~kg}$ greater than that of the controls ( $\mathrm{P}$ value $<0.001$ ); according to the graphs, the gain was 
much greater in younger children (below 7 and 7 to 8 years) than in the older children ( 8 and 9 year old) age groups (significance not given). In the Tisdall study, children in the school lunch group gained an average of $0.32 \mathrm{~kg}$ more than the controls (n.s.) over the 27 month period of the study (Tisdall 1951).

\section{A2 Height gain in $\mathrm{cm}$}

\section{A2.1. Lower Income Countries: RCTs.}

Three RCTs (Du 2004; Neumann 2003; Powell 1998 (A)) were included in a meta-analysis; these studies were heterogeneous (Chisquare $=7.9, \mathrm{df}=2, \mathrm{p}$ value $=0.02 ; \mathrm{I}$-square $=74.8 \%)$. Overall, there was a small, non- statistically difference in change in height between experimental and control groups (WMD $=0.38,95 \%$ confidence interval -0.32 to 1.08 ). The height gain of 0.38 represented a $0.2 \%$ difference relative to baseline height $(134.5 \mathrm{~cm})$ and a $5 \%$ difference relative to the control group (Additional Table 6 ). The duration of these studies ranged from 7 months (Powell 1998) to 24 months (Du 2004).

\section{A2.2. Lower Income Countries: CBAs.}

Three CBAs with six independent samples (Agarwal 1989 - boys; Bailey 1962; Devadas1979: 5-6) were included in the meta-analysis. There was severe heterogeneity (Chi-square $=81.8, \mathrm{df}=5, \mathrm{P}$ $<.0001$, I-square $=96 \%$ ). Significant gains in height were seen; children in the intervention groups gained an average of $1.43 \mathrm{~cm}$ more than children in the control groups (95\% confidence interval 0.46 to 2.41 ) (Analysis 3.5 ). Sensitivity analyses made little difference. This height difference represented a difference of $1.2 \%$ relative to the baseline height (of $116.6 \mathrm{~cm}$ ), and a $33 \%$ difference relative to control group rate of height gain (Table 7).

\section{A2.3 Higher-Income Countries: RCTs.}

Only one RCT (Baker 1980 ( boys)) studied height. Our analyses in RevMan indicate that children who were given school milk gained a small amount more than controls over two years (WMD $=0.28,95 \%$ confidence interval: -0.01 to 0.56 ) (Analysis 5.1 ).

\section{A2.4 Higher-Income Countries: CBAs.}

Height gain was studied in four CBAs. In a meta-analysis of the Corry-Mann (Corry-Mann 1926) and 1928 Orr (Orr 1928 - 13 yrs) studies, high heterogeneity was observed (Chi-Square $=29.66$, $\mathrm{df}=3, \mathrm{P}<0.0001$, I-squared $=89.9 \%)$. Children who received milk gained an average of $0.92 \mathrm{~cm}$ more in height than children in the control group (95\% C.I.: 0.16 to 1.69) (Analysis 12.7). In the 7-month long Paige study, the average height gain in the experimental group was greater than that of controls by $0.5 \mathrm{~cm}$ in the 6 year old group (n.s.), $1.0 \mathrm{~cm}$ in the 7 year old group, $(\mathrm{p}<$
$0.01), 0.6 \mathrm{~cm}$ in the 8 year olds $(\mathrm{p}<0.01)$ and $0.2 \mathrm{~cm}$ in the 9 year olds (n.s.) (Paige 1976). In the Tisdall study, the intervention group grew $0.25 \mathrm{~cm}$ more than the controls over two years; this was non-significant (Tisdall 1951).

\section{A3. Change in Weight-for-age z-scores}

\section{A3.1 Lower Income Countries: RCTs.}

Powell 1998 (A) assessed change in weight-for-age $\mathrm{z}$-scores in Jamaica using the U.S. National Center for Health Statistics references. Analyses showed a statistically significant effect of treatment on weight-for-age; the change in z-score was 0.07 higher in the experimental group than in the control group (95\% confidence interval 0.04 to 0.10 ) (Analysis 1.3).

\section{A3.2. Lower-Income Countries: CBAs.}

In the 1983 Powell study (Powell 1983) there was no difference in final percentage of expected weight-for-age between children who were given breakfast and children in two control groups; one given a low energy syrup and a no treatment control group (WMD = $0.75,95 \%$ C.I. $=-0.61,2.40)($ Analysis 11.30$)$ Sensitivity analyses did not change the outcome.

\section{A4. Change in Weight-for-height z-scores}

\section{A4.1 Lower-Income Countries: RCTs.}

Grillenberger reported that in the Kenya study the decline in zscore was 0.20 less for the children who received meat as a snack than for the control group; this difference was not statistically significant (95\% confidence interval, -0.24 to 0.64 ) (Analysis 1.23) (Grillenberger 2003; Neumann 2003).

\section{A5. Change in Height-for-age z-scores}

\section{A5.1 Lower-Income Countries: RCTs.}

In a meta-analysis of two RCTs (Neumann 2003; Powell 1998 (A)) there was no heterogeneity (Chi-square $=0.49, \mathrm{df}=1, \mathrm{p}=$ 0.49 ; I-square $=0 \%)$. A small, significant effect of school feeding on height-for-age (z-score diff $=0.04,95 \%$ confidence interval 0.02 to 0.06 ) (Analysis 1.4 ) was seen. 


\section{A6. Percentage of Height-for-age}

\section{A6.1. Lower-Income Countries: CBAs.}

Our analyses for Powell's study (Powell 1983) show a small, significant difference in percentage height that favors control children $(\mathrm{WMD}=-.75,95 \%$ C.I. $=-0.75,95 \%$ C.I. $=-1.19,-0.32)$ (Analysis 11.11).

A7. Change in mid-arm muscle area, mid-arm fat area, and mid-upper arm circumference

\section{A7.1 Lower-Income Countries: RCT.}

Authors of the Kenya study presented data on change in midarm muscle area, mid-arm fat area, and MUAC (Neumann 2003). They reported that children who were given meat gained significantly more mid-upper arm muscle area than controls (WMD $=68.22 \mathrm{~mm}$-squared (95\% confidence interval 39.57 to 96.87 ) (Analysis 1.21). No differences were found for change in midupper arm fat area between the experimental children who were given meat and the controls (WMD $=-0.31 \mathrm{~mm}$-squared; $95 \%$ confidence interval $=-26.12$ to 25.50) (Analysis 1.22). There was a significant increase in MUAC in the meat group compared to controls (WMD $=0.31 \mathrm{~cm}(95 \%$ confidence interval 0.14 to 0.48$))$ (Analysis 1.14).

\section{A8. Change in bone mass and body composition}

\section{A8.1 Lower-Income Countries: RCT.}

Du and his colleagues (Du 2004) studied the effects of milk fortified with calcium. These results were initially not adjusted for clustering, but in a later letter to the editor reporting on an updated analysis controlling for clustering, results showed no significant differences in percentage change in Bone Mineral Content $($ Exp - Control $=1.7, \mathrm{P}=0.12)$ and bone area $($ Exp - control $=$ $-1.2, \mathrm{P}=0$.22). However, for Bone Mineral Density, the group who received milk with calcium experienced a $3.1 \%$ greater gain than the control group $(\mathrm{P}=0.03)$.

\section{A9. Biochemical outcomes}

\section{A9.1. Lower-income countries: RCT}

In the Kenya study (Neumann 2003), a number of micronutrient status indicators including hemoglobin, plasma ferritin, serum iron, serum zinc, serum copper, plasma vitamin B-12, folate and retinol, and erythrocyte riboflavin were assessed. After a year of intervention, the only significant difference was in plasma vitamin
B-12. While plasma Vitamin B-12 concentration increased by 47 $\mathrm{pmol} / \mathrm{L}$ (s.d. = 66) in children who received a meat supplement, it decreased by 13 (s.d. = 65) in the control group ( $<<0.0001)$.

\section{A9.2. Higher income countries.}

Tisdall (Tisdall 1951) compared 'good attenders', 'poor attenders' and controls on serum ascorbic acid, serum carotene, and serum Vitamin A. Statistically significant differences were found favouring the school lunch children.

\section{Al 0. Hemoglobin and hematocrit}

\section{A10.1 Lower-Income countries. RCT.}

One paper produced from the Kenya study (an RCT in a lowerincome country) found no differences in hemoglobin increase between the experimental (meat) and the control group; the mean increase in $\mathrm{g} / \mathrm{L}$ was $7.5(\mathrm{~s} . \mathrm{d}=15.1)$ in the experimental group and 11.5 (s.d. = 19.8) in the control group (Siekmann 2003; Neumann 2003).

\section{A10.2. Lower-Income Countries: CBAs.}

Devadas (Devadas1979: 5-6) reported a greater increase in haemoglobin in the experimental groups of $0.38 \mathrm{~g} / \mathrm{dl}$. Significance was not reported. Bailey (Bailey 1962) reported a decrease of 0.83 percent in the experimental group and no change in the iron-supplemented control group. However, iron supplementation is not an appropriate control group for this outcome.

\section{A10.3 Higher income countries: CBAs.}

Tisdall (Tisdall 1951) reported no significant difference in increase in hemoglobin between 'good attenders', 'poor attenders', and controls (statistics not given). Paige (Paige 1976) reported a larger increase in \% hematocrit in the supplemented group $35.9 \%$ to $39.4 \%$ ) than in the control group (increase from $35.8 \%$ to $38.2 \%$; $\mathrm{p}<0.001)$. Paige reported that the end-of-study difference in percent of children with levels below $33.9 \%$ was significant $(\mathrm{p}$ value $<0.01$ ).

\section{B. Psychosocial Outcomes (Educational outcomes, short and long-term cognition)}

\section{BI. School Attendance}

B1.1 Lower-Income Countries: RCTs. 
Jacoby and colleagues (Jacoby 1996) and Powell and colleagues (Powell 1998 (A)) assessed school attendance. In the Powell study, multilevel analysis (school, class and pupil as fixed parameters) and with initial score, sex, grade, and nutrition group as covariates revealed a significant effect of breakfast on attendance (b (unstandardized regression coefficient $)=2.32$, s.e. $=0.78, p<.05$ ). This means that children in the experimental group attended school $2.3 \%$ more days in the study period than children in the control group. Jacoby and his colleagues (Jacoby 1996) performed descriptive analyses on attendance, and reported significant effects of school feeding on attendance (note that they were unable to provide us with standard deviations). In the experimental group, attendance increased by $0.58 \%$ while it decreased by $2.92 \%$ in the control group. In the first month of the intervention, the attendance of the experimental group was 5.1\% higher than that of the control group. The difference in change between the experimental and control groups is $3.4 \%$.

\section{B1.2 Lower-Income Countries: CBAs.}

Our meta-analyses adjusting for clustering in the control groups showed that change in attendance was not significantly different between the breakfast group and the pooled control groups $(\mathrm{WMD}=4.95,95 \%$ C.I. $=-3.95,13.46)$ (Analysis 3.56). Sensitivity analyses at 0.10 and 0.20 did not change the outcome. Agarwal (Agarwal 1989) provided a very sparse report on attendance; in his discussion, he noted that there was 'significant improvement in attendance' (p.172). It is unclear whether this was based on statistical analyses or was merely impressionistic.

\section{B2.1.3 Higher-Income Countries: CBAs.}

Three authors (Paige 1976; Tisdall 1951; Lieberman 1976) all reported that children who received school meals attended school more days per year than children in control groups. Paige found that children who received school meals attended, on average, 2.5 more days per year than children in the control group (significance not reported). Lieberman reported that in the group of children who received school breakfast, attendance increased from 158 to 161 days per year while in the control group, attendance decreased from 158 to 156 days (non-significant). Tisdall found that students who received school lunch attended 1.4 days more than controls (non-significant); it is not clear whether this was over the two-year period of the study, or per year. Tisdall also reported that the rate of absence for medical causes per 1000 pupil days was 36.0 for school lunch children and 39.8 for control children; the rate was only 31.8 per 1000 pupil days among the group of children who regularly attended the school lunch program.

\section{B2. Math performance}

\section{B2.1. Lower-Income Countries: RCTs.}

Two RCTs (Powell 1998 (A)); and the Kenya study (Whaley 2003; Neumann 2003)) reported data measuring change in math performance. Powell (Powell 1998 (A)) used the Wide Range Achievement Test (WRAT), and Whaley used an adapted arithmetic test from the Wechsler Intelligence Scale for Children (WISC). In the 1998 Powell study, multilevel analyses were performed; predictors included initial score, sex, grade, nutrition group, treatment group, school, class, pupil, and a treatment by grade interaction (Powell 1998 (A)). Powell reported a significant effect of breakfast on arithmetic achievement over the seven month period of the study; children in the experimental group gained significantly more than those in the control group; $(\mathrm{b}=0.71$, s.e. $=.0 .31, \mathrm{P}$ value $<0.05)$. Multi-level regression analyses in the Kenya study performed by some of the authors of the Kenyan study showed that children who were given meat gained 0.17 points per year, $(\mathrm{s} . \mathrm{e}=0.10, \mathrm{P}$ value $<0.05)$ in math knowledge than children in the control group (Whaley 2003; Neumann 2003).

\section{B2.2. Lower income Countries: CBAs.}

Two CBAs (Powell 1983; Agarwal 1989) assessed math achievement. Results of our adjusted meta-analysis (with ICC $=.15$ ) show no heterogeneity (Chi-Square $=0.02, \mathrm{df}=1, \mathrm{P}=0.86$, I-squared $=0$ ). Change in math achievement was significantly greater for children who had received school meals than those who did not (SMD $=0.31,95$ C.1. $=0.09$ to 0.53 ). We also performed an analysis in which Agarwal was broken down into four nutritional subgroups; results were very similar $(\mathrm{SMD}=0.44,95 \%$ C.I. $=0.22$ to 0.67) (Analysis 3.3) (Agarwal 1989). Sensitivity analyses for ICCs of 0.10 and 0.20 made little difference.

\section{B3. Spelling achievement}

\section{B3.1 Lower Income Countries: RCTs.}

Multilevel regression analyses performed by Powell (Powell 1998) showed no difference in change in spelling achievement as measured by an adapted version of the WRAT for the experimental group than for the controls $(b=-0.5$, s.e. $=0.27$, ns. $)$.

\section{B3.2 Lower Income Countries: CBAs.}

In one CBA (Powell 1983), our adjusted meta-analysis (ICC = 0.15 ) shows a small, significant difference between children in the experimental and two control groups combined $(\mathrm{SMD}=0.24$, $95 \%$ C.I. $=0.01,0.47$ ). Sensitivity analysis with an ICC of 0.10 showed much the same results, however, the sensitivity analysis with an ICC of 0.20 was non-significant. 


\section{B4. Reading achievement}

\section{B4.1 Lower-Income countries: RCTs.}

Powell and colleagues (Powell 1998 (A)) assessed change in reading performance on an adapted version of the WRAT. A multi-level regression analysis demonstrated that there was no difference in reading performance between experimental and control groups after adjusting for baseline performance, age, and sex $(b=0.12$, s.e. $=.29$, n.s.).

\section{B4.2}

Powell and colleagues (Powell 1983) assessed the effect of school breakfast on reading performance using the adapted version of the WRAT. Our adjusted meta-analyses demonstrated no difference between children in the experimental groups and those in the control groups combined $(\mathrm{SMD}=0.09,95 \%$ C.I. $=-0.11,0.29)$ (Analysis 3.44). Sensitivity analyses made little difference.

\section{B5. Intelligence-type test scores}

\section{B5.1 Lower Income Countries: RCTs.}

Some trialists (Whaley 2003) involved with the Kenya study (Neumann 2003) studied effects of a school snack on fluid intelligence using Raven's Progressive Matrices. They found a significant effect of treatment: children in the group who received meat gained an average of 0.34 points per year more than the control group who were not fed (P value $<0.05$ ).

\section{B5.2. Lower Income Countries: CBAs.}

In the Agarwal study (Agarwal 1989 - boys), our adjusted analyses (ICC $=0.15$ ) show moderate positive, but non-significant effects of school feeding on Full Scale, Performance, and Verbal IQ. Children who were given school lunches had an end-of-study FullScale IQ that was 3.9 points higher than those who were not given school lunch (WMD $=3.9,95 \%$ C.I. $=-2.88,10.68$ ) (Analysis 3.13). The end-of study Performance IQ was 5 points higher for those children who were given lunch than for the controls (WMD $=5.0,95 \%$ C.I. $=-2.60$ to 12.6) (Analysis 3.26). Differences in Verbal IQ were smaller $(\mathrm{WMD}=3.10,95 \%$ C.I. $=-2.99,9.19)$ (Analysis 3.29). Sensitivity analyses made very little difference to either the point estimate or the significance.

In another analysis, we used subgroups from Agarwal (Agarwal 1989). Here, our adjusted analyses (ICC $=0.15$ ) show significant effects of school feeding on Full Scale and performance IQ. Children who were given school lunches had an end-of-study FullScale IQ that was 3.8 points higher than those who were not given school lunch (WMD $=3.80,95 \%$ C.I. $=0.51,7.10$ ) (Analysis
3.21). Sensitivity analyses with ICCs at 0.10 and 0.20 were still significant. Larger differences were seen in performance IQ; the end-of study Performance IQ was nearly 6 points higher for those children who were given lunch than for the controls (WMD = 5.74, 95\% C.I. $=1.75$, 9.74) (Analysis 3.24). Sensitivity analyses with ICCs at 0.10 and 0.20 were both significant. Differences in Verbal IQ were smaller and non-significant (WMD $=3.32,95 \%$ C.I. $=-0.21,6.92$ ) (Analysis 3.28). Sensitivity analyses made very little difference to either the point estimates or the significance.

Another CBA (Devadas1979: 5-6) provided very sparse reports on mental ability; she found no differences between experimental and control groups in end-of-study mental ability.

\section{B5.3. Higher Income Countries: CBAs.}

One CBA in a higher income country (Lieberman 1976) reported no difference in magnitude of improvement on Raven's Progressive Matrices and other psychological tests (figure copying, making x's, listening attention, and memory for numbers). Another CBA (Tisdall 1951) reported no significant differences in change in intelligence test scores, school marks, and reading and math tests.

\section{B6. Short-term effects on cognition}

\section{B6.1 Lower-income countries. RCTs.}

Chandler and her colleagues (Chandler 1995) performed a randomized cross-over study of the short-term effects of providing breakfast on four cognitive tasks. They report significant treatment effects for verbal fluency (P value $<0.02$ ) and a significant treatment by nutritional status interaction $(P$ value $<0.05)$. Those children who were undernourished (defined as 1 or more than 1 standard deviation below National Centre for Health Statistics references) had scores (unadjusted for clustering) that were 1.5 points higher after receiving breakfast than when they received the placebo (P value $<0.01$ ). However, breakfast made no difference to the children who were classified as adequately nourished (above - 1 s.d. for weight- for-age). No significant effects of school feeding were found on information processing, visual search or digit span for either well-nourished or undernourished children.

Jacoby and his colleagues (Jacoby 1996) studied the short-term effects on performance in a battery of psycho educational tests: 1) the coding subtest from the Weschler Intelligence Scale for Children, 2) a test of reading comprehension from the Inter-American Series, 3) a test of vocabulary from the Inter-American Series, and 4) a test of functions and abilities related to the math curriculum. An Analysis of Covariance controlling for sex, height-for-age z-score, weight - residual (weight regressed on age and height), SES, home language, repetition of any grade, and age on entry to school; current enrolment in grade, school nested in treatment group, and interactions between height-for-age and treatment and weight-for-age and height was used. Significant effects were seen 
for vocabulary only; the main effect of breakfast overall was not significant, but there was a significant interaction between baseline weight-for-age and height and treatment (parameter estimate $=0.37, \mathrm{~F}=4.97, \mathrm{P}$ value $<0.05)$. This interaction meant that the heavier children benefited most from school breakfast. The authors noted that the combination of smaller than average stature and normal weight for height are common among poor Peruvians, and that 'this phenomenon reflects a protracted deficit of critical nutrients due to poor diet and infection' (p. 62) (Jacoby 1996). Thus he hypothesized that those who were heavier than normal were likely to be of poorer health and less well nourished than the other children.

\section{B6.2. Higher Income Countries: RCTs.}

One cluster RCT in a high income country (Shemilt 2004) assessed concentration with the Trail Making Test three months after breakfast clubs were initiated in a number of schools where each school decided on meal content. For children in school years 2-11, the time taken to complete the Trail Making Test was significantly shorter in the intervention group at 3 months; the time taken by the intervention group was 3.70 seconds logged and the time taken by the control group was 3.71 seconds. The ratio of adjusted geometric means was $0.90,95 \%$ confidence interval 0.81 -1.00). It is important to note that contamination had occurred; by the time of first follow-up, 2 schools randomized to the control group were running breakfast clubs. Furthermore, not all of the 17 schools randomized to the experimental conditions ran breakfast clubs.

\section{Behavioural Outcomes}

\section{Lower Income Countries: RCTs.}

In the Kenyan RCT, eight aspects of playground activity were considered; high activity, low activity, positive emotion, leadership, initiates, ongoing behaviour, aggression, and solitary play. The children who were given meat outperformed those who were given no snack in comparisons; high activity, low activity, leadership, and initiating social interactions ( $\mathrm{p}<.001$ for all) (Neumann 2003). In a sub-study of the larger Chandler study (Chandler 1995), Chang and colleagues reported that the behaviour of a sub-sample of children was observed during structured teaching and during work on an assigned task (Chang 1996). Behaviour only improved with school breakfast in one school, deteriorated in two schools, and was not affected in the other. The authors noted that the school in which behaviour improved was the only school that had separate classrooms for each class and where each child had his or her own desk.

\section{C.2. Higher-Income Countries: RCTs.}

One cluster RCT of breakfast clubs in the UK (Shemilt 2004) examined differences in abnormal or borderline conduct and hyperactivity after three months (first follow-up). Although the percentage of students with borderline/abnormal conduct, hyperactivity, and total difficulties was lower in the intervention group, these differences were not significant in multilevel regression analyses.

\section{C3. Higher Income Countries: ITS.}

Two small interrupted time series studies (Bro 1994; Bro 1996) found improvements in the percentage of time students were engaged in on task behaviour when they were given breakfast. In the first study (Bro 1994), the percentage of time that students were on task rose from an average of $41 \%$ during the second baseline to an average of $93 \%$ in the second phase when they were given breakfast (significance not reported). Results of the second study (Bro 1996) were similar. In the first class, mean percentage of on task behaviour rose from an average of $49 \%$ to an average of $90 \%$, while in the second class, mean percentage of time spent in on task behaviour rose from an average of $62 \%$ to an average of $70 \%$ (significance not reported). These are small studies, and there are some issues around whether the intervention is confounded by other interventions so we place less importance on them.

\section{Subgroup analyses}

\section{Effects by socio-economic status}

\section{D1.1. Lower-Income countries: RCT.}

None of the included studies displayed data on outcome by SES. However, Grillenberger and her colleagues (part of Neumann 2003) reported that the effect of school meals on weight was greater for children of lower SES (Grillenberger 2003).

\section{D2. Effects by baseline nutritional status}

\section{D2.1. Lower-Income Countries}

\section{D.2.1.1. Weight.}

A subgroup analysis for change in weight from the Powell study (Powell 1998 (A)) showed no interaction between treatment and baseline nutritional status (fixed and mixed effects: $Q / Z=0.01$, P-value $=0.97$ ). 


\section{D.2.1.2. Height.}

Subgroup analysis of the Powell RCT (Powell 1998 (A) in RevMan demonstrate a significant gain of $0.30 \mathrm{~cm}$ in the undernourished group and a non-significant gain of 0.17 in the well-nourished group. However, formal analyses showed a non-significant interaction between baseline nutritional status and height gain (fixed and mixed effects $\mathrm{Q} / \mathrm{Z}=69.7, \mathrm{P}=0.404$ ). Grillenberger (Grillenberger 2003, Neumann 2003) presented a graph showing results by baseline height-for-age z-score. They reported that height gain was not significantly different between the meat and control group for either the low HAZ $(<-1.4$ standard deviations below the mean) or the high HAZ (>-1.4) groups.

D2.1.3. As previously described, Jacoby (Jacoby 1996) reported an interaction between weight-residual (based on regressing weighton-height and age) and treatment; those children in the experimental group with higher initial weights showed significantly improved vocabulary scores. Chandler (Chandler 1995) found that breakfast significantly improved verbal fluency only for children who were underweight $(<=-1$ s.d. below reference values in weightfor-age).

Another way of looking at effectiveness by need is to compare lower-income countries and higher income countries. The assumption here is that if school meals are more effective for those in greatest need, they should show larger effects in lower-income countries where the need is presumably greatest. As Table 1 and Table 2 show, effect sizes for weight and height are generally higher in lower-income countries when comparing studies in lower-income countries to studies in higher income countries from the latter half of this century (Paige is the exception to this (Paige 1976)). However, if one examines studies done in the 1920s in higher income countries, effect sizes for weight and height are very similar (or higher) than those for later studies in lower-income countries. The study by Paige also resulted in significant effects on weight and height (Paige 1976).

\section{D3. Age}

\section{D.3.1. Lower Income countries: weight.}

In a meta-regression of the three RCTs (Du 2004; Neumann 2003; Powell 1998 (A)) with a total N of 1462, no significant treatment by age interaction for weight was found ( $(\mathrm{Q})$ Fixed and mixed effects $=-4.58, \mathrm{P}=0.67$ ).

In a meta-regression of the 3 CBAs (Agarwal 1989; Bailey 1962; Devadas 1979: 5-6) with a total $\mathrm{N}$ of 1022, there was a significant age-by-treatment interaction. The greatest benefit of school meals was shown for 5-6 year olds and 9 to 10 year olds (.95 and .89 $\mathrm{kg}$ respectively). The effect for 6 to 8 year old children was also large at $.67 \mathrm{~kg}$, but there was no effect in the Bailey study which included children up to age 13 in the analyses.

\section{D.3.2. Higher Income Countries: weight.}

As previously shown, in the Paige study (Paige 1976), weight gain was highest in the youngest children and lower and non-significant for older children.

\section{D.3.3. Lower Income Countries: height.}

Meta-regression analysis for height in three RCTS (Du 2004; Neumann 2003; Powell 1998 (A)) with an overall $\mathrm{N}$ of 1462 showed a significant interaction between age and treatment $(\mathrm{Z}(\mathrm{Q})$ Fixed and Mixed (moment) $=-2.284, \mathrm{P}=0.022)$. An examination of the subgroup data shows that children who were 9 to 10 years old grew more relative to controls $(0.40 \mathrm{~cm} ., 95 \% \mathrm{CI}=0.03$, 0.77 ) (Analysis 10.11) than did children in a group aged 6 to 16 $(-0.37 \mathrm{~cm}, 95 \%$ C.I. $=-1.30,0.56)$. Meta-regression of the CBAs also showed a significant interaction with age $((\mathrm{Z}(\mathrm{Q})$ Fixed $=$ 9.608, $\mathrm{p}=.000$ : Mixed $=-2.137, \mathrm{P}=0.033)$. In the three CBAs (Agarwal 1989; Bailey 1962; Devadas 1980) with an overall $\mathrm{N}$ of 1022 , significant effects of feeding were seen only for the youngest children (aged 5-6 and 6 to 8 years). These children gained 2.26 $\mathrm{cm}$ and $1.25 \mathrm{~cm}$, respectively, more than children in the control groups. In the 9-10 and 6-13 year old groups children who were fed did not gain significantly more in height than children in the control groups.

The relative differences in weight and height also show a gradient in benefit across age, with a relative benefit of $98 \%, 41 \%, 45 \%$, $0.9 \%$ for the ages $5-6,6-8,9-10$ and mixed ages respectively.

\section{D.3.4. Higher income countries: height.}

As mentioned previously, the average height gain was larger in the middle two age groups ( 7 and 8 year olds) in the Paige study (Paige 1976).

For cognition, Powell (Powell 1998 (A)) reported a significant grade by treatment interaction for math $(b=-0.85$, s.e. $=0.44, p=$ 0.05 ) indicating that the effect of school breakfast mainly occurred for younger children.

\section{D4. Sex}

\section{D4.1. Lower Income countries: RCTs.}

Powell (Powell 1998 ) found no significant sex by treatment interaction for height and weight. However, Grillenberger (Neumann 2003) reported that school feeding (meat versus control) had a greater effect on weight and MUAC for boys than for girls. Furthermore, while feeding with meat had a significant positive effect on WHZ for boys, there was no significant effect for girls (for boys, WHZ declined less in the experimental group than in the control group). 


\section{D4.2 Lower Income: CBAs.}

In the Agarwal study (Agarwal 1989), effects of feeding on weight and height were very similar for boys and girls. For girls, weight gain of the experimental group relative to the control group was 0.70 (significant) while for boys, the weight gain relative to controls was 0.80 . There was no significant relationship between feeding and height for either boys or girls.

\section{D4.3. Higher Income countries: RCTs.}

In the Baker study, no differences were evident between boys and girls in weight gain of the experimental group relative to the controls (Baker total 1980). For height, girls in the experimental group grew 0.45 of a cm more than controls (n.s.); results boys in the experimental group grew only 0.11 of a $\mathrm{cm}$ (n.s.).

None of the studies tested a treatment by sex interaction for cognition.

\section{E. Potential Confounders}

\section{EI. Study quality}

\section{E1.1. Comparison of RCTs and CBAs.}

Our meta-analyses of height and weight gain described above show there was a large difference between RCTs and CBAs in height gain $(0.35 \mathrm{~cm}$ (n.s) in RCTs and $1.45 \mathrm{~cm}$ (sig) in the CBAs). For weight, differences between RCTs and CBAs in meta-analyses were smaller $(0.39 \mathrm{~kg}$ in RCTS and $0.71 \mathrm{~kg}$ in CBAs); both showed significant overall effects. For most of the cognitive functions, comparisons of effect sizes are difficult, as every study used different scales and different methods of reporting. For arithmetic, two RCTs and two combined CBAs showed significant effects.

In higher income countries, both weight and height gains were non-significant and very small in one RCT, but higher in the CBAs. However, it must be noted that the \% RDA for energy provided in that RCT was very low. No comparison of cognitive functions is possible, as this RCT did not assess cognitive function.

\section{E1.2. Comparison of blinding to unclear blinding}

Findings for this comparison were very similar to findings from comparisons of study types. However, for attendance, one of two RCTs in lower-income countries that assessed attendance had unclear blinding. This study had a very slightly larger effect size than the one that did blind outcome assessment.

\section{E2. Substitution}

Only three included studies (Agarwal 1989; Jacoby 1996; Murphy 2003 in Neumann 2003) assessed this issue, and all report evidence of substitution. They all found that the net increase in energy intake was far lower than the amount of energy provided by the meal. For example, Agarwal reported that the mid-day meal program provided $450-500 \mathrm{kcal}$ and $25 \%$ of the RDA for energy, but that the average daily increase in the supplemented group was only $200 \mathrm{kcal}$ while in the Peruvian breakfast study (Jacoby 1996), the meal contained an average of $600 \mathrm{kcal}$ but the net increase in intake was $288 \mathrm{kcal}$. In the Kenyan study, the net increase in the meat group was only 140 calories when 239 were given; the milk and energy groups actually showed decreases in net intake, and the control group showed an increase of 196 calories a day.

\section{E3. Compliance}

Compliance was very poor in some studies from higher income countries. For example, in the Lieberman study, only $10 \%$ of children attended breakfast $90 \%$ of the time, and less than half attended $55 \%$ or more of the time (Lieberman 1976). In this study, non-significant results were found on cognitive tests. The Tisdall study (Tisdall 1951) sheds important light on the issue as they compared 'good attenders 'to 'poor attenders' (nearly $2 / 3$ of the school lunch groups) in many analyses. In these analyses, the'good attenders' did better than the 'poor attenders'.

\section{DISCUSSION}

In performing this review, we found that many of the articles on school feeding did not use rigorous outcome assessment. Many articles simply provide descriptions of the nutritional quality of school meals and /or the dietary intake of participants, others describe program operation, management, or cost, others simply survey participants, parents, or providers. Another group of studies comprise cross-sectional comparisons of participants and nonparticipants; still others are longitudinal studies with no control. The 18 included and 12 excluded studies included in this review are the only studies we found which assessed effectiveness with a reasonable degree of rigour. Despite the practical difficulties involved in undertaking research on school meals, it is clear that more high quality research on school feeding programs needs to be undertaken in both higher and lower income countries.

We included a wide range of studies in this review; they were conducted over eight decades and in many different countries. Their heterogeneity in terms of setting, historical/policy context, sample, inclusion criteria, interventions, and outcomes is striking. Sorting the studies into historical order gives a feel for the way the focus of the research has moved from en masse feeding of the disadvantaged and measuring growth plus 'general condition' 
of the children to a much tighter focus on selected samples of the socially excluded and measuring cognitive and educational performance as well as growth.

The quality of included studies improved over time. Some of the earlier studies (which go back to the 1920s) were probably excellent according to standards of their time, but were not described in enough detail to allow them to meet current quality criteria. Reports from studies in the 1960s and 1970s also lacked sufficient detail. Methodological quality was highest in the more recent studies from lower-income countries. Our process evaluation showed a great deal of variability in study implementation and in attention to important confounders. This is discussed more fully under potential confounders.

\section{A. Effects of school feeding on growth}

In this review, we found positive, significant effects of school feeding on weight in lower-income countries and mixed, but generally positive effects in higher income countries. Extrapolating from the average yearly gain seen in RCTS in our review, if meals were given throughout six years of primary school as suggested by Powell 1998 (A), total gains could be $1.3 \mathrm{~kg}$. Extrapolating from the CBA results suggests gains of $4.5 \mathrm{~kg}$ over the six year period of primary school.

In terms of height, results from lower income countries were mixed, but in higher income countries, results were moderate and positive. Interestingly, evidence from our subgroup analyses in lower income countries shows that height gain was significantly greater for younger children than for mixed age groups. However, it is difficult to determine whether this trend is due to age, or to low energy content of the interventions that did not seperate out children by age.

It is difficult to determine clinical significance for growth, particularly in this review. There are a number of reasons for this: 1) lack of standards for weight and height gain in school age children, 2) few studies presented data on baseline nutritional status and the importance of change depends on this, and 3) growth velocity will differ among different ages of school age children, and in most studies, results were not presented by age group. It is important to note, however, that effects on weight were small.

As noted in the introduction, growth may not be the most important outcome of school feeding. Other outcomes may have an important impact on education and on later functioning. These outcomes include: decreased morbidity, increased muscle mass, improved attention and behaviour, improved academic achievement and improved cognitive functioning. Although these benefits are sometimes seen at the same time as improved growth, it is essential to study them separately rather than infer them from increased growth.

\section{B. Other physical outcomes}

Results from one study suggested that school feeding with meat led to an increase in muscle mass. Grillenberger et al, when considering the Kenya study, hypothesized that the higher quality protein and more available micronutrients in the meat supplement may have been responsible for these differences. If this finding on increased muscle mass was replicated, it could be important, as increased muscle mass has important practical implications, including the potential for increased work and play capacity. However, it is important to note that, as this outcome was only assessed in one study, results can only be taken as preliminary (Grillenberger 2003, Neumann 2003).

One study (Du 2004) reported increased bone mineral content and bone mineral density in pre-adolescent Chinese girls who had been given milk fortified with calcium at school. The percentage change from baseline $(3.1 \%)$ is comparable to a $2 \%$ change reported in a systematic review of the effectiveness of calcium in post-menopausal women and of $1.8 \%$ found in a systematic review of the effectiveness of exercise in post-menopausal women. Higher BMD means stronger bones through life, and lower possibility of fracture. Further study in this area is clearly warranted.

\section{Effects on Biochemical outcomes}

It is difficult to draw any firm conclusions about the effects of school feeding on biochemical outcomes, as only a few studies reported on them. In those that did, results for haemoglobin and hematocrit were mixed, and except for Vitamin B12 and Vitamin $A$, other biochemical outcomes were unaffected by feeding. In the case of Vitamin A, Tisdall noted that differences were not clinically meaningful (Tisdall 1951). However, Seikmann (Neumann 2003) noted that the high prevalence of disease and infections among the children in their study could have accounted for their null biochemical findings. Furthermore, studies in this review focused on feeding rather than micronutrient supplementation.

\section{Psychological outcomes/ clinical relevance}

In general, there are two ways through which school feeding may impact on cognitive function; 1) long-term contributions of feeding to overall health and brain function and 2) short-term metabolic changes due to immediate energy supply (Pollitt 1995). Thus far in school feeding studies, only a few researchers have paid attention to the selection of appropriate cognitive outcome measures (Hughes 2003). None of the studies administered a comprehensive battery of neuropsychological tests, which would include intelligence, attention, processing speed, executive functioning, learning and memory, visual skills, motor and sensory performance, and academic achievement. With the exception of a few studies, test selection largely appeared arbitrary. The finding of affected cognitive functions is partially dependent on tests given. 
Most of the tasks administered in the reviewed studies emphasize processing speed, attention, working memory, semantic retrieval, and academic achievement. Very few studies focused on long-term memory retention, sensory or motor abilities.

In the majority of the studies included in this review, it is difficult to determine the clinical significance of the findings. Many of the reports fail to include the range, mean and standard deviation of the specific cognitive measures, fail to adequately describe the cognitive measures used or how conventional measures were adapted or modified, and how the reported scores were derived. Furthermore, there is no universally agreed-upon definition of clinical significance in this field. However, we were able to draw some inferences about clinical relevance.

Significant improvements in math performance were consistently found in studies from low income countries. Thus, we conclude that school feeding can result in improvements in math performance. The arithmetic measures used in these 4 studies vary and it is difficult to determine the clinical relevance of these statistically significant findings without further information about the psychometric properties of the tests. However, it seems as if the small effect found in the Kenya study (Whaley 2003; Neumann 2003)is probably not clinically significant. In contrast, authors of the Powell RCT (Powell 1998 (A)) noted that although the improvement in arithmetic as a result of breakfast was small, the increase represents about $30 \%$ of the average yearly progress. Furthermore, the difference found in the two CBAs represents a gain in the experimental group that is $1 / 3$ of a standard deviation greater thathe gain in controls.

Results from two studies suggest that school feeding may impact on intelligence type tests, but these results are far from conclusive. Results from the Agarwal study (a small CBA) are difficult to interpret because we had to use ICCs from achievement tests and significance differed according to whether subgroups or totals were used (this was due to differences in cluster size). If replicated, these results would be important. For example, the Performance IQ increase of 5 points represents a third of a standard deviation. The observed FSIQ increase of 4 points (one-fourth of a standard deviation) is comparable to that seen between breast-fed and formula fed infants, which is considered to be clinically significant and is used extensively to promote breast-feeding (Anderson 1999). For the Kenya study (Neumann 2003) on Raven's progressive Matrices, as the authors report that the range of scores on this test is 0-30, a 0.34-point per year advantage seems rather modest. In the Chandler study those who received breakfast generated 1.5 more words on average on the semantic verbal fluency task than controls. Assuming that scores across two categories were summed, the undernourished children in the treatment group generated less than 1 additional word per category relative to controls. A review of norms for 1 minute semantic verbal fluency tasks (similar to those used by Chandler et al) for 8 and 9 year olds reveal standard deviations in the range of 2.7 to 3.9 words per category (Halperin 1989). Thus, a relative increase of less than one word per category is probably not clinically significant.

Although there are discrepancies, most of the psychosocial outcomes in this review that improved as a result with school feeding are related. These include: fluid intelligence, processing speed, and arithmetic. These functions require more concentration and attention; and application of skills and/or rules to novel situations. In contrast, outcomes such as spelling achievement are done by rote. It has been hypothesized that these cognitive functions are highly dependent on the functional integrity of the central nervous system (CNS) and may fluctuate from moment to moment due to physical or emotional factors (Belsky 1990).

\section{Effects on School Attendance}

One of the most commonly cited benefits of school feeding is in improved attendance. The mechanisms for enhancing attendance may include not only the attraction of a free meal, but also possible effects on immune function that reduce illness and the effect on concentration that may make school more enjoyable.

The results of this review are consistent with other findings showing that school meals can improve school attendance in lower income countries. However, effects were small. Taking estimates from the two RCTs together, in a school year of 172 days a year (i.e. Peru), this would mean an increase of 4 to 6 days per year. The improvement in attendance noted in three CBAs in the United States was lower (and non-significant). This difference may be due to the fact that children in higher-income countries had more regular attendance at baseline than those from lower-income countries. It may also be due to the fact that families in lower-income countries were more motivated by the prospects of receiving food. This fits well with the high non-compliance rate we observed in many of the North American studies. These studies suggest that the impact of free school meals on school attendance may be greatest in areas of greatest poverty.

Improved attendance could mean greater opportunities for learning and mental stimulation and consequently, improved academic performance, more opportunities for social interaction with adults and peers, and possibly, a better attitude towards school. However, it is difficult to say whether the projected 4 to 6 days of increased attendance per year in lower and lower-middle income countries is sufficient to result in such changes.

\section{Behaviour}

Playground activity. Results from one study in our review indicate that playground activity levels, particularly pro-social activity, are higher for those who received school meals; although absolute differences are small, relative differences are large.

Evidence from three of our included studies shows that school feeding may have positive effects on classroom behaviour in both high and low income countries. However, as discussed below, effects may depend on the quality of the educational environment. 


\section{Possible Confounders}

There are a number of factors that could have impacted on effectiveness; here we provide details on a few of them. It is important to note that although potential confounders are looked at individually, the reality is much more complex and confounders are likely highly intertwined.

\section{Substitution}

As mentioned in the introduction, one important concern in school feeding studies is substitution. In poor families, to spread limited resources, the home diet may be reduced for children who are receiving food at school. In two studies that assessed substitution (Agarwal 1989; Jacoby 1996), the net increase in energy realized by the children was less than half of that provided by school feeding (breakfast and lunch). In the Kenyan study, the net increase was 140 out of 239 calories for the meat group (our experimental group). Children who were given the 'milk' and 'energy' supplements actually showed net decreases of more than 100 calories. This may reduce the effectiveness of school feeding programs on children's growth and cognitive performance. Therefore, experts recommend that the amount and composition of food should be sufficient to overcome this problem. It may be that a mid-morning meal could help prevent substitution since it would be seen as a snack, not a meal (personal communication, Galloway 2006). Our data do not allow us to explore this hypothesis since none of these three studies with data on substitution used mid-morning snacks.

Interestingly, the results from the Kenyan Study (Murphy 2003; Neumann 2003) suggest that parents of control children may compensate for the fact that their children don't get fed at school. Over the 24 month period of the study, energy increase for the children in the control group increased by nearly 200 calories. This finding may be peculiar to this particular study, but it is quite interesting.

\section{D2. Energy intensity of meal/snack}

It seems logical that the energy intensity provided by school meals would impact on outcome. Our review provides some support for this hypothesis. Three (Bailey 1962; Baker 1980; Neumann 2003) that provided low energy levels ( 9,5 , and 13 percent, respectively) showed either small or null effects on weight and height, while two (Du 2003; Paige 1976) showed effectiveness for both, and another one (Leiberman 1976) did not report changes in weight relative to controls. However, in the two low energy studies that showed effectiveness (Du 2003; Paige 1976) fortified milk or drink was provided; this may have produced positive results in the absence of high energy. Furthermore, students in the Du study that did not drink the milk on $>4$ days were excluded from the analyses, indicating a high compliance rate for this study (Du 2004). Therefore, although the energy content was higher in some studies, children may have been ingesting more calories and other nutrients due to higher compliance.

\section{D3. Pupil / student compliance}

Another factor that is almost certain to impact on effectiveness is compliance. While compliance rates were very high in the Kenya study (Neumann 2003), two studies from higher income countries (Lieberman 1976; Tisdall 1951) reported very low compliance rates. It is therefore, not surprising that these studies showed little effect. Results from Tisdall (Tisdall 1951) substantiate the idea that children who attend regularly are more likely to benefit. In analyses comparing 'good attenders' to 'poor attenders' and controls, the 'good attenders' did better than the poor attenders. In addition, Du 2004 eliminated non-compliant children (those not taking the milk supplement on $>4$ days for any reason) from analyses and had large effects for both weight and height gain. Thus, it seems as if compliance can indeed affect outcomes of school feeding. Most studies in the review did not report on compliance. We suggest that in the future, compliance be carefully monitored and reported.

The lack of compliance shown in several studies in high income countries suggests that school feeding programs in higher income countries should take measures to increase compliance. Timing of the meal may be important in high income countries; it seems logical that students would be less likely to attend school breakfast (which means leaving home early) than they would be to attend lunch or a snack session.

The degree to which those who implement the intervention comply with the protocol (e.g. continuous provision of food, complying with group assignment) is very likely to impact on results. For example, in the Shemilt study, some experimental schools implemented breakfast clubs before baseline measurements could be taken; others (4 out of 17) did not have breakfast clubs at the time of first follow-up (Shemilt 2004). Also, two of the control groups provided breakfast at the time of the first follow-up. This type of contamination could have influenced results, although the extent of this influence is not clear.

\section{D4. Short-term reduction in hunger}

Evidence from this and other reviews (Pollitt 1995) shows that short-term relief of hunger through breakfast can improve performance on cognitive tasks carried out on the same morning. Thus, in long-term studies, it is quite important to control for this by giving a meal to all children on the day of testing. In that way, researchers can determine whether results are due to the longterm effects of providing food rather than simply to immediate improvements as a result of morning feeding. However, only one of the longer-term studies in this review (Powell 1983) did this. We would suggest that in the future, all studies assessing the impact of feeding on outcomes such as intelligence, neuropsychological functioning, and academic achievement should consider 
controlling for the effects of hunger by feeding children in both the intervention and control groups.

\section{D5. Study duration}

For growth, one would expect to see effects on weight with shorter study durations, and effects on height only with longer durations. In this review, studies that assessed growth were generally of long duration; the shortest was seven months. In reviewing the results, it is difficult to discern any clear pattern by duration of the study. The Du study (Du 2004) was the longest at 24 months and showed large changes in height, but others with similar durations of 23 months (e.g. Grillenberger (Neumann 2003) had smaller effects. It is possible that the very large changes shown in the Du study were due to factors other than study duration (e.g. compliance and addition of calcium).

For cognition, the importance of study length depends on the outcome measure. It is reasonable to expect to see improved attention and concentration following short-term interventions, while increased performance in other cognitive domains may be demonstrated only following longer feeding intervals. Two studies in this review have suggested that when performance is evaluated using a mechanical, stimulus-response format (for example, "put a ring round all the letter As on this page"), short-term feeding has little impact on performance, whereas if the test involves a greater degree of creativity and motivation and the expenditure of cognitive effort (for example, "name as many animals as you can in time limit $Y^{\prime \prime}$ ), feeding has a significant effect. For example, the Chandler study (Chandler 1995) showed a small impact on verbal fluency for children who were at least one standard deviation below normal weight-for-age. However, this improvement was not seen in other tasks that are more rote such as digit span or information processing.

Within the longer-term interventions, it is difficult to discern whether or not a pattern exists according to length of the study. This is largely due to the fact that outcomes were so different, and few could be combined. For math, effects were strongest for the Agarwal study (Agarwal 1989 ), which lasted longest 24 months. The Kenya study (Neumann 2003)) lasted 23 months, however, and effects were quite small.

The interval between feeding and cognitive testing may also prove to be an important variable. It is expected that feeding would have immediate, but short-lived effects on cognitive processes such as processing speed and attention. Measurement of these functions should occur within minutes or hours of the feeding in order to quantify these changes. In contrast, feeding programs of a longer duration, such as months to years would be required to effect improvements on language, learning or academic tests and the interval between feeding and testing is less important when measuring these functions.

\section{D6. Benevolent attention}

A mechanism of action, implicit in some later studies, is that provision of school breakfast makes children feel valued and increases the general attention given to them. According to Powell (Powell 1983), benevolent attention may be possible confounding factor in school feeding studies. Thus it is important to ensure that children in the control group receive the same amount of attention as those in the experimental group. However, in the Powell 1983 study, benevolent attention didn't seem to make a difference. Despite this, we conclude that control groups in school-based feeding studies should receive benevolent attention in order to control for this potential confounder.

D7. Quality of the educational environment

The quality of the educational environment plays an important role in learning. For example, Levinger (Levinger 1996) noted that quality of instruction, teacher quality, and quality of the learning materials can play an important role in improving children's capacity to learn. There is some evidence for this in a sub-study of the larger Chandler study. Here, improvements in behaviour were only seen in one school that was 'adequately equipped and organized'. Chang speculated that when classroom conditions were conducive to learning, the extra energy provided by breakfast could result in improved behaviour. However, when the atmosphere for learning was poor, this extra energy could not be channelled appropriately.

\section{E Effect modifiers}

\section{EI Age}

Evidence from this review shows that younger children realize greater height benefits than older children. However, it is important to note that few studies on growth involved older children and that some of our studies did not separate out age groups.

Few studies in our review assessed the interaction between age and treatment effectiveness on cognition, although one study did show that younger children benefited more from feeding.

\section{E4. Sex}

We found that there was generally little evidence for difference in effectiveness by sex.

In terms of cognition, developmental studies have shown that sex differences in cognition in children are evident as early as the age of five. For example, girls are more proficient than boys in verbal memory, (Maccoby 1974; Kramer 1997) verbal fluency and spelling (Gaddes 1975; Barr 2003) and one study suggested that in adolescence, females surpass males in information processing speed and working memory (Barr 2003). Thus, we might expect to find sex differences in cognitive responsiveness to school feeding. However, none of the studies presented data on this topic. We also found no discussion of potential cultural and social differences (e.g. in food intake at home) according to sex. 
Considering that the World Food Program strategic plan includes reduction of sex disparities as a goal of school-feeding, the relationship between sex and the effectiveness of school meals clearly warrants further investigation.

\section{F. Equity question: Effectiveness by level of disadvantage}

Results from this review provide some preliminary evidence that school meals may be more effective for those who are more in need. Furthermore, relative to controls, undernourished children showed greater gains in short-term cognitive performance than did well nourished children. The findings on short-term cognition support Pollitt's (Pollitt 1995) conclusions that children who are undernourished seem to be more responsive cognitively to shortterm increases in energy.

A further bit of evidence for greater effectiveness in poorer children is suggested by our findings that: 1) effects on attendance and cognition were greater in low income countries, 2) within more recent studies, effects on weight were higher in lower income countries, and 3) effects from very old studies in higher income countries were highest. The latter finding can be explained by that fact that children in the Corry-Mann study were from a home for destitute, or orphaned boys in 1920s England, and that the Orr study was performed in a mining village in 1920s Scotland in a time of recession and, unemployment. Thus these children were very disadvantaged.

However, it is very important to note that data on effectiveness by level of disadvantage was very limited.

\section{A U THORS' CONCLUSIONS}

\section{Implications for practice}

School meals may have a number of small benefits for children. In the studies reviewed, school meals resulted in small improvements in weight, height in younger children, attendance, math performance, and behaviour. Evidence suggests a possible impact on intelligence tests, but replication is needed. Evidence from single studies shows that school meals may also increase bone mineral density, arm muscle, and Vitamin B concentrations. The magnitude of benefits realized are probably dependent on the design of the program, amount of energy and other nutrients provided by the meal/snack, baseline nutritional status, conditions for learning in the classroom, timing of meal/snack, substitution and social environment at home, age of the child, and not surprisingly, on compliance. However, it is unrealistic to expect that school meals or any other single intervention can be a panacea for all of the deprivation of children living in poverty.
In considering the worth of school meals, it is also important to consider intangibles such as the worth and pleasure derived from having a full stomach and eating a good meal. This is something qualitative that it is difficult to measure adequately, but the relief of hunger alone is important.

School meal programs should be well-designed, and provide sufficient energy, protein, fat and micronutrient content for children's age and baseline nutritional status. Special attention should be paid to ensure that micronutrients important for growth, physical health, and cognition such as iodine, iron, zinc, Vitamin B12 , and calcium are provided. The amount and type of fat and cholesterol should also be taken into account given their role in structure and function of parts of the brain which continue to develop into adolescence and influence cognitive outcome. Since 1969, the pattern of nutritional status in high-income countries has shifted from under-nutrition to increasing obesity (Dubois 2006). Thus, in higher income countries, it is important to provide well-balanced meals that are not overly energy or fat laden.

Palatability and special needs of the target population are also extremely important. Food should be appealing, acceptable, and locally available. Most of the researchers in included studies went to a great deal of trouble to ensure that foods were culturally acceptable and tempting to the palate. In terms of digestibility, Paige hypothesized that the African-American children in the population studied had a high prevalence of lactose deficiency (that is, they were intolerant of milk), as evidenced by the fact that in a pilot study, $25 \%$ of them had rejected a cow's milk supplement even when chocolate flavoured. The definitive intervention comprised a specially formulated low-lactose milk supplement tailored to the particular physiological make-up of the population and refined in response to the children's feedback on its palatability; a significant impact on growth was demonstrated. This study prompts the additional conclusion that piloting a school nutrition intervention is not just about confirming palatability, but about identifying specific nutritional issues / needs in the program's target population. Follow-up results from one study in the developing world reported that most effects of feeding with milk disappeared three years after feeding stopped; this would suggest that school feeding should be continued throughout school years (Du 2004).

\section{Implications for research}

Considering the dearth of high quality evidence on school meals, as well as the complexity of our findings, we conclude that further well-designed research is needed in both lower and higher income countries. RCTs are needed in order to ensure that causality can be attributed. We suggest randomisation by school, and appropriate statistical methods to account for cluster randomization. In order to more clearly answer the question about effects by level of disadvantage, we would like to see all primary researchers provide breakdowns of effects by socio-economic status of parents as well as by sex and baseline nutritional status. Double blinding should 
also be considered in terms of providing, meals/snacks with similar appearance but high and negligible content of energy and other nutrients (e.g. high and low calorie milk shakes).

In conducting studies, attention needs to be paid to ensuring that the intervention is delivered as intended. Process evaluation is crucial. As shown in this review, it is very important to encourage full participation, and to measure participation, and consumption carefully.. We might tentatively conclude for future trials that measuring non-consumption of food is best done for each individual child. Substitution should also be monitored. We also conclude that studies on long-term effects of school feeding should feed children in both groups on the day of testing to control for the relief of short-term hunger. Other factors such as benevolent attention and quality of educational environment should also be considered.

We suggest that in terms of physical health, important outcomes are: changes in weight and height, muscle mass, body fat percentage, micronutrient status, physical activity, and bone mineral density. Weight is an important outcome, both in lower income countries where programs seek to increase growth of under-nourished children, and in high income countries where school feeding programs increasingly aim to reduce childhood obesity rather than increase growth.

For psychosocial outcomes, attendance, enrolment, and retention in school are all highly important for lower-income countries. This is particularly true for girls. As education of the populace is key to a country's improved development, school feeding should be combined with other interventions that aim to improve country educational attainment. It is essential to measure educational achievement and cognitive outcomes in all countries. We suggest that in the next generation of studies of school feeding on cognitive performance, the choice of tests should be explicitly hypothesis-driven so as to discriminate between different cognitive and motivational effects. It is important to measure a full range of brain function with neuropsychological testing: we suggest a comprehensive assessment of intelligence, processing speed, attention, executive functions, memory, language, visual-abilities and motor and sensory function. In order to disentangle the effects of short-term hunger relief from long-term physiological changes, we suggest that all children be fed before psychological testing.

School meal programs take place in a context which may sig- nificantly impact on their effectiveness. As noted by Levinger (Levinger 1986), greater improvements can be expected if the environment in which children live and learn is also improved. Thus, in addition to school meals, schools should have the basic amenities necessary to good education: adequate materials, good teaching, and an emphasis on development of the whole child. Others such as Glew have emphasized the importance of improvements in water supply, health, and health education (Glew 1980) while Del Rosso (Del Rosso 1999) emphasized micronutrient fortification or supplementation and health and nutrition education. As others have suggested (Levinger 1986; Del Rosso 1999) we conclude that school meals should be one of multiple interventions designed to improve the health and development of poor and marginalized children.

\section{ACKNOW LEDGEMENTS}

We would like to express our thanks and sincere gratitude to Geraldine Macdonald, Jane Dennis, Jo Abbott and Georgia Salanti for all of their help and hard work on this review. We would also like to thank three anonymous reviewers and two Campbell methods reviewers for their important feedback. This review has benefited immensely from all of their input.

We would like to thank the Cochrane Health Promotion and Public Health Field for providing a bursary to fund protocol development, and the Canadian Institutes of Health Research for personnel funding in the form of a postdoctoral fellowship to the primary author.

Importantly, we need to thank the primary study authors who went above and beyond the call of duty to send us needed information: Susan Walker of the Powell study team, Quang Zhang of the Du study team, Ernesto Pollitt and Cueto of the Peruvian study team, Charlotte Neumann of the Kenyan study team, and Ian Shemilt. We greatly appreciate their help.

We would also like to thank Francisco Espejo, Chiara Bruneli, and Aulo Gelli of the World Food Program for references and for helpful comments.

Finally, we would also like to thank the following research assistants for their dedicated and careful work: Carl Wilkins, Daniel Francis, Caitlin Burley, Alicia Ashton, Megan Kendall, and Joan Peterson. 


\section{R E F E R E N C E S}

\section{References to studies included in this review}

Agarwal 1989 \{published data only\}

Agarwal DK, Agarwal KN, Upadhyay SK. Effect of mid-day meal programme on physical growth \& mental function. Indian Journal of Medical Research 1989;90:163-174.

Agarwal 1989 (girls) \{published data only\} Agarwal DK, Agarwal KN, Upadhyay SK. Effect of mid-day meal programme on physical growth \& mental function. Indian Journal of Medical Research 1989;90:163-174.

Agarwal 1989 - boys \{published data only\} * Agarwal DK, Agarwal KN, Upadhyay SK. Effect of mid-day meal programme on physical growth $\&$ mental function. Indian Journal of Medical Research 1989;90: 163-174.

Agarwal 1989 boy 10y \{published data only\} Agarwal DK, Agarwal KN, Upadhyay SK. Effect of mid-day meal programme on physical growth $\&$ mental function. Indian Journal of Medical Research 1989;90:163-174.

Agarwal 1989 boys $7 y$ \{published data only\} Agarwal DK, Agarwal KN, Upadhyay SK. Effect of mid-day meal programme on physical growth \& mental function. Indian Journal of Medical Research 1989;90:163-174.

Agarwal 1989 boys 8y \{published data only\} Agarwal DK, Agarwal KN, Upadhyay SK. Effect of mid-day meal programme on physical growth \& mental function. Indian Journal of Medical Research 1989;90:163-174.

Agarwal 1989 boys 9y \{published data only\} Agarwal DK, Agarwal KN, Upadhyay SK. Effect of mid-day meal programme on physical growth \& mental function. Indian Journal of Medical Research 1989;90:163-174.

Agarwal 1989 girl 10 \{published data only\} Agarwal DK, Agarwal KN, Upadhyay SK. Effect of mid-day meal programme on physical growth $\&$ mental function. Indian Journal of Medical Research 1989;90:163-174.

Agarwal 1989 girl 7y \{published data only\} Agarwal DK, Agarwal KN, Upadhyay SK. Effect of mid-day meal programme on physical growth \& mental function. Indian Journal of Medical Research 1989;90:163-174.

Agarwal 1989 girl 8y \{published data only\} Agarwal DK, Agarwal KN, Upadhyay SK. Effect of mid-day meal programme on physical growth $\&$ mental function. Indian Journal of Medical Research 1989;90:163-174.

Agarwal 1989 girl 9y \{published data only\} Agarwal DK, Agarwal KN, Upadhyay SK. Effect of mid-day meal programme on physical growth \& mental function. Indian Journal of Medical Research 1989;90:163-174.

Agarwal 1989 grade I \{published data only\} Agarwal DK, Agarwal KN, Upadhyay SK. Effect of mid-day meal programme on physical growth $\&$ mental function. Indian Journal of Medical Research 1989;90:163-174.
Agarwal 1989 grade2 \{published data only\}

Agarwal DK, Agarwal KN, Upadhyay SK. Effect of mid-day meal programme on physical growth $\&$ mental function. Indian Journal of Medical Research 1989;90:163-174.

Agarwal 1989 grade3 \{published data only\} Agarwal DK, Agarwal KN, Upadhyay SK. Effect of mid-day meal programme on physical growth \& mental function. Indian Journal of Medical Research 1989;90:163-174.

Agarwal 1989 normal \{published data only\} Agarwal DK, Agarwal KN, Upadhyay SK. Effect of mid-day meal programme on physical growth \& mental function. Indian Journal of Medical Research 1989;90:163-174.

Agarwal total \{published data only\} Agarwal DK, Agarwal KN, Upadhyay SK. Effect of mid-day meal programme on physical growth \& mental function. Indian Journal of Medical Research 1989;90:163-174.

Bailey 1961 \{published data only\} Bailey KV. Rural nutrition studies in Indonesia IX. Feeding trial on schoolboys. Tropical and Geographical Medicine 1962;14:129-139.

Bailey 1962 \{published data only\}

Bailey KV. Rural nutrition studies in Indonesia IX. Feeding trial on schoolboys. Tropical and Geographical Medicine 1962;14:129-139.

Baker 1980 ( boys) \{published data only\}

* Baker I, Elwood PC, Hughes J, Jones M, Moore F, Sweetnam PM. A randomized controlled trial of the effect of the provision of free school milk on the growth of children. Journal of Epidemiology and Community Health 1980;34: 31-34.

Baker girls 1980 \{published data only\}

Baker I, Elwood PC, Hughes J, Jones M, Moore F, Sweetnam PM. A randomized controlled trial of the effect of the provision of free school milk on the growth of children. Journal of Epidemiology and Community Health 1980;34: 31-34.

Baker total 1980 \{published data only\}

Baker I, Elwood PC, Hughes J, Jones M, Moore F, Sweetnam PM. A randomized controlled trial of the effect of the provision of free school milk on the growth of children. Journal of Epidemiology and Community Health 1980;34: 31-34.

Bro 1994 \{published data only\}

Bro, R.T, Shank, L, Williams, R, McLaughlin. T.F. The effects of an in-class breakfast program on attendance and on-task behaviour of high school students. Child and Family Behaviour Therapy 1994;16:1-8.

Bro 1996 \{published data only\}

Bro RT, Shank LL, McLaughlin TF, Williams RL. Effects of a breakfast program on on-task behaviors of vocational high school students. Journal of Educational Research 1996; 90(2):111-115. 
Chandler 1995 \{published data only\}

* Chandler AM, Walker SP, Connolly K, GranthamMcGregor SM. School breakfast improves verbal fluency in undernourished Jamaican children. Journal of Nutrition 1995;125(4):894-900.

Devadas RP, Jamala S, Surabhi A, Murthy NK. Evaluation of a food supplement to school children. Indian Journal of Nutrition and Dietetics 1979;16:335-341.

Chandler Under \{published data only\}

Chandler AM, Walker SP, Connolly K, GranthamMcGregor S. School Breakfast improves verbal fluency in undernourished Jamaican children. Journal of Nutrition 1995;125:894-900.

Chang SM, Walker SP, Himes J, Grantham-McGregor SM. Effects of breakfast on classroom behavioru in rural Jamaican schoolchildren. Food and Nutrition Bulletin 1996; 17:248-257.

Corry-Mann 1926 \{published data only\}

* Corry-Mann, H.C. Diets for boys during the school age. Medical Research Council Special Report Series 1051926.

Devadas1979: 5-6 \{published data only\}

Devadas RP, Jamala S, Surabhi A, Murthy NK. Evaluation of a food supplement to school children. Indian Journal of Nutrition and Dietetics 1979;16:335-341.

Devadas 1979: 6-7 \{published data only\}

Devadas RP, Jamala S, Surabhi A, Murthy NK. Evaluation of a food supplement to school children. Indian Journal of Nutrition and Dietetics 1979;16:335-341.

Devadas 1979:7-8 \{published data only\}

Devadas RP, Jamala S, Surabhi A, Murthy NK. Evaluation of a food supplement to school children. Indian Journal of Nutrition and Dietetics 1979;16:335-341.

Du 2004 \{published data only\}

Du X. Personal Communication: Calculations accounting for clustering 2006.

Du X, Zhu K, Trube A, Fraser DR, Greenfield H. Effects of school-milk intervention on growth and bone mineral accretion in Chinese girls aged 10-12 year: accounting for cluster randomisation (Letter). British Journal of Nutrition 2005;94:1038-1039.

Du X, Zhu K, Trube A, Zhang Q, Ma G, Hu X, Fraser $\mathrm{D}$, Greenfield H. School-milk intervention trial enhances growth and bone mineral accretion in Chinese girls aged 10-12 years in Beijing. British Journal of Nutrition 2004;92: 159-168.

Shu K, Du X, Greenfield H, Zhang Q, Ma G, Hu X, Fraser DR. Bone mass in Chinese premenarcheal girls: the roles of body composition, calcium intake and physical activity. British Journal of Nutrition 2004;92:985-93.

Zhu K, Du X, Cowell CT, Greenfield H, Blades B, Dobbins TA, Zhang Q, Fraser DR. Effects of school milk intervention on cortical bone accretion and indicators relevant to bone metabolism in Chinese girls aged 10-12 y in Beijing. American Journal of Clinical Nutrition 2005;81: 1168-75.

Zhu K, Zhang Q, Foo LH, Trube A, Ma G, Hu X, Du X, Cowell CT, Fraser DR, Greenfield H. Growth, bone mass and vitamin D status of Chinese adolescent girls $3 \mathrm{y}$ after withdrawal of milk supplementation. American Journal of Clinical Nutrition 2006;83:714-21.

Jacoby 1996 \{published data only\}

* Jacoby E, Cueto S, Pollitt E. Benefits of a school breakfast among Andean children in Huaraz, Peru. Food and Nutrition Bulletin 1996;1:54-64.

Jacoby ER, Cueto S, Pollitt E. When science and politics listen to each other: good prospects from a new school breakfast program in Peru. American Journal of Clinical Nutrition 1998;67(4):795S-797S.

Lieberman 1976 \{published data only\} Lieberman H.M, Hunt I.F, Coulson A.H, Clark V.A, Swendseid M.E, Ho L. Evaluation of a ghetto school breakfast program. J Am Diet Assoc 1976;68(2):132-138.

Neumann 2003 \{published data only\} Grillenberger, M, Neumann, C.G, Murphy, S. P, Bwibo, N.O, van't Veer. P, Hautvast, J, West. C. Food supplements have a positive impact on weight gain and the addition of animal source foods increases lean body mass of Kenyan schoolchildren. Journal Nutr. 2003;133 (11 Suppl 2.): 3957S-3964S.

Murphy SP, Gewa C, Liang LJ, Grillenberger M, Bwibo NO, Neumann CG School snacks containing animal source foods improve dietary quality for children in rural Kenya. J Nutr 2003, 133(11 Suppl 2):3950S-3956S. School snacks containing animal source foods improve dietary quality for children in rural Kenya School snacks containing animal source foods improve dietary quality for children in rural Kenya. J Nutr 2003;133(11 Suppl 2):3950S-3956S. Journal of Nutrition 2003;133(11 (Suppl 2)):3950S-3956S * Neumann C, Bwibo NO, Murphy SP, Sigman M, Whaley S, Allen L.H, et al.Animal Source Foods improve Distary quality, micronutrient status, growth, and cognitive function in Kenyan school children: Background, study design, and baseline findings.. Journal of Nutrition 2003; 133 (11 Supplement 2):3941S-3949S.

Siekmann, J.H, Allen, L.H, Bwibo, N.O, Demment, M.W, Murphy, S.P, Neumann. C.G. Kenyan school children have multiple micronutrient deficiencies, but increased plasma Vitamin B-12 is the only detectable micronutrient response to meat or mild supplementation. Journal of Nutr. 2003; 133 (11 Suppl. 2):3972S-3980S.

Whaley, S.E, Sigman, M, Neumann, C, Bwibo, N, Guthrie, D, Weiss, R.E, Alber, S, Murphy. S.P. The impact of dietary intervention on the cognitive development of Kenyan schoolchildren. Journal Nutr. 2003;133 (11 Suppl. 2): 3965S-3971S.

Orr 1928 - 13 yrs \{published data only\}

Leighton, G, Clark, M. Milk consumption and the growth of school-childrren. Lancet 1929;1:40-43.

Orr JE. Milk consumption and the growth of school children. Lancet 1928;i:202-203.

Orr 1928 - 6 yrs \{published data only\}

Orr JE. Milk consumption and the growth of school children. Lancet 1928;i:202-203. 
Orr 1928 - 9 yrs \{published data only\}

Orr JE. Milk consumption and the growth of school children. Lancet 1928;i:202-203.

Paige 1976 \{published data only\}

Paige DM, Cordano AP, Huang SS. Nutritional supplementation of disadvantaged elementary-school children. Pediatrics 1976;58:697-703.

Paige 7 year olds \{published data only\} Paige DM, Cordano AP, Huang SS. Nutritional supplementation of disadvantaged elementary-school children. Pediatrics 1976;58:697-703.

Paige 8 year olds \{published data only\} Paige DM, Cordano AP, Huang SS. Nutritional supplementation of disadvantaged elementary-school children. Pediatrics 1976;58:697-703.

Powell 1983 \{published data only\}

Powell C, Grantham-McGregor S, Elston M. An evaluation of giving the Jamaican government school meal to a class of children. Human Nutrition - Clinical Nutrition 1983;37C (5):381-388.

Powell CA, Walker SP, Grantham-McGregor, SM. Nutrition and education: a randomized trial of the effects of breakfast in rural primary school children. American Journal of Clinical Nutrition 1998;68:873-879.

Powell 1998 (A) \{published data only\}

* Powell CA, Walker SP, Grantham-McGregor, SM. Nutrition and education: a randomized trial of the effects of breakfast in rural primary school children. American Journal of Clinical Nutrition 1998;68:873-879.

Powell 1998 Total \{published data only\}

Powell CA, Walker SP, Grantham-McGregor, SM. Nutrition and education: a randomized trial of the effects of breakfast in rural primary school children. American Journal of Clinical Nutrition 1998;68:873-879.

Powell 1998(u) \{published data only\} Powell CA, Walker SP, Grantham-McGregor, SM. Nutrition and education: a randomized trial of the effects of breakfast in rural primary school children. American Journal of Clinical Nutrition 1998;68:873-879.

Shemilt 2004 \{published data only\} Shemilt I, Harvey I, Shepstone L, Swift L, Reading R, Mugford M, Belderson P, Norris N, Thoburn J, Robinson J. A national evaluation of school breakfast clubs: evidence from a cluster randomized controlled trial and an observational analysis. Child: Care, Health and Development 2004;30(5):413-427.

Shemilt I, Mugford M, Moffatt P, Harvey I, Reading R, Shepstone L, Belderson P. A national evaluation of school breakfast clubs: where does economics fit in?. Child: Care, Health \& Development 2004;30(5):429-37.

Tisdall 1951 \{published data only\}

Tisdall FF, Robertson EC, Drake TG, Jackson SH, Fowler HM, Long JA, et al.The Canadian Red Cross School Meals Study. Canadian Medical Association Journal 1951;64: 477-489.

\section{References to studies excluded from this review}

Ahmed 2004 \{published data only\}

Ahmed AU. Impact of Feeding Children in School: Evidence from Bangladesh. Washington, DC: International Food Policy Research Institute (IFPRI), 2004.

Arvedson 1969 \{published data only\} Ardvedson I, Sterky G, Tjernstrom K. Breakfast habits of Swedish school children. Journal of the American Dietetic Association 1969;55:257-61.

Cadogan 1997 \{published data only\} Cadogan J, Eastell R, Jones N, Barker ME. Milk intake and bone mineral acquisition in adolescent girls: randomized, controlled intervention trial. British Medical Journal 1997; 315:1255-60.

Cook 1996 \{published data only\} Cook JT, Ohri-Vachaspati P, Kelly GL. Evaluation of a Universally-Free School Breakfast Program Demonstration Project. Centre on Hunger, Poverty and Nutrition Policy. Tufts University School of Nutrition Science and Policy 1996:1-20.

Cromer 1990 \{published data only\} Cromer BA, Tarnowski KJ, Stein A, Harton P, Thornton DJ. The school breakfast program and cognition in adolescents. Developmental and Behavioral Pediatrics 1990; 11(6):295-300.

Fellers 1967 \{published data only\} Fellers S. A study of the effects of breakfast on scholastic attainment, drop-out rate, and knowledge of nutrition among high school sophomores. Unpublished Doctorate Dissertation 1967.

Guthrie 1977 \{published data only\} Guthrie HA. Effect of a flavoured milk option in a school lunch program. Journal of the American Dietetic Association 1977;71(1):35-40.

Lopez 1993 \{published data only\} Lopez I, de Andraca I, Perales CG, Heresi E, Castillo M, Colombo M. Breakfast omission and cognitive performance of normal, wasted and stunted schoolchildren. European Journal of Clinical Nutrition 1993;47:533-42.

Morrell 2002 \{published data only\}

Morrell G, Atkinson DR. Effects of breakfast program on school performance and attendance of elementary school children. Education 2002;98(2):111-6.

Simeon 1989 \{published data only\} Simeon DT, Grantham-McGregor S. Effects of missing breakfast ont he cognitive functions of school children of differing nutritional status. American Journal of Clinical Nutrition 1989;49:646-53.

Tuttle 1954 \{published data only\} Tuttle WW, Daum K, Larsen R, Salzano J, Roloff Louise. Effect on school boys of omitting breakfast. Journal of the American Dietetic Association 1954;30:674-7.

Vaisman 1996 \{published data only\} Vaisman N, Voet H, Akivis A, Vakil E. Effect of breakfast timing on the cognitive functions of elementary school 
students. Archives of Pediatric Adolescent Medicine 1996; 150:1089-92.

\section{Additional references}

Allen 2001

Allen LH, Gillespie SR. What works? A Review of the Efficacy and Effectiveness of Nutrition Interventions. Manila, Philippines: Asian Development Bank with UN ACC/ ACN, 2001

Anderson 1999

Anderson JW, Johnstone BM, Remley DT. Breast-feeding and cognitive development: a meta-analysis. American Journal of Clinical Nutrition 1999;70(4):525-35.

Barr 2003

Barr WB. Neuropsychological testing of high school athletes: Preliminary norms and test-retest indices. Archives of Clinical Neuropsychology 2003;18:91-101.

Beaton 1982

Beaton G, Ghassemi H. Supplementary feeding programs for children in developing countries. American Journal of Clinical Nutrition 1982;35(4 Suppl):863-916.

\section{Beaton 1993}

Beaton G. Nutritional issues in food aid - which age groups should be targeted for supplementary feeding. Nutritional Issues in Food Aid, ACC/SCN Symposium Report. Nutrition Policy Discussion paper No. 12. Geneva: ACC/SCN, 1993.

Belsky 1990

Belsky J. The Psychology of Aging Theory, Research, and Interventions. Pacific Grove: Brooks/Cole Publishing Company, 1990

Calnan 2003

Calnan M, Ferlie E. Analysing process in healthcare; the methodological and theoretical challenges. Policy and Politics 2003;31(2):185-93.

\section{Campbell 2000}

Campbell M, Fitzpatrick R, Haines A, Kinmonth AL, Sandercock P, Spiegelhalter D, et al.Framework for design and evaluation of complex interventions to improve health. BMJ 2000;321(7262):694-6.

\section{Chang 1996}

Chang SM, Walker SP, Himes J, Grantham-McGregor $S$. Effects of breakfast on classroom behaviour in rural Jamaican schoolchildren. Food and Nutrition Bulletin 1996; 17(3):248-57.

\section{Coleman 2005}

Coleman KJ, Tiller CL, Sanchez J, Heath EM, Sy O, Milliken G, Dzewaltowski DA. Prevention of the epidemic increase in child risk of overweight in low-income schools: the El Paso coordinated approach to child health. Arch Pediatr Adolesc Med 2005;159(3):217-24.

Del Rosso 1999

Del Rosso JM. School Feeding Programs: Improving Effectiveness and Increasing the Benefit to Education A Guide for Program Managers. Oxford, UK: Partnership for Child Development, 1999.

\section{Dickie 1982}

Dickie $\mathrm{NH}$, Bender AE. Breakfast and performance in schoolchildren. British Journal of Nutrition 1982;48: 483-96.

Diderichsen 2001

Diderichsen F, Evans T, Whitehead M. The Social Basis of Disparities. In: Evans T, Whitehead M, Diderichsen F, Bhuiya A, Wirth M editor(s). Challenging Inequities in Health. From Ethics to Action. New York: Oxford University Health, 2001:12-23.

\section{Du 2005}

Du X, Zhu K, Trube A, Fraser DR, Greenfield H. Effects of school-milk intervention on growth and bone mineral accretion in Chinese girls aged 10-12 year: accounting for cluster randomisation (Letter). British Journal of Nutrition 2005;94:1038-1039.

Du 2006

Du X. Personal Communication: Calculations accounting for clustering 2006

Dubois 2006

Dubois L. Food, nutrition and population health: from scarcity to social inequalities. Chapter 6. In: Heyman J, Hertzman C, Barer ML, Evans RG editor(s). Healthier Societies: From analysis to action. New York: Oxford University Press, 2006.

Egger 1997

Egger M, Davey Smith G, Schneider M, Minder CE. Bias in meta-analysis detected by a simple graphical test. British Medical Journal 1997;315:629-634.

EPOC 2002

Cochrane Effective Practice and Organization of Care Group. The Data Collection Checklist. http:// www.epoc.uottawa.ca/checklist2002.doc 2002.

FAO 2004

Food, Agriculture Organization of the United Nations. The State of Food Insecurity in the World: 2004. Rome: Food and Angriculture Organization of the United Nations, 2004.

Gaddes 1975

Gaddes WH, Crockett DJ. The Spreen-Benton aphasia tests: Normative data as a measure of normal language development. Brain and Language 1975;2:257-80.

Galloway 2006

Galloway R. Personal email communication to author BK 2006 (August).

Glew 1980

Glew G. The contribution of large-scale feeding operations to nutrition. World Revue of Nutrition and Diet 1980;34: $1-45$.

Grantham-McGregor 05 Grantham-McGregor S. Can the provision of breakfast benefit school performance?. Food and Nutrition Bulletin 2005;26(2 (supplement 2)):S144-S158.

Grillenberger 2003

Grillenberger M, Neumann CG, Murphy SP, Bwibo NO, van't Veer P, Hautvast J, West C. Food supplements have 
a positive impact on weight gain and the addition of animal source foods increases lean body mass of Kenyan schoolchildren. Journal Nutrition 2003;133(11 (Suppl 2)): 3957S-3964S.

Halperin 1989

Halperin JM, Healey JM, Zeitchik E, Ludman WL, Weinstein L. Developmental aspects of linguistic and mnestic abilities in normal children. Journal of Clinical and Experimental Neuropsychology 1989;11:518-28.

\section{Hembroff 2004}

Hembroff LA, Holmes-Rovner M, Wills CE. Treatment decision-making and the form of risk communication: results of a factorial survey. BMC Medical Informatics and Decision Making 2004;4:20.

Higgins 2003

Higgins, JM, Thompson, SG, Deeks, JJ, Altman, DJ. Measuring Inconsistency in meta-analysis. British Medical Journal 2003;327:557-560.

\section{Higgins 2005}

Higgins JPT, Green S, editors. Cochrane Handbook for Systematic Reviews of Interventions 4.2.5 [updated May 2005] In: The Cochrane Library. Chichester, UK: John Wiley \& Sons, 2005.

Hughes 2003

Hughes D, Bryan J. The assessment of cognitive performance in children: considerations for detecting nutritional influences. Nutrition Reviews 2003;62(12): 413-22.

\section{Jadad 1996}

Jadad AR, Moore RA, Carroll D, Jenkinson C, Reynolds JM, Gavaghan DJ, McQuay HJ. Assessing the quality of reports of randomized clinical trials: is blinding necessary. Controlled Clinical Trials 1996;17:1-12.

\section{Kramer 1997}

Kramer J, Delis D, Kaplan E, O’Donnell L, Prifitera

A. Developmental sex differences in verbal learning.

Neuropsychology 1997;11:577-84.

\section{Last 1995}

Last JM (ed). A Dictionary of Epidemiology. London: Oxford University Press, 1995.

\section{Leslie 1990}

Leslie J, Jamison T. Health and nutrition considerations in education planning. 1. Educational consequences of health problems among school-age children. Food and Nutrition Bulletin 1990;12:191-203.

\section{Levinger 1986}

Levinger B. School feeding programs in developing countries: an analysis of actual and potential impact (Aid Evaluation Special Study No. 30, Document order number PN-AAL060). Washington, DC: U.S. Agency for International Development, 1986.

\section{Levinger 1996}

Levinger B. Nutrition, health and education for all. Education and Development Centre. Newton MA: Education and Development Center, Inc, 1996.
Luepker 1996

Luepker RV, Perry CL, McKinlay SM, Nader PR, Parcel GS, Stone EJ, Webber LS, Elder JP, Feldman HA, Johnson CC, et al.Outcomes of a field trial to improve children's dietary patterns and physical activity. The Child and Adolescent Trial for Cardiovascular Health. CATCH collaborative group. JAMA 1996;275(10):768-76.

\section{Maccoby 1974}

Maccoby EM, Jacklin CN. The psychology of sex differences. Palo Alto: Stanford University Press, 1974.

\section{Marchand 1998}

Marchand S, Wikler D, Landesman B. Class, health, and justice. The Milbank Quarterly 1998;76:449-67.

\section{McIntyre 1992}

McIntyre L, Dayle JB. Exploratory analysis of children's nutrition programs in Canada. Social Science and Medicine 1992;35:1123-9.

Murphy 2003

Murphy SP, Gewa C, Liang LJ, Grillenberger M, Bwibo NO, Neumann CG. School snacks containing animal source foods improve dietary quality for children in rural Kenya. Journal of Nutrition 2003;133(11 (Suppl 2)): 3950S-3956S.

\section{Papamandjaris 2000}

Papamandjaris A. Breakfast and learning in children: a review of the effects of breakfast on scholastic performance. York, Ontario: Breakfast for Learning Canadian Living Foundation, 2000.

\section{Peter 2001}

Peter F, Evans T. Ethical Dimensions of Health Equity. In: Evans T, Whitehead M, Diderichsen F, Bhuiya A, Wirth M editor(s). Challenging Inequities in Health. From Ethics to Action. New York: Oxford University Press, 2001:25-33.

\section{PHAC 1999}

Public Health Agency of Canada. Toward a healthy future: Second report on the health of Canadians ( http://www.phacaspc.gc.calph-sp/phdd/report/toward/: accessed November 2006). Ottawa: Minister of Public Works and Government Services, 1999.

\section{Pollitt 1978}

Pollitt E, Gersovitz M, Gargiulo M. Educational benefits of the United States School Feeding Program: A critical review of the literature. American Journal of Public Health 1978;68 (5):477-81.

\section{Pollitt 1995}

Pollitt E. Does breakfast make a difference in school?. Journal of the American Dietetic Association 1995;95(10): 1134.

\section{Read 1973}

Read MS. Malnutrition, hunger, and behavior. II. Hunger, school feeding programs, and behavior. Journal of American Dietetics Association 1973;63(4):386-391. 


\section{Sanchez 2005}

Sanchez P, Swaminathan MS, Dobie P, Yuksel N. Halving the hunger: it can be done (Summary version). New York: UN Millenium Project Task Force on Hunger, 2005.

\section{Schochet 2005}

Schochet PZ. Statistical power for Random Assignment Evaluations for Edication Programs. Contract No.: ED-01CO-0038-0009, MPR Reference No.: 6046-310. Princeton, NJ: Mathematica Policy Research Inc, 2005 (Available at: http://www.mathematica-mpr.com/publications/PDFs/ statisticalpower.pdf (Accessed Aug 15, 2006)).

\section{Scrimshaw 1998}

Scrimshaw NS. Malnutrition, Brain Development, Learning, and Behaviour. Nutrition Research 1998;18(2): 351-379.

Siekmann 2003

Siekmann JH, Allen LH, Bwibo NO, Demment MW, Murphy SP, Neumann CG. Kenyan school children have multiple micronutrient deficiencies, but increased plasma Vitamin B-12 is the only detectable micronutrient response to meat or mild supplementation. Journal of Nutrition 2003;133(11 (Suppl 2)):3972S-3980S.

Sullivan 2002

Sullivan DK, et al.A low-fat after school snack improves the nutritional quality of elementary school children's diets. Journal of the American Dietetic Association 2002;102(5): 707-9.

\section{Tan-Torres 2001}

Tan-Torres A, Edejar T. Health, poverty and equity at the close of the century. Forging Links for Health Research. Ottawa: Newfeld V, Johnson N, 2001

Ukoumunne 1999

Ukoumunne OC, Gulliford MC, Chinn S, Sterne JAC, Burney PGJ. Methods for evaluating area-wide and organisation based interventions in health and health care: a systematic review. Health Technology Assessment 1999;3(5): $1-108$.

UNESCO 2005

UNESCO Institute for Statistics. Children Out of School. Montreal: UNESCO Institute for Statistics, 2005.

\section{Walker 1986}

Walker, A, Walker. B. School nutrition programmes: do they fulfill their purpose?. Applied Nutrition 1986;40A: 125-135.

\section{Walker 2006}

Walker S. Personal communication to BK (email) 21 January 2006.

\section{WFB 2005a}

World Food Programme. WFO head calls on leaders to support universal school feeding for world's poor children. http://www.wfp.org/english/?ModuleID=137\&Key=464 2005.

\section{WFP 2005b}

World Food Programme. Fact Sheet: Food for Education. http://www.friendsofwfp.org/atf/cf/ \%7B90E7E160-957C-41E4-9FAB-87E2B662894B\%7D/ WFP\%20School\%20Feeding\%20Fact\%20SheetFeb\%2006.pdf 2005 .

Whaley 2003

Whaley SE, Sigman M, Neumann C, Bwibo N, Guthrie D, Weiss RE, Alber S, Murphy SP. The impact of dietary intervention on the cognitive development of Kenyan schoolchildren. Journal of Nutrition 2003;133(11 (Suppl 2)):3965S-3971S.

\section{Wilkins 1983}

Wilkins R, Adams O. Healthfulness of Life. Montreal: Institute for Research on Public Policy, 1983.

Wilkinson 1996

Wilkinson RG. The Afflictions of Inequality. London and New York: Routledge, 1996.

\section{World Bank 2005}

World Bank Group. Country classifications. http:// www.worldbank.org/data/countryclass/countryclass.html (Accessed November 2006) 2005.

\section{Worobey 1999}

Worobey J, Worobey HS. The impact of a two-year school breakfast program for preschool-aged children on their nutrient intake and pre-academic performance. Child Study Journal 1999;29:113-31.

\section{Wynn 1987}

Wynn A. Inequalities in nutrition. Nutrition and Health 1987:5(1-2):79-94.

Zhang 2006

Zhang Qian. Personal communication (emails to authors and editorial base of the CDPLPG) June 2006

* Indicates the major publication for the study 


\section{CHARACTERISTICS OF STUDIES}

\section{Characteristics of included studies [ordered by study ID]}

\section{Agarwal 1989}

Methods

LLMIC: India Study Design: CBA Unit of allocation: schools Duration: 2 years. Feeding for 175 days in first year, 181 days in second year Total N in all groups: 450 at end (146 in exp, 304 control) Subgroup analysis: weight and height by age group, cognitive tests by grade of nutrition. Withdrawals: Not described. Fewer in cognitive analyses than in weight analyses

\begin{tabular}{ll} 
Participants & $\begin{array}{l}\text { SES: All rural Age: } 6-10 \text { yrs Gender: Experimental: } 103 \text { boys, } 40 \text { girls. Control: } 228 \text { boys, } 75 \text { girls } \\
\text { Nutritional status: } 80 \% \text { malnourished at baseline. Exp: } 29 \text { normal, } 56 \text { Grade I malnutrition, } 48 \text { Grade II } \\
\text { malnutrition, } 6 \text { Grade } 3 \text { malnutrition. Control: } 15 \text { normal, } 47 \text { Grade 1, } 28 \text { Grade II, } 2 \text { Grade III Height, } \\
\text { weight: Not mentioned (NM) }\end{array}$ \\
\hline Interventions & $\begin{array}{l}\text { Feeding: mid-day meal Protein: } 10-12 \mathrm{~g} \text { Calories: } 450-500 \text { calories Intensity: \% RDA for energy: } 25 \\
\text { Sufficient } \% \text { DRI for protein: } 58 \text { Control: no food Provider: Field workers Supervised: Seems like Y } \\
\text { Compliance: } 72 \% \text { in supplementation group attended first year and } 77 \% \text { attended second year. Dietary } \\
\text { survey of subsample found increase of only } 200 \text { calories a day in supplemented children. Substitution was } \\
\text { occurring }\end{array}$ \\
\hline
\end{tabular}

Outcomes Gain in height,weight, change in Grade of Malnutrition Full, Performance, and Verbal IQ Arithmetic acheivement Piagetian tasks

\begin{tabular}{l|l}
\hline Notes & Baseline measurement:A for all: Weight, height, intelligence, math Reliable Outcome: U for all Protection \\
& against contamination: A Blinded assessment: U Co-intervention: U Loss to follow-up: U
\end{tabular}

\section{Risk of bias}

\begin{tabular}{l|ll}
\hline Item & Authors' judgement & Description \\
\hline Allocation concealment? & Unclear & D - Not used \\
\hline
\end{tabular}

\section{Agarwal 1989 (girls)}

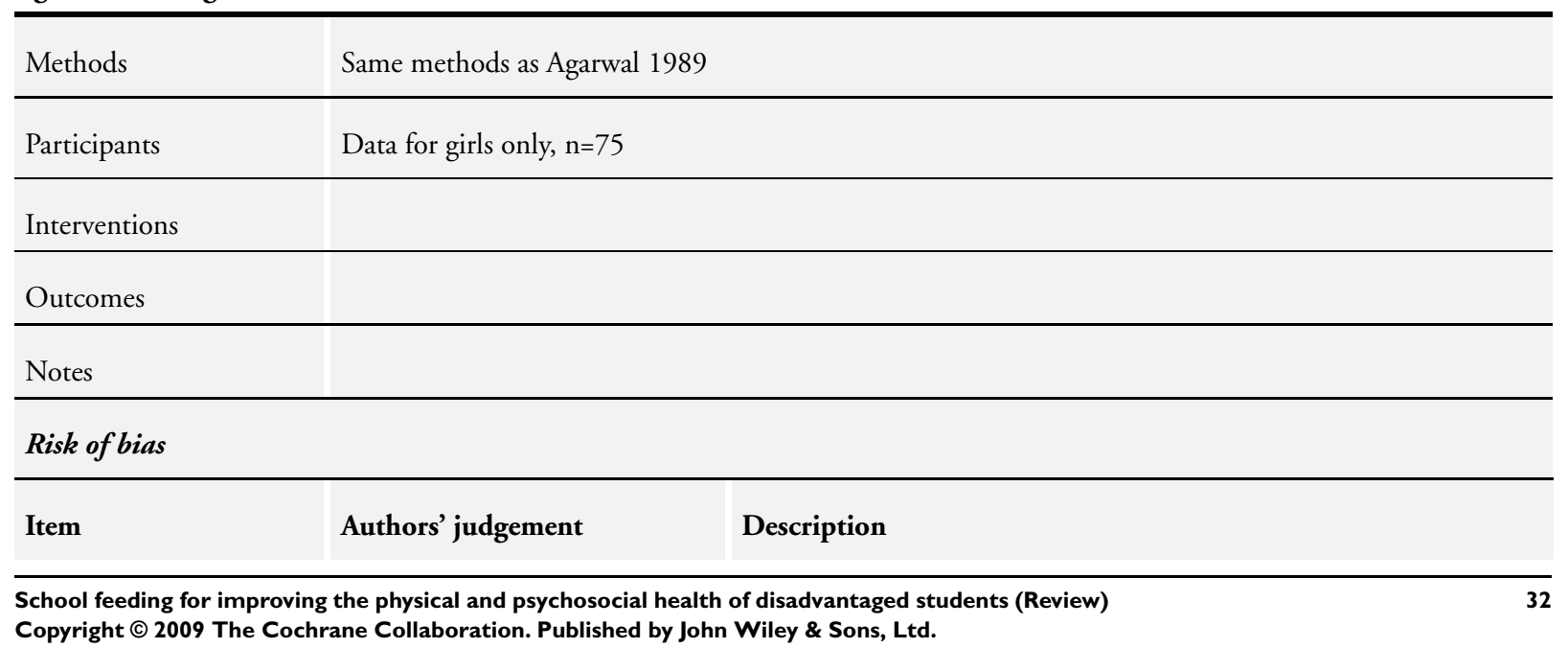


Agarwal 1989 (girls) (Continued)

\begin{tabular}{|c|c|c|}
\hline Allocation concealment? & Unclear & D - Not used \\
\hline \multicolumn{3}{|l|}{ Agarwal 1989 - boys } \\
\hline Methods & \multicolumn{2}{|l|}{ Same methods as Agarwal 1989} \\
\hline Participants & \multicolumn{2}{|l|}{ Data for boys only, $n=228$} \\
\hline \multicolumn{3}{|l|}{ Interventions } \\
\hline \multicolumn{3}{|l|}{ Outcomes } \\
\hline \multicolumn{3}{|l|}{ Notes } \\
\hline \multicolumn{3}{|l|}{ Risk of bias } \\
\hline Item & Authors' judgement & Description \\
\hline Allocation concealment? & Unclear & D - Not used \\
\hline
\end{tabular}

Agarwal 1989 boy 10y

\begin{tabular}{|c|c|c|}
\hline Methods & \multicolumn{2}{|c|}{ Same methods as Agarwal 1989} \\
\hline Participants & \multicolumn{2}{|c|}{ Data for boys, aged 10 years old only, $n=21$} \\
\hline \multicolumn{3}{|l|}{ Interventions } \\
\hline \multicolumn{3}{|l|}{ Outcomes } \\
\hline \multicolumn{3}{|l|}{ Notes } \\
\hline \multicolumn{3}{|l|}{ Risk of bias } \\
\hline Item & Authors' judgement & Description \\
\hline Allocation concealment? & Unclear & D - Not used \\
\hline
\end{tabular}

\section{Agarwal 1989 boys $7 y$}

\begin{tabular}{l|l}
\hline Methods & Same methods as Agarwal 1989 \\
\hline Participants & Data for boys aged 7 years old, $\mathrm{n}=84$ \\
\hline Interventions &
\end{tabular}


Agarwal 1989 boys $7 y \quad$ (Continued)

Outcomes

Notes

Risk of bias

\begin{tabular}{|c|c|c|}
\hline Item & Authors' judgement & Description \\
\hline Allocation concealment? & Unclear & D - Not used \\
\hline
\end{tabular}

Agarwal 1989 boys 8y

\begin{tabular}{|c|c|c|}
\hline Methods & \multicolumn{2}{|c|}{ Same methods as Agarwal 1989} \\
\hline Participants & \multicolumn{2}{|c|}{ Data for boys aged 8 years old only, $n=126$} \\
\hline \multicolumn{3}{|l|}{ Interventions } \\
\hline \multicolumn{3}{|l|}{ Outcomes } \\
\hline \multicolumn{3}{|l|}{ Notes } \\
\hline \multicolumn{3}{|l|}{ Risk of bias } \\
\hline Item & Authors' judgement & Description \\
\hline Allocation concealment? & Unclear & D - Not used \\
\hline
\end{tabular}

\section{Agarwal 1989 boys 9y}

\begin{tabular}{|c|c|c|}
\hline Methods & \multicolumn{2}{|c|}{ Same methods as Agarwal 1989} \\
\hline Participants & \multicolumn{2}{|c|}{ Data for boys aged 9 years old, $n=105$} \\
\hline \multicolumn{3}{|l|}{ Interventions } \\
\hline \multicolumn{3}{|l|}{ Outcomes } \\
\hline \multicolumn{3}{|l|}{ Notes } \\
\hline \multicolumn{3}{|l|}{ Risk of bias } \\
\hline Item & Authors' judgement & Description \\
\hline Allocation concealment? & Unclear & D - Not used \\
\hline
\end{tabular}


Agarwal 1989 girl 10

\begin{tabular}{l|l}
\hline Methods & Same methods as Agarwal 1989 \\
\hline Participants & Data for girls aged 10 years old, $n=9$ \\
\hline Interventions & \\
\hline Outcomes & \\
\hline Notes & \\
\hline
\end{tabular}

\section{Risk of bias}

\begin{tabular}{|c|c|c|}
\hline Item & Authors' judgement & Description \\
\hline Allocation concealment? & Unclear & D - Not used \\
\hline
\end{tabular}

Agarwal 1989 girl $7 y$

\begin{tabular}{|c|c|c|}
\hline Methods & \multicolumn{2}{|c|}{ Same methods as Agarwal 1989} \\
\hline Participants & \multicolumn{2}{|c|}{ Data for girls aged 7 years old, $n=22$} \\
\hline \multicolumn{3}{|l|}{ Interventions } \\
\hline \multicolumn{3}{|l|}{ Outcomes } \\
\hline \multicolumn{3}{|l|}{ Notes } \\
\hline \multicolumn{3}{|l|}{ Risk of bias } \\
\hline Item & Authors' judgement & Description \\
\hline Allocation concealment? & Unclear & D - Not used \\
\hline
\end{tabular}

Agarwal 1989 girl 8y

\begin{tabular}{l|l}
\hline Methods & Same methods as Agarwal 1989 \\
\hline Participants & Data for girls aged 8 years old, $\mathrm{n}=42$ \\
\hline Interventions & \\
\hline Outcomes & \\
\hline Notes & \\
\hline
\end{tabular}

\section{Risk of bias}


Agarwal 1989 girl 8y (Continued)

\begin{tabular}{lll}
\hline Item & Authors' judgement & Description \\
\hline Allocation concealment? & Unclear & D - Not used \\
\hline
\end{tabular}

Agarwal 1989 girl 9y

\begin{tabular}{|c|c|c|}
\hline Methods & \multicolumn{2}{|c|}{ Same methods as Agarwal 1989} \\
\hline Participants & \multicolumn{2}{|c|}{ Data for girls aged 9 years old, $n=77$} \\
\hline \multicolumn{3}{|l|}{ Interventions } \\
\hline \multicolumn{3}{|l|}{ Outcomes } \\
\hline \multicolumn{3}{|l|}{ Notes } \\
\hline \multicolumn{3}{|l|}{ Risk of bias } \\
\hline Item & Authors' judgement & Description \\
\hline Allocation concealment? & Unclear & D - Not used \\
\hline \multicolumn{3}{|l|}{ Agarwal 1989 grade I } \\
\hline Methods & \multicolumn{2}{|c|}{ Same methods as Agarwal 1989} \\
\hline Participants & \multicolumn{2}{|c|}{$\begin{array}{l}\text { Data for children with grade I nutritional status }(\mathrm{n}=103) \text {, defined using Gomez's cut off points and the } \\
\text { 50th percentile of National Centre for Health Statistics (1977) as a reference point }\end{array}$} \\
\hline \multicolumn{3}{|l|}{ Interventions } \\
\hline \multicolumn{3}{|l|}{ Outcomes } \\
\hline \multicolumn{3}{|l|}{ Notes } \\
\hline \multicolumn{3}{|l|}{ Risk of bias } \\
\hline Item & Authors' judgement & Description \\
\hline Allocation concealment? & Unclear & D - Not used \\
\hline
\end{tabular}


Agarwal 1989 grade2

\begin{tabular}{l|l}
\hline Methods & Same methods as Agarwal 1989 \\
\hline $\begin{array}{l}\text { Participants } \\
\text { Data for children with grade II nutritional status ( } \mathrm{n}=76) \text {, defined using Gomez's cut off points and the } \\
\text { 50th percentile of National Centre for Health Statistics (1977) as a reference point }\end{array}$ \\
\hline Interventions & \\
\hline Outcomes & \\
\hline Notes &
\end{tabular}

\section{Risk of bias}

\begin{tabular}{|c|c|c|}
\hline Item & Authors' judgement & Description \\
\hline Allocation concealment? & Unclear & D - Not used \\
\hline
\end{tabular}

Agarwal 1989 grade3

\begin{tabular}{l|l}
\hline Methods & Same methods as Agarwal 1989 \\
\hline Participants & $\begin{array}{l}\text { Data for children with grade I nutritional status ( } \mathrm{n}=8) \text {, defined using Gomez's cut off points and the 50th } \\
\text { percentile of National Centre for Health Statistics (1977) as a reference point }\end{array}$ \\
\hline Interventions & \\
\hline Outcomes & \\
\hline Notes & \\
\hline
\end{tabular}

\section{Risk of bias}

\begin{tabular}{|c|c|c|}
\hline Item & Authors' judgement & Description \\
\hline Allocation concealment? & Unclear & D - Not used \\
\hline
\end{tabular}

\section{Agarwal 1989 normal}

\begin{tabular}{l|l}
\hline Methods & Same methods as Agarwal 1989 \\
\hline Participants & $\begin{array}{l}\text { Data for children with normal nutritional status ( } \mathrm{n}=44 \text { ), defined using Gomez's cut off points and the } \\
\text { 50th percentile of National Centre for Health Statistics (1977) as a reference point }\end{array}$ \\
\hline Interventions & \\
\hline Outcomes & \\
\hline Notes & \\
\hline $\begin{array}{l}\text { School feeding for improving the physical and psychosocial health of disadvantaged students (Review) } \\
\text { Copyright } \odot \mathbf{2 0 0 9} \text { The Cochrane Collaboration. Published by John Wiley \& Sons, Ltd. }\end{array}$
\end{tabular}


Agarwal 1989 normal (Continued)

\section{Risk of bias}

\begin{tabular}{lll}
\hline Item & Authors' judgement & Description \\
\hline Allocation concealment? & Unclear & D - Not used \\
\hline
\end{tabular}

Agarwal total

\begin{tabular}{|c|c|c|}
\hline Methods & \multicolumn{2}{|l|}{ Agarwal total } \\
\hline Participants & \multicolumn{2}{|c|}{ Same methods as Agarwal 1989} \\
\hline Interventions & \multicolumn{2}{|c|}{ Data for all children, boys and girls } \\
\hline \multicolumn{3}{|l|}{ Outcomes } \\
\hline \multicolumn{3}{|l|}{ Notes } \\
\hline \multicolumn{3}{|l|}{ Risk of bias } \\
\hline Item & Authors' judgement & Description \\
\hline Allocation concealment? & Unclear & D - Not used \\
\hline
\end{tabular}

Bailey 1961

\begin{tabular}{|c|c|c|}
\hline Methods & \multicolumn{2}{|l|}{ As below } \\
\hline Participants & \multicolumn{2}{|l|}{ As below } \\
\hline Interventions & \multicolumn{2}{|l|}{ As below } \\
\hline Outcomes & \multicolumn{2}{|l|}{ As below } \\
\hline Notes & \multicolumn{2}{|l|}{ As below } \\
\hline \multicolumn{3}{|l|}{ Risk of bias } \\
\hline Item & Authors' judgement & Description \\
\hline Allocation concealment? & Unclear & D - Not used \\
\hline
\end{tabular}




\begin{tabular}{|c|c|c|}
\hline Methods & \multicolumn{2}{|c|}{$\begin{array}{l}\text { LLMIC: India } \\
\text { Study Design: CBA } \\
\text { Unit of allocation: schools } \\
\text { Duration: } 12 \text { months } \\
\text { Total N in all groups: Originally sounds like } 100 \text { in each group ages } 7 \text { to } 15 \text {. Analyses restricted to boys } \\
\text { age } 13 \text { and below; about } 80 \text { in each group. Results given for } 140 \text { in selected groups } \\
\text { Subgroup analysis: None } \\
\text { Withdrawals: Not clear }\end{array}$} \\
\hline Participants & \multicolumn{2}{|c|}{$\begin{array}{l}\text { SES: All Indian schoolboys in government schools. From ordinary village homes. } \\
\text { Age: } 7-13 \\
\text { Gender: all male } \\
\text { Nutritional status: Height: Initial heights ranged from } 112 \mathrm{~cm} \text { for } 7 \text { year olds to } 133 \mathrm{~cm} \text { for } 13 \text { year olds. } \\
\text { Weight: Initial weights ranged from } 18 \mathrm{~kg} \text { for } 7 \text { year olds to } 31 \mathrm{~kg} \text { for } 13 \text { year olds }\end{array}$} \\
\hline Interventions & \multicolumn{2}{|c|}{$\begin{array}{l}\text { Feeding: Green gram and palm sugar given mid-morning. } \\
\text { Protein: } 12 \mathrm{~g} \\
\text { Calories: } 195 \\
\text { Intensity: } \\
\text { \% RDA for energy: } 8-10 \% \text {. Insufficient } \\
\% \text { DRI for protein: } 35-63 \% \\
\text { Control: } 100 \mathrm{mg} \text { iron } \\
\text { Provider: NC } \\
\text { Supervised: NC } \\
\text { Free: NC } \\
\text { Compliance: NC }\end{array}$} \\
\hline Outcomes & \multicolumn{2}{|c|}{$\begin{array}{l}\text { Change in Height } \\
\text { Weight } \\
\text { Haemoglobin over } 12 \text { months. }\end{array}$} \\
\hline Notes & \multicolumn{2}{|c|}{$\begin{array}{l}\text { Baseline measurement: } U \\
\text { Reliable Outcome: } U \text { for height/weight. A for hemoglobin } \\
\text { Protection against contamination: } U \\
\text { Blinded assessment: } U \\
\text { Co-intervention: } U \\
\text { Loss to follow-up: } U\end{array}$} \\
\hline \multicolumn{3}{|l|}{ Risk of bias } \\
\hline Item & Authors' judgement & Description \\
\hline Allocation concealment? & Unclear & D - Not used \\
\hline
\end{tabular}


Baker 1980 ( boys)

\begin{tabular}{|c|c|c|}
\hline Methods & \multicolumn{2}{|c|}{$\begin{array}{l}\text { Upper Income country: Wales } \\
\text { Study Design: RCT } \\
\text { Unit of allocation: Individual } \\
\text { Duration: } 6 \text { school terms ( } 21 \text { and a half months) } \\
\text { Total N in all groups: } 581 \\
\text { Subgroup analysis: describes results by SES. } \\
\text { Withdrawals: } 8 \%\end{array}$} \\
\hline Participants & \multicolumn{2}{|c|}{$\begin{array}{l}\text { SES: Mid Glamorgan, South Wales, from families with } 4 \text { or more children. } 1.5 \% \text { in Class II, } 41 \% \text { in class } \\
\text { III, } 19 \% \text { in Class IV and } 6 \% \text { in Class V. } 23 \% \text { had unemployed fathers; } 9 \% \text { fathers 'other employment' } \\
\text { Age: } 7-8 \text { yrs, Gender: Exp group= } 51.2 \text { male } \% \text {, Control }=51.5 \% \text { male } \\
\text { Nutritional status: children in both groups } 2-3 \mathrm{~cm} \text { shorter and } 1.5 \mathrm{~kg} \text { lighter than other children in the } \\
\text { country. } \\
\text { Height: ranged from } 120.6 \text { to } 130.2 \mathrm{~cm} \\
\text { Weight: ranged from } 23 \mathrm{~kg} \text { to } 28.7 \mathrm{~kg}\end{array}$} \\
\hline Interventions & \multicolumn{2}{|c|}{$\begin{array}{l}\text { Feeding: Milk supplement- } 1 / 3 \text { pint }(190 \mathrm{ml}) \text { daily. } \\
\text { Protein: } 6.5 \mathrm{~g} \\
\text { Calories: } 126 \\
\text { Intensity: } \\
\text { \% RDA for energy: } 6.3 \text {, or insufficient } \\
\% \text { DRI for protein: } 19-34 \% \\
\text { Control: no milk } \\
\text { Provider: NC } \\
\text { Supervised: Y } \\
\text { Compliance: } 13 \text { in milk group disliked milk }\end{array}$} \\
\hline Outcomes & \multicolumn{2}{|c|}{ Growth difference for weight and height. } \\
\hline Notes & \multicolumn{2}{|c|}{$\begin{array}{l}\text { Jadad R: } 1 \\
\text { Jadad B: } 0 \\
\text { Jadad W: } 1 \\
\text { Baseline measure: A height, U weight. } \\
\text { Reliable outcome: U } \\
\text { Protection against contamination: I } \\
\text { Blinded assessment: A } \\
\text { Co-intervention: U } \\
\text { Loss to follow-up: A }\end{array}$} \\
\hline \multicolumn{3}{|l|}{ Risk of bias } \\
\hline Item & Authors' judgement & Description \\
\hline Allocation concealment? & Unclear & B - Unclear \\
\hline
\end{tabular}


Baker girls 1980

\begin{tabular}{|c|c|c|}
\hline Methods & \multicolumn{2}{|c|}{ Same methods as Baker 1980 boys } \\
\hline Participants & \multicolumn{2}{|l|}{ Data for girls only } \\
\hline \multicolumn{3}{|l|}{ Interventions } \\
\hline \multicolumn{3}{|l|}{ Outcomes } \\
\hline \multicolumn{3}{|l|}{ Notes } \\
\hline \multicolumn{3}{|l|}{ Risk of bias } \\
\hline Item & Authors' judgement & Description \\
\hline Allocation concealment? & Unclear & B - Unclear \\
\hline \multicolumn{3}{|l|}{ Baker total 1980} \\
\hline Methods & \multicolumn{2}{|l|}{ Baker total 1980} \\
\hline \multicolumn{3}{|l|}{ Participants } \\
\hline Interventions & \multicolumn{2}{|c|}{ Data for overall results from Baker 1980, combined data for boys and girls } \\
\hline \multicolumn{3}{|l|}{ Outcomes } \\
\hline \multicolumn{3}{|l|}{ Notes } \\
\hline \multicolumn{3}{|l|}{ Risk of bias } \\
\hline Item & Authors' judgement & Description \\
\hline Allocation concealment? & Unclear & D - Not used \\
\hline
\end{tabular}

\section{Bro 1994}

Methods

Upper Income country: USA

Study Design: ITS. ABAB design. 10 observations at baseline 1, 10 during breakfast program, 10 at baseline 2, and 10 during breakfast program

Unit of allocation: student

Duration: 10 days baseline, 10 days intervention, 10 days 2 nd baseline, 10 days 2 nd intervention.

Total N:10

Subgroup analysis:

Withdrawals: None

Participants

SES: residence: urban. Male vocational high school students. 6 of 10 'at risk' (living alone, living with one parent, living with other than natural parents, and/or single teen parent).

Age: $14-18$ yrs 
Gender: $100 \%$ male

Nutritional status: NM

Feeding: nutritious, well-balanced breakfast
Protein: not mentioned (NM)
Calories: NM
Intensity:
\%RDA for Energy:
\% DRI for Protein:
Unclear, but large meals provided.
Control: subjects were their own controls
Provider: U.S. Government through School Breakfast Supervised : Y
Compliance: NM

Outcomes

Cognition: On-task behaviour (defined as percentage of time that students were engaging in clearly defined tasks in the class)

Behavioural: school attendance.

\begin{tabular}{ll}
\hline Notes & Baseline measurement: NA \\
& Reliable outcome: A \\
& Protection against contamination: NA \\
& Blinded assessment: I \\
Co-intervention: NA \\
Loss to followup: NA \\
Intervention ind of other changes; U \\
Data analyzed appropriately: I Reason for number of pre and post intervention points given: U \\
Shape of intervention: I \\
Intervention affect data collection: A \\
Completeness: A
\end{tabular}

\section{Risk of bias}

\begin{tabular}{lll}
\hline Item & Authors' judgement & Description \\
\hline Allocation concealment? & Unclear & D - Not used \\
\hline
\end{tabular}

Bro 1996

Methods

Upper Income country: USA

Study design: ITS

Unit of allocation: student. Two classes used.

Duration: Baseline: 5 days and 10 days, 21- 30 school days

Total $\mathrm{N}$ in all groups: 18

Subgroup analysis: No

Withdrawals: not mentioned

Participants

SES: all Caucasian, 9 out of 12 in Class One "at risk " (living alone, living with single parent, alone, teenage parent, living with other than natural parent). Some special needs. All 6 students in second class at risk for dropping out. 
Age: $15-19$ yrs in class 1, 16-18 yrs in class 2

Gender: 11 boys, 1 girl in class 1; 6 boys in class 2

Nutritional status: NC

\begin{tabular}{|c|c|}
\hline Interventions & $\begin{array}{l}\text { Feeding: Nutritious breakfast in school. } \\
\text { Protein: NM Calories: NM } \\
\text { Intensity: unclear, but large meals provided. } \\
\text { \%RDA for Energy: NM } \\
\text { \% DRI for Protein: NM } \\
\text { Control: subjects were their own controls } \\
\text { Provider: teacher } \\
\text { Supervised : Y } \\
\text { Compliance: NM }\end{array}$ \\
\hline Outcomes & $\begin{array}{l}\text { Cognition: On-task behaviour } \\
\text { Class 1, welding: setting up, welding, and putting away } \\
\text { Class 2: retrieving study materials, reading, answering questions, written tests }\end{array}$ \\
\hline Notes & $\begin{array}{l}\text { Baseline } \\
\text { measurement: NA } \\
\text { Reliable outcome: I } \\
\text { Protection against contamination: NA } \\
\text { Blinded assessment: I } \\
\text { Co-intervention: NA } \\
\text { Loss to followup: NA } \\
\text { Intervention ind of changes :U Data analyzed appropriately: I Reason for number of pre and post inter- } \\
\text { vention points given: U } \\
\text { Shape of intervention: A } \\
\text { Intervention affect data collection: A } \\
\text { Completeness: A } \\
\text { Intervention affect data collection: U } \\
\text { Completeness: A }\end{array}$ \\
\hline
\end{tabular}

Risk of bias

\begin{tabular}{|c|c|c|}
\hline Item & Authors' judgement & Description \\
\hline Allocation concealment? & Unclear & D - Not used \\
\hline
\end{tabular}




\begin{tabular}{|c|c|}
\hline Methods & $\begin{array}{l}\text { LLMIC: Jamaica } \\
\text { Study Design: Crossover RCT } \\
\text { Unit of allocation: class, stratified by school } \\
\text { Duration: feeding } 1 \text { week before testing, and during testing. } \\
\text { Total N in all groups: } 200 \\
\text { Subgroup analysis: undernourished vs adequately nourished } \\
\text { Withdrawals: } 3 / 100(3 \%) \text { in undernourished. None in adequately nourished }\end{array}$ \\
\hline Participants & $\begin{array}{l}\text { SES: all rural in mountainous area. School served children of subsistence farmers. } \\
\text { Age: } 9.3 \text { yrs } \\
\text { Gender: } 99 \text { male, } 98 \text { female } \\
\text { Nuritional Status: } 97 \text { undernourished. (weight for age }<=1 \text { s.d. below NHS references. } \\
100 \text { adequately nourished. } \\
\text { Height, weight not given. }\end{array}$ \\
\hline Interventions & $\begin{array}{l}\text { Feeding: Breakfast in school, } 225 \mathrm{~mL} \text { chocolate milk+ cheese sandwich. } \\
\text { Protein: } 21.3 \mathrm{~g} \\
\text { Calories: } 2174 \mathrm{~kJ} \\
\text { Intensity: } \\
\% \text { of RDA for energy: } 26 \% \text {, sufficient } \\
\% \text { of DRI for protein: } 63 \% \\
\text { Control: } 1 / 4 \text { orange } \\
\text { Provider: teacher } \\
\text { Supervised : Y } \\
\text { Compliance: NM }\end{array}$ \\
\hline Outcomes & $\begin{array}{l}\text { Verbal fluency, } \\
\text { digit span } \\
\text { visual search, speed of } \\
\text { information } \\
\text { processing } \\
\text { Classroom attention and behaviour (on a subset). }\end{array}$ \\
\hline Notes & $\begin{array}{l}\text { Jadad R: } 1 \\
\text { Jadad B: } 0 \\
\text { Jadad W: } 1 \\
\text { Baseline measurement: NA } \\
\text { Reliable outcome: A } \\
\text { Protection against contamination: A } \\
\text { Blinded assessment: A } \\
\text { Co-interventions: U } \\
\text { Loss to follow-up: A }\end{array}$ \\
\hline
\end{tabular}

\section{Risk of bias}

\begin{tabular}{|c|c|c|}
\hline Item & Authors' judgement & Description \\
\hline Allocation concealment? & Unclear & B - Unclear \\
\hline
\end{tabular}


Chandler Under

\begin{tabular}{|c|c|c|}
\hline Methods & \multicolumn{2}{|l|}{ Same study as Chandler } \\
\hline Participants & \multicolumn{2}{|c|}{ Data for under-nourished children from Chandler study } \\
\hline \multicolumn{3}{|l|}{ Interventions } \\
\hline \multicolumn{3}{|l|}{ Outcomes } \\
\hline \multicolumn{3}{|l|}{ Notes } \\
\hline \multicolumn{3}{|l|}{ Risk of bias } \\
\hline Item & Authors' judgement & Description \\
\hline Allocation concealment? & Unclear & D - Not used \\
\hline
\end{tabular}

\section{Corry-Mann 1926}

\begin{tabular}{|c|c|}
\hline Methods & $\begin{array}{l}\text { Upper Income country: England } \\
\text { Study Design: CBA } \\
\text { Unit of allocation: Individual } \\
\text { Duration: } 1 \text { year, } 2 \text { years and } 3 \text { years all year round } \\
\text { Total N in all groups: } 102 \text { with complete data for a year } \\
\text { Subgroup analysis: None Withdrawals: } \\
\text { Says that boys were replaced as they moved out of houses. But analysis seems to include only boys with } \\
\text { data for full year }\end{array}$ \\
\hline Participants & $\begin{array}{l}\text { SES: All in foundling home, many came there destitute and in poor condition. } \\
\text { Lived in 'colony' } 11 \text { miles outsider of London } \\
\text { Age: } 6 \text { to } 11 \text { years. } \\
\text { Gender: All male } \\
\text { Nutritional status: Control baseline weight: } 53.54 \text {, Exp: baseline weight: } 55.18 \text {, Control: baseline height: } \\
\text { 48.5, Exp: baseline height: } 48.76\end{array}$ \\
\hline Interventions & $\begin{array}{l}\text { Feeding: Milk supplement in addition to basic diet: } 1 \text { pint daily; } 1 / 2 \text { pint given in morning and } 1 / 2 \text { half } \\
\text { pint given in afternoon. } \\
\text { Protein: } 18 \mathrm{~g} \\
\text { Calories: } 388 \mathrm{cal} \text {. } \\
\text { Intensity: } \\
\% \text { RDA for energy: } \\
\% \text { DRI for protein: } 19-34 \% \\
\text { Control: no milk } \\
\text { Provider: NM } \\
\text { Supervised: seems like Y } \\
\text { Compliance: NM }\end{array}$ \\
\hline
\end{tabular}

Outcomes

Change in height, weight 
Corry-Mann 1926 (Continued)

\begin{tabular}{ll}
\hline Notes & Baseline \\
& measurement: A \\
& Reliable outcome: $U$ \\
& Protection against contamination: $U$ \\
& Blinded assessment: $U$ \\
& Co-intervention: $U$ \\
& Loss to followup: $U$ \\
\hline
\end{tabular}

Risk of bias

\begin{tabular}{|c|c|c|}
\hline Item & Authors' judgement & Description \\
\hline Allocation concealment? & Unclear & D - Not used \\
\hline
\end{tabular}

Devadas1979: 5-6

\begin{tabular}{|c|c|}
\hline Methods & $\begin{array}{l}\text { LLMIC: India } \\
\text { Study design: CBA } \\
\text { Unit of Allocation: } \\
\text { individual } \\
\text { Duration: } 10 \text { months } \\
\text { Total N in all groups: } 400 \\
\text { Subgroup analysis: reported by age group. } \\
\text { Withdrawals: Not clear }\end{array}$ \\
\hline Participants & $\begin{array}{l}\text { SES: Six villages. Children consumed fewer calories and m } \\
\text { Age: } 3 \text { groups: } 5-6,6-7 \text {, and } 7-8 \\
\text { Gender: } 107 \text { boys and } 93 \text { girls in exp. Similar in control. } \\
\text { Nutritional status: Height: } 104.5 \mathrm{~cm} \text { for } 5-6 \text { year olds to } 1 \\
\text { Weight: } 14.9 \mathrm{~kg} \text { for } 5-6 \text { year olds to } 18.2 \mathrm{Kg} \text { for } 7-8 \text { year o }\end{array}$ \\
\hline Interventions & $\begin{array}{l}\text { Feeding: Vegetable protein mixture } \\
\text { Protein: } 14 \mathrm{~g} \text {. Calories: } 345-395 \mathrm{cal} \text { per day } \\
\text { Intensity: } \\
\% \text { RDA for energy: } 17-19 \% \text {; sufficient } \\
\% \text { DRI for protein: } 50 \% \\
\text { Control: No food } \\
\text { Provider: NM } \\
\text { Supervised : Y, at least for selected school children. } \\
\text { Compliance: No plate waste. Children "relished the mixtu }\end{array}$ \\
\hline Outcomes & $\begin{array}{l}\text { Mean initial and final heights and weights, change: mean }+ \\
\text { Mean initial and final haemoglobin. }\end{array}$ \\
\hline Notes & $\begin{array}{l}\text { Baseline measurement: A } \\
\text { Reliable outcome: U for height/weight: A for hemoglobin } \\
\text { Protection against contamination: } U \\
\text { Blinded assessment: } U\end{array}$ \\
\hline
\end{tabular}


Devadas1979: 5-6 (Continued)

Co-intervention: U

Loss to follow-up: U

\section{Risk of bias}

\begin{tabular}{|c|c|c|}
\hline Item & Authors' judgement & Description \\
\hline Allocation concealment? & Unclear & D - Not used \\
\hline
\end{tabular}

Devadas1979: 6-7

\begin{tabular}{|c|c|c|}
\hline Methods & \multicolumn{2}{|c|}{ Same study as Devadas 1979 5-6 } \\
\hline Participants & \multicolumn{2}{|c|}{ Data for age group 6-7 years old, $n=136$} \\
\hline \multicolumn{3}{|l|}{ Interventions } \\
\hline \multicolumn{3}{|l|}{ Outcomes } \\
\hline \multicolumn{3}{|l|}{ Notes } \\
\hline \multicolumn{3}{|l|}{ Risk of bias } \\
\hline Item & Authors' judgement & Description \\
\hline Allocation concealment? & Unclear & D - Not used \\
\hline \multicolumn{3}{|l|}{ Devadas1979:7-8 } \\
\hline Methods & \multicolumn{2}{|c|}{ Same study as Devadas 1979 5-6 } \\
\hline Participants & \multicolumn{2}{|c|}{ Data for age group $7-8$ years old, $n=158$} \\
\hline \multicolumn{3}{|l|}{ Interventions } \\
\hline \multicolumn{3}{|l|}{ Outcomes } \\
\hline \multicolumn{3}{|l|}{ Notes } \\
\hline \multicolumn{3}{|l|}{ Risk of bias } \\
\hline Item & Authors' judgement & Description \\
\hline Allocation concealment? & Unclear & D - Not used \\
\hline
\end{tabular}




\begin{tabular}{|c|c|c|}
\hline Methods & \multicolumn{2}{|c|}{$\begin{array}{l}\text { LLMIC: China } \\
\text { Study design: RCT } \\
\text { Unit of allocation: school } \\
\text { Duration: } 24 \text { months on school days. } \\
\text { Total N in all groups: } 757 \\
\text { Subgroup analysis: no } \\
\text { Withdrawals: } 7.8 \% \text {, many of these excluded bc of non-compliance, others moved, were concerned about } \\
\text { venepuncture, }\end{array}$} \\
\hline Participants & \multicolumn{2}{|c|}{$\begin{array}{l}\text { SES: School girls from Bejing. Low calcium intake ( } 43 \% \text { of normal), Vitamin D intake only } 9 \% \text { that of } \\
\text { recommended value. } \\
\text { Age: average } 10.1,10.1 \text {, and } 10.0 \text { in } 3 \text { groups. } \\
\text { Gender: female } \\
\text { Nutritional status: Height: } 140.4 \text { to } 140.7 \mathrm{~cm} \\
\text { Weight: } 33.45 \text { to } 33.9 \mathrm{Kg} \text {. BMI: } 16.8 \text { to } 17.1 \text {. }\end{array}$} \\
\hline Interventions & \multicolumn{2}{|c|}{$\begin{array}{l}\text { Feeding: Milk with Calcium added. } \\
\text { Protein: } \\
\text { Calories: } \\
\% \text { RDA for energy: } 10 \% \text {. Insufficient } \\
\% \text { DRI for protein: } \\
\text { Control: no milk } \\
\text { Provider: Health worker distributed to one student in charge in each class. } \\
\text { Supervised: Y, by teachers. Students kept records of compliance. } \\
\text { Compliance: Not fully given, but mentions that } 33 \text { from both groups were excluded due to failure to } \\
\text { drink milk on } 4 \text { days or more }\end{array}$} \\
\hline Outcomes & \multicolumn{2}{|c|}{$\begin{array}{l}\text { Pre-test and end of study weight, height, BMI, BMC, BMD, Bone Area, Plasma Vitamin D, Serum PTH, } \\
\text { Plasma Calcium, and Urine Calcium. Also report percentage change from baseline in all variables }\end{array}$} \\
\hline Notes & \multicolumn{2}{|c|}{$\begin{array}{l}\text { Jadad R: } 1 \\
\text { Jadad B: } 0 \\
\text { Jadad W: } 0 \\
\text { Baseline measurement: A } \\
\text { Reliable outcome: U for height/weight. A for BMD } \\
\text { Protection against contamination: U } \\
\text { Blinded assessment: A } \\
\text { Co-intervention: U } \\
\text { Loss to follow-up: A }\end{array}$} \\
\hline \multicolumn{3}{|l|}{ Risk of bias } \\
\hline Item & Authors' judgement & Description \\
\hline Allocation concealment? & Unclear & B - Unclear \\
\hline
\end{tabular}




\begin{tabular}{|c|c|}
\hline Methods & $\begin{array}{l}\text { LLMIC: Peru } \\
\text { Study Design: RCT } \\
\text { Unit of allocation: School } \\
\text { Duration: Program } 5 \text { weeks. Data collection started after } 2 \text { weeks. } \\
\text { Total N in all groups: } 352 \\
\text { Subgroup analysis: Tested interaction between baseline nutritional status and treatment Withdrawals: } \\
\text { NM }\end{array}$ \\
\hline Participants & $\begin{array}{l}\text { SES: all schools were located in rural periphery }(1 \mathrm{hr}) \text { of city, mostly agricultural communities. Houses } \\
\text { adobe, typically no more than } 3 \text { rooms. Avg. maternal education: } 2.3 \text { treatment and } 2.7 \text { control. } \\
\text { Age: Exp: } 136.2 \text { months. Control: } 138.9 \text { months } \\
\text { Gender: experimental group: } 90 \% \text { male control group: } 80 \% \text { male } \\
\text { Nutritional status: Weight for height z-score: exp: } \\
0.51 \text { (0.7), Control: } 0.43 \\
\text { Height for age z-score: exp: }-2.21 \text { Control: }-2.20\end{array}$ \\
\hline Interventions & $\begin{array}{l}\text { Feeding: Breakfast of } 4 \text { cookies and an instant drink, sometimes a cake and drinks of different flavours. } \\
\text { Protein: } 19.5 \mathrm{~g} \\
\text { Calories: } 600 \mathrm{kcal} \\
\text { Intensity: } \\
\% \text { RDA for energy: } 23-33 \% \text { : sufficient } \\
\% \text { DRI for protein: High: } 57-103 \% \\
\text { Control: no feeding. All received food in another phase. } \\
\text { Provider: Institute de Investigacion Nutritional (IIN), a local private NGO } \\
\text { Supervised (Y/N): not given } \\
\text { Compliance: }\end{array}$ \\
\hline Outcomes & $\begin{array}{l}\text { Energy intake } \\
\text { Protein intake } \\
\text { Iron intake } \\
\text { Attendance } \\
\text { Coding Test } \\
\text { Math Test } \\
\text { Reading Test } \\
\text { Vocabulary Test } \\
\text { Pre/post breakfast. }\end{array}$ \\
\hline Notes & $\begin{array}{l}\text { Jadad R: } 1 \\
\text { Jadad B: } 0 \\
\text { Jadad W: } 0 \\
\text { Baseline measurement: A Reliable outcome: A } \\
\text { Protection against contamination: A } \\
\text { Blinded assessment: Attendance: I psychoed; U } \\
\text { Co-intervention: U } \\
\text { Loss to follow-up: U }\end{array}$ \\
\hline
\end{tabular}

Risk of bias

Item

Authors' judgement

Description

School feeding for improving the physical and psychosocial health of disadvantaged students (Review)

Copyright @ 2009 The Cochrane Collaboration. Published by John Wiley \& Sons, Ltd. 
Jacoby 1996 (Continued)

Allocation concealment? Unclear $\quad$ B - Unclear

Lieberman 1976

Methods

Upper income country: USA

Study Design: CBA

Unit of allocation: school

Duration: 8 months between 1970-1971 (school year)

Total $\mathrm{N}$ in all groups: 539

Funding: in part by a grant from the Department of Health, Education, and Welfare

Subgroup analysis:

Withdrawals: Experimental- 14.6\%, Ctrl- 9.3\%

Participants

SES: Predominately black, low-income area of L.A. County, CA. Highest grade parent attended- experimental: 10.2, control: 10.6, Percentage of children living in families receiving NO welfare- exp: 37, Control: 33

Age: Grade 3: Exp- 8.7, Control- 8.9 Grade 4: Exp-9.8, Control- 9.7 Grade 5: Exp- 10.7, Control- 10.9 Grade 6: Exp- 11.6, Control- 11.8

Gender (\%male): Grade 3- Exp: 52, Ctrl: 51; Grade 4- Exp: 44, Ctrl: 49; Grade 5- Exp: 49, Ctrl: 59; Grade 6- Exp: 46, Ctrl: 49

Nutritional status: no unequivocal signs of malnutrition

noted. Study groups slightly taller and heavier than reference groups. Height: $130.3 \mathrm{~cm}$ to $149.6 \mathrm{~cm}$

Weight: 27.5 to $43 \mathrm{~kg}$.

Interventions

Feeding: Breakfast described as traditional and hot, designed to provide $-1 / 4$ of the RDA for 9 and $10 \mathrm{yr}$ olds.

Protein: $3-5 \mathrm{~g}$ per breakfast

Calories: NM

Intensity: sufficient

$\%$ RDA for energy: NM

$\%$ DRI for protein: NM

Control: no breakfast

Provider: NM

Supervised: NM

Compliance: Poor.

Only $30 \%$ of children attended $75 \%$ or more of breakasts.

Outcomes

Assessed anthropometry, but not before and after.

Looked at change in cognition: five psychological tests assessing ability to concentrate, remembrance, thinking abstractly, and working in a classroom.

Change in reading and math performance

Change in school attendance

Report very few numbers, except for change in attendance.

Notes Baseline measurement: $U$

Reliable outcome: $U$ for growth and for psychological measurements.

Protection against contamination: A

Blinded assessment: $U$ 
Lieberman 1976 (Continued)

Co-Intervention: U

Loss to follow up: A

\section{Risk of bias}

\begin{tabular}{l|ll}
\hline Item & Authors' judgement & Description \\
\hline Allocation concealment? & Unclear & D - Not used \\
\hline
\end{tabular}

Neumann 2003

\begin{tabular}{|c|c|}
\hline Methods & $\begin{array}{l}\text { LLMIC: Kenya } \\
\text { Study design:RCT. } \\
\text { Unit of allocation: school } \\
\text { Duration: } 23 \text { months } \\
\text { Total N in our selected groups: } 236 \\
\text { Subgroup analysis: mention effects by SES } \\
\text { Withdrawals: Exp. } 3 \text { left school, } 11 \text { excluded. } \\
\text { Control: } 2 \text { left school, } 10 \text { excluded. }\end{array}$ \\
\hline Participants & $\begin{array}{l}\text { SES: rural Kenya. } \\
\text { Maternal schooling: } 6 \text { years. Fathers schooling: } 7 \text { years } \\
\text { Age: } 6-14 \text { years. Median age } 7.4 \text { years. Exp: mean age: } 93.6 \text { months. Control: mean age: } 88 \text { months. } \\
\text { Gender: Exp: } 50 \% \text { male. Control: } 53 \% \text { male } \\
\text { Nutritional Status: Height:, Weight: } 19.4 \% \text { of sample stunted. } 30 \% \text { underweight (<2 WAZ). Mild } \\
\text { underweight in } 42.1 \% \text { of of boys and } 31.1 \% \text { of girls }\end{array}$ \\
\hline Interventions & $\begin{array}{l}\text { Feeding: Githeri + meat: } \\
\text { Protein: } 19.2 \mathrm{~g} 1 \text { st year, } 21.7 \text { second. } \\
\text { Calories: } 239 \text { kcal first year, } 313 \text { second. } \\
\text { Intensity: } \\
\text { \% RDA for energy: } 15-20 \% \text { sufficient. } \\
\text { \% DRI for protein: } \\
\text { Control: nothing } \\
\text { Provider: } \\
\text { Supervised: Y } \\
\text { Compliance: }\end{array}$ \\
\hline
\end{tabular}

Outcomes

Average increase in height, weight, weight for age, triceps skinfold, mid-upper arm muscle and fat area. Yearly increase in Raven's progressive matrices, Verbal meaning, arithmetic performance.

Regression used; mean growth and s.e. calculated.

Jadad R: 1
Jadad B: 0
Jadad W: 1
Baseline measurement: A for all
Reliable outcome: A for growth, A for psychological measurement, U for hemoglobin, hemotocrit. Pro-
tection against contamination: A Blinded assessment: A


Neumann 2003 (Continued)

Co-intervention: A

Loss to follow-up: A

\section{Risk of bias}

\begin{tabular}{l|l} 
Item Authors' judgement $\quad$ Description
\end{tabular}

Allocation concealment? Unclear B - Unclear

\section{Orr $1928-13$ yrs}

Methods

Upper income country: Scotland Study design:CBA

Unit of allocation: individual

Duration: 7 months in 1927 and another 7 months study in 1928

Total $\mathrm{N}$ in all groups: unclear. First study: took 40 to 50 in each of 4 exp. groups from each of 7 centers; thus 1120 to 1400 altogther. But one center started late, and one center not given whole milk. Also, those who missed feeds or were ill, were not included in analysis.

Second study (Leighton, 1929): Same children, but in all centers. Total of 1425. 268 excluded from analysis.

Subgroup analysis: NM

Withdrawals: Not clear.

Original study: Dropped those who missed more than $25 \%$ of school days, had severe illnesses, or who had problematic weights and heights from analysis. Also, whole milk was not given continuously in Glasgow so these children weren't in analysis.

Second study: CBA done on same children in same centers the next school year.

$\mathrm{N}=1425$ to start. Dropped 268 from analysis due to poor school attendance.

In second study, did some cross-over with children of certain ages from a few centers

Participants SES: urban, from working class families.

Ages: 5-6, 8-9, and 13-14 in first, and same children 6, 913 in second

Gender: NM

Nutritional status: Height: weight: NM

Interventions

Feeding: Whole milk; $3 / 4$ pint to $1 / 1 / 4$ pint depending on aget. Second study: same, except said 1 pint for oldest group Orr study: Protein: 13.8 to $23.6 \mathrm{~g}$

Calories: 213 to $355 \mathrm{kcal}$

Intensity:

$\%$ RDA for energy: $14-17 \%$. Sufficient

$\%$ DRI for protein: $44-72 \%$

Control: nothing

Provider: NM

Supervised : Yes, at least in 1928

Compliance: NM

Outcomes

Mean increase in height, weight. 


\section{Orr 1928 - 13 yrs (Continued)}

\begin{tabular}{|c|c|c|}
\hline Notes & $\begin{array}{l}\text { Baseline measurement: } U \\
\text { Reliable outcome: } U \\
\text { Proection against contamination: A } \\
\text { Blinded assessment: } U \\
\text { Co-Intervention: } U \\
\text { Loss to follow-up: } U\end{array}$ & \\
\hline \multicolumn{3}{|l|}{ Risk of bias } \\
\hline Item & Authors' judgement & Description \\
\hline Allocation concealment? & Unclear & D - Not used \\
\hline
\end{tabular}

Orr 1928 - 6 yrs

\begin{tabular}{|c|c|c|}
\hline Methods & \multicolumn{2}{|c|}{ Same study as Orr 1928} \\
\hline Participants & \multicolumn{2}{|c|}{ Data for children aged 6 years old only $(n=251)$} \\
\hline \multicolumn{3}{|l|}{ Interventions } \\
\hline \multicolumn{3}{|l|}{ Outcomes } \\
\hline \multicolumn{3}{|l|}{ Notes } \\
\hline \multicolumn{3}{|l|}{ Risk of bias } \\
\hline Item & Authors' judgement & Description \\
\hline Allocation concealment? & Unclear & D - Not used \\
\hline
\end{tabular}

Orr 1928 - 9 yrs

\begin{tabular}{l|l}
\hline Methods & Same study as Orr 1928 \\
\hline Participants & Data for children aged 9 years old only ( $=216)$ \\
\hline Interventions & \\
\hline Outcomes & \\
\hline Notes & Authors' judgement $\quad$ Description
\end{tabular}


Orr 1928 - 9 yrs (Continued)

Allocation concealment? Unclear D - Not used

Paige 1976

\begin{tabular}{|c|c|c|}
\hline Methods & \multicolumn{2}{|c|}{$\begin{array}{l}\text { Upper income country: USA } \\
\text { Study design: CBA. } \\
\text { Unit of allocation: school } \\
\text { Duration: } 9 \text { months. } \\
\text { Total N in all groups: } 344 \\
\text { Subgroup analysis: results reported by age group } \\
\text { Withdrawals: } 20 \% \text { of exp, } 22 \% \text { of control }\end{array}$} \\
\hline Participants & \multicolumn{2}{|c|}{$\begin{array}{l}\text { SES: urban poor black children from lower socio-economic decile tracts. } 60 \text { and } 64 \% \text { of families on public } \\
\text { assistance } \\
\text { Age: Exp: } 5 \text { years } 1 \text { month to } 9 \text { years } 1 \text { month } \\
\text { Control: } 5 \text { years } 1 \text { month to } 9 \text { years } 5 \text { month } \\
\text { Gender: } \\
\text { Nutritional Status: Height:, Weight: }\end{array}$} \\
\hline Interventions & \multicolumn{2}{|c|}{$\begin{array}{l}\text { Feeding: High protein drink supplement providing iron, calcium, protein. vitamin D. Snack given mid- } \\
\text { morning. All children got school lunch, and some got school breakfast too. } \\
\text { Protein: } 14.5 \mathrm{~g} \\
\text { Calories: } 240 \text { Intensity: \% RDA for energy: } 12-13 \% \text {. Insufficient. } \\
\% \text { RDI for protein: } 46-73 \% \text {. Control: no supplementation } \\
\text { Provider: In classroom } \\
\text { Supervised : Y } \\
\text { Compliance: Consumption of supplement was about } 88 \% \text { overall. }\end{array}$} \\
\hline Outcomes & \multicolumn{2}{|c|}{ Mean increase in height, weight, hemoglobin. Change in proportion considered anemic } \\
\hline Notes & \multicolumn{2}{|c|}{$\begin{array}{l}\text { Baseline measurement: A for weight, } \mathrm{U} \text { for height } \\
\text { Reliable Outcome: A for height weight. and for hemotocrit. } \\
\text { Protection against Contamination: A Blinded assessment: U } \\
\text { Co-intervention: U } \\
\text { Loss to follow-up: I }\end{array}$} \\
\hline \multicolumn{3}{|l|}{ Risk of bias } \\
\hline Item & Authors' judgement & Description \\
\hline Allocation concealment? & Unclear & D - Not used \\
\hline
\end{tabular}


Paige 7 year olds

\begin{tabular}{|c|c|c|}
\hline Methods & \multicolumn{2}{|c|}{ Same study as Paige 1976} \\
\hline Participants & \multicolumn{2}{|c|}{ Data for children aged 7 years old only } \\
\hline \multicolumn{3}{|l|}{ Interventions } \\
\hline \multicolumn{3}{|l|}{ Outcomes } \\
\hline \multicolumn{3}{|l|}{ Notes } \\
\hline \multicolumn{3}{|l|}{ Risk of bias } \\
\hline Item & Authors' judgement & Description \\
\hline Allocation concealment? & Unclear & D - Not used \\
\hline
\end{tabular}

Paige 8 year olds

\begin{tabular}{|c|c|c|}
\hline Methods & \multicolumn{2}{|c|}{ Same study as Paige 1976} \\
\hline Participants & \multicolumn{2}{|c|}{ Data for children aged 8 years old only } \\
\hline \multicolumn{3}{|l|}{ Interventions } \\
\hline \multicolumn{3}{|l|}{ Outcomes } \\
\hline \multicolumn{3}{|l|}{ Notes } \\
\hline \multicolumn{3}{|l|}{ Risk of bias } \\
\hline Item & Authors' judgement & Description \\
\hline Allocation concealment? & Unclear & D - Not used \\
\hline
\end{tabular}

Powell 1983

\begin{tabular}{|c|c|}
\hline Methods & $\begin{array}{l}\text { LLMIC: Jamaica } \\
\text { Study Design: CBA } \\
\text { Unit of allocation: Class } \\
\text { Duration: } 3 \text { months (January to March 1977) } \\
\text { Total N in all groups: } 44 \text { in exp group, } 38 \text { in no placebo control; } 33 \text { in syrup control. } \\
\text { Subgroup analysis: } \\
\text { Withdrawals: } 4 \text { from experimental group and } 3 \text { from } 2 \text { control groups }\end{array}$ \\
\hline Participants & $\begin{array}{l}\text { SES: Rural, mountainous area, most from "poor" farming families } \\
\text { Age: Breakfast- } 12.6 \text {, Control- } 12.5 \text {, Syrup- } 12.6 \\
\text { Gender: Breakfast- } 36 \text { boys, } 8 \text { girls; Control- } 13 \text { boys, } 25 \text { girls; Syrup- } 27 \text { boys, } 6 \text { girls } \\
\text { Nutritional status: Height: Breakfast- } 94.29 \% \text { of std; Control- } 95.28 \% \text { of std; Syrup- } 93.5 \% \text { of std }\end{array}$ \\
\hline
\end{tabular}


Weight: Breakfast- $82.68 \%$ of std wt for age; Control- $87.58 \%$ of std wt for age; Syrup- $82.25 \%$ of std wt for age

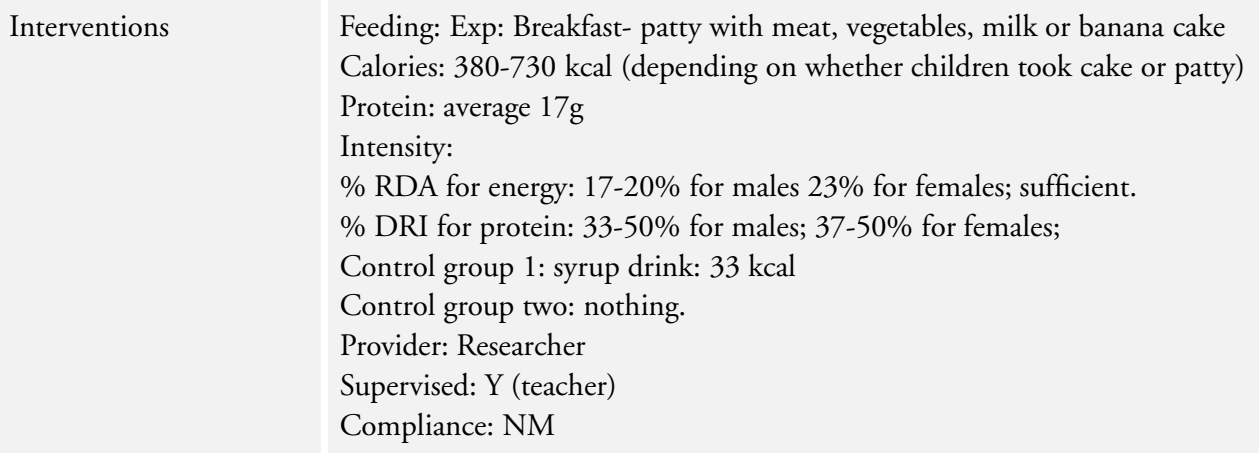

Outcomes

Nutritional status: percent of standard weight for age and height for age

School performance: WRAT- reading, spelling, arithmetic

Behavioural: School attendance

Notes

Baseline measurement: I for reading, spelling, unclear for math. A for weight for age, height for age

Reliable Outcome: $U$ for weight, height. U for psychological tests.

Protection against contamination: A

Blinded assessment: A

Co-intervention: $\mathrm{U}$

Loss to follow-up: A

\section{Risk of bias}

\begin{tabular}{lll}
\hline Item & Authors' judgement & Description \\
\hline Allocation concealment? & Unclear & D - Not used \\
\hline
\end{tabular}

\section{Powell 1998 (A)}

Methods

LLMIC: Jamaica Study design: RCT Unit of allocation: Children stratified by class and nutritional group. Duration: 8 months. Total $\mathrm{N}$ in all groups: 813 Subgroup analysis: tested interaction between nutritional status and treatment. Withdrawals: 3 in undernourished placebo; 7 in undernourished breakfast; 7 adequate nourished placebo; 6 adequate nourished breakfast

Participants

SES: all rural (mountainous), children mostly from poor families. Age: across both - 107.6 \pm 14.7 months Gender: DK Nutritional status: Height for age: Exp: $=1.44$ and .43 . Control: $-1,26$ and .33 . Weight for age: exp: -1.65 s.d for undernourished and .12 for adequately nourished. Control: -1.49 s.d. for undernourished and and .13 s.d. for adequately nourished

Interventions

Feeding: breakfast in school - cheese sandwich or spiced bun and cheese + flavoured milk Protein: $27.1 \mathrm{~g}$ Calories: $576-703 \mathrm{kcal}$ Intensity: \% RDA for energy: 32\%, sufficient \% DRI for protein: $80 \%$ Control: 1/4 orange $(18 \mathrm{Kcal})$ Provider: teacher Supervised: Y Compliance: 
Powell 1998 (A) (Continued)

\begin{tabular}{lll}
\hline Outcomes & $\begin{array}{l}\text { Arithmetic Reading, Spelling from Wide Range Achievement Test, Attendance, Height, Weight, Weight } \\
\text { for age, Height for age, Body mass index }\end{array}$ \\
\hline Notes & $\begin{array}{l}\text { Jadad R: 1 Jadad B: 0 Jadad W: 1 Baseline measurement: A for all Reliable Outcome: A for all Protection } \\
\text { against contamination: A Blinded assessment: A Co-interventions: U Loss to follow-up: A }\end{array}$ \\
\hline Risk of bias & & Description \\
\hline Item & Authors' judgement & B - Unclear \\
\hline Allocation concealment? & Unclear &
\end{tabular}

\section{Powell 1998 Total}

\begin{tabular}{|c|c|c|}
\hline Methods & \multicolumn{2}{|c|}{$\begin{array}{l}\text { LLMIC: Jamaica Study design: RCT Unit of allocation: Children stratified by class and nutritional group. } \\
\text { Duration: } 8 \text { months. Total N in all groups: } 813 \text { Subgroup analysis: tested interaction between nutritional } \\
\text { status and treatment. Withdrawals: } 3 \text { in undernourished placebo; } 7 \text { in undernourished breakfast; } 7 \text { ade- } \\
\text { quate nourished placebo; } 6 \text { adequate nourished breakfast }\end{array}$} \\
\hline Participants & \multicolumn{2}{|c|}{$\begin{array}{l}\text { SES: all rural (mountainous), children mostly from poor families. Age: across both }-107.6 \pm 14.7 \text { months } \\
\text { Gender: DK Nutritional status: Height for age: Exp: }=1.44 \text { and } .43 \text {. Control: }-1,26 \text { and } .33 \text {. Weight } \\
\text { for age: exp: }-1.65 \text { s.d for undernourished and } .12 \text { for adequately nourished. Control: }-1.49 \text { s.d. for } \\
\text { undernourished and and } .13 \text { s.d. for adequately nourished }\end{array}$} \\
\hline Interventions & \multicolumn{2}{|c|}{$\begin{array}{l}\text { Feeding: breakfast in school - cheese sandwich or spiced bun and cheese + flavoured milk Protein: } 27.1 \mathrm{~g} \\
\text { Calories: } 576-703 \mathrm{kcal} \text { Intensity: \% RDA for energy: } 32 \% \text {, sufficient } \% \text { DRI for protein: } 80 \% \text { Control: } \\
1 / 4 \text { orange }(18 \mathrm{Kcal}) \text { Provider: teacher Supervised: Y Compliance: }\end{array}$} \\
\hline Outcomes & \multicolumn{2}{|c|}{$\begin{array}{l}\text { Arithmetic Reading, Spelling from Wide Range Achievement Test, Attendance, Height, Weight, Weight } \\
\text { for age, Height for age, Body mass index }\end{array}$} \\
\hline Notes & \multicolumn{2}{|c|}{$\begin{array}{l}\text { Jadad R: } 1 \text { Jadad B: } 0 \text { Jadad W: } 1 \text { Baseline measurement: A for all Reliable Outcome: A for all Protection } \\
\text { against contamination: A Blinded assessment: A Co-interventions: U Loss to follow-up: A }\end{array}$} \\
\hline \multicolumn{3}{|l|}{ Risk of bias } \\
\hline Item & Authors' judgement & Description \\
\hline Allocation concealment? & Unclear & D - Not used \\
\hline
\end{tabular}


Powell 1998(u)

Methods

Participants Data for under-nourished children only $(\mathrm{n}=396)$

Interventions

Outcomes

Notes

Risk of bias

\begin{tabular}{l|l|l}
\hline Item & Authors' judgement & Description \\
\hline Allocation concealment? & Unclear & D - Not used \\
\hline
\end{tabular}

Shemilt 2004

\begin{tabular}{|c|c|}
\hline Methods & $\begin{array}{l}\text { High income country: UK } \\
\text { Study design: cluster RCT for first } 3 \text { months, observational for second followup at } 1 \text { year } \\
\text { Unit allocation: school } \\
\text { Duration: Sept } 1999 \text { to Sept } 2000: 12 \text { months } \\
\text { Total n in all groups: } 29 \text { schools, } 5837 \text { children } \\
\text { Funding: National Department of Health } \\
\text { Withdrawals: } 10 \text { schools declined to provide data after randomization. Designed as pragmatic cluster RCT } \\
\text { while program was being rolled out on a national level, by the end of } 3 \text { months, } 4 \text { out of } 17 \text { schools in the } \\
\text { intervention group did not have breakfast clubs, and } 2 \text { of the schools in the control group had breakfast } \\
\text { clubs. At the } 1 \text { year, } 72 \% \text { of intervention and } 76 \% \text { of control schools had a breakfast club operating in } \\
\text { the schools, Contamination occurred; at first follow-up, } \\
\text { Designed as a pragmatic cluster trial }\end{array}$ \\
\hline Participants & $\begin{array}{l}\text { SES: deprived areas in England } \\
\text { Age: control: } 10.13 \text { yrs, intervention: } 9.59 \text { yrs } \\
\text { Gender: } 52 \% \text { male, } 49 \% \text { female } \\
\text { Nutritional status: not assessed } \\
\text { Height: } n / a \\
\text { Weight: } n / a\end{array}$ \\
\hline Interventions & $\begin{array}{l}\text { Feeding: Breakfast club before school, each school planned own breakfast club. Caloric content below is } \\
\text { from case studies of } 5 \text { schools (Norwich 2001) Protein: 8.9-13.7 g } \\
\text { Calories: } 334-695 \mathrm{kcal} \\
\% \text { RDA for energy: } \\
\text { \%DRI for protein: } \\
\text { Provider: Childen could choose from available foods } \\
\text { Supervised: minimal } \\
\text { Compliance: Feeding: } 13 \text { out of } 17 \text { schools had breakfast club (BC) at first follow-up; control: } 2 \text { out of } \\
10 \text { schools had BC at first follow-up } \\
\text { Attendance records: median } 34 \% \text {, range } 8-72 \% \text { of children reported ever attending breakfast clubs }\end{array}$ \\
\hline
\end{tabular}




\section{Shemilt 2004 (Continued)}

\begin{tabular}{ll} 
Outcomes & Primary outcome: behaviour difficulties with Strengths and Difficulties Questionnaire (Goodman 1997) \\
Nutritional status: not measured \\
General health: Life, health and school questionnaire \\
Parent family assessment: Family Questionnaire on employment, access to child care. \\
We report on the first follow-up only. \\
\hline Notes & Jadad R: 1 \\
Jadad B: 0 \\
Jadad W: 1 \\
Baseline Measurement:: U for Total Difficulties (10\% difference), days of school skipped, and number of \\
days on which classes skipped. A for Rutter's score. \\
Reliable Outcome: A for trail-making, strengths and difficultiies, Rutter's. U for health, lifestyle questions. \\
Protection against contamination: I, Blinded assessment of primary outcomes: U, Co-Intervention: U, \\
Loss to Follow-up: U
\end{tabular}

Risk of bias

\begin{tabular}{l|ll}
\hline Item & Authors' judgement & Description \\
\hline Allocation concealment? & Unclear & B - Unclear \\
\hline
\end{tabular}

Tisdall 1951

\begin{tabular}{|c|c|}
\hline Methods & $\begin{array}{l}\text { Upper income country: Canada } \\
\text { Study Design: CBA } \\
\text { Unit of allocation: Student } \\
\text { Duration: January 1947- April 1949. } 25 \text { months (excluding summers). } \\
\text { Total N in all groups: Estimated that they needed } 600 \text { at beginning. Had } 416 \text { at end of study } \\
\text { Funding: The Canadian Red Cross Society } \\
\text { Subgroup analysis: } \\
\text { Withdrawals: Seems like } 33 \% \text { exp, } 26 \% \text { control. }\end{array}$ \\
\hline Participants & $\begin{array}{l}\text { SES: Moss Park area of Toronto, urban, schools in low income area } \\
\text { Age: } 5.5 \text { to } 10.5 \text { yrs for both. control and experimental groups } \\
\text { Gender: DK } \\
\text { Nutritional status: Height: } 49.6 \text { inches exp, } 49.3 \text { controls. Weight: } 97.5 \text { on McLoy weight index at start } \\
\text { of study. McLoy is actual weight divided by 'ideal weight' }\end{array}$ \\
\hline Interventions & $\begin{array}{l}\text { Feeding: Lunch at school } \\
\text { Protein: } 26 \mathrm{~g} \\
\text { Calories: } 705 \mathrm{cal} \\
\text { Intensity: } \\
\% \text { RDA for energy: } 28-39 \% \text {. Sufficient. } \\
\% \text { DRI for protein: } 77-131 \% \\
\text { Control: Went home for lunch as usual } \\
\text { Provider: } \\
\text { Supervised: Y } \\
\text { Compliance: Very poor. Most of exp group attended lunch less than } 90 \% \text { of time }\end{array}$ \\
\hline
\end{tabular}


Tisdall 1951 (Continued)

Nutrient and micro-nutrient intake: home dietary surveys for one week were done on 1/4 families.
Nutrition and micronutrient status: Weight (McLoy Weight indices), change in weight, height, change
in height, change in forearm and calf circumference. Serum absorbic acid, serum carotene, and Vitamin
A.
Cognition: Intelligence tests.
School performance: marks, achievement tests (different tests administered before and after)
Behavioural: Attendance, change in attendance

\section{Risk of bias}

\begin{tabular}{l|ll}
\hline Item & Author' judgement & Description \\
\hline Allocation concealment? & Unclear & D - Not used \\
\hline
\end{tabular}

Characteristics of excluded studies [ordered by study ID]

\begin{tabular}{ll}
\hline Study & Reason for exclusion \\
\hline Ahmed 2004 & $\begin{array}{l}\text { Mixed cross-sectional survey and retrospective CBA. For CBA, } 2 \text { control upsalas were excluded due to contamina- } \\
\text { tion, and 3 new control schools selected }\end{array}$ \\
\hline Arvedson 1969 & $\begin{array}{l}\text { CBA } \\
\text { - type of breakfast not school feeding }\end{array}$ \\
\hline Cadogan 1997 & $\begin{array}{l}\text { RCT } \\
\text { - not in school, mixed SES }\end{array}$ \\
\hline Cook 1996 & $\begin{array}{l}\text { CBA } \\
\text { - changes made in cost of the program, not implementation of the program }\end{array}$ \\
\hline Cromer 1990 & $\begin{array}{l}\text { RCT } \\
\text { - in lab setting } \\
\text { - predominantly white, middle class }\end{array}$ \\
\hline Fellers 1967 & $\begin{array}{l}\text { CBA } \\
\text { - High school was for all students in town. Not enough information on SES }\end{array}$ \\
\hline
\end{tabular}


(Continued)

Guthrie 1977 RCT

- Inappropriate intervention. Compares chocolate milk with white milk

Lopez 1993 RCT

-omission of breakfast

- also self-selected experimental in some

\section{Morrell 2002 CBA}

-school meal modification (high protein, low carbohydrate)

Simeon 1989 Cross-over

- not feeding. Omission of breakfast.

Tuttle 1954 ITS

-not in school setting; lab study

Vaisman 1996 RCT

-mixed SES. Author is unable to provide

SES breakdowns. 
DATA ANDANALYSES

Comparison 1. Developing country: School meal vs control. RCT

\begin{tabular}{lccll} 
Outcome or subgroup title & $\begin{array}{c}\text { No. of } \\
\text { studies }\end{array}$ & $\begin{array}{c}\text { No. of } \\
\text { participants }\end{array}$ & Statistical method & Effect size \\
\hline 1 Weight gain kg & 3 & 1462 & Mean Difference (IV, Random, 95\% CI) & $0.39[0.11,0.67]$ \\
2 Height gain (cm) & 3 & 1462 & Mean Difference (IV, Random, 95\% CI) & $0.38[-0.32,1.08]$ \\
3 Weight for age: z-scores & 1 & 785 & Mean Difference (IV, Random, 95\% CI) & $0.07[0.04,0.10]$ \\
4 Height for age: z-scores & 2 & 1021 & Mean Difference (IV, Random, 95\% CI) & $0.04[0.02,0.06]$ \\
14 MUAC & 1 & 236 & Mean Difference (IV, Random, 95\% CI) & $0.31[0.16,0.46]$ \\
21 Mid-upper arm muscle area & 1 & 236 & Mean Difference (IV, Random, 95\% CI) & $68.22[39.57,96.87]$ \\
22 Mid upper arm fat area & 1 & 236 & Mean Difference (IV, Random, 95\% CI) & $-0.31[-26.12,25$. \\
& & & & \\
23 weight for height gain & 1 & 236 & Mean Difference (IV, Random, 95\% CI) & $0.2[-0.24,0.64]$ \\
\hline
\end{tabular}

\section{Comparison 2. Developing country RCT: Subgroup analysis: meals vs control}

\begin{tabular}{|c|c|c|c|c|}
\hline Outcome or subgroup title & $\begin{array}{l}\text { No. of } \\
\text { studies }\end{array}$ & $\begin{array}{c}\text { No. of } \\
\text { participants }\end{array}$ & Statistical method & Effect size \\
\hline $\begin{array}{l}1 \text { Undernourished vs adequately } \\
\text { nourished: Weight gain in } \mathrm{kg}\end{array}$ & 2 & & Mean Difference (IV, Random, 95\% CI) & Subtotals only \\
\hline 1.1 Undernourished & 1 & 392 & Mean Difference (IV, Random, 95\% CI) & $0.25[0.08,0.42]$ \\
\hline 1.2 Adequately Nourished & 1 & 393 & Mean Difference (IV, Random, 95\% CI) & $0.47[0.16,0.78]$ \\
\hline $\begin{array}{l}2 \text { Undernourished versus } \\
\text { adequately nourished, height in } \\
\mathrm{cm}\end{array}$ & 2 & & Mean Difference (IV, Random, 95\% CI) & Subtotals only \\
\hline 2.1 Undernourished & 1 & 392 & Mean Difference (IV, Random, 95\% CI) & $0.30[0.05,0.55]$ \\
\hline 2.2 Adequately nourished & 1 & 393 & Mean Difference (IV, Random, 95\% CI) & $0.17[-0.11,0.45]$ \\
\hline $\begin{array}{l}3 \text { Age subgroup analysis: weight } \\
\text { gain in } \mathrm{kg}\end{array}$ & 4 & & Mean Difference (IV, Random, 95\% CI) & Subtotals only \\
\hline 3.1 Ages $5-6$ years & 0 & 0 & Mean Difference (IV, Random, 95\% CI) & Not estimable \\
\hline 3.2 Age $6-8$ years & 0 & 0 & Mean Difference (IV, Random, 95\% CI) & Not estimable \\
\hline 3.3 Age $9-10$ years & 3 & 1226 & Mean Difference (IV, Random, 95\% CI) & $0.42[0.09,0.75]$ \\
\hline 3.4 Age $6-16$ years & 1 & 236 & Mean Difference (IV, Random, 95\% CI) & $0.28[-0.07,0.63]$ \\
\hline $\begin{array}{l}4 \text { Age subgroup analysis: height } \\
\text { gain }(\mathrm{cm})\end{array}$ & 4 & & Mean Difference (IV, Random, 95\% CI) & Subtotals only \\
\hline 4.1 Ages $5-6$ years & 0 & 0 & Mean Difference (IV, Random, 95\% CI) & Not estimable \\
\hline 4.2 Age 6-8 years & 0 & 0 & Mean Difference (IV, Random, 95\% CI) & Not estimable \\
\hline 4.3 Age $9-10$ years & 3 & 1226 & Mean Difference (IV, Random, 95\% CI) & $0.40[0.03,0.77]$ \\
\hline 4.4 Age $6-16$ years & 1 & 236 & Mean Difference (IV, Random, 95\% CI) & $-0.37[-1.30,0.56]$ \\
\hline
\end{tabular}




\begin{tabular}{|c|c|c|c|c|}
\hline Outcome or subgroup title & $\begin{array}{l}\text { No. of } \\
\text { studies }\end{array}$ & $\begin{array}{c}\text { No. of } \\
\text { participants }\end{array}$ & Statistical method & Effect size \\
\hline $\begin{array}{l}1 \text { Weight gain } \mathrm{kg} \text { - adjusted ICC } \\
0.025\end{array}$ & 6 & 984 & Mean Difference (IV, Random, 95\% CI) & $0.71[0.48,0.95]$ \\
\hline 2 Math change overall icc .15 & 2 & 337 & Std. Mean Difference (IV, Fixed, 95\% CI) & $0.31[0.09,0.53]$ \\
\hline $\begin{array}{l}3 \text { Math change by nutritional } \\
\text { status, icc } 0.15\end{array}$ & 5 & 337 & Std. Mean Difference (IV, Fixed, 95\% CI) & $0.44[0.22,0.67]$ \\
\hline $\begin{array}{l}\begin{array}{l}5 \text { Height gain }(\mathrm{cm}) \text { - adjusted ICC } \\
=0.016\end{array}\end{array}$ & 6 & 986 & Mean Difference (IV, Random, 95\% CI) & $1.43[0.46,2.41]$ \\
\hline 9 subgroup analysis weight by sex & 2 & & Mean Difference (IV, Fixed, 95\% CI) & Subtotals only \\
\hline 9.1 Agarwal boys & 1 & 331 & Mean Difference (IV, Fixed, 95\% CI) & $0.70[0.42,0.98]$ \\
\hline 9.2 Agarwal: girls & 1 & 118 & Mean Difference (IV, Fixed, 95\% CI) & $0.80[0.32,1.28]$ \\
\hline $\begin{array}{l}10 \text { Subgroup analysis: height by } \\
\text { sex }\end{array}$ & 2 & 446 & Mean Difference (IV, Fixed, 95\% CI) & $-0.14[-0.73,0.44]$ \\
\hline 10.1 agarwal boys & 1 & 331 & Mean Difference (IV, Fixed, 95\% CI) & $-0.30[-1.01,0.41]$ \\
\hline 10.2 agarwal girls & 1 & 115 & Mean Difference (IV, Fixed, 95\% CI) & $0.20[-0.85,1.25]$ \\
\hline $\begin{array}{l}11 \text { Subgroup by age: weight gain } \\
\text { in kg - Agarwal adjusted }\end{array}$ & 12 & & Mean Difference (IV, Random, 95\% CI) & Subtotals only \\
\hline 11.1 Ages 5-6 years & 1 & 106 & Mean Difference (IV, Random, 95\% CI) & $0.95[0.70,1.20]$ \\
\hline 11.2 Age 6-8 years & 6 & 564 & Mean Difference (IV, Random, 95\% CI) & $0.53[0.16,0.91]$ \\
\hline 11.3 Age $9-10$ years & 4 & 212 & Mean Difference (IV, Random, 95\% CI) & $0.90[0.59,1.21]$ \\
\hline 11.4 Age $6-16$ years & 1 & 140 & Mean Difference (IV, Random, 95\% CI) & $0.21[-0.86,1.28]$ \\
\hline $\begin{array}{l}12 \text { Subgroup by age: height gain } \\
\text { in } \mathrm{cm} \text { - Agarwal adjusted }\end{array}$ & 12 & & Mean Difference (IV, Random, 95\% CI) & Subtotals only \\
\hline 12.1 Ages 5-6 years & 1 & 106 & Mean Difference (IV, Random, 95\% CI) & $2.62[2.22,3.02]$ \\
\hline 12.2 Age 6-8 years & 6 & 564 & Mean Difference (IV, Random, 95\% CI) & $1.25[-0.02,2.51]$ \\
\hline 12.3 Age $9-10$ years & 4 & 178 & Mean Difference (IV, Random, 95\% CI) & $-0.22[-0.88,0.44]$ \\
\hline 12.4 Age 6-16 years & 1 & 140 & Mean Difference (IV, Random, 95\% CI) & $0.20[-1.35,1.75]$ \\
\hline $\begin{array}{l}13 \text { Full scale IQ (total): } \\
\text { adjusted-ICC } 0.15\end{array}$ & 1 & 231 & Mean Difference (IV, Fixed, 95\% CI) & $3.90[-2.88,10.68]$ \\
\hline $\begin{array}{l}21 \text { Full scale IQ (separated): } \\
\text { cluster size as in analysis: icc = } \\
.15\end{array}$ & 4 & 231 & Mean Difference (IV, Random, 95\% CI) & $3.80[0.51,7.10]$ \\
\hline $\begin{array}{l}24 \text { Performance IQ (separated): } \\
\text { numbers as in analysis: ICC = } \\
0.15\end{array}$ & 4 & 231 & Mean Difference (IV, Fixed, 95\% CI) & $5.74[1.73,9.74]$ \\
\hline $\begin{array}{l}26 \text { Performance IQ (total): } \\
\text { adjusted-ICC } 0.15\end{array}$ & 1 & 231 & Mean Difference (IV, Fixed, 95\% CI) & $5.0[-2.60,12.60]$ \\
\hline $\begin{array}{l}28 \text { Verbal IQ (separated): cluster } \\
\text { size as in analysis: } \mathrm{ICC}=0.15\end{array}$ & 4 & 231 & Mean Difference (IV, Random, 95\% CI) & $3.35[-0.21,6.92]$ \\
\hline $\begin{array}{l}29 \text { Verbal IQ (total): adjusted- } \\
\text { ICC } 0.15\end{array}$ & 1 & 231 & Mean Difference (IV, Fixed, 95\% CI) & $3.10[-2.99,9.19]$ \\
\hline $\begin{array}{l}36 \text { Percent weight for age: } \mathrm{ICC}= \\
.025\end{array}$ & 1 & 106 & Mean Difference (IV, Fixed, 95\% CI) & $0.90[-0.40,2.20]$ \\
\hline $\begin{array}{l}40 \text { Percent height for age: } \mathrm{ICC}= \\
0.016\end{array}$ & 1 & 106 & Mean Difference (IV, Fixed, 95\% CI) & $-0.75[-1.11,-0.39]$ \\
\hline 44 Change in reading: $\mathrm{ICC}=.15$ & 1 & 106 & Mean Difference (IV, Random, 95\% CI) & $0.09[-0.11,0.29]$ \\
\hline 47 change in spelling: $\mathrm{ICC}=.15$ & 1 & 106 & Mean Difference (IV, Fixed, 95\% CI) & $0.24[0.01,0.47]$ \\
\hline
\end{tabular}

School feeding for improving the physical and psychosocial health of disadvantaged students (Review) 
Comparison 4. developed country: school meal versus control: CBA

\begin{tabular}{lcccc} 
Outcome or subgroup title & $\begin{array}{c}\text { No. of } \\
\text { studies }\end{array}$ & $\begin{array}{c}\text { No. of } \\
\text { participants }\end{array}$ & Statistical method & Effect size \\
\hline 2 Weight gain: Corry-Mann alone & 1 & 102 & Mean Difference (IV, Fixed, 95\% CI) & $1.42[1.19,1.65]$ \\
$\begin{array}{l}\text { 7 Height gain in cm. adjusted } \\
\text { ICC }=0.016\end{array}$ & 4 & 703 & Mean Difference (IV, Random, 95\% CI) & $0.92[0.16,1.67]$ \\
\hline
\end{tabular}

Comparison 5. Developed country: School meal vs control RCT

\begin{tabular}{|c|c|c|c|c|}
\hline Outcome or subgroup title & $\begin{array}{l}\text { No. of } \\
\text { studies }\end{array}$ & $\begin{array}{c}\text { No. of } \\
\text { participants }\end{array}$ & Statistical method & Effect size \\
\hline 1 change in height & 1 & 520 & Mean Difference (IV, Random, 95\% CI) & $0.28[-0.01,0.57]$ \\
\hline 2 Subgroup analysis: height by sex & 2 & & Mean Difference (IV, Fixed, 95\% CI) & Subtotals only \\
\hline 2.1 bakerboys & 1 & 267 & Mean Difference (IV, Fixed, 95\% CI) & $0.11[-0.22,0.44]$ \\
\hline 2.2 baker girls & 1 & 253 & Mean Difference (IV, Fixed, 95\% CI) & $0.45[-0.03,0.93]$ \\
\hline 3 change in weight $(\mathrm{kg})$ & 1 & 520 & Mean Difference (IV, Random, 95\% CI) & $0.13[-0.23,0.49]$ \\
\hline 4 Subgroup analysis: weight by sex & 2 & 520 & Mean Difference (IV, Fixed, 95\% CI) & $0.15[-0.19,0.49]$ \\
\hline 4.1 bakerboys & 1 & 267 & Mean Difference (IV, Fixed, 95\% CI) & $0.21[-0.23,0.65]$ \\
\hline 4.2 baker girls & 1 & 253 & Mean Difference (IV, Fixed, 95\% CI) & $0.05[-0.51,0.61]$ \\
\hline
\end{tabular}

Comparison 10. Developing country: School meal vs control. RCT- Sensitivity

\begin{tabular}{|c|c|c|c|c|}
\hline Outcome or subgroup title & $\begin{array}{l}\text { No. of } \\
\text { studies }\end{array}$ & $\begin{array}{c}\text { No. of } \\
\text { participants }\end{array}$ & Statistical method & Effect size \\
\hline $\begin{array}{l}5 \text { Weight gain kg- sensitivity ICC } \\
0.01\end{array}$ & 3 & 1462 & Mean Difference (IV, Random, 95\% CI) & $0.47[0.10,0.84]$ \\
\hline $\begin{array}{l}6 \text { Weight gain kg- sensitivity ICC } \\
0.05\end{array}$ & 3 & 1462 & Mean Difference (IV, Random, 95\% CI) & $0.36[0.18,0.54]$ \\
\hline $\begin{array}{l}7 \text { Weight gain kg- sensitivity ICC } \\
0.1\end{array}$ & 3 & 1462 & Mean Difference (IV, Random, 95\% CI) & $0.36[0.19,0.52]$ \\
\hline $\begin{array}{l}9 \text { Height gain }(\mathrm{cm}) \text {, sensitivity } \\
\text { ICC } 0.01\end{array}$ & 3 & 1462 & Mean Difference (IV, Random, 95\% CI) & $0.40[-0.32,1.11]$ \\
\hline $\begin{array}{l}10 \text { Height gain }(\mathrm{cm}) \text {, sensitivity } \\
\text { ICC } 0.05\end{array}$ & 3 & 1462 & Mean Difference (IV, Random, 95\% CI) & $0.29[-0.34,0.91]$ \\
\hline $\begin{array}{l}11 \text { Height gain }(\mathrm{cm}) \text {, sensitivity } \\
\text { ICC } 0.1\end{array}$ & 3 & 1462 & Mean Difference (IV, Random, 95\% CI) & $0.21[-0.33,0.76]$ \\
\hline
\end{tabular}




\begin{tabular}{|c|c|c|c|c|}
\hline Outcome or subgroup title & $\begin{array}{l}\text { No. of } \\
\text { studies }\end{array}$ & $\begin{array}{c}\text { No. of } \\
\text { participants }\end{array}$ & Statistical method & Effect size \\
\hline 1 Math change overall icc .1 & 2 & 337 & Mean Difference (IV, Fixed, 95\% CI) & $0.27[0.03,0.51]$ \\
\hline $\begin{array}{l}2 \text { Weight gain kg- sensitivity ICC } \\
0.01\end{array}$ & 6 & 989 & Mean Difference (IV, Random, 95\% CI) & $0.71[0.49,0.94]$ \\
\hline $\begin{array}{l}3 \text { Weight gain kg- sensitivity ICC } \\
0.05\end{array}$ & 6 & 989 & Mean Difference (IV, Random, 95\% CI) & $0.72[0.47,0.96]$ \\
\hline $\begin{array}{l}4 \text { Weight gain kg- sensitivity ICC } \\
0.1\end{array}$ & 6 & 989 & Mean Difference (IV, Random, 95\% CI) & $0.72[0.46,0.97]$ \\
\hline 5 Math change overall icc .2 & 2 & 337 & Mean Difference (IV, Fixed, 95\% CI) & $0.27[-0.03,0.56]$ \\
\hline $\begin{array}{l}6 \text { Height gain }(\mathrm{cm})-\text { sensitivity } \\
\text { ICC } 0.01\end{array}$ & 6 & 986 & Mean Difference (IV, Random, 95\% CI) & $1.42[0.41,2.43]$ \\
\hline $\begin{array}{l}7 \text { Height gain }(\mathrm{cm}) \text { - sensitivity } \\
\text { ICC } 0.05\end{array}$ & 6 & 986 & Mean Difference (IV, Random, 95\% CI) & $1.50[0.62,2.37]$ \\
\hline $\begin{array}{l}8 \text { Height gain }(\mathrm{cm}) \text { - sensitivity } \\
\text { ICC } 0.1\end{array}$ & 6 & 986 & Mean Difference (IV, Random, 95\% CI) & $1.61[0.83,2.39]$ \\
\hline $\begin{array}{l}11 \text { Percent height for age: icc }= \\
0.05\end{array}$ & 1 & 106 & Mean Difference (IV, Random, 95\% CI) & $-0.75[-1.18,-0.32]$ \\
\hline 12 Percent height for age: icc $=.1$ & 1 & 106 & Mean Difference (IV, Random, 95\% CI) & $-0.75[-1.27,-0.23]$ \\
\hline $\begin{array}{l}14 \text { Full scale IQ (total)- sensitivity } \\
0.1\end{array}$ & 1 & 231 & Mean Difference (IV, Fixed, 95\% CI) & $3.90[-1.96,9.76]$ \\
\hline $\begin{array}{l}16 \text { Math (change) by nutritional } \\
\text { status: cluster size as in analysis } \\
\text { Sensitivity ICC }=0.2\end{array}$ & 5 & 337 & Std. Mean Difference (IV, Random, 95\% CI) & $0.41[0.18,0.63]$ \\
\hline $\begin{array}{l}17 \text { Math (change) by nutritional } \\
\text { status: cluster size as in analysis } \\
\text { Sensitivity ICC }=0.1\end{array}$ & 5 & 337 & Std. Mean Difference (IV, Random, 95\% CI) & $0.49[0.27,0.72]$ \\
\hline $\begin{array}{l}18 \text { Full scale IQ (total)- sensitivity } \\
0.20\end{array}$ & 1 & 231 & Mean Difference (IV, Fixed, 95\% CI) & $3.90[-3.69,11.49]$ \\
\hline $\begin{array}{l}20 \text { Full scale IQ (end study): } \\
\text { sensitivity cluster size as in } \\
\text { analysis ICC }=0.1\end{array}$ & 4 & 231 & Mean Difference (IV, Random, 95\% CI) & $3.85[0.79,6.91]$ \\
\hline $\begin{array}{l}22 \text { Full scale IQ (end study): } \\
\text { sensitivity cluster size as in } \\
\text { analysis: ICC }=0.2\end{array}$ & 4 & 231 & Mean Difference (IV, Random, 95\% CI) & $3.76[0.26,7.26]$ \\
\hline $\begin{array}{l}23 \text { Performance IQ (end study): } \\
\text { Sensitivity cluster size as in } \\
\text { analysis: ICC }=0.1\end{array}$ & 4 & 231 & Mean Difference (IV, Random, 95\% CI) & $5.78[2.12,9.45]$ \\
\hline $\begin{array}{l}25 \text { Performance IQ (end study): } \\
\text { Sensitivity cluster size as in } \\
\text { analysis: ICC }=0.2\end{array}$ & 4 & 231 & Mean Difference (IV, Fixed, 95\% CI) & $5.69[1.38,10.00]$ \\
\hline $\begin{array}{l}27 \text { Verbal IQ (end study): } \\
\text { Sensitivity cluster size as in } \\
\text { analyses: ICC }=0.1\end{array}$ & 4 & 231 & Mean Difference (IV, Random, 95\% CI) & $3.32[-0.03,6.67]$ \\
\hline $\begin{array}{l}29 \text { Verbal IQ (end study): } \\
\text { Sensitivity cluster size as in } \\
\text { analysis: ICC }=0.2\end{array}$ & 4 & 231 & Mean Difference (IV, Random, 95\% CI) & $3.36[-0.48,7.20]$ \\
\hline
\end{tabular}

School feeding for improving the physical and psychosocial health of disadvantaged students (Review) 
30 Percentage standard weight. Sensitivity $=0.01$

32 Percent weight for age: Sensitivity ICC $=0.05$

33 Percent weight for age: Sensitivity ICC $=0.1$

36 Verbal IQ (total): sensitivity- 0.10

37 Verbal IQ (total): sensitivity- 0.20

38 Performance IQ (total): sensitivity- 0.10
39 Percentage standard height. Sensitivity $=.01$

41 Performance IQ (total): sensitivity- 0.20

45 change in reading: sensitivity $\mathrm{ICC}=.1$

46 change in reading: sensitivity $\mathrm{ICC}=.2$

50 change in spelling: sensitivity $\mathrm{ICC}=.1$

52 change in spelling: sensitivity $\mathrm{ICC}=0.2$

58 Change in attendance: sensitivity $=.10$

59 change in attendance: sensitivity $=.20$

60 End of study attendance: sensitivity icc $=.10$

61 End of study attendance: sensitvity icc at .2

62 Change in Attendace: Sensitivity $=.05$

\begin{tabular}{|c|c|c|c|}
\hline 1 & 70 & Mean Difference (IV, Random, 95\% CI) & $0.90[-0.59,2.39]$ \\
\hline 1 & 106 & Mean Difference (IV, Random, 95\% CI) & $0.90[-0.56,2.36]$ \\
\hline 1 & 106 & Mean Difference (IV, Random, 95\% CI) & $0.90[-0.83,2.63]$ \\
\hline 1 & 231 & Mean Difference (IV, Fixed, 95\% CI) & $3.10[-2.17,8.37]$ \\
\hline 1 & 231 & Mean Difference (IV, Fixed, 95\% CI) & $3.10[-3.72,9.92]$ \\
\hline 1 & 231 & Mean Difference (IV, Fixed, 95\% CI) & $5.0[-1.57,11.57]$ \\
\hline 1 & 70 & Mean Difference (IV, Random, 95\% CI) & $-0.74[-1.18,-0.30]$ \\
\hline 1 & 231 & Mean Difference (IV, Fixed, 95\% CI) & $5.00[-3.50,13.50]$ \\
\hline 1 & 106 & Mean Difference (IV, Random, 95\% CI) & $0.09[-0.09,0.27]$ \\
\hline 1 & 106 & Mean Difference (IV, Random, 95\% CI) & $0.09[-0.13,0.31]$ \\
\hline 1 & 106 & Mean Difference (IV, Fixed, 95\% CI) & $0.23[0.02,0.44]$ \\
\hline 1 & 106 & Mean Difference (IV, Random, 95\% CI) & $0.23[-0.01,0.47]$ \\
\hline 1 & 108 & Mean Difference (IV, Fixed, 95\% CI) & $4.95[-2.64,12.54]$ \\
\hline 1 & 108 & Mean Difference (IV, Fixed, 95\% CI) & $4.95[-4.40,14.30]$ \\
\hline 1 & 72 & Mean Difference (IV, Fixed, 95\% CI) & $\begin{array}{l}-0.23[-14.69,14 . \\
23]\end{array}$ \\
\hline 1 & 72 & Mean Difference (IV, Fixed, 95\% CI) & $\begin{array}{l}-0.23[-18.69,18 \\
23]\end{array}$ \\
\hline 1 & 106 & Mean Difference (IV, Fixed, 95\% CI) & $4.95[-1.65,11.55]$ \\
\hline
\end{tabular}

\section{Comparison 12. Developed country: school meal versus control: CBA - Sensitivity}

\begin{tabular}{lcccc} 
Outcome or subgroup title & $\begin{array}{c}\text { No. of } \\
\text { studies }\end{array}$ & $\begin{array}{c}\text { No. of } \\
\text { participants }\end{array}$ & Statistical method & Effect size \\
\hline $\begin{array}{l}3 \text { Weight gain in kg- sensitivity } \\
\text { icc=0.01. Leighton 1929 used } \\
\text { for Orr }\end{array}$ & 4 & 703 & Mean Difference (IV, Random, 95\% CI) & 0.84 [0.34, 1.34] \\
$\begin{array}{l}4 \text { Weight gain in kg.- sensitivity } \\
\text { icc=0.05. Leighton used for }\end{array}$ & 4 & 703 & Mean Difference (IV, Random, 95\% CI) & $0.86[0.31,1.41]$ \\
$\quad$ Orr & & & & \\
\hline
\end{tabular}

School feeding for improving the physical and psychosocial health of disadvantaged students (Review)

Copyright @ 2009 The Cochrane Collaboration. Published by John Wiley \& Sons, Ltd. 
5 Weight gain in kg. - sensitivity

ICC $=0.1$. Leighton used for $\mathrm{Orr}$

7 Height gain in $\mathrm{cm}$. adjusted ICC $=0.016$

8 Height gain in $\mathrm{cm}$. sensitivity ICC $=0.01$

9 Height gain in $\mathrm{cm}$. sensitivity

10 Height gain in $\mathrm{cm}$. sensitivity ICC $=0.1$

12 Height gain in $\mathrm{cm}$. Leighton used for Orr. Sensitivity 0.01

13 Height gain in $\mathrm{cm}$. Sensitivity ICC $=0.05$. Leighton used for Orr

14 Height gain in $\mathrm{cm}$. Sensitivity $\mathrm{ICC}=.1$. Leighton used for $\mathrm{Orr}$

\section{Analysis I.I. Comparison I Developing country: School meal vs control. RCT, Outcome I Weight gain kg.}

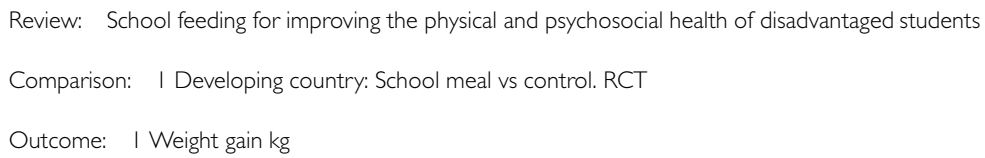

\begin{tabular}{|c|c|c|c|c|c|c|c|c|c|}
\hline \multirow{3}{*}{$\frac{\text { Study or subgroup }}{\text { Du } 2004}$} & \multirow{3}{*}{$\begin{array}{r}\text { Treatment } \\
N\end{array}$} & \multirow{3}{*}{\multicolumn{2}{|c|}{$\begin{array}{r}\text { Control } \\
N\end{array}$}} & \multirow{3}{*}{$\frac{\operatorname{Mean}(\mathrm{SD})}{10.1(6.57)}$} & \multirow{2}{*}{\multicolumn{3}{|c|}{$\begin{array}{c}\text { Mean } \\
\text { Difference } \\
\text { IV,Random,95\% Cl }\end{array}$}} & \multirow{3}{*}{$\begin{array}{r}\text { Weight } \\
4.8 \%\end{array}$} & \multirow{3}{*}{$\begin{array}{r}\text { Mean } \\
\text { Difference } \\
\text { IV,Random,95\% Cl } \\
\text { I.50[0.25, 2.75 ] }\end{array}$} \\
\hline & & & & & & & & & \\
\hline & & & & & & & $\longrightarrow$ & & \\
\hline Neumann 2003 & 120 & $3.75(1.31)$ & 116 & $3.47(1.4)$ & & & + & $36.1 \%$ & $0.28[-0.07,0.63]$ \\
\hline Powell 1998 Total & 391 & $2.24(1.3)$ & 394 & $1.87(1.34)$ & & & + & $59.2 \%$ & $0.37[0.19,0.55]$ \\
\hline Total (95\% CI) & 718 & & 744 & & & & $\bullet$ & $100.0 \%$ & $0.39[0.11,0.67]$ \\
\hline \multirow{2}{*}{\multicolumn{10}{|c|}{$\begin{array}{l}\text { Heterogeneity: } \text { Tau }^{2}=0.03 ; \mathrm{Chi}^{2}=3.40, \mathrm{df}=2(\mathrm{P}=0.18) ;\left.\right|^{2}=41 \% \\
\text { Test for overall effect: } Z=2.73(P=0.0064)\end{array}$}} \\
\hline & & & & & & & & & \\
\hline & & & & & -4 & -2 & 2 & 4 & \\
\hline & & & & & Favou & ontr & Favours & & \\
\hline
\end{tabular}


Analysis I.2. Comparison I Developing country: School meal vs control. RCT, Outcome 2 Height gain (cm).

Review: School feeding for improving the physical and psychosocial health of disadvantaged students

Comparison: I Developing country: School meal vs control. RCT

Outcome: 2 Height gain $(\mathrm{cm})$

\begin{tabular}{|c|c|c|c|c|c|c|c|c|c|}
\hline \multirow{3}{*}{$\begin{array}{l}\text { Study or subgroup } \\
\text { Du } 2004\end{array}$} & \multirow{3}{*}{$\begin{array}{r}\text { Treatment } \\
\text { N } \\
207\end{array}$} & \multirow{3}{*}{\multicolumn{2}{|c|}{$\begin{array}{r}\text { Control } \\
N\end{array}$}} & \multirow{2}{*}{\multicolumn{4}{|c|}{$\begin{array}{c}\text { Mean } \\
\text { Difference } \\
\text { IV,Random,95\% Cl }\end{array}$}} & \multirow[t]{2}{*}{ Weight } & \multirow{2}{*}{$\begin{array}{r}\text { Mean } \\
\text { Difference } \\
\text { IV,Random,95\% Cl }\end{array}$} \\
\hline & & & & & & & & & \\
\hline & & & & $12.2(4.18)$ & & & $\longrightarrow$ & $30.2 \%$ & $1.20[0.46,1.94]$ \\
\hline Neumann 2003 & 120 & $9.67(3.61)$ & 116 & $10.04(3.66)$ & & $\longrightarrow$ & - & $25.4 \%$ & $-0.37[-1.30,0.56]$ \\
\hline Powell 1998 Total & 391 & $3.63(1.45)$ & 394 & $3.38(1.24)$ & & & ت & $44.4 \%$ & $0.25[0.06,0.44]$ \\
\hline Total (95\% CI) & 718 & & 744 & & & & & $100.0 \%$ & $0.38[-0.32,1.08]$ \\
\hline \multicolumn{10}{|c|}{ Heterogeneity: $\mathrm{Tau}^{2}=0.28 ; \mathrm{Chi}^{2}=7.87, \mathrm{df}=2(\mathrm{P}=0.02) ; \mathrm{I}^{2}=75 \%$} \\
\hline \multicolumn{10}{|c|}{ Test for overall effect: $Z=1.06(P=0.29)$} \\
\hline & & & & & -4 & -2 & 2 & 4 & \\
\hline
\end{tabular}

Analysis I.3. Comparison I Developing country: School meal vs control. RCT, Outcome 3 Weight for age: z-scores.

Review: School feeding for improving the physical and psychosocial health of disadvantaged students

Comparison: I Developing country: School meal vs control. RCT

Outcome: 3 Weight for age: $z$-scores

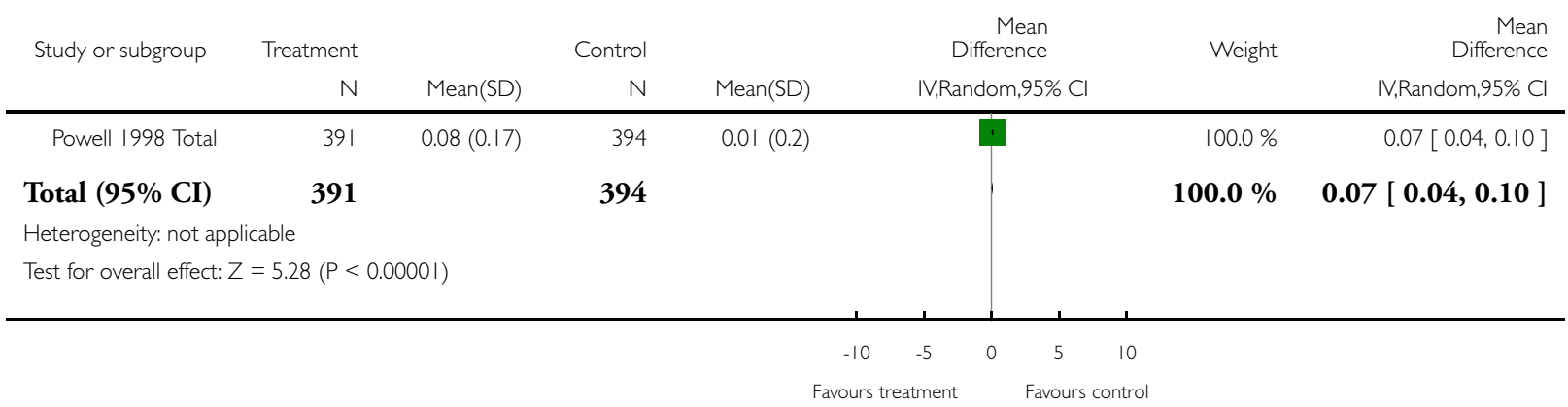


Analysis I.4. Comparison I Developing country: School meal vs control. RCT, Outcome 4 Height for age: zscores.

\begin{tabular}{|c|c|c|c|c|c|c|c|}
\hline \multicolumn{8}{|c|}{ Comparison: I Developing country: School meal vs control. RCT } \\
\hline Outcome: 4 Height & or age: z-score & & & & \multirow{3}{*}{$\begin{array}{c}\text { Mean } \\
\text { Difference } \\
\text { IV,Random,95\% Cl }\end{array}$} & & \\
\hline \multirow[t]{2}{*}{ Study or subgroup } & \multirow{2}{*}{$\begin{array}{r}\text { Treatment } \\
\mathrm{N}\end{array}$} & \multicolumn{3}{|c|}{ Control } & & \multirow[t]{2}{*}{ Weight } & \multirow{2}{*}{$\begin{array}{r}\text { Mear } \\
\text { Difference } \\
\text { IV,Random,95\% C }\end{array}$} \\
\hline & & Mean(SD) & $\mathrm{N}$ & Mean(SD) & & & \\
\hline Neumann 2003 & 120 & $-0.03(0.55)$ & 116 & $-0.02(0.54)$ & & $1.8 \%$ & $-0.01[-0.15,0.13]$ \\
\hline Powell 1998 Total & 391 & $0.04(0.15)$ & 394 & $0(0.12)$ & & $98.2 \%$ & $0.04[0.02,0.06]$ \\
\hline Total $(95 \% \mathrm{CI})$ & 511 & & 510 & & & $100.0 \%$ & $0.04[0.02,0.06]$ \\
\hline \multicolumn{8}{|c|}{ Heterogeneity: $\mathrm{Tau}^{2}=0.0 ; \mathrm{Chi}^{2}=0.49, \mathrm{df}=\mathrm{I}(\mathrm{P}=0.49) ; \mathrm{I}^{2}=0.0 \%$} \\
\hline \multicolumn{8}{|c|}{ Test for overall effect: $Z=4.07(P=0.000048)$} \\
\hline
\end{tabular}

\section{Analysis I.I4. Comparison I Developing country: School meal vs control. RCT, Outcome I4 MUAC.}

Review: School feeding for improving the physical and psychosocial health of disadvantaged students

Comparison: I Developing country: School meal vs control. RCT

Outcome: 14 MUAC

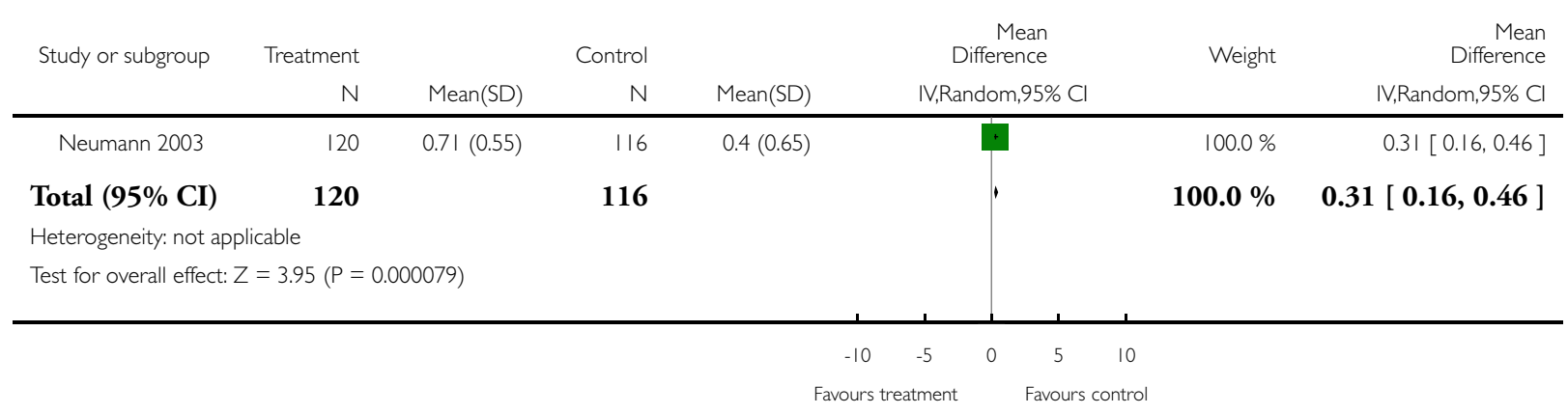


Analysis I.2I. Comparison I Developing country: School meal vs control. RCT, Outcome 2 I Mid-upper arm muscle area.

Review: School feeding for improving the physical and psychosocial health of disadvantaged students

Comparison: I Developing country: School meal vs control. RCT

Outcome: 21 Mid-upper arm muscle area

\begin{tabular}{|c|c|c|c|c|c|c|c|}
\hline \multirow[t]{2}{*}{ Study or subgroup } & \multirow{2}{*}{$\begin{array}{r}\text { Treatment } \\
N\end{array}$} & \multicolumn{3}{|c|}{ Control } & \multirow{2}{*}{$\begin{array}{c}\text { Mean } \\
\text { Difference } \\
\text { IV,Random,95\% Cl }\end{array}$} & \multirow[t]{2}{*}{ Weight } & $\begin{array}{r}\text { Mean } \\
\text { Difference }\end{array}$ \\
\hline & & Mean(SD) & $\mathrm{N}$ & Mean(SD) & & & IV,Random,95\% Cl \\
\hline Neumann 2003 & 120 & | 54.22 ( | | 3.05) & 116 & $86(111.47)$ & & $100.0 \%$ & $68.22[39.57,96.87]$ \\
\hline Total (95\% CI) & 120 & & 116 & & & $100.0 \%$ & $68.22[39.57,96.87]$ \\
\hline
\end{tabular}

Heterogeneity: not applicable

Test for overall effect: $Z=4.67(P<0.0000$ I)

\begin{tabular}{ccccc}
-10 & -5 & 0 & 5 & 10 \\
Favours treatment & & \multicolumn{3}{c}{ Favours control }
\end{tabular}

Analysis I.22. Comparison I Developing country: School meal vs control. RCT, Outcome 22 Mid upper arm fat area.

Review: School feeding for improving the physical and psychosocial health of disadvantaged students

Comparison: I Developing country: School meal vs control. RCT

Outcome: 22 Mid upper arm fat area

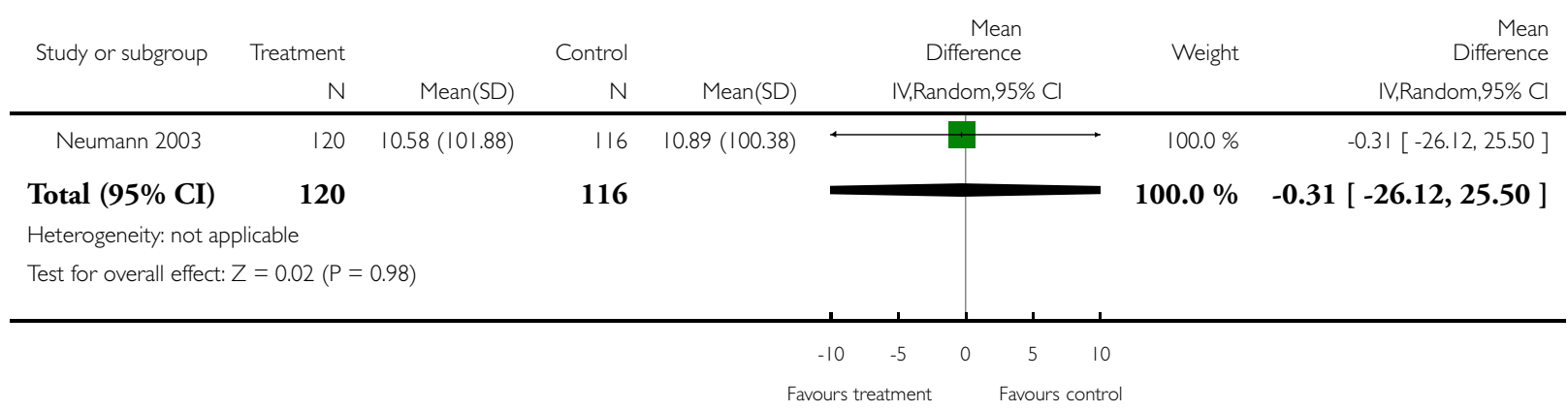


Analysis I.23. Comparison I Developing country: School meal vs control. RCT, Outcome 23 weight for height gain.

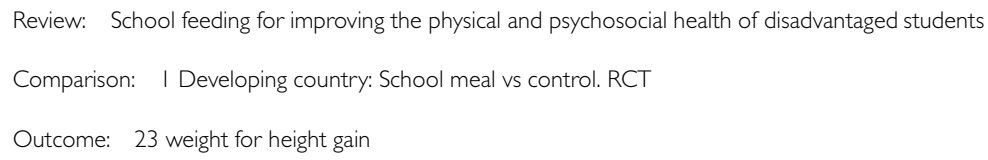

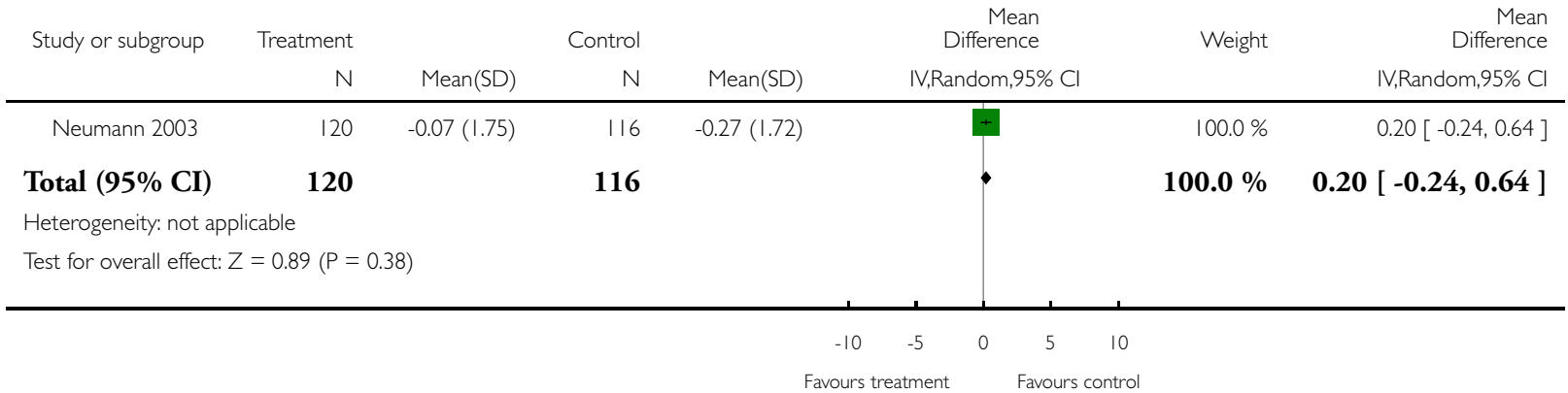

\section{Analysis 2.I. Comparison 2 Developing country RCT: Subgroup analysis: meals vs control, Outcome I} Undernourished vs adequately nourished: Weight gain in $\mathbf{k g}$.

Review: School feeding for improving the physical and psychosocial health of disadvantaged students

Comparison: 2 Developing country RCT: Subgroup analysis: meals vs control

Outcome: I Undernourished vs adequately nourished: Weight gain in $\mathrm{kg}$

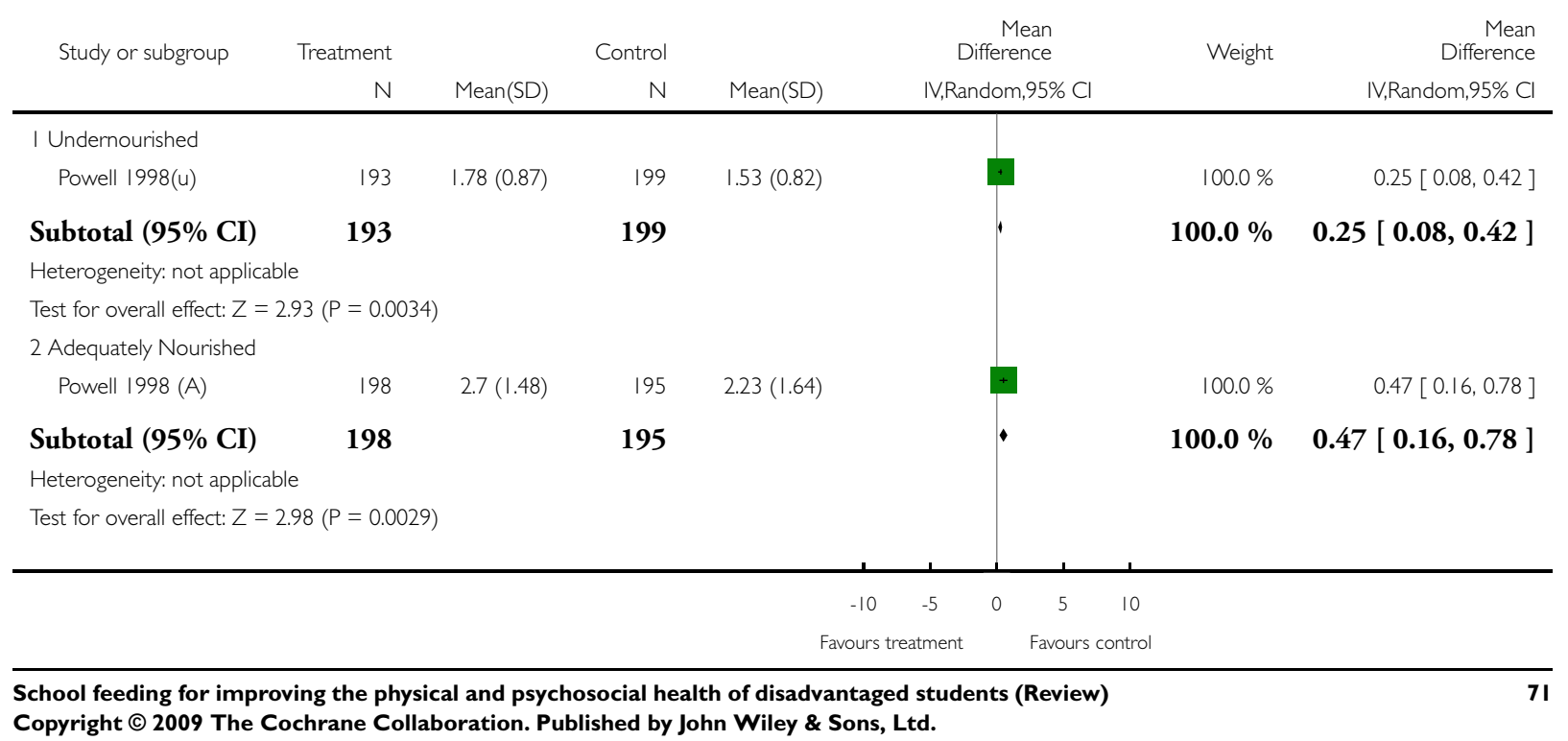


Analysis 2.2. Comparison 2 Developing country RCT: Subgroup analysis: meals vs control, Outcome 2 Undernourished versus adequately nourished, height in $\mathrm{cm}$.

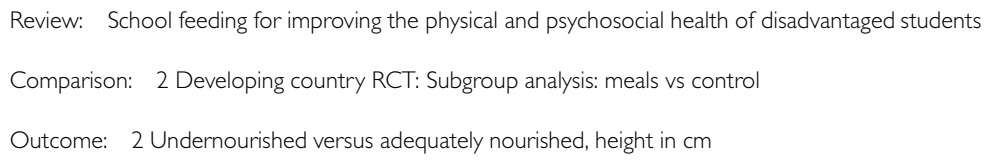

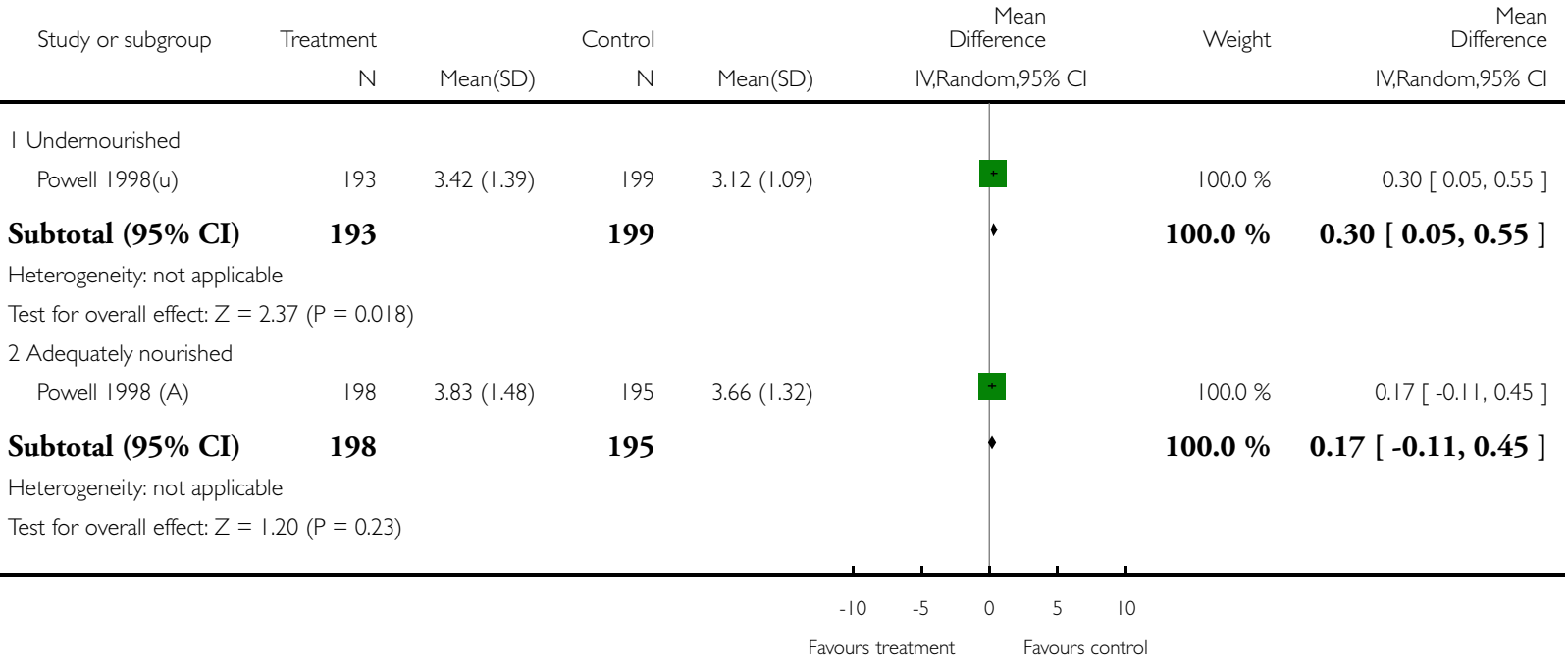


Analysis 2.3. Comparison 2 Developing country RCT: Subgroup analysis: meals vs control, Outcome 3 Age subgroup analysis: weight gain in $\mathbf{k g}$.

Review: School feeding for improving the physical and psychosocial health of disadvantaged students

Comparison: 2 Developing country RCT: Subgroup analysis: meals vs control

Outcome: 3 Age subgroup analysis: weight gain in $\mathrm{kg}$

Study or subgroup Treatment_ Control_ Mean Mean

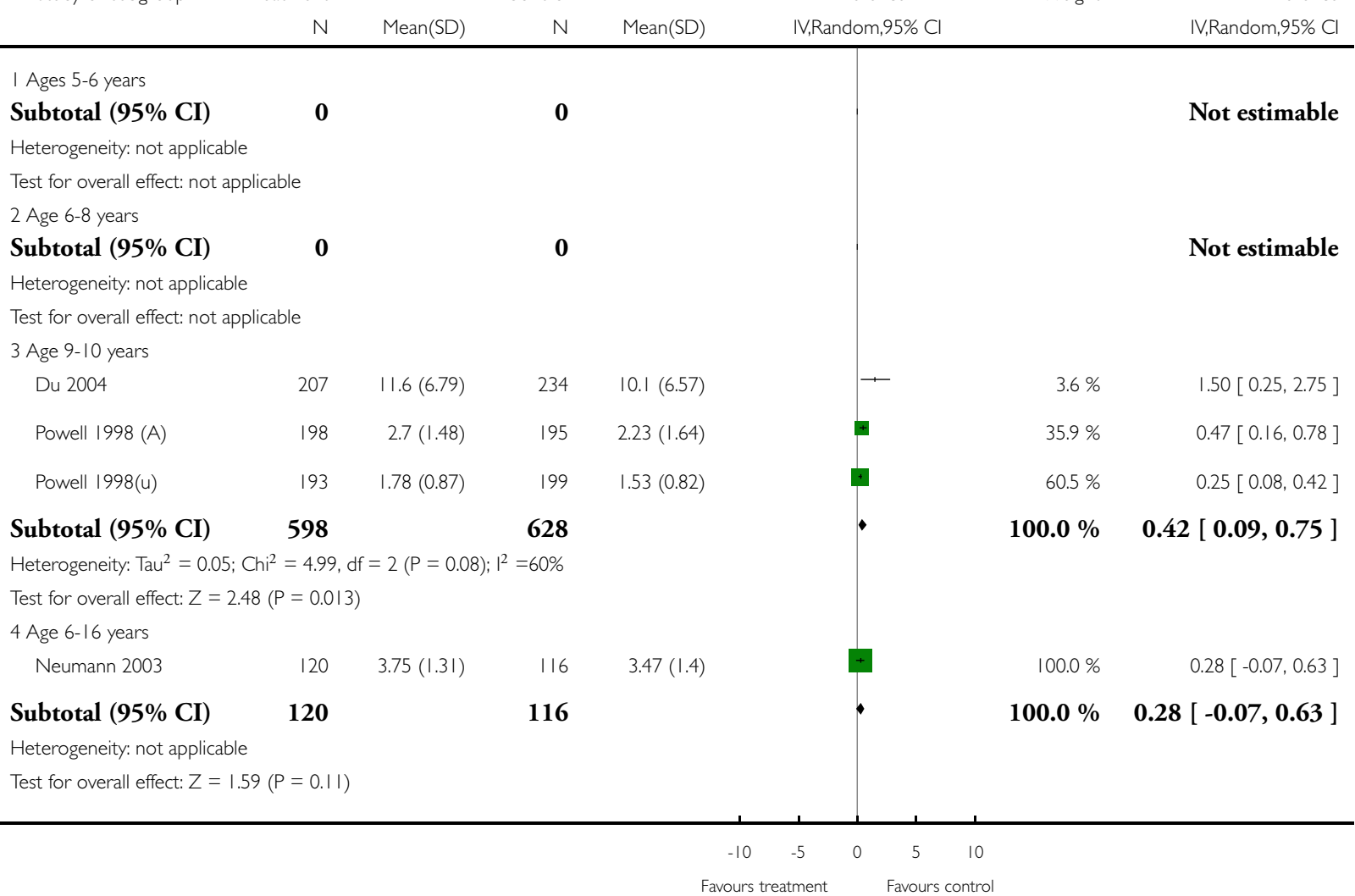


Analysis 2.4. Comparison 2 Developing country RCT: Subgroup analysis: meals vs control, Outcome 4 Age subgroup analysis: height gain $(\mathrm{cm})$.

Review: School feeding for improving the physical and psychosocial health of disadvantaged students

Comparison: 2 Developing country RCT: Subgroup analysis: meals vs control

Outcome: 4 Age subgroup analysis: height gain $(\mathrm{cm})$

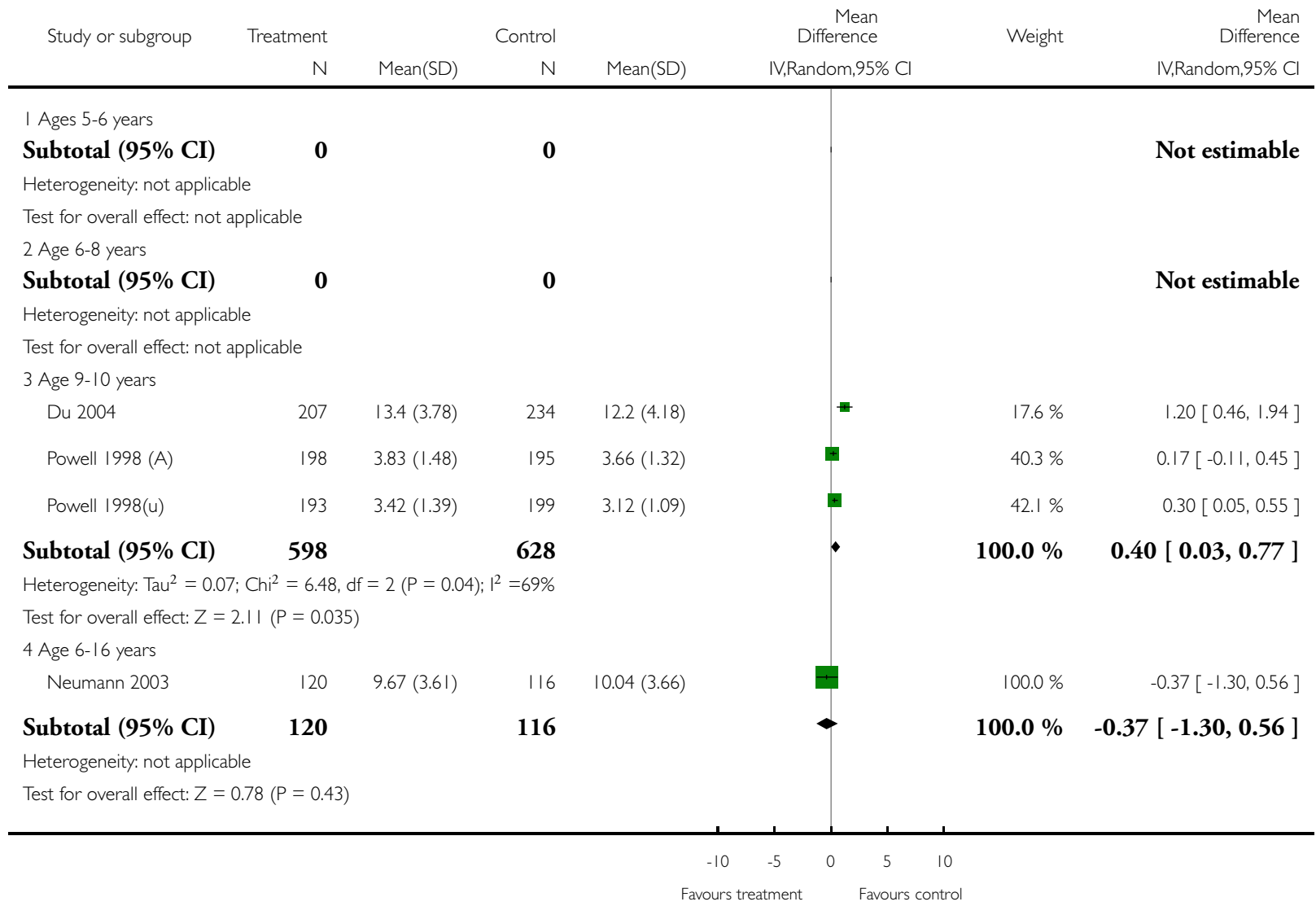


Analysis 3.I. Comparison 3 Developing country: School meal vs control. CBA, Outcome I Weight gain kgadjusted ICC 0.025 .

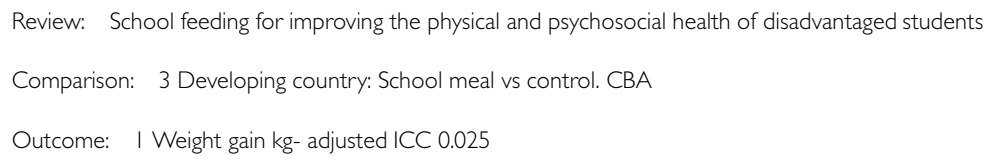

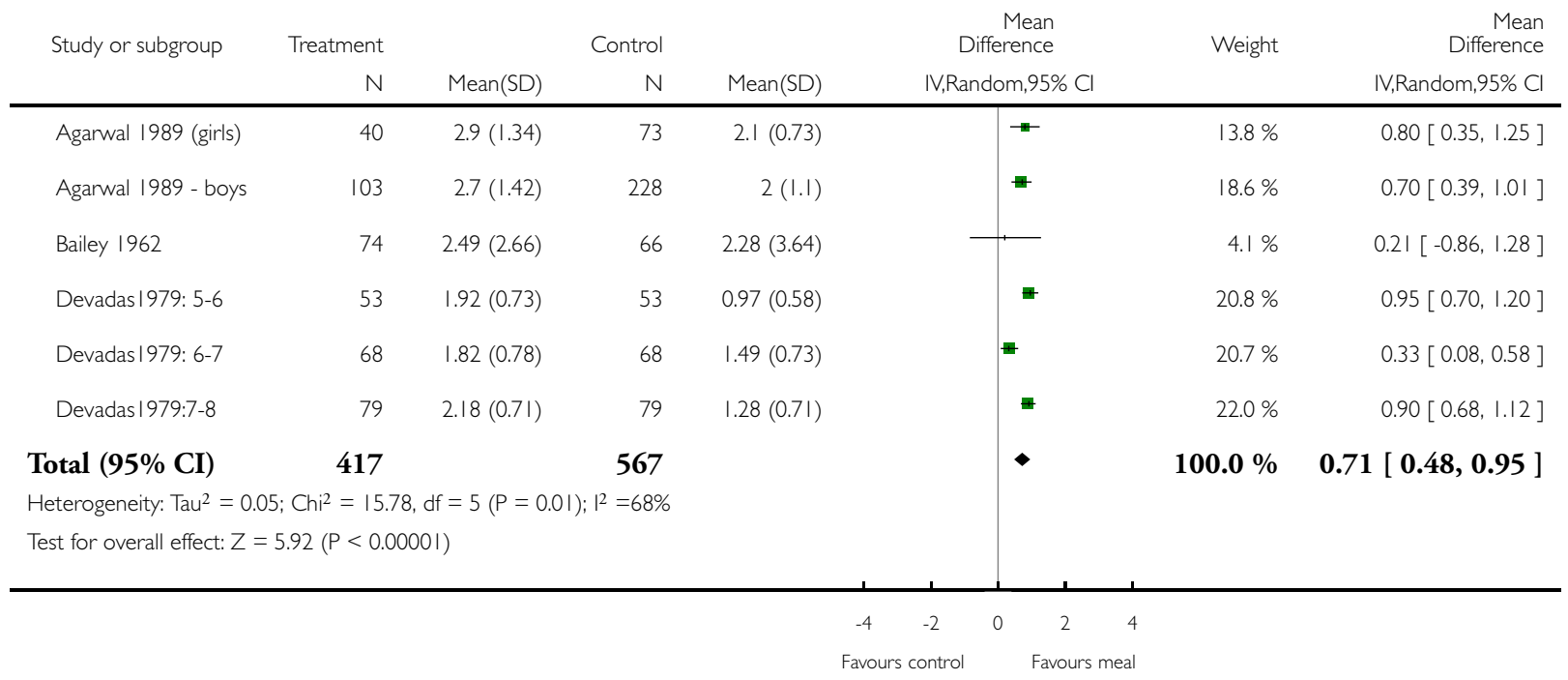


Analysis 3.2. Comparison 3 Developing country: School meal vs control. CBA, Outcome 2 Math change overall icc .I 5.

Review: School feeding for improving the physical and psychosocial health of disadvantaged students

Comparison: 3 Developing country: School meal vs control. CBA

Outcome: 2 Math change overall icc .15

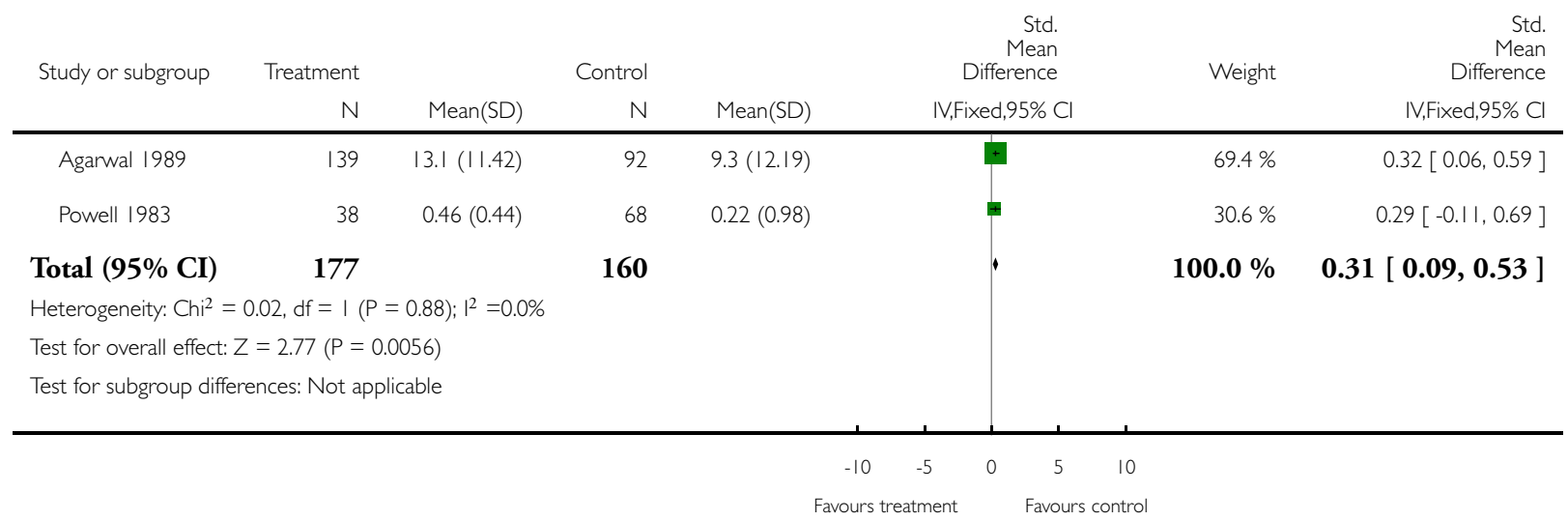


Analysis 3.3. Comparison 3 Developing country: School meal vs control. CBA, Outcome 3 Math change by nutritional status, icc $\mathbf{0 . 1 5}$.

Review: School feeding for improving the physical and psychosocial health of disadvantaged students

Comparison: 3 Developing country: School meal vs control. CBA

Outcome: 3 Math change by nutritional status, icc 0.15

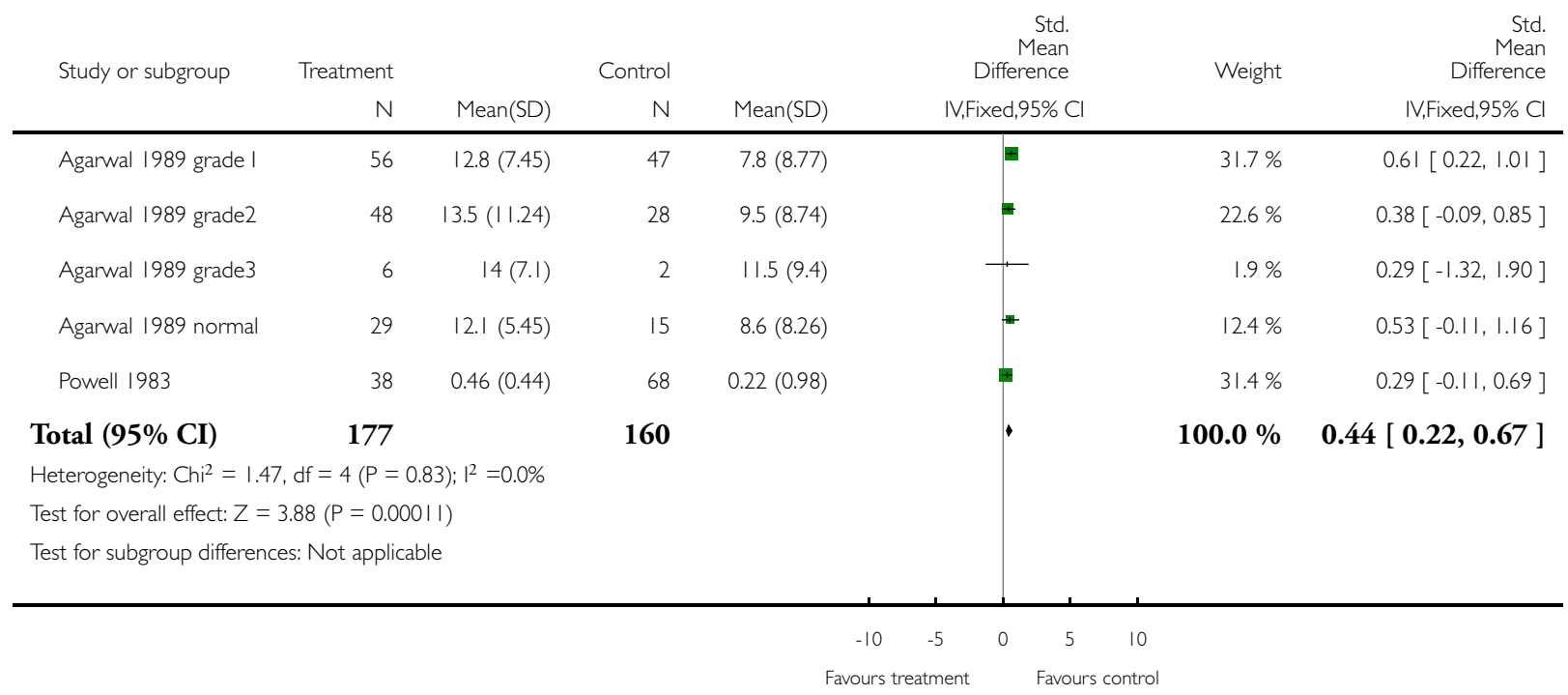


Analysis 3.5. Comparison 3 Developing country: School meal vs control. CBA, Outcome 5 Height gain $(\mathrm{cm})$ - adjusted ICC $=0.016$.

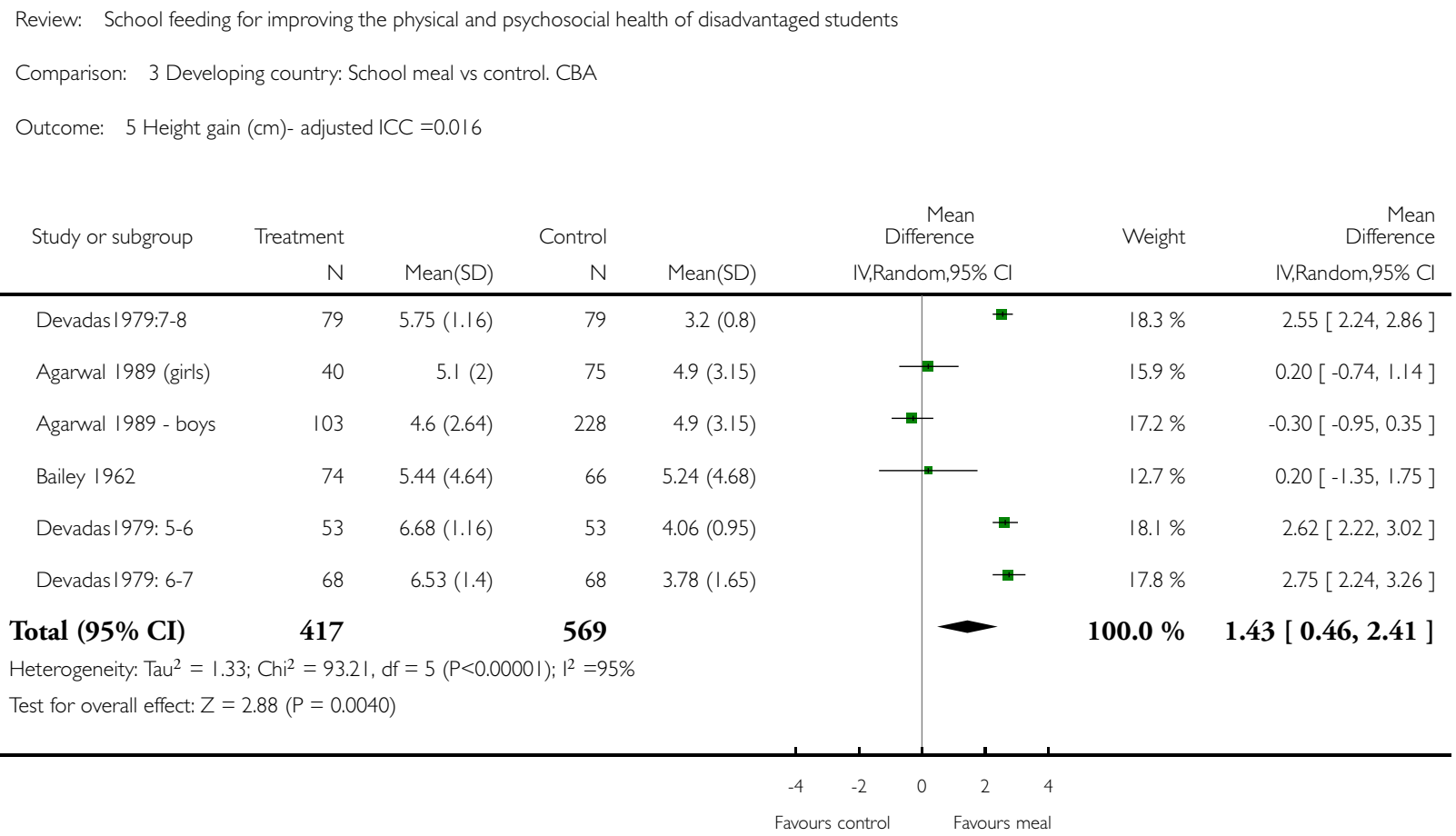


Analysis 3.9. Comparison 3 Developing country: School meal vs control. CBA, Outcome 9 subgroup analysis weight by sex.

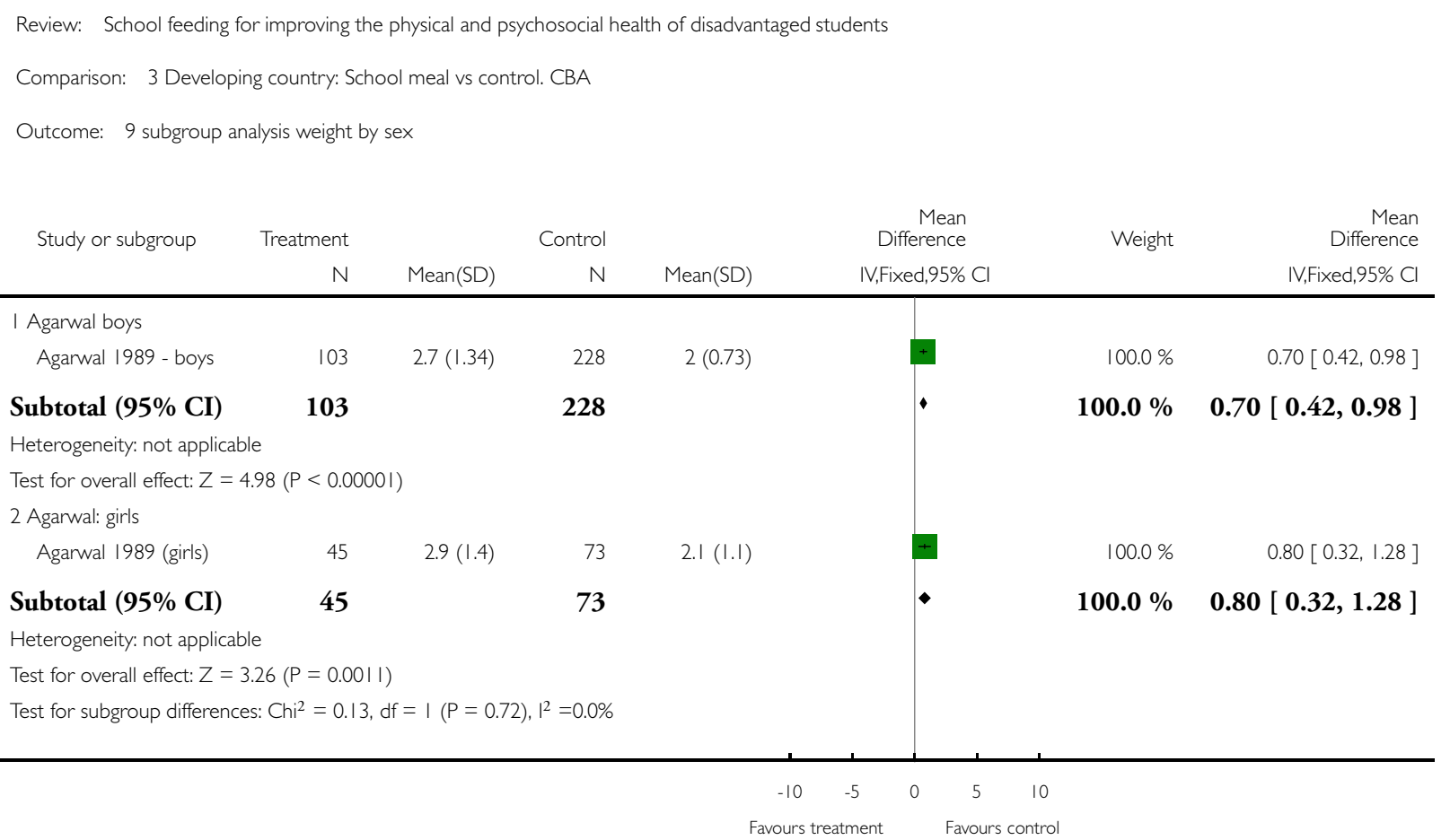


Analysis 3.10. Comparison 3 Developing country: School meal vs control. CBA, Outcome 10 Subgroup analysis: height by sex.

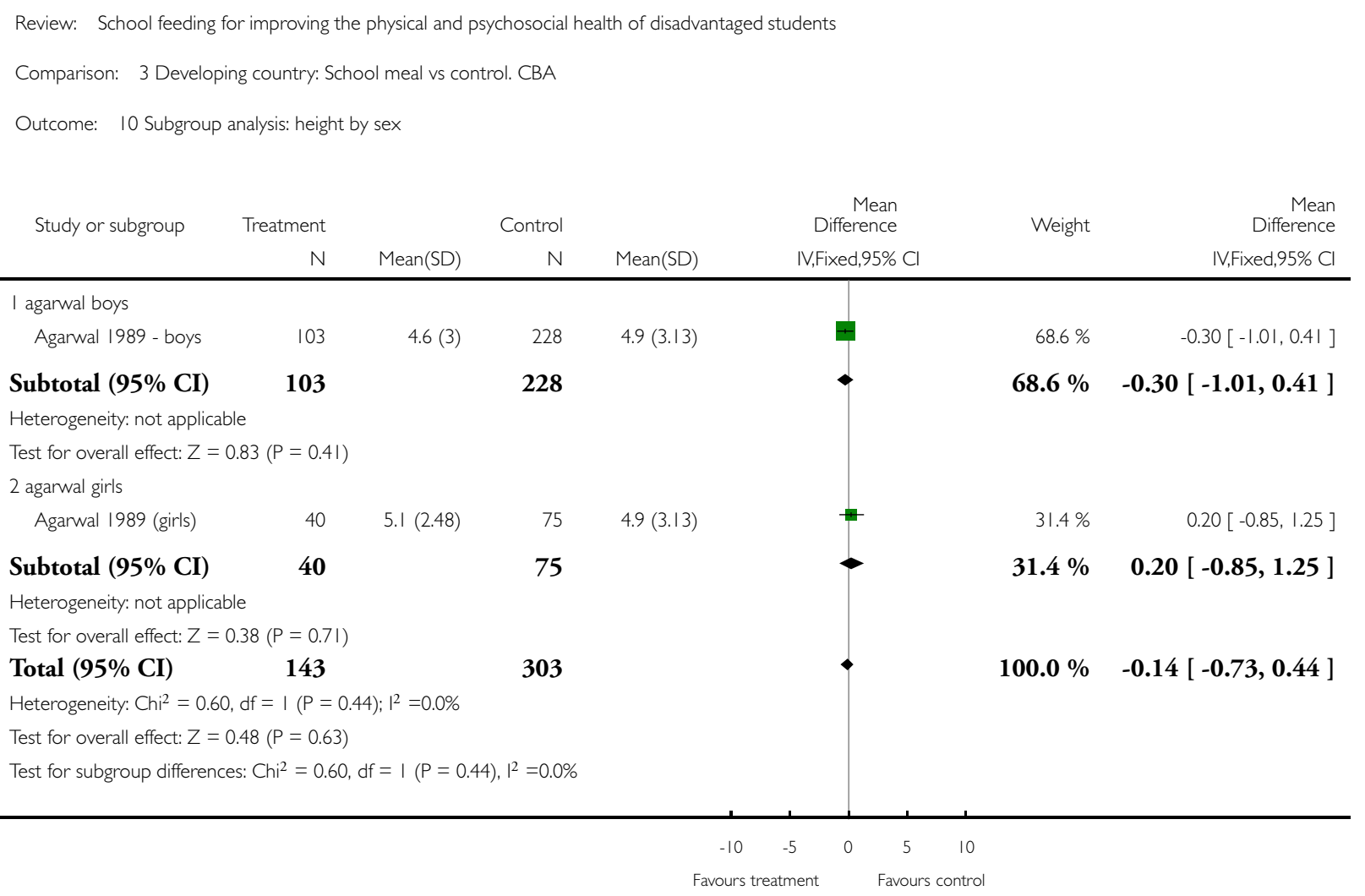




\section{Analysis 3.I I. Comparison 3 Developing country: School meal vs control. CBA, Outcome I I Subgroup by age: weight gain in $\mathrm{kg}$ - Agarwal adjusted.}

Review: School feeding for improving the physical and psychosocial health of disadvantaged students

Comparison: 3 Developing country: School meal vs control. CBA

Outcome: II Subgroup by age: weight gain in $\mathrm{kg}$ - Agarwal adjusted

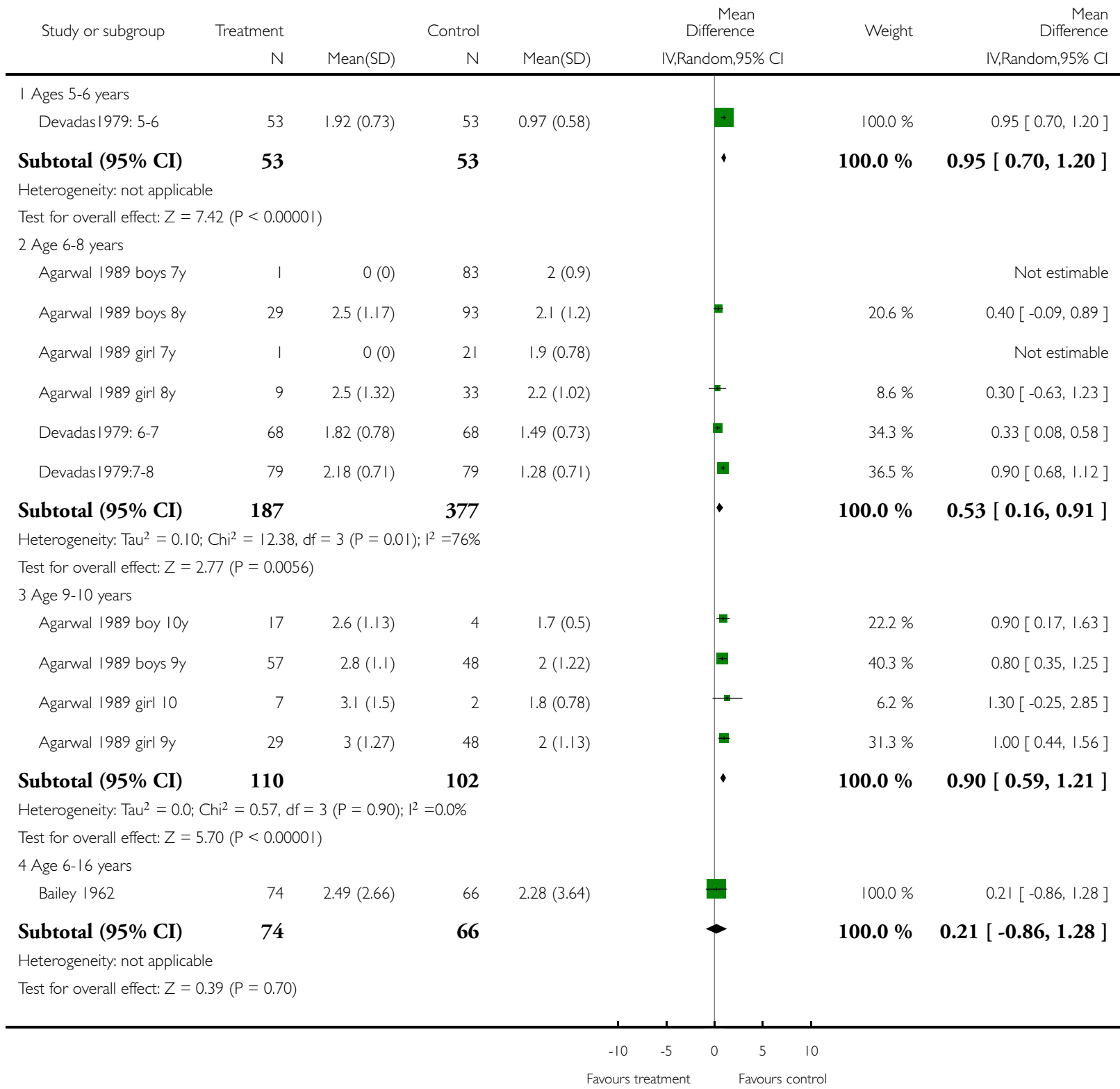




\section{Analysis 3.12. Comparison 3 Developing country: School meal vs control. CBA, Outcome 12 Subgroup by age: height gain in cm - Agarwal adjusted.}

Review: School feeding for improving the physical and psychosocial health of disadvantaged students

Comparison: 3 Developing country: School meal vs control. CBA

Outcome: 12 Subgroup by age: height gain in $\mathrm{cm}$ - Agarwal adjusted

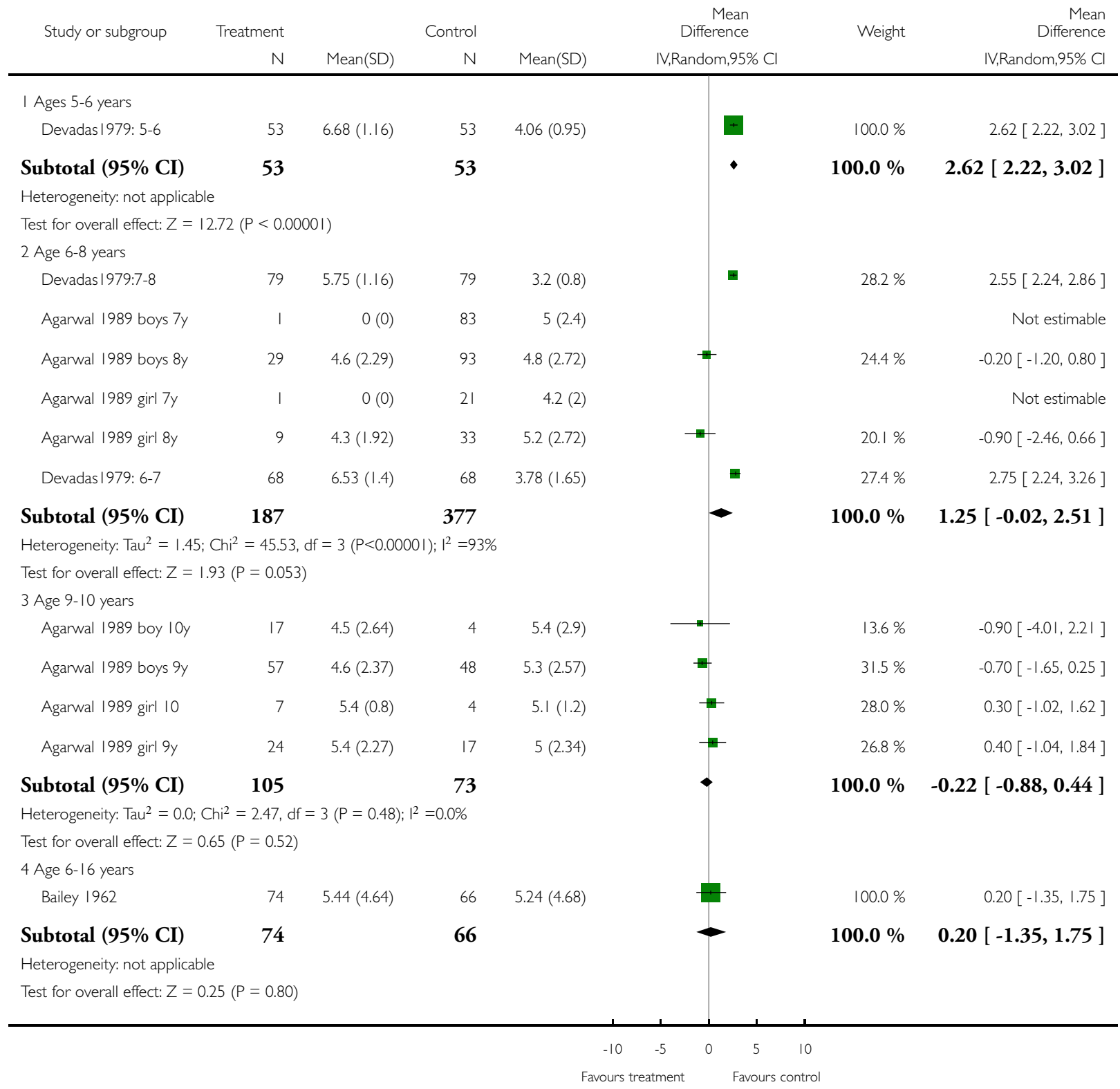


Analysis 3.13. Comparison 3 Developing country: School meal vs control. CBA, Outcome I3 Full scale IQ (total): adjusted-ICC 0.15 .

Review: School feeding for improving the physical and psychosocial health of disadvantaged students

Comparison: 3 Developing country: School meal vs control. CBA

Outcome: 13 Full scale IQ (total): adjusted-ICC 0.15

\begin{tabular}{|c|c|c|c|c|c|c|c|}
\hline \multirow[t]{2}{*}{ Study or subgroup } & \multirow{2}{*}{$\begin{array}{r}\text { Treatment } \\
N\end{array}$} & \multicolumn{3}{|c|}{ Control } & \multirow{2}{*}{$\begin{array}{c}\text { Mean } \\
\text { Difference } \\
\text { IV,Fixed,95\% Cl }\end{array}$} & \multirow[t]{2}{*}{ Weight } & \multirow{2}{*}{$\begin{array}{r}\text { Mean } \\
\text { Difference } \\
\text { IV,Fixed,95\% Cl }\end{array}$} \\
\hline & & Mean(SD) & $\mathrm{N}$ & Mean(SD) & & & \\
\hline Agarwal total & 139 & $99.7(26.45)$ & 92 & $95.8(25.25)$ & + & $100.0 \%$ & $3.90[-2.88,10.68]$ \\
\hline Total (95\% CI) & 139 & & 92 & & & $100.0 \%$ & $3.90[-2.88,10.68]$ \\
\hline \multicolumn{8}{|c|}{ Heterogeneity: not applicable } \\
\hline \multicolumn{8}{|c|}{ Test for overall effect: $Z=1.13(P=0.26)$} \\
\hline Test for subgroup diff & nces: Not ap & icable & & & & & \\
\hline
\end{tabular}

Favours treatment Favours control

Analysis 3.2I. Comparison 3 Developing country: School meal vs control. CBA, Outcome 2 I Full scale IQ (separated): cluster size as in analysis: icc $=.15$.

Review: School feeding for improving the physical and psychosocial health of disadvantaged students

Comparison: 3 Developing country: School meal vs control. CBA

Outcome: 2I Full scale IQ (separated): cluster size as in analysis: icc $=.15$

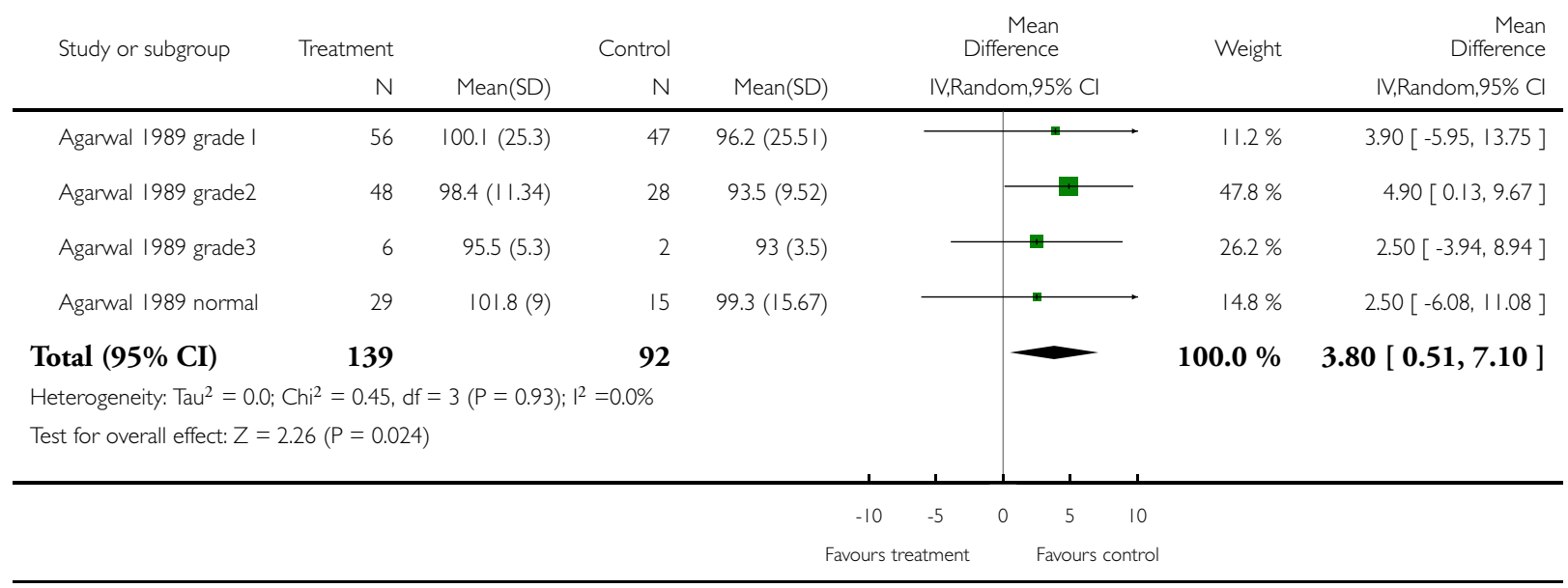

School feeding for improving the physical and psychosocial health of disadvantaged students (Review) 


\section{Analysis 3.24. Comparison 3 Developing country: School meal vs control. CBA, Outcome 24 Performance}

IQ (separated): numbers as in analysis: ICC $=0.15$.

Review: School feeding for improving the physical and psychosocial health of disadvantaged students

Comparison: 3 Developing country: School meal vs control. CBA

Outcome: 24 Performance IQ (separated): numbers as in analysis: ICC $=0.15$

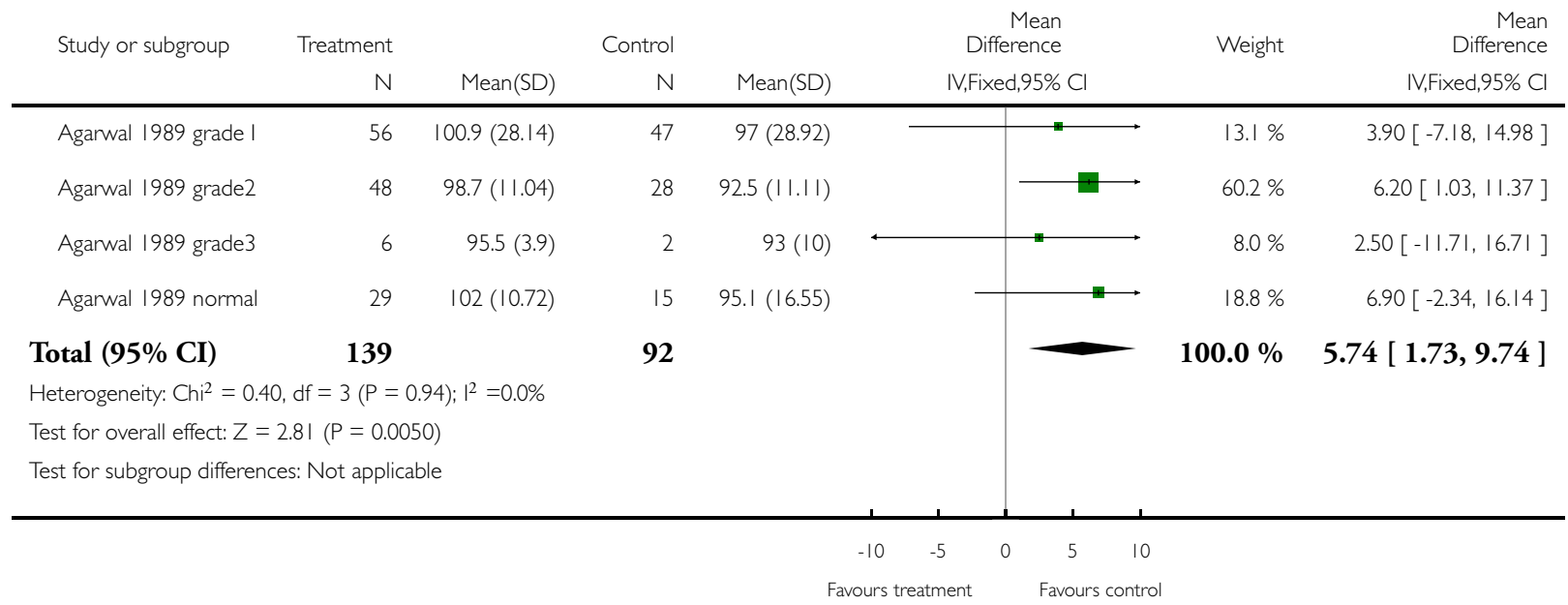




\section{Analysis 3.26. Comparison 3 Developing country: School meal vs control. CBA, Outcome 26 Performance} IQ (total): adjusted-ICC 0.15 .

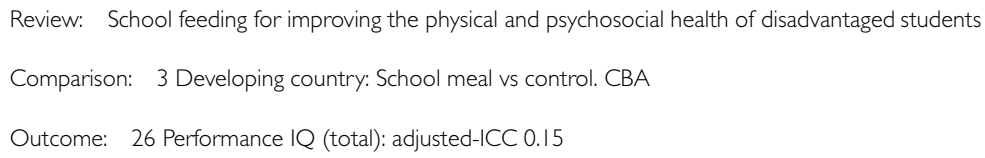

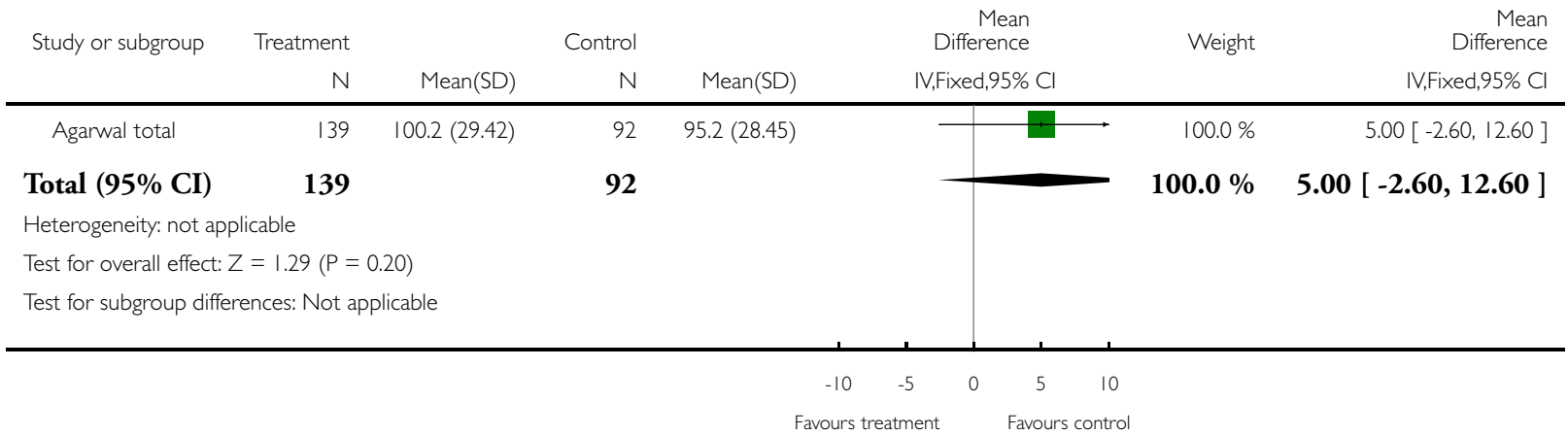

\section{Analysis 3.28. Comparison 3 Developing country: School meal vs control. CBA, Outcome 28 Verbal IQ} (separated): cluster size as in analysis: $I C C=0.15$.

Review: School feeding for improving the physical and psychosocial health of disadvantaged students

Comparison: 3 Developing country: School meal vs control. CBA

Outcome: 28 Verbal IQ (separated): cluster size as in analysis: ICC $=0.15$

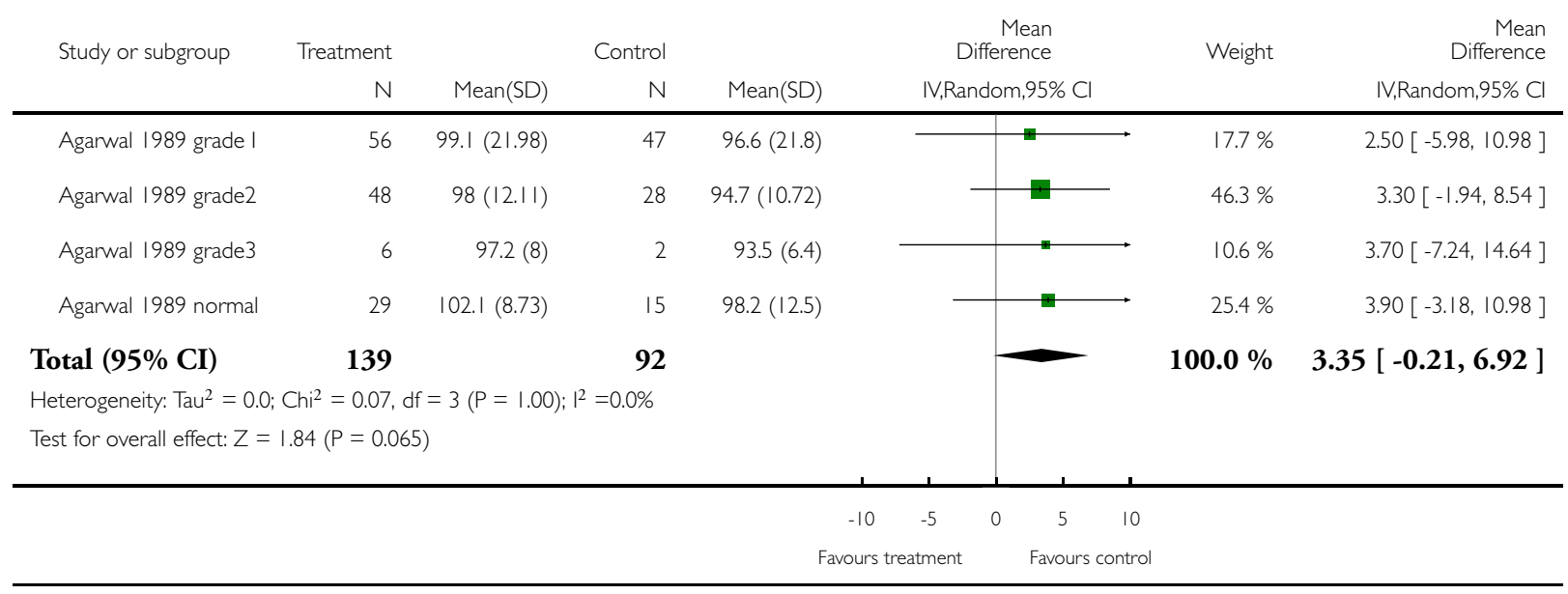

School feeding for improving the physical and psychosocial health of disadvantaged students (Review) 


\section{Analysis 3.29. Comparison 3 Developing country: School meal vs control. CBA, Outcome 29 Verbal IQ}

(total): adjusted- ICC 0.15 .

Review: School feeding for improving the physical and psychosocial health of disadvantaged students

Comparison: 3 Developing country: School meal vs control. CBA

Outcome: 29 Verbal IQ (total): adjusted- ICC 0.15

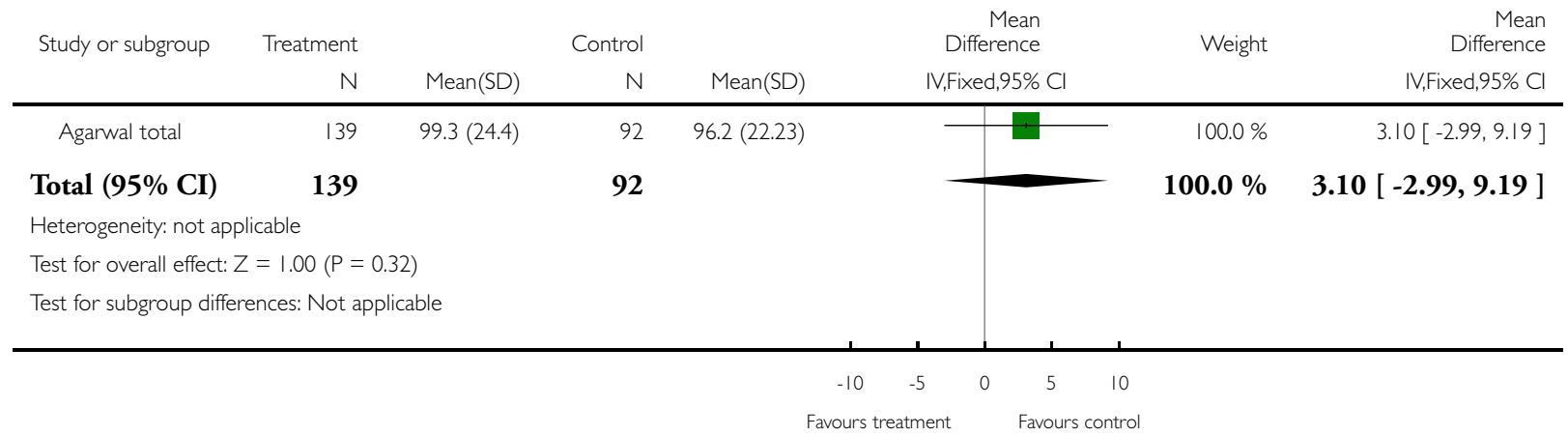


Analysis 3.36. Comparison 3 Developing country: School meal vs control. CBA, Outcome 36 Percent weight for age: ICC= .025 .

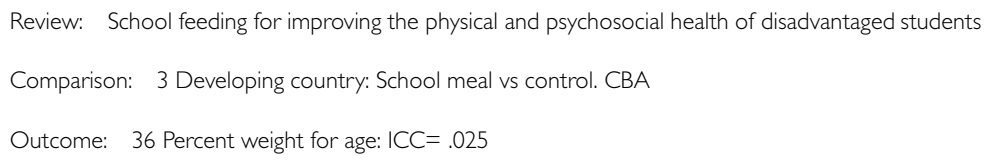

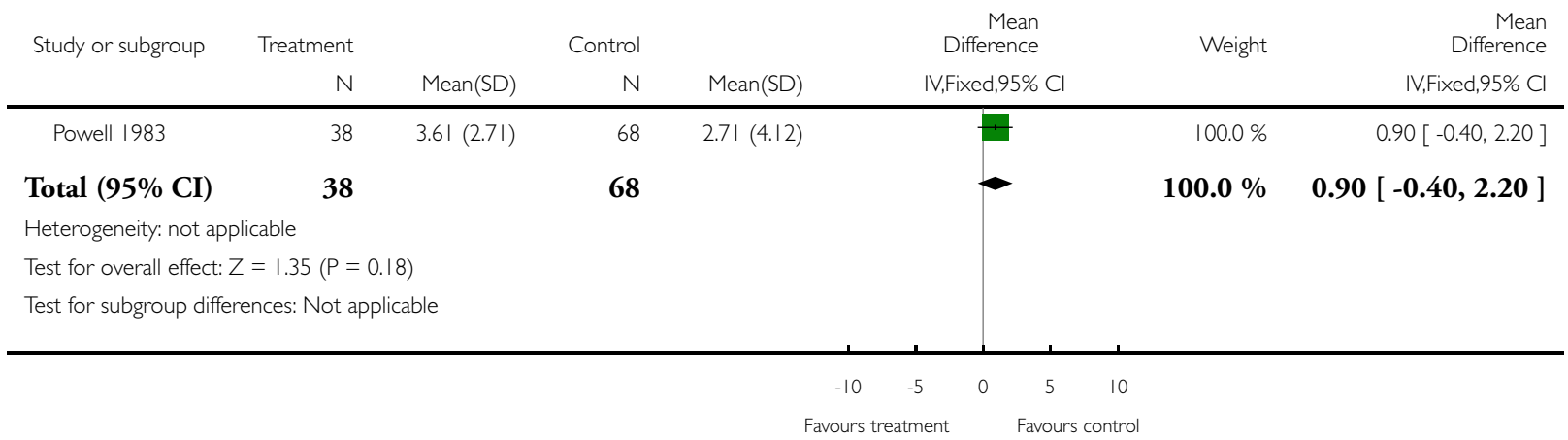

\section{Analysis 3.40. Comparison 3 Developing country: School meal vs control. CBA, Outcome 40 Percent height for age: ICC $=0.016$.}

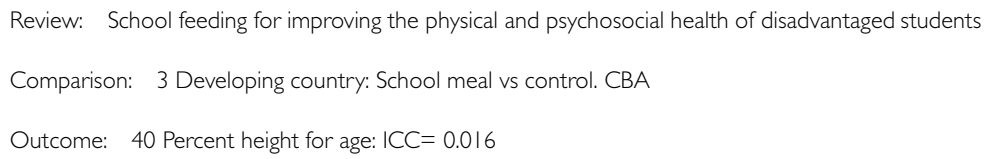

\begin{tabular}{|c|c|c|c|c|c|c|c|}
\hline \multirow[t]{2}{*}{ Study or subgroup } & \multirow{2}{*}{$\begin{array}{r}\text { Treatment } \\
\mathrm{N}\end{array}$} & \multicolumn{3}{|c|}{ Control } & \multirow{2}{*}{$\begin{array}{c}\text { Mean } \\
\text { Difference } \\
\text { IV,Fixed,95\% Cl }\end{array}$} & \multirow[t]{2}{*}{ Weight } & \multirow{2}{*}{$\begin{array}{r}\text { Mean } \\
\text { Difference } \\
\text { IV,Fixed,95\% C }\end{array}$} \\
\hline & & Mean(SD) & $N$ & Mean(SD) & & & \\
\hline Powell 1983 & 38 & $-0.24(0.7)$ & 68 & $0.51(1.17)$ & + & $100.0 \%$ & $-0.75[-1.11,-0.39]$ \\
\hline Total (95\% CI) & 38 & & 68 & & $\bullet$ & $100.0 \%$ & $-0.75[-1.11,-0.39]$ \\
\hline \multicolumn{8}{|c|}{ Heterogeneity: not applicable } \\
\hline \multicolumn{8}{|c|}{ Test for overall effect: $Z=4.13(P=0.000037)$} \\
\hline \multicolumn{8}{|c|}{ Test for subgroup differences: Not applicable } \\
\hline
\end{tabular}

$$
\text { Favours treatment Favours control }
$$


Analysis 3.44. Comparison 3 Developing country: School meal vs control. CBA, Outcome 44 Change in reading: $I C C=. I 5$.

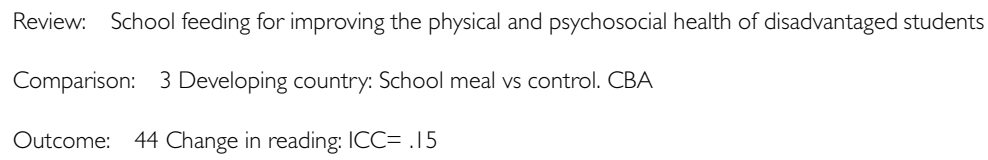

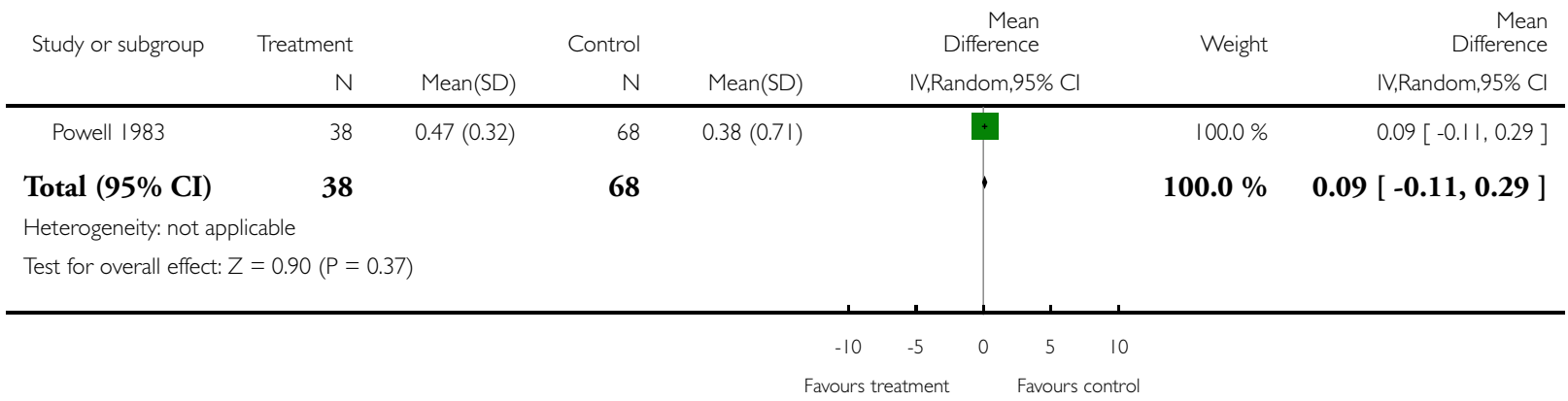

\section{Analysis 3.47. Comparison 3 Developing country: School meal vs control. CBA, Outcome 47 change in} spelling: $I C C=. \mid 5$.

Review: School feeding for improving the physical and psychosocial health of disadvantaged students

Comparison: 3 Developing country: School meal vs control. CBA

Outcome: 47 change in spelling: ICC $=.15$

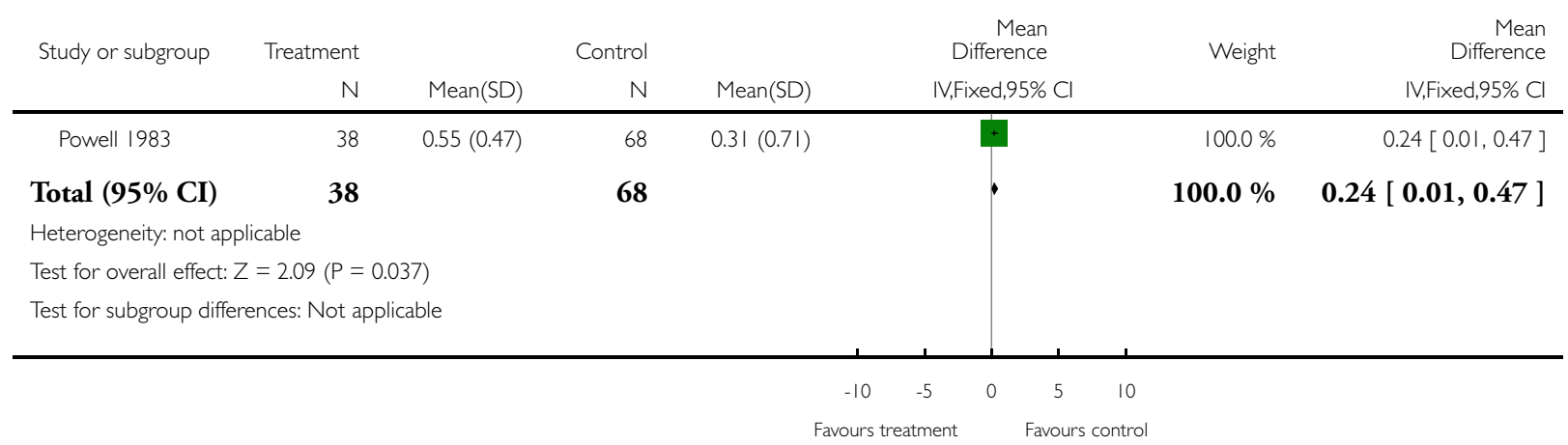


Analysis 3.56. Comparison 3 Developing country: School meal vs control. CBA, Outcome 56 change in attendance: icc $=.15$.

Review: School feeding for improving the physical and psychosocial health of disadvantaged students

Comparison: 3 Developing country: School meal vs control. CBA

Outcome: 56 change in attendance: icc $=.15$

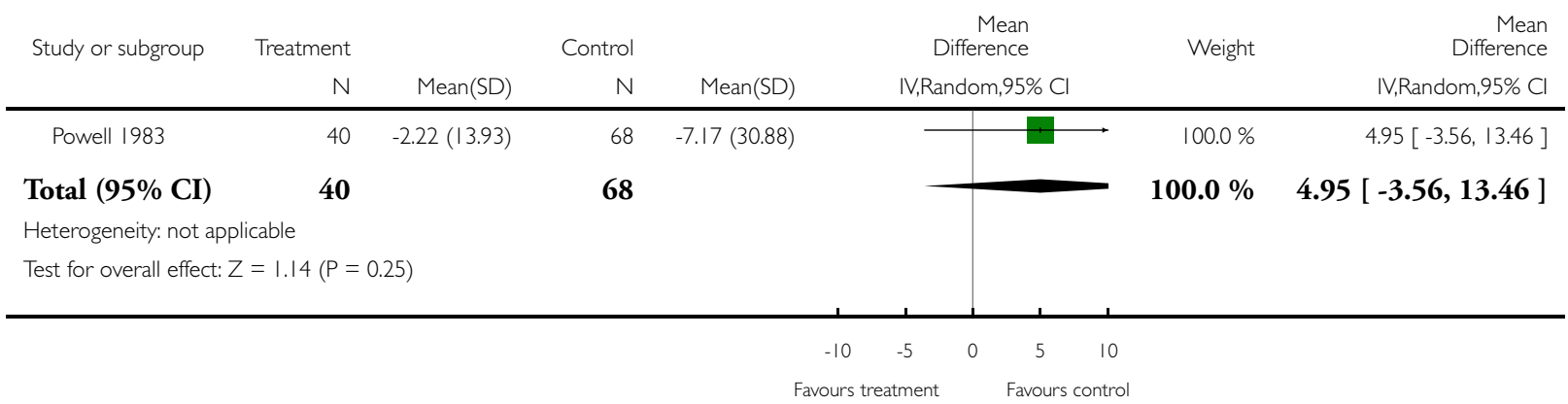

Analysis 3.57. Comparison 3 Developing country: School meal vs control. CBA, Outcome 57 End of study: attendance: icc $=.15$.

Review: School feeding for improving the physical and psychosocial health of disadvantaged students

Comparison: 3 Developing country: School meal vs control. CBA

Outcome: 57 End of study: attendance: icc $=.15$

\begin{tabular}{|c|c|c|c|c|c|c|c|c|}
\hline \multirow[t]{2}{*}{ Study or subgroup } & \multirow{2}{*}{$\begin{array}{r}\text { Treatment } \\
N\end{array}$} & \multicolumn{3}{|c|}{ Control } & \multicolumn{2}{|r|}{$\begin{array}{r}\text { Mean } \\
\text { Difference }\end{array}$} & \multirow[t]{2}{*}{ Weight } & \multirow{2}{*}{$\begin{array}{r}\text { Mean } \\
\text { Difference } \\
\text { IV,Random,95\% Cl}\end{array}$} \\
\hline & & Mean(SD) & $\mathrm{N}$ & Mean(SD) & & IV,Random,95\% Cl & & \\
\hline Powell 1983 & 40 & $69.53(19.83)$ & 32 & $69.76(47.91)$ & $\longleftarrow$ & & $100.0 \%$ & $-0.23[-17.93,17.47]$ \\
\hline Total $(95 \%$ CI $)$ & 40 & & 32 & & & & $100.0 \%$ & $-0.23[-17.93,17.47]$ \\
\hline \multicolumn{9}{|c|}{ Heterogeneity: not applicable } \\
\hline \multicolumn{9}{|c|}{ Test for overall effect: $Z=0.03(P=0.98)$} \\
\hline & & & & & -10 & -5 & 10 & \\
\hline
\end{tabular}


Analysis 4.2. Comparison 4 developed country: school meal versus control: CBA, Outcome 2 Weight gain: Corry-Mann alone.

Review: School feeding for improving the physical and psychosocial health of disadvantaged students

Comparison: 4 developed country: school meal versus control: CBA

Outcome: 2 Weight gain: Corry-Mann alone

\begin{tabular}{|c|c|c|c|c|c|c|c|c|c|}
\hline \multirow[t]{2}{*}{ Study or subgroup } & \multirow{2}{*}{$\begin{array}{r}\text { Treatment } \\
N\end{array}$} & \multicolumn{2}{|c|}{ Control } & \multicolumn{4}{|c|}{$\begin{array}{l}\text { Mean } \\
\text { Difference }\end{array}$} & Weight & \multirow[t]{2}{*}{$\begin{array}{r}\text { Mean } \\
\text { Difference } \\
\text { IV,Fixed,95\% Cl }\end{array}$} \\
\hline & & Mean(SD) & N & Mean(SD) & & & $\mathrm{ed}, 95 \% \mathrm{Cl}$ & & \\
\hline Corry-Mann 1926 & 41 & $3.17(0.65)$ & 61 & $1.75(0.47)$ & & & & $100.0 \%$ & $1.42[1.19,1.65]$ \\
\hline Total (95\% CI) & 41 & & 61 & & & & - & $100.0 \%$ & $1.42[1.19,1.65]$ \\
\hline \multicolumn{10}{|c|}{ Heterogeneity: not applicable } \\
\hline \multicolumn{10}{|c|}{ Test for overall effect: $Z=12.03(P<0.0000 I)$} \\
\hline \multicolumn{10}{|c|}{ Test for subgroup differences: Not applicable } \\
\hline & & & & & -10 & -5 & 5 & 10 & \\
\hline
\end{tabular}

Analysis 4.7. Comparison 4 developed country: school meal versus control: CBA, Outcome 7 Height gain in cm. adjusted ICC $=0.016$.

Review: School feeding for improving the physical and psychosocial health of disadvantaged students

Comparison: 4 developed country: school meal versus control: CBA

Outcome: 7 Height gain in $\mathrm{cm}$. adjusted ICC $=0.016$

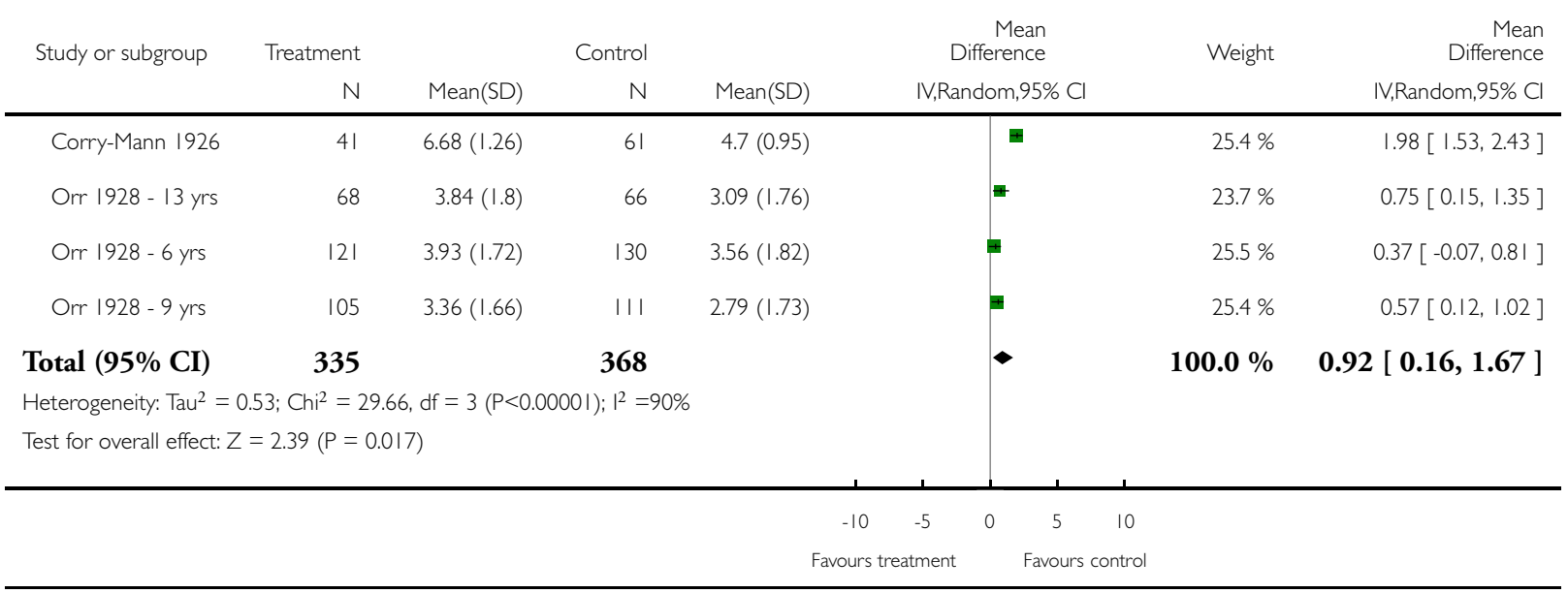

School feeding for improving the physical and psychosocial health of disadvantaged students (Review) 
Analysis 5.I. Comparison 5 Developed country: School meal vs control RCT, Outcome I change in height.

Review: School feeding for improving the physical and psychosocial health of disadvantaged students

Comparison: 5 Developed country: School meal vs control RCT

Outcome: I change in height

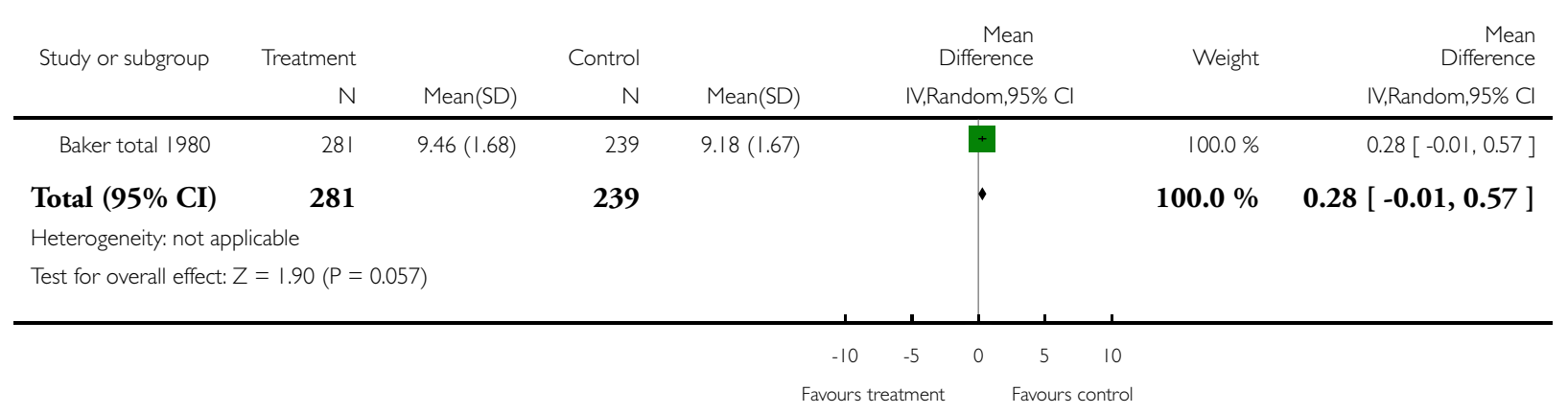


Analysis 5.2. Comparison 5 Developed country: School meal vs control RCT, Outcome 2 Subgroup analysis: height by sex.

\begin{tabular}{|c|c|c|c|c|c|c|c|}
\hline \multicolumn{8}{|c|}{ Comparison: 5 Developed country: School meal vs control RCT } \\
\hline \multicolumn{8}{|c|}{ Outcome: 2 Subgroup analysis: height by sex } \\
\hline \multirow[t]{2}{*}{ Study or subgroup } & Treatment & \multicolumn{3}{|c|}{ Control } & \multirow{2}{*}{$\begin{array}{c}\text { Mean } \\
\text { Difference } \\
\text { IV,Fixed,95\% Cl }\end{array}$} & \multirow[t]{2}{*}{ Weight } & $\begin{array}{r}\text { Mean } \\
\text { Difference }\end{array}$ \\
\hline & $\mathrm{N}$ & Mean(SD) & N & Mean(SD) & & & IV,Fixed,95\% Cl \\
\hline \multicolumn{8}{|l|}{ I bakerboys } \\
\hline Baker 1980 ( boys) & 144 & $9.21(1.35)$ & 123 & $9.1(1.4)$ & + & $100.0 \%$ & $0.11[-0.22,0.44]$ \\
\hline Subtotal $(95 \% \mathrm{CI})$ & 144 & & 123 & & 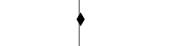 & $100.0 \%$ & $0.11[-0.22,0.44]$ \\
\hline \multicolumn{8}{|c|}{ Heterogeneity: not applicable } \\
\hline \multicolumn{8}{|c|}{ Test for overall effect: $Z=0.65(P=0.52)$} \\
\hline \multicolumn{8}{|l|}{2 baker girls } \\
\hline Agarwal 1989 (girls) & 137 & $9.72(1.94)$ & 116 & $9.27(1.91)$ & + & $100.0 \%$ & $0.45[-0.03,0.93]$ \\
\hline Subtotal $(95 \% \mathrm{CI})$ & 137 & & 116 & & $\bullet$ & $100.0 \%$ & $0.45[-0.03,0.93]$ \\
\hline \multicolumn{8}{|c|}{ Heterogeneity: not applicable } \\
\hline \multicolumn{8}{|c|}{ Test for overall effect: $Z=1.85(P=0.064)$} \\
\hline \multicolumn{8}{|c|}{ Test for subgroup differences: $\mathrm{Chi}^{2}=1.32, \mathrm{df}=1(P=0.25),\left.\right|^{2}=24 \%$} \\
\hline
\end{tabular}




\section{Analysis 5.3. Comparison 5 Developed country: School meal vs control RCT, Outcome 3 change in weight} (kg).

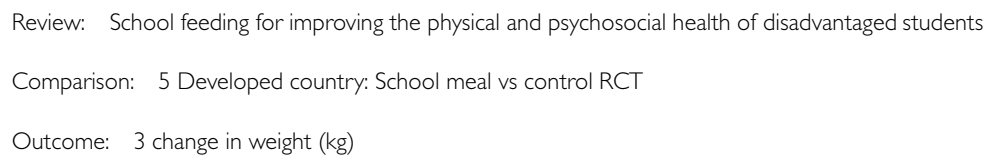

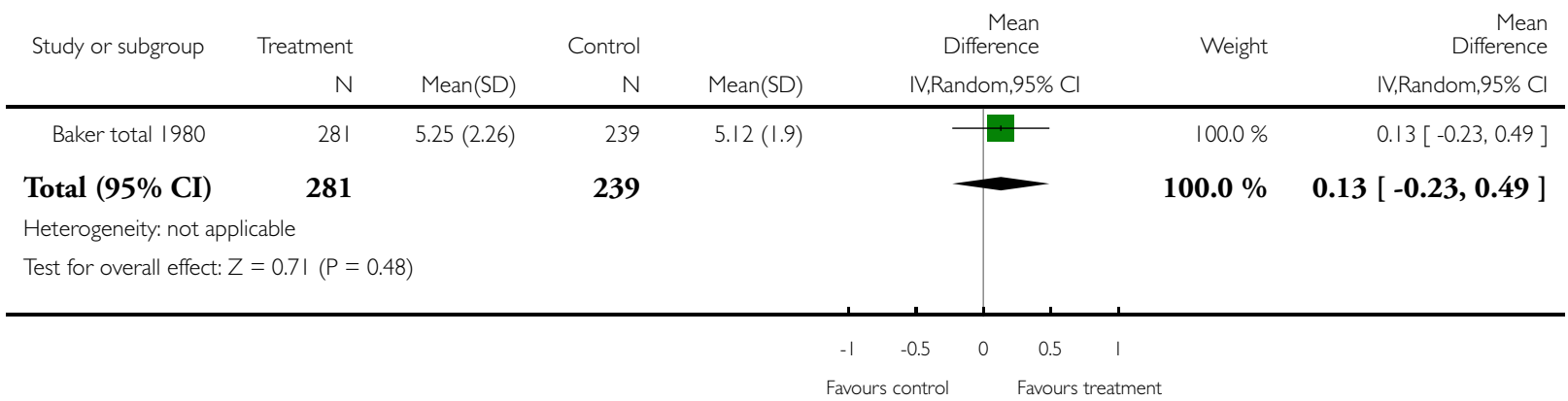


Analysis 5.4. Comparison 5 Developed country: School meal vs control RCT, Outcome 4 Subgroup analysis: weight by sex.

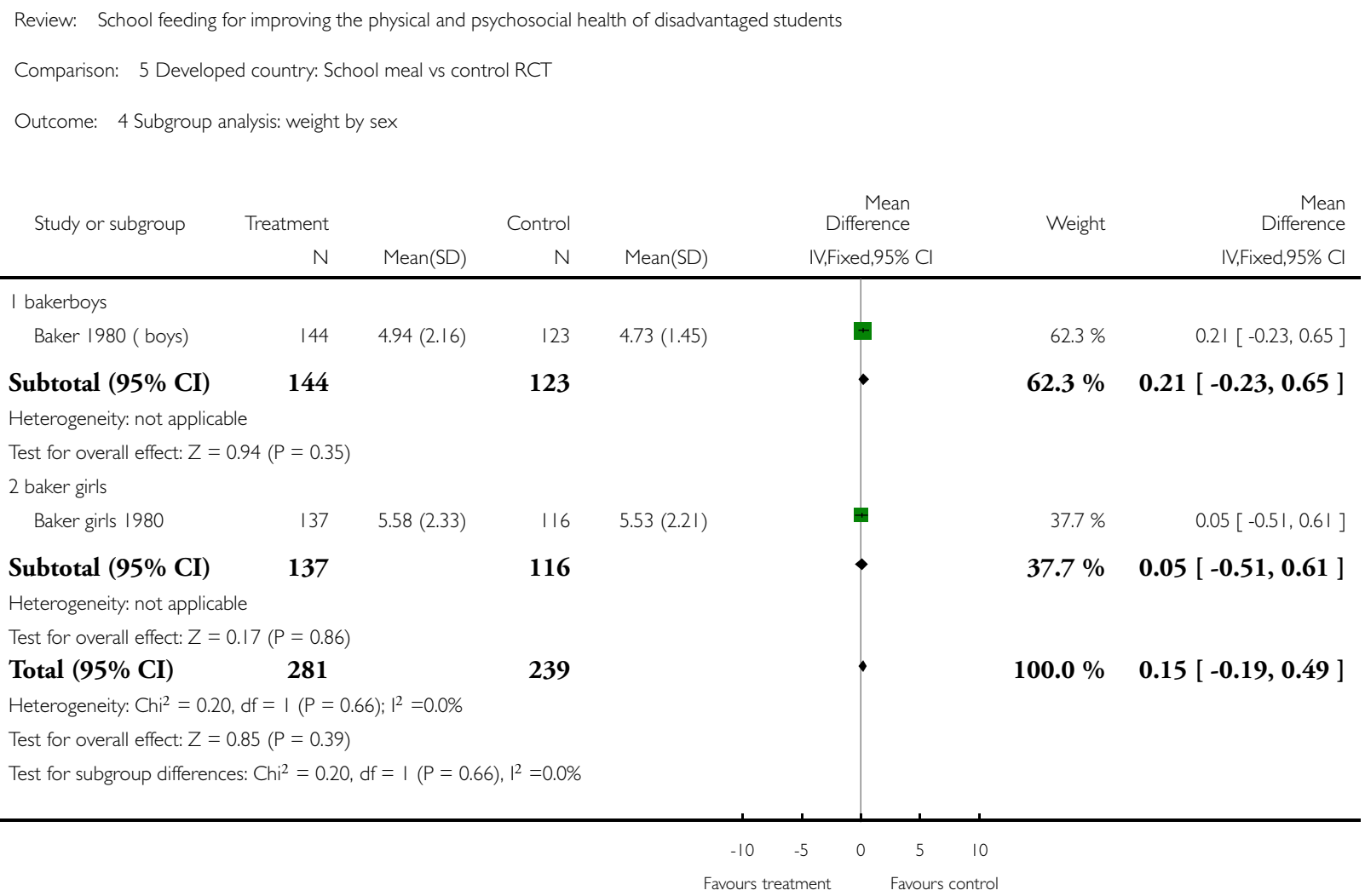


Analysis 10.5. Comparison 10 Developing country: School meal vs control. RCT- Sensitivity, Outcome 5 Weight gain kg- sensitivity ICC 0.01 .

Review: School feeding for improving the physical and psychosocial health of disadvantaged students

Comparison: 10 Developing country: School meal vs control. RCT- Sensitivity

Outcome: 5 Weight gain kg- sensitivity ICC 0.01

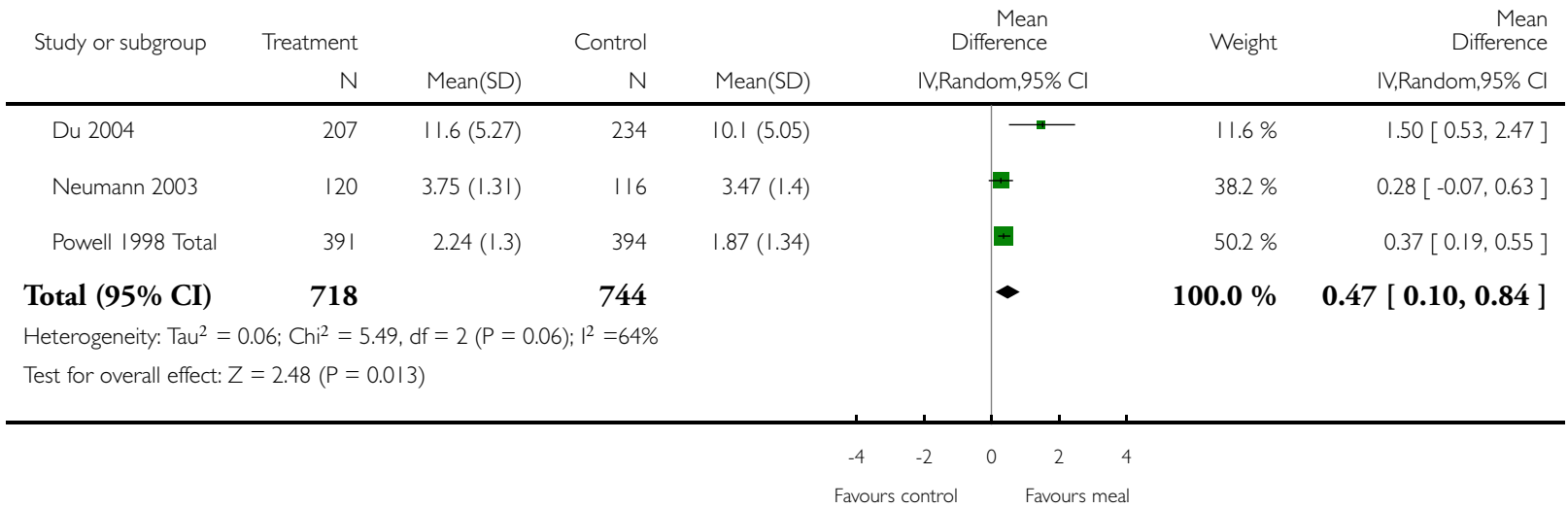

\section{Analysis 10.6. Comparison IO Developing country: School meal vs control. RCT- Sensitivity, Outcome 6} Weight gain kg- sensitivity ICC 0.05 .

Review: School feeding for improving the physical and psychosocial health of disadvantaged students

Comparison: 10 Developing country: School meal vs control. RCT- Sensitivity

Outcome: 6 Weight gain $\mathrm{kg}$ - sensitivity ICC 0.05

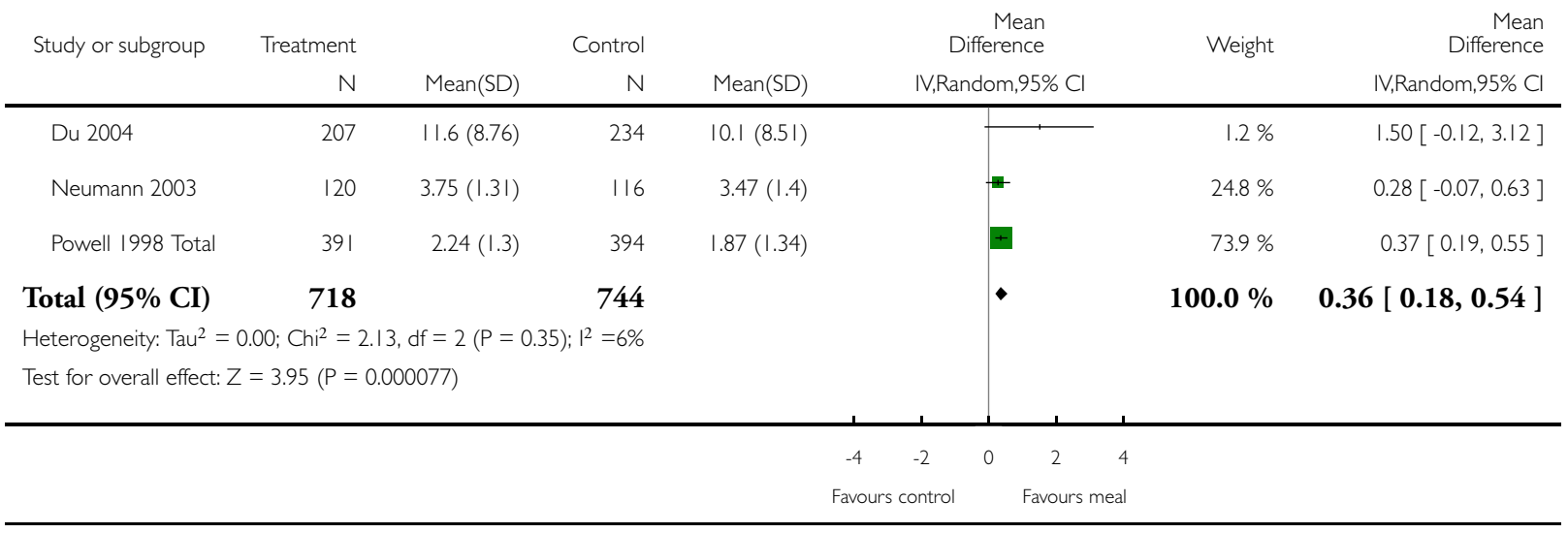

School feeding for improving the physical and psychosocial health of disadvantaged students (Review) 


\section{Analysis 10.7. Comparison 10 Developing country: School meal vs control. RCT- Sensitivity, Outcome 7}

Weight gain kg- sensitivity ICC 0.1 .

Review: School feeding for improving the physical and psychosocial health of disadvantaged students

Comparison: 10 Developing country: School meal vs control. RCT- Sensitivity

Outcome: 7 Weight gain $\mathrm{kg}$ - sensitivity ICC 0.1

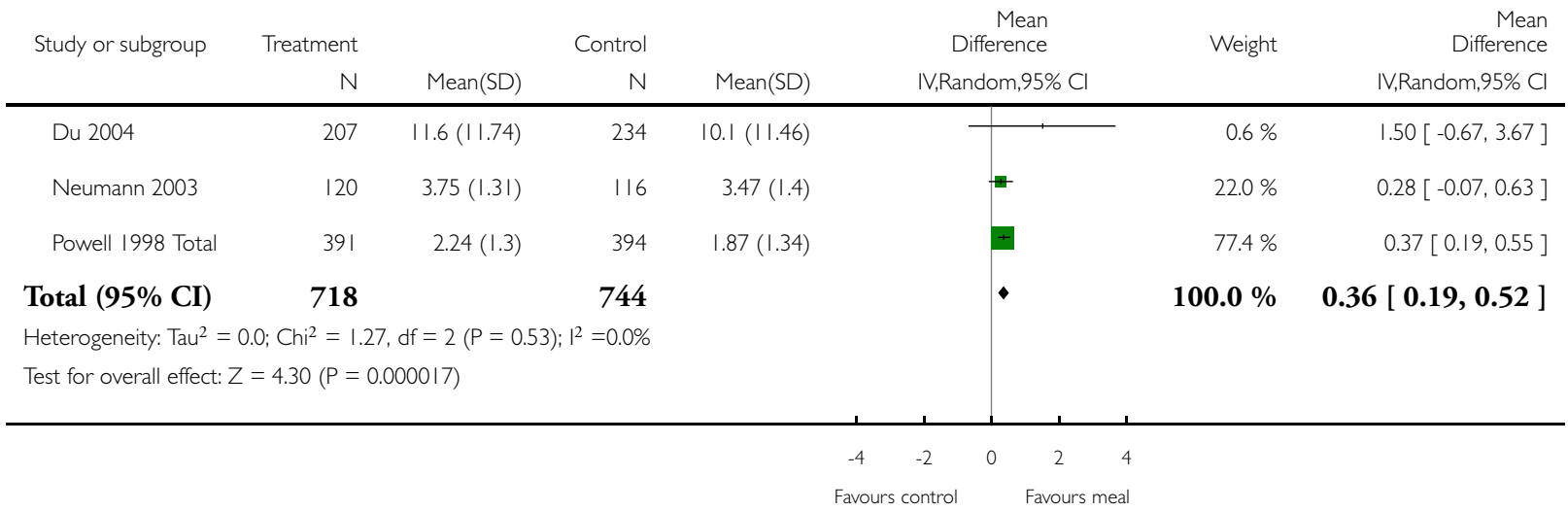


Analysis 10.9. Comparison 10 Developing country: School meal vs control. RCT- Sensitivity, Outcome 9 Height gain $(\mathrm{cm})$, sensitivity ICC 0.01 .

Review: School feeding for improving the physical and psychosocial health of disadvantaged students

Comparison: 10 Developing country: School meal vs control. RCT- Sensitivity

Outcome: 9 Height gain $(\mathrm{cm})$, sensitivity ICC 0.0 I

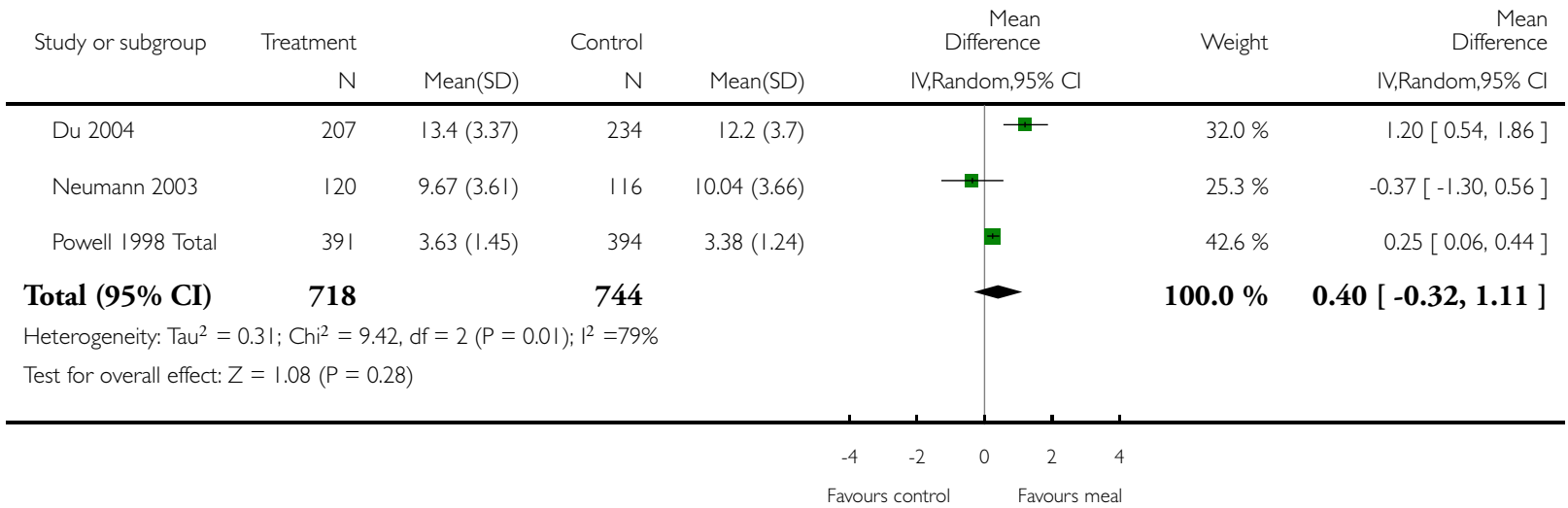

Analysis 10.10. Comparison 10 Developing country: School meal vs control. RCT- Sensitivity, Outcome 10 Height gain (cm), sensitivity ICC 0.05 .

Review: School feeding for improving the physical and psychosocial health of disadvantaged students

Comparison: 10 Developing country: School meal vs control. RCT- Sensitivity

Outcome: 10 Height gain $(\mathrm{cm})$, sensitivity ICC 0.05

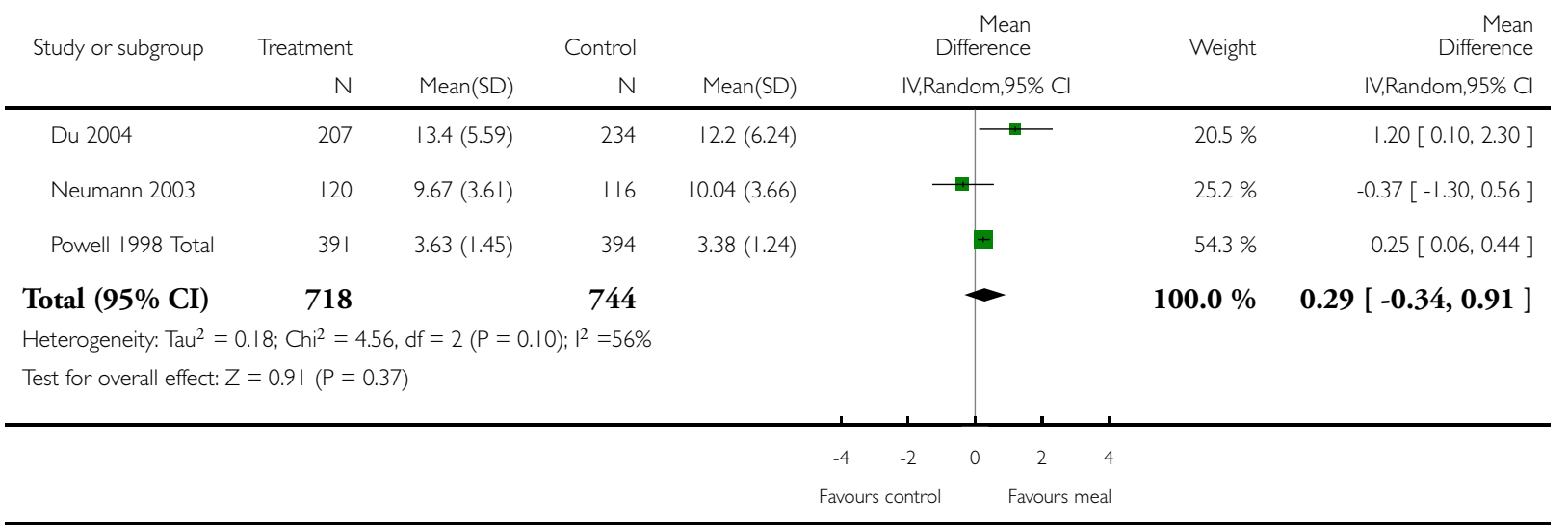

School feeding for improving the physical and psychosocial health of disadvantaged students (Review) 


\section{Analysis I0.I I. Comparison IO Developing country: School meal vs control. RCT- Sensitivity, Outcome I I}

Height gain $(\mathrm{cm})$, sensitivity ICC 0.1 .

Review: School feeding for improving the physical and psychosocial health of disadvantaged students

Comparison: 10 Developing country: School meal vs control. RCT- Sensitivity

Outcome: I I Height gain (cm), sensitivity ICC 0.1

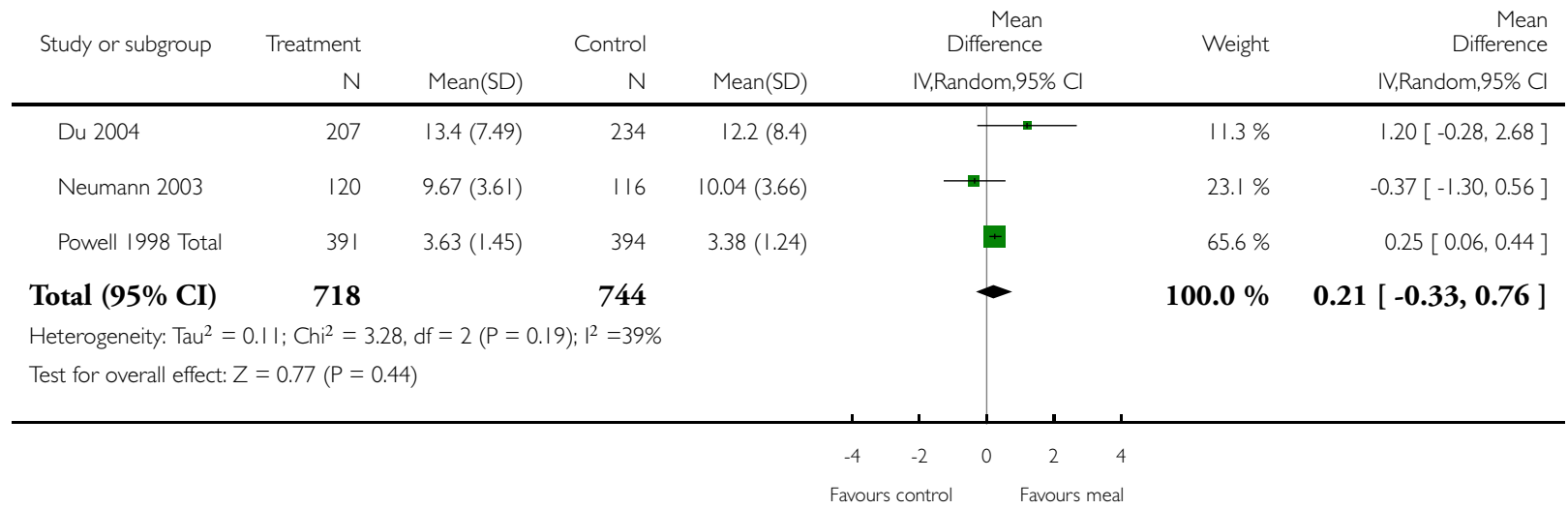


Analysis II.I. Comparison I I Developing country: School meal vs control. CBA - Sensitivity, Outcome I Math change overall icc .I.

Review: School feeding for improving the physical and psychosocial health of disadvantaged students

Comparison: II Developing country: School meal vs control. CBA - Sensitivity

Outcome: I Math change overall icc . I

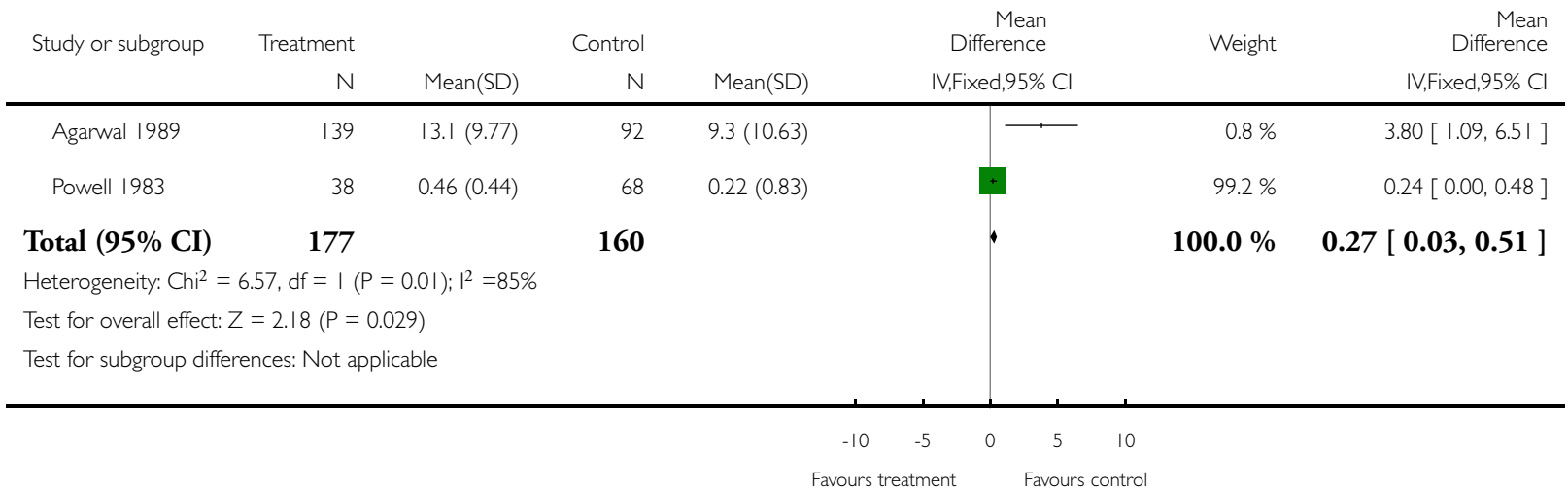


Analysis II.2. Comparison I I Developing country: School meal vs control. CBA - Sensitivity, Outcome 2 Weight gain kg- sensitivity ICC 0.01 .

Review: School feeding for improving the physical and psychosocial health of disadvantaged students

Comparison: II Developing country: School meal vs control. CBA - Sensitivity

Outcome: 2 Weight gain kg- sensitivity ICC 0.01

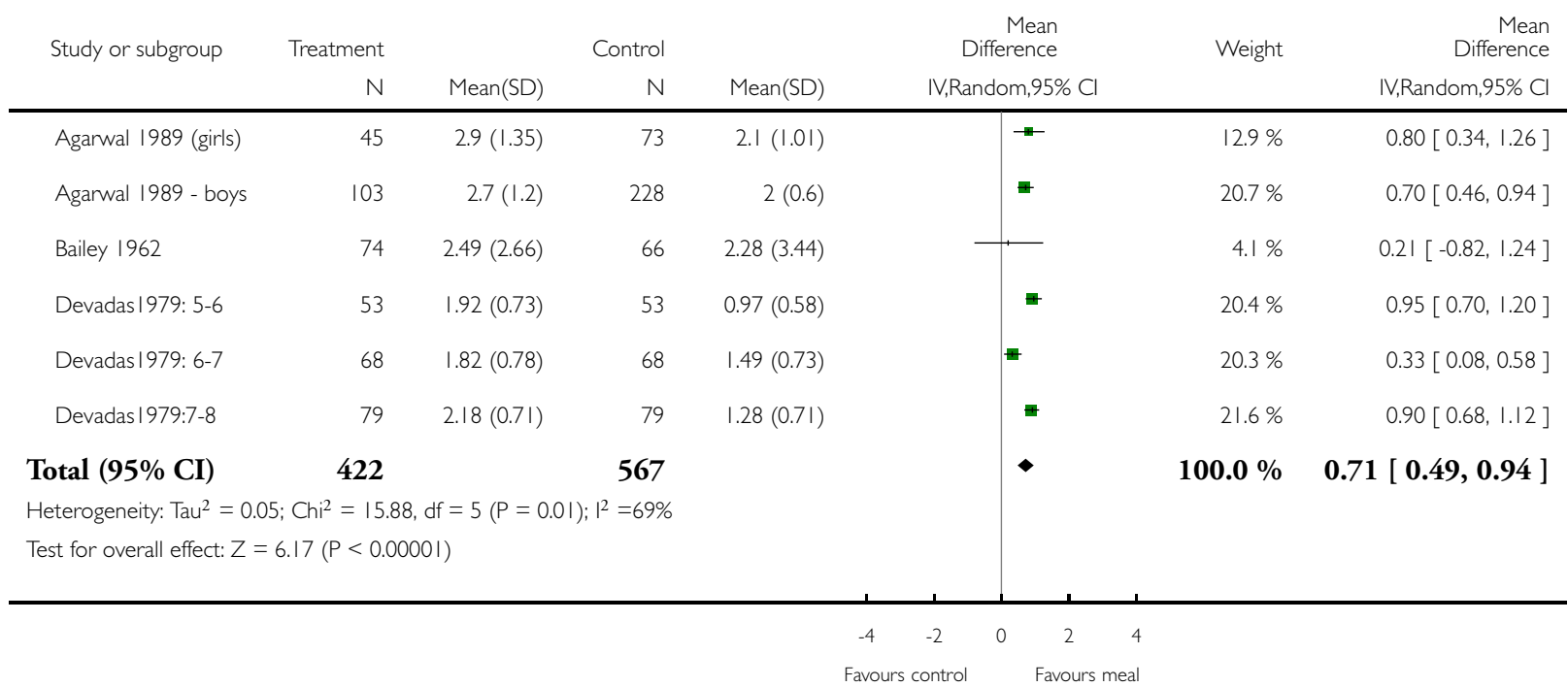


Analysis II.3. Comparison II Developing country: School meal vs control. CBA - Sensitivity, Outcome 3 Weight gain kg- sensitivity ICC 0.05 .

Review: School feeding for improving the physical and psychosocial health of disadvantaged students

Comparison: II Developing country: School meal vs control. CBA - Sensitivity

Outcome: 3 Weight gain kg- sensitivity ICC 0.05

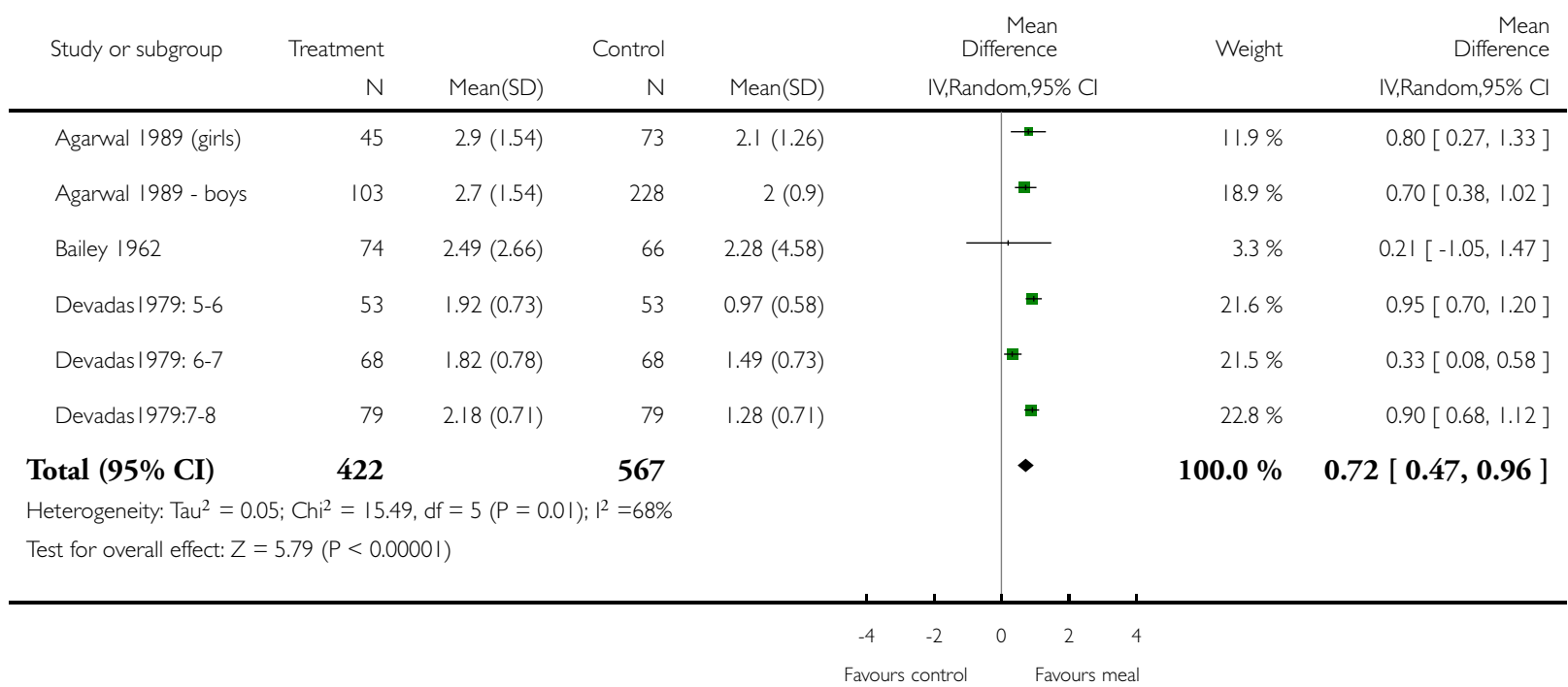


Analysis I I.4. Comparison I I Developing country: School meal vs control. CBA - Sensitivity, Outcome 4 Weight gain kg- sensitivity ICC 0.I.

Review: School feeding for improving the physical and psychosocial health of disadvantaged students

Comparison: II Developing country: School meal vs control. CBA - Sensitivity

Outcome: 4 Weight gain $\mathrm{kg}$ - sensitivity ICC 0.1

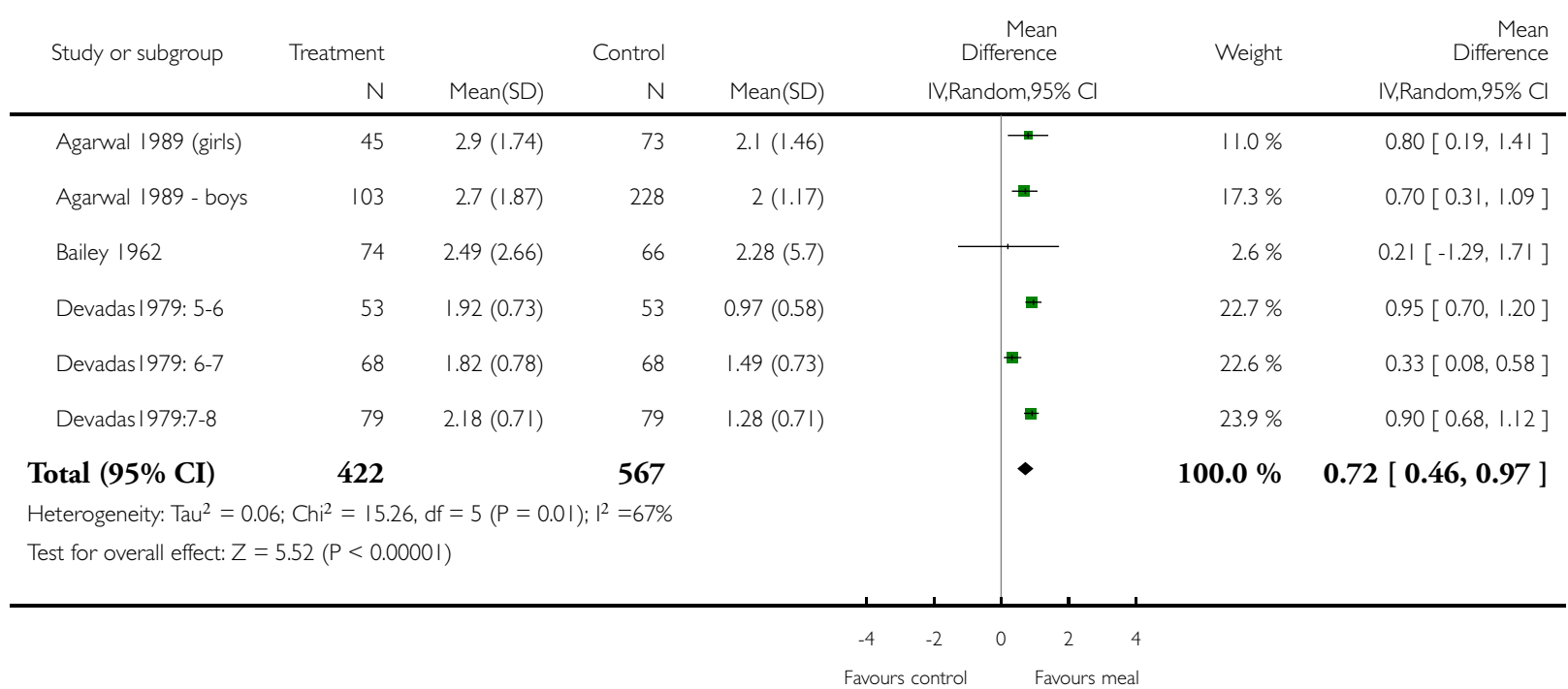


Analysis I I.5. Comparison II Developing country: School meal vs control. CBA - Sensitivity, Outcome 5 Math change overall icc .2.

Review: School feeding for improving the physical and psychosocial health of disadvantaged students

Comparison: II Developing country: School meal vs control. CBA - Sensitivity

Outcome: 5 Math change overall icc .2

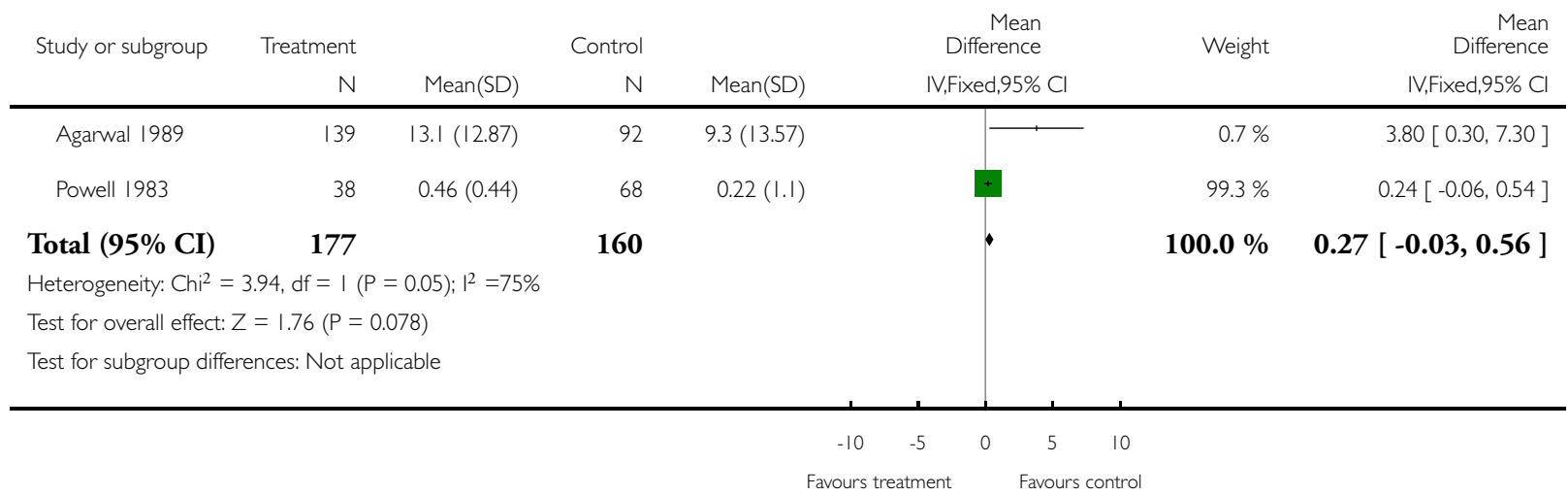


Analysis I I.6. Comparison I I Developing country: School meal vs control. CBA - Sensitivity, Outcome 6 Height gain $(\mathrm{cm})$ - sensitivity ICC 0.01 .

Review: School feeding for improving the physical and psychosocial health of disadvantaged students

Comparison: II Developing country: School meal vs control. CBA - Sensitivity

Outcome: 6 Height gain $(\mathrm{cm})$ - sensitivity ICC 0.01

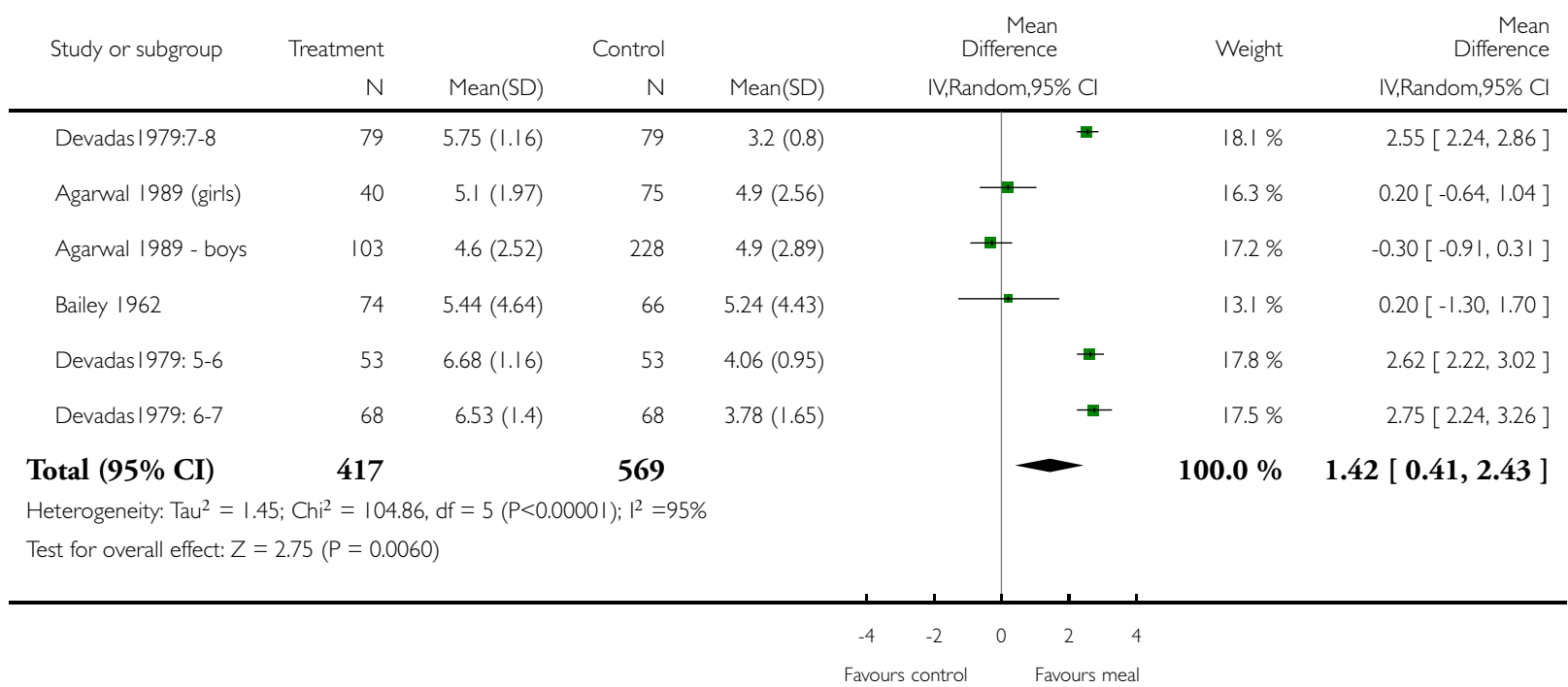


Analysis I I.7. Comparison I I Developing country: School meal vs control. CBA - Sensitivity, Outcome 7 Height gain (cm)- sensitivity ICC 0.05 .

Review: School feeding for improving the physical and psychosocial health of disadvantaged students

Comparison: II Developing country: School meal vs control. CBA - Sensitivity

Outcome: 7 Height gain (cm)- sensitivity ICC 0.05

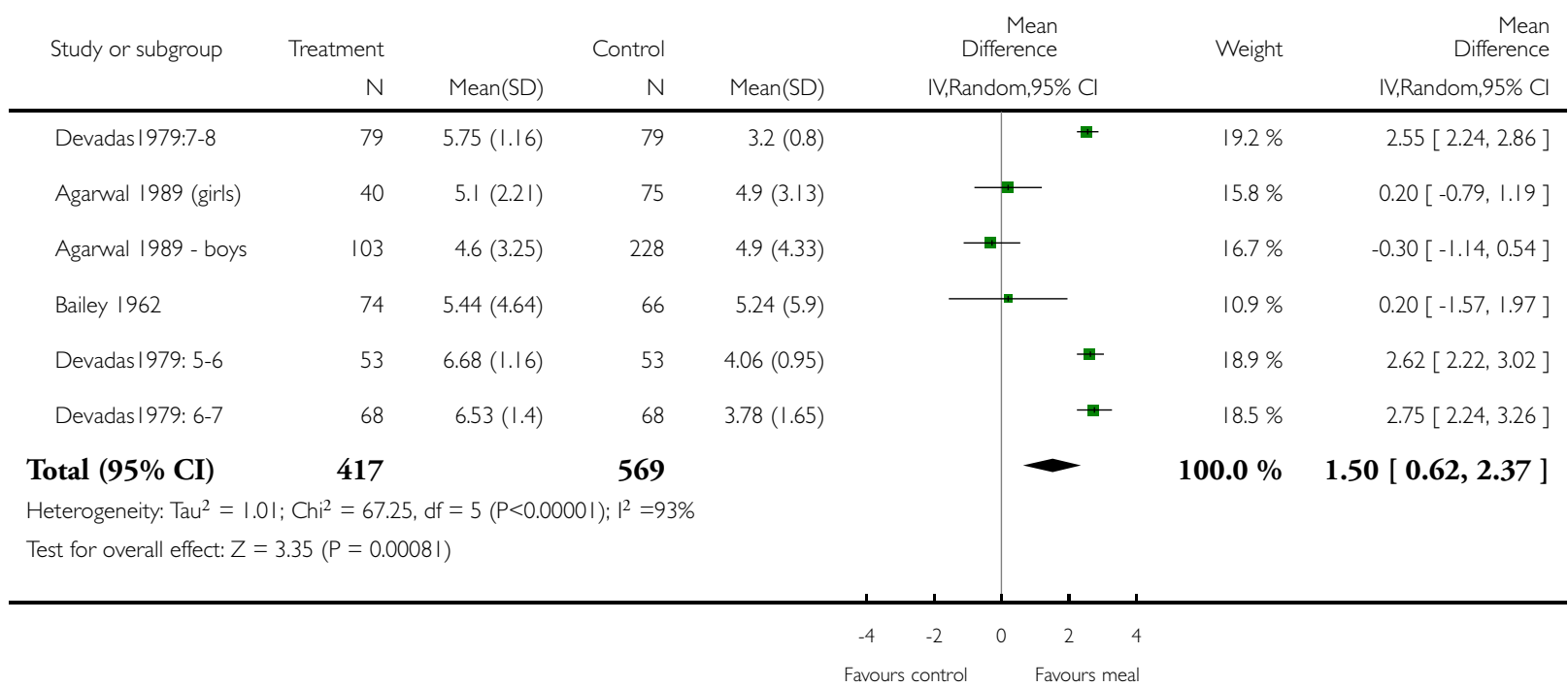


Analysis I I.8. Comparison I I Developing country: School meal vs control. CBA - Sensitivity, Outcome 8 Height gain (cm)- sensitivity ICC 0.I.

Review: School feeding for improving the physical and psychosocial health of disadvantaged students

Comparison: II Developing country: School meal vs control. CBA - Sensitivity

Outcome: 8 Height gain (cm)- sensitivity ICC 0.1

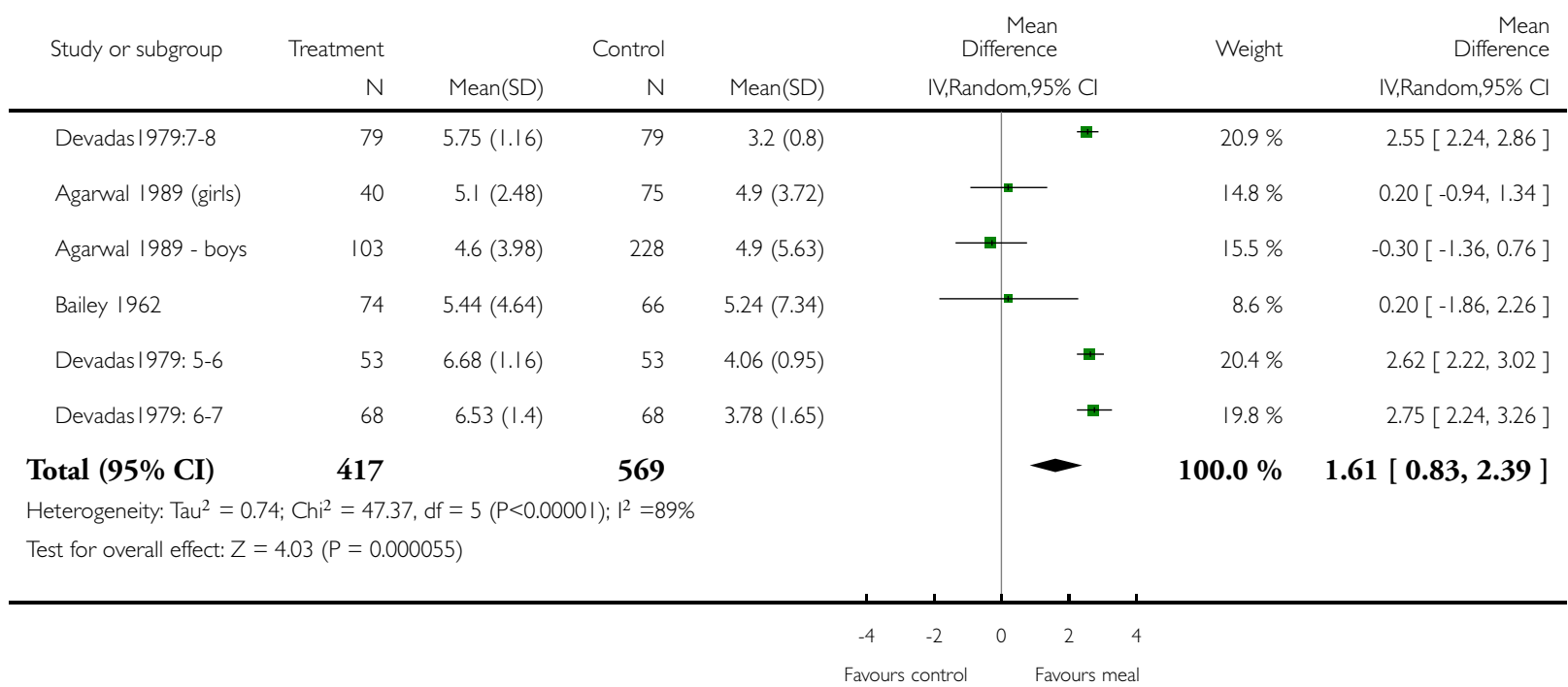




\section{Analysis I I.I I. Comparison I I Developing country: School meal vs control. CBA - Sensitivity, Outcome I I Percent height for age: icc $\mathbf{= 0 . 0 5}$.}

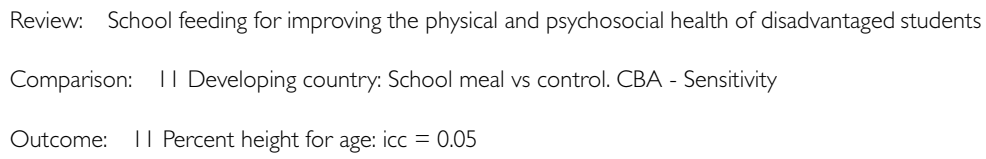

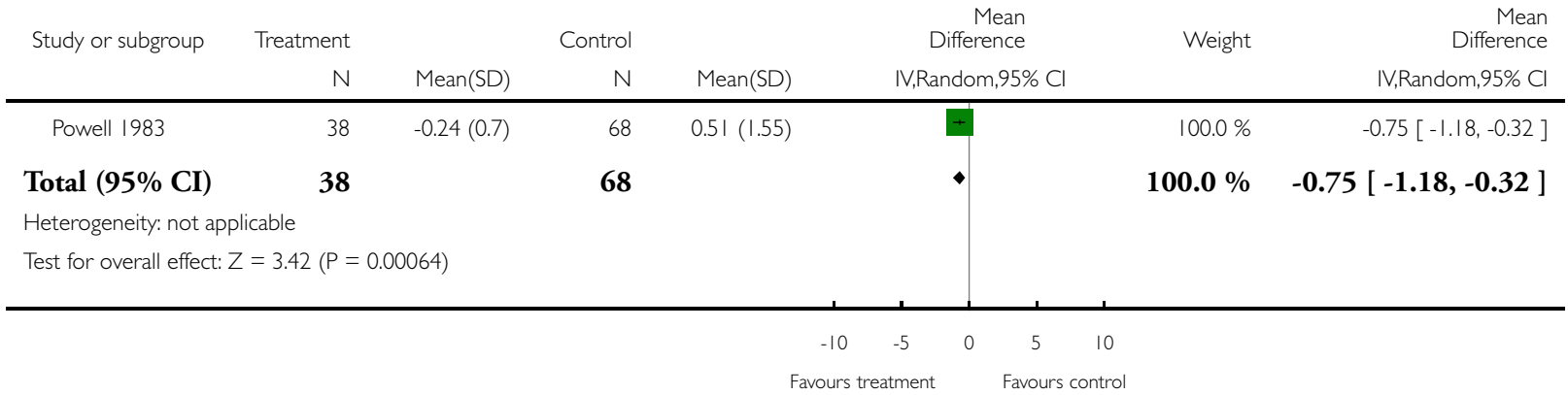

Analysis I I.I2. Comparison I I Developing country: School meal vs control. CBA - Sensitivity, Outcome I 2 Percent height for age: icc $=. I$.

Review: School feeding for improving the physical and psychosocial health of disadvantaged students

Comparison: II Developing country: School meal vs control. CBA - Sensitivity

Outcome: 12 Percent height for age: icc $=.1$

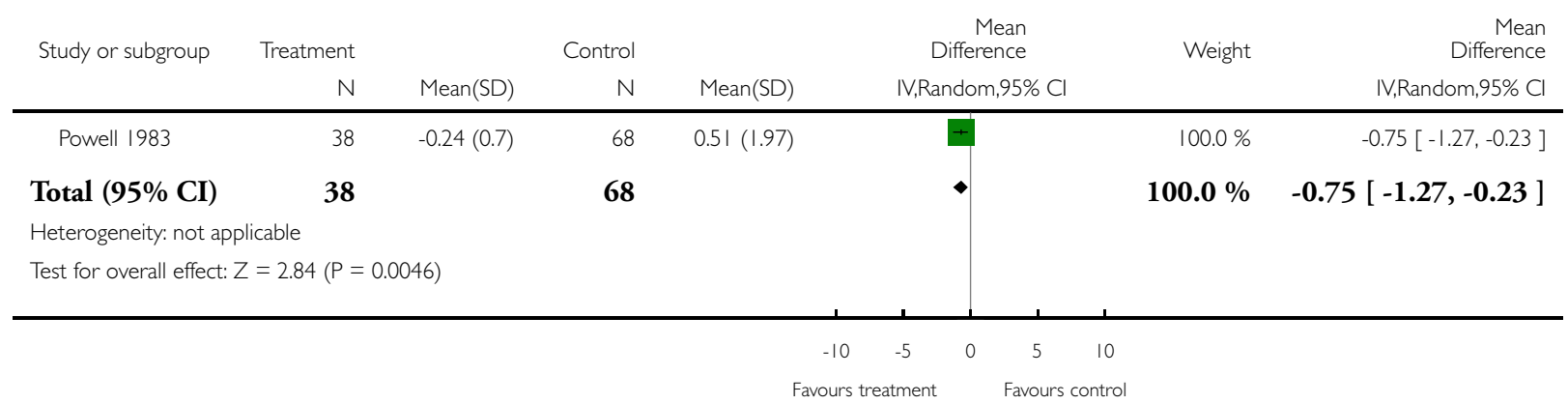




\section{Analysis I I.I4. Comparison II Developing country: School meal vs control. CBA - Sensitivity, Outcome I4} Full scale IQ (total)- sensitivity 0.1 .

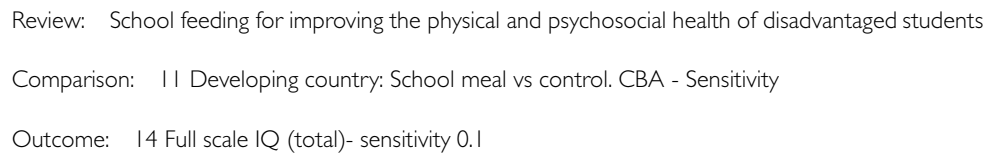

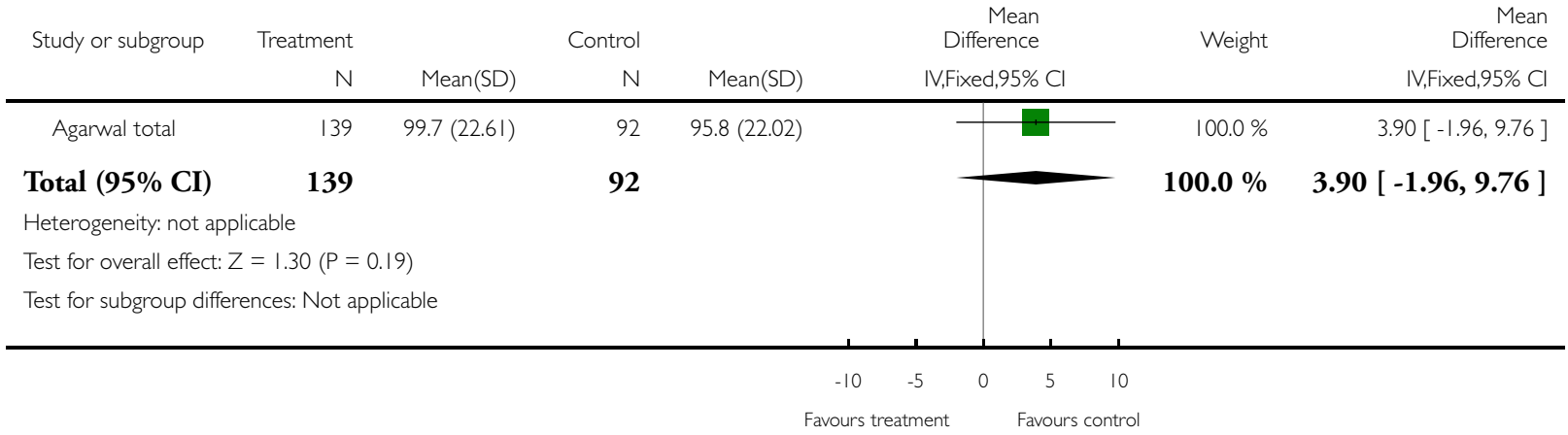

Analysis I I.16. Comparison I I Developing country: School meal vs control. CBA - Sensitivity, Outcome I6 Math (change) by nutritional status: cluster size as in analysis Sensitivity ICC $=0.2$.

Review: School feeding for improving the physical and psychosocial health of disadvantaged students

Comparison: II Developing country: School meal vs control. CBA - Sensitivity

Outcome: 16 Math (change) by nutritional status: cluster size as in analysis Sensitivity ICC $=0.2$

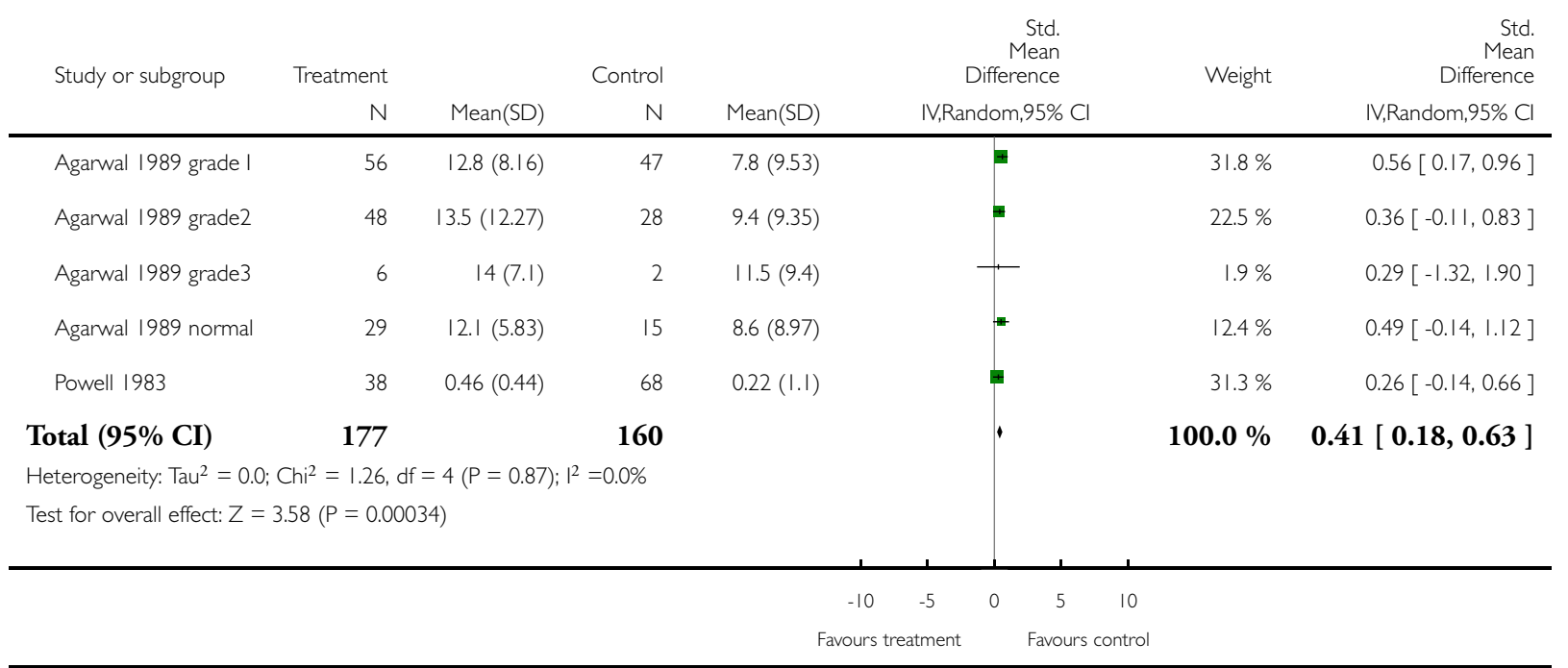


Analysis I I.I7. Comparison I I Developing country: School meal vs control. CBA - Sensitivity, Outcome I7 Math (change) by nutritional status: cluster size as in analysis Sensitivity ICC $=0.1$.

Review: School feeding for improving the physical and psychosocial health of disadvantaged students

Comparison: II Developing country: School meal vs control. CBA - Sensitivity

Outcome: 17 Math (change) by nutritional status: cluster size as in analysis Sensitivity ICC $=0.1$

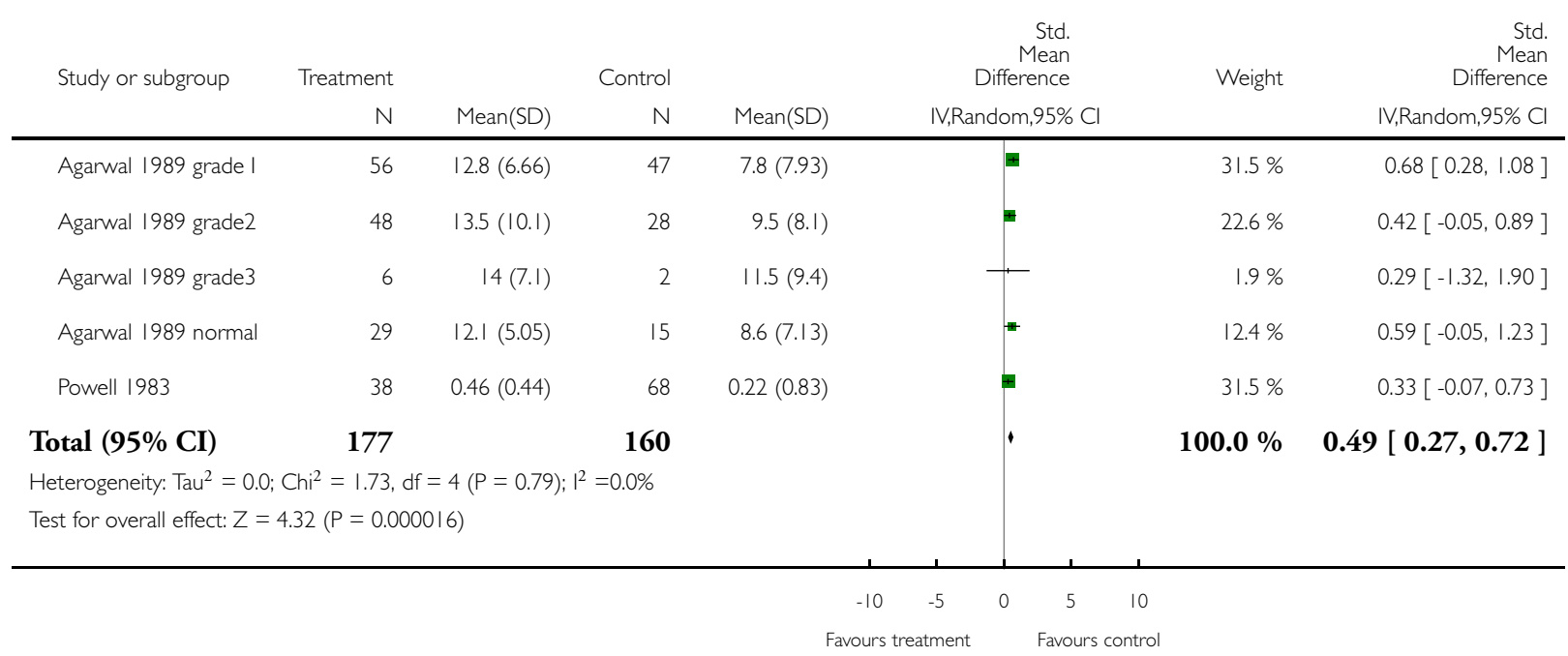


Analysis I I.I8. Comparison I I Developing country: School meal vs control. CBA - Sensitivity, Outcome I8 Full scale IQ (total)- sensitivity 0.20 .

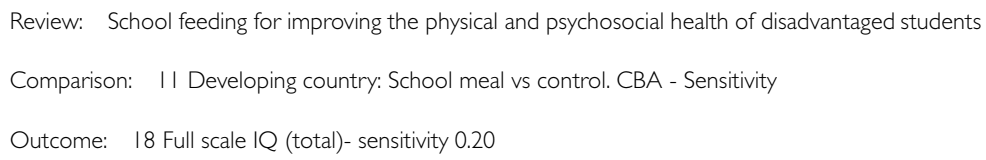

\begin{tabular}{|c|c|c|c|c|c|c|c|}
\hline & $N$ & Mean(SD) & $N$ & Mean(SD) & IV,Fixed,95\% Cl & & IV,Fixed,95\% Cl \\
\hline Agarwal total & 139 & $99.7(29.8)$ & 92 & $95.8(28.11)$ &,+ & $100.0 \%$ & $3.90[-3.69,11.49]$ \\
\hline Total $(95 \% \mathrm{CI})$ & 139 & & 92 & & & $100.0 \%$ & $3.90[-3.69,11.49]$ \\
\hline \multicolumn{8}{|c|}{ Heterogeneity: not applicable } \\
\hline \multicolumn{8}{|c|}{ Test for overall effect: $Z=1.0 \mathrm{I}(P=0.3 \mathrm{I})$} \\
\hline \multicolumn{8}{|c|}{ Test for subgroup differences: Not applicable } \\
\hline
\end{tabular}

Analysis II.20. Comparison I I Developing country: School meal vs control. CBA - Sensitivity, Outcome 20 Full scale IQ (end study): sensitivity cluster size as in analysis ICC $=0.1$.

Review: School feeding for improving the physical and psychosocial health of disadvantaged students

Comparison: II Developing country: School meal vs control. CBA - Sensitivity

Outcome: 20 Full scale IQ (end study): sensitivity cluster size as in analysis ICC $=0.1$

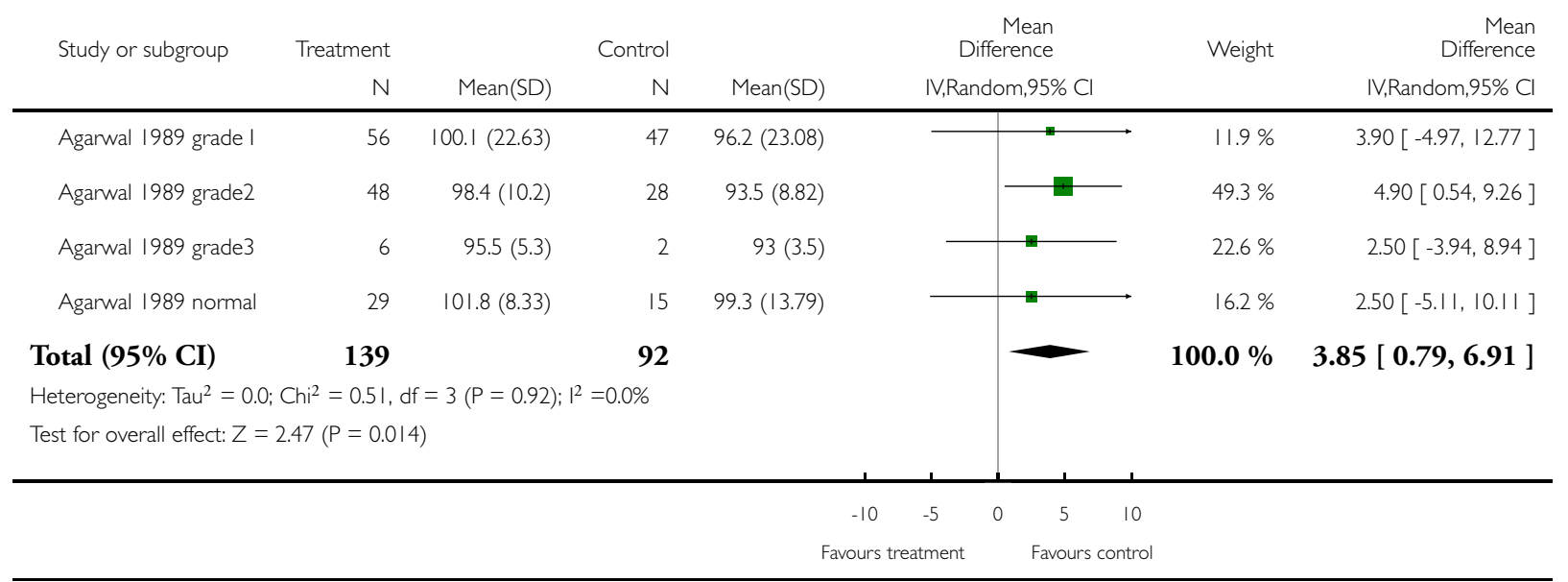


Analysis I I.22. Comparison I I Developing country: School meal vs control. CBA - Sensitivity, Outcome 22 Full scale IQ (end study): sensitivity cluster size as in analysis: ICC $=0.2$.

Review: School feeding for improving the physical and psychosocial health of disadvantaged students

Comparison: II Developing country: School meal vs control. CBA - Sensitivity

Outcome: 22 Full scale IQ (end study): sensitivity cluster size as in analysis: ICC $=0.2$

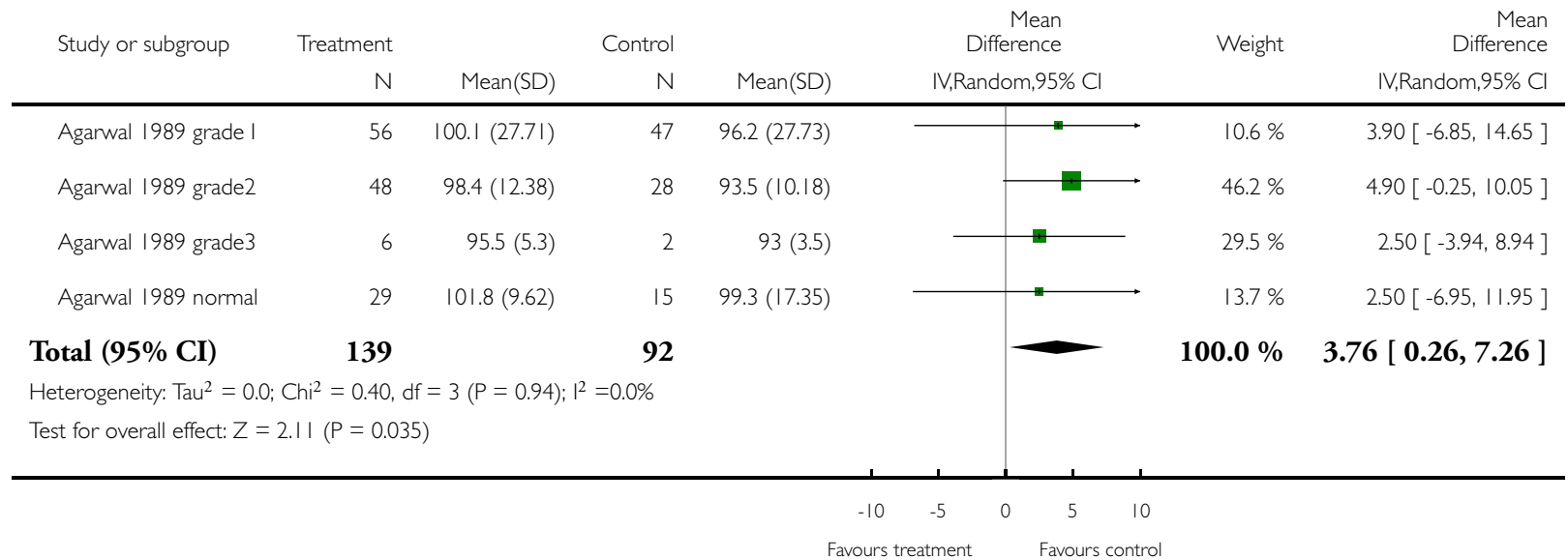


Analysis II.23. Comparison I I Developing country: School meal vs control. CBA - Sensitivity, Outcome 23 Performance IQ (end study): Sensitivity cluster size as in analysis: ICC $=0.1$.

Review: School feeding for improving the physical and psychosocial health of disadvantaged students

Comparison: II Developing country: School meal vs control. CBA - Sensitivity

Outcome: 23 Performance IQ (end study): Sensitivity cluster size as in analysis: ICC = 0.1

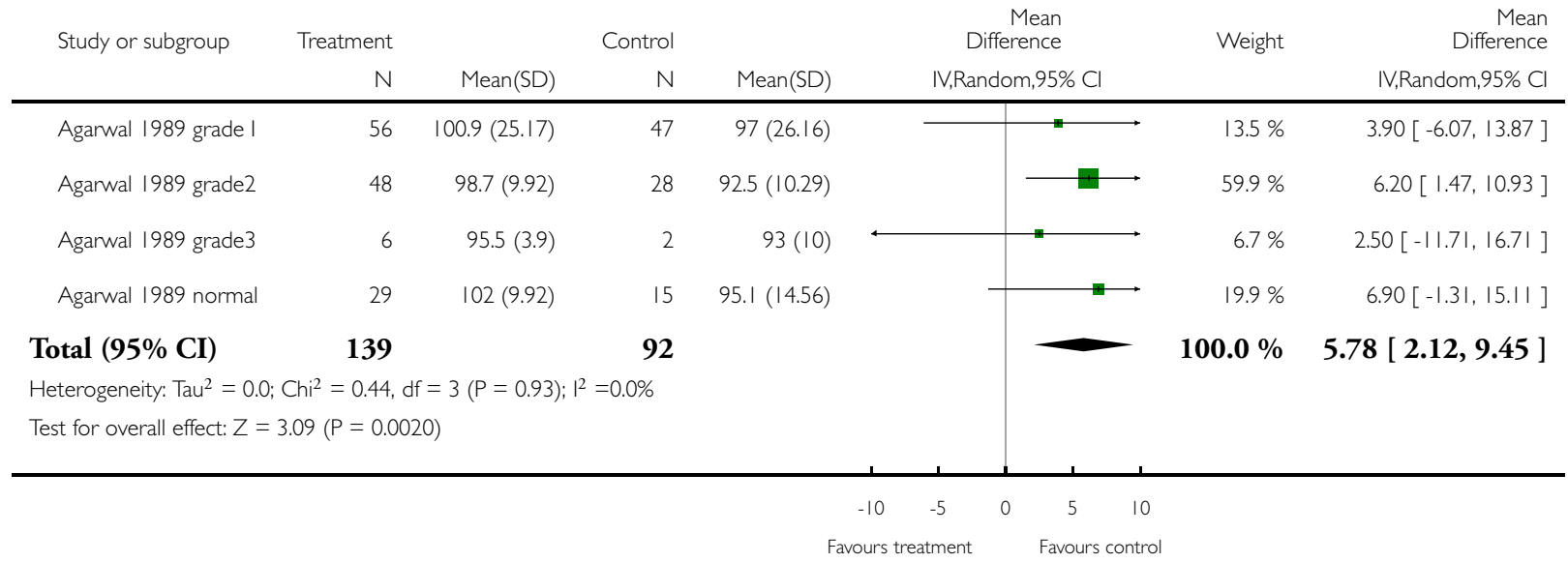


Analysis II.25. Comparison I I Developing country: School meal vs control. CBA - Sensitivity, Outcome 25 Performance IQ (end study): Sensitivity cluster size as in analysis: ICC $=0.2$.

Review: School feeding for improving the physical and psychosocial health of disadvantaged students

Comparison: II Developing country: School meal vs control. CBA - Sensitivity

Outcome: 25 Performance IQ (end study): Sensitivity cluster size as in analysis: ICC $=0.2$

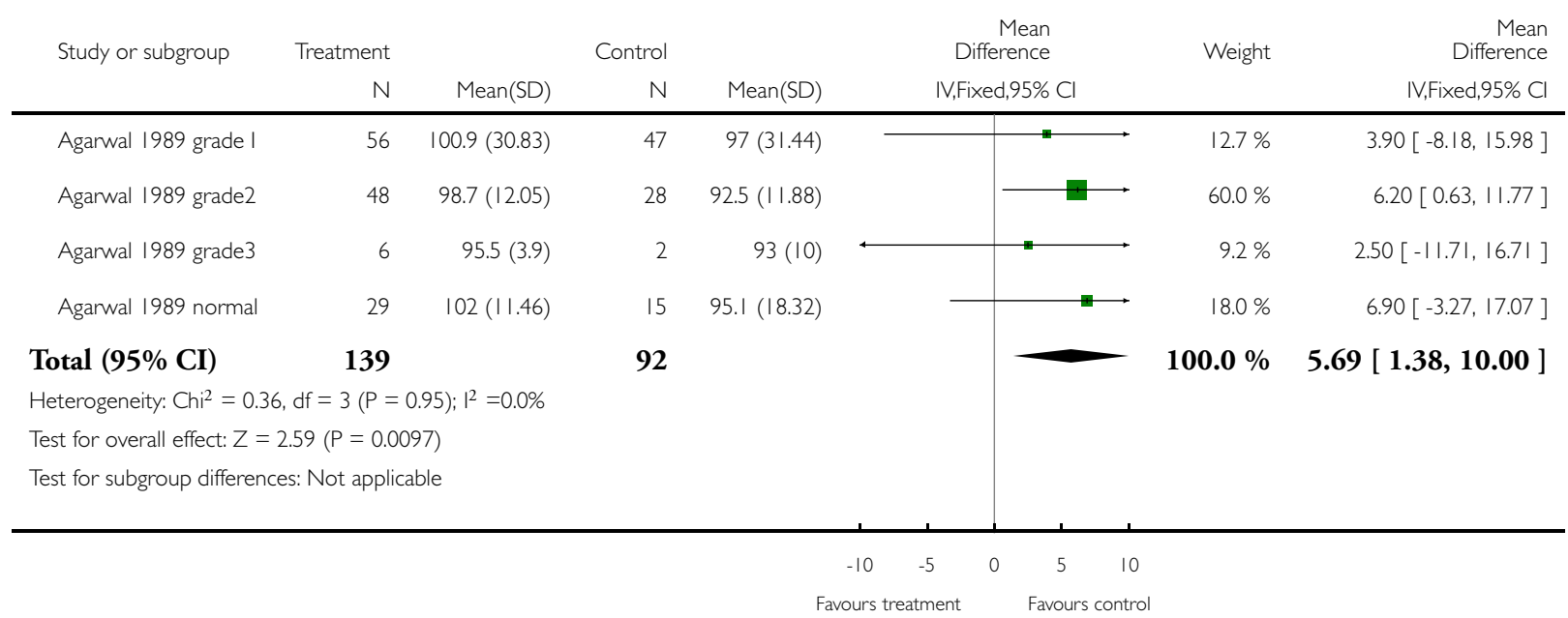


Analysis II.27. Comparison I I Developing country: School meal vs control. CBA - Sensitivity, Outcome 27 Verbal IQ (end study): Sensitivity cluster size as in analyses: ICC $=0.1$.

Review: School feeding for improving the physical and psychosocial health of disadvantaged students

Comparison: II Developing country: School meal vs control. CBA - Sensitivity

Outcome: 27 Verbal IQ (end study): Sensitivity cluster size as in analyses: ICC $=0.1$

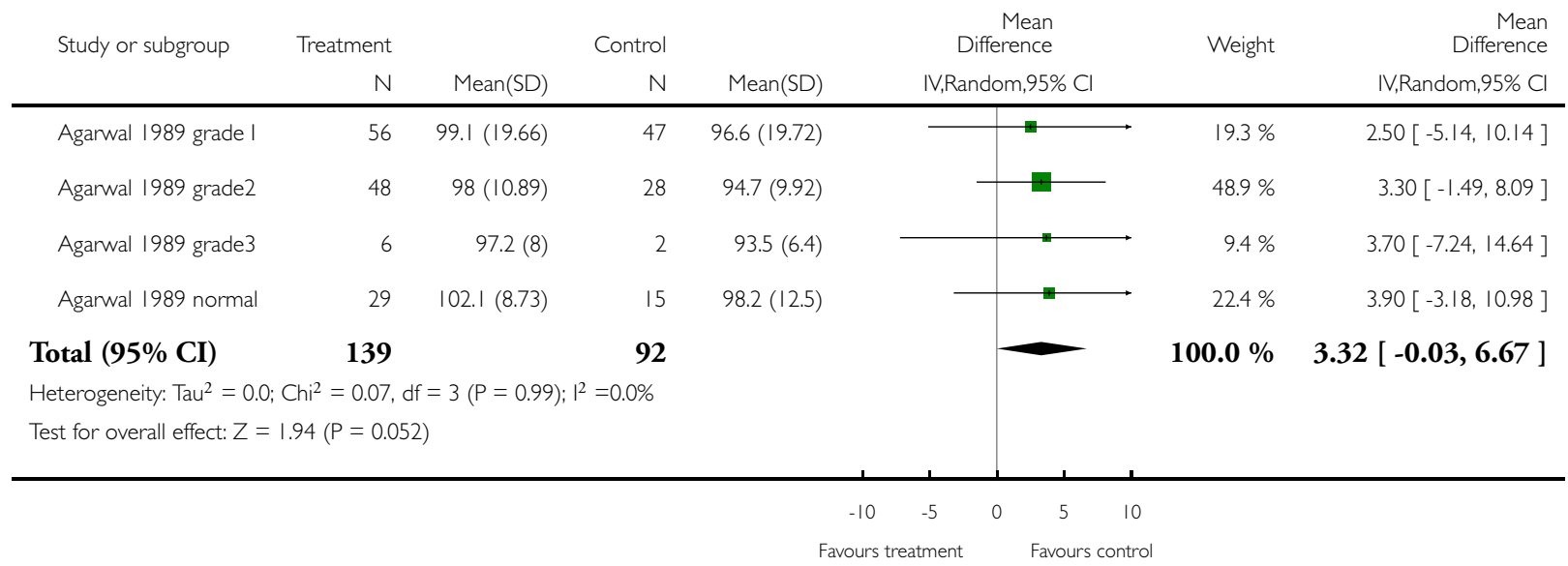


Analysis II.29. Comparison I I Developing country: School meal vs control. CBA - Sensitivity, Outcome 29 Verbal IQ (end study): Sensitivity cluster size as in analysis: ICC = 0.2.

Review: School feeding for improving the physical and psychosocial health of disadvantaged students

Comparison: II Developing country: School meal vs control. CBA - Sensitivity

Outcome: 29 Verbal IQ (end study): Sensitivity cluster size as in analysis: ICC $=0.2$

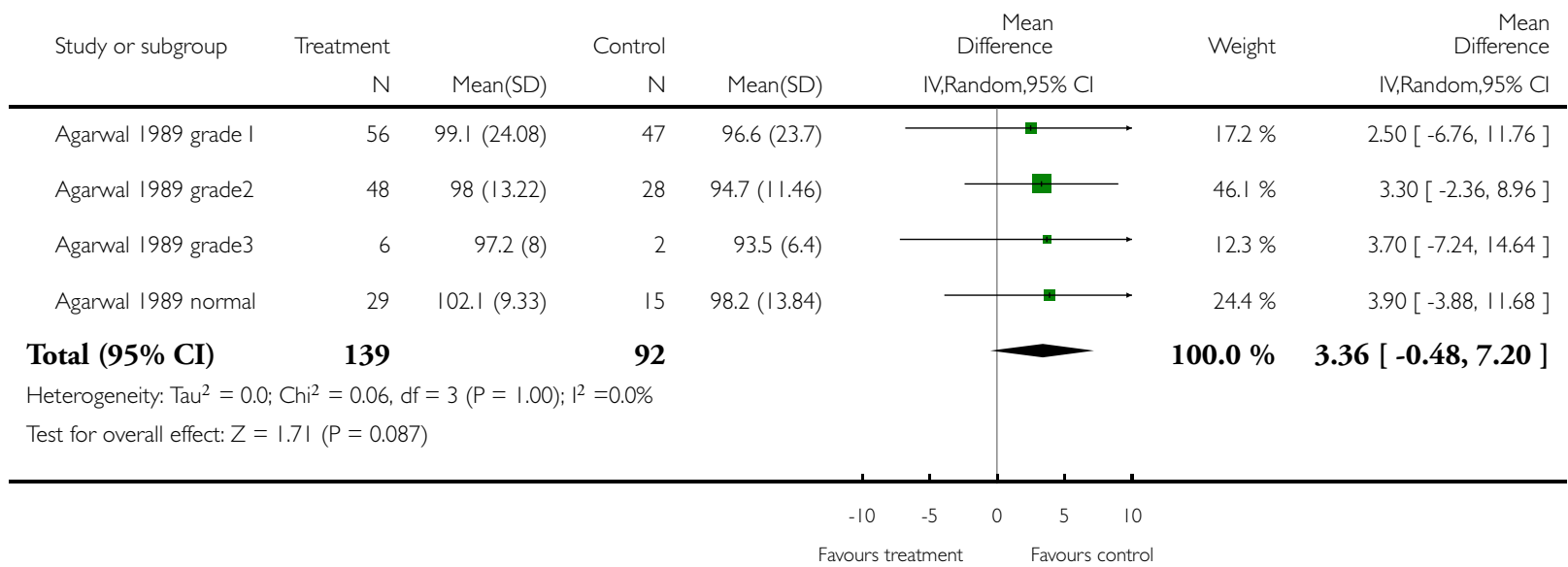

Analysis I I.30. Comparison I I Developing country: School meal vs control. CBA - Sensitivity, Outcome 30 Percentage standard weight. Sensitivity $=0.0 \mathrm{I}$.

Review: School feeding for improving the physical and psychosocial health of disadvantaged students

Comparison: II Developing country: School meal vs control. CBA - Sensitivity

Outcome: 30 Percentage standard weight. Sensitivity $=0.01$

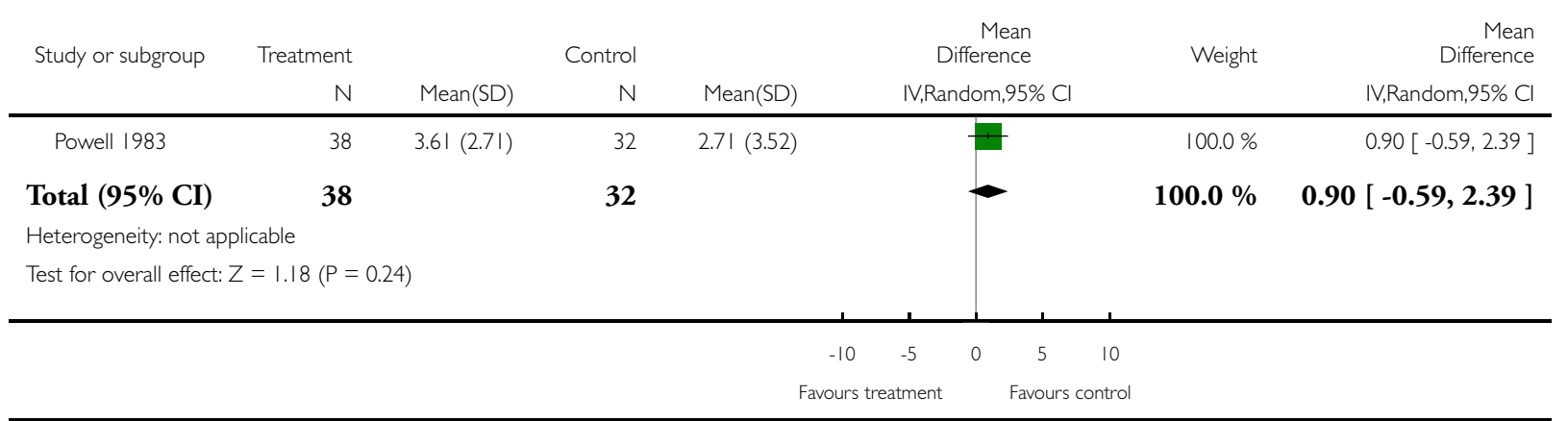

School feeding for improving the physical and psychosocial health of disadvantaged students (Review) 
Analysis I I.32. Comparison I I Developing country: School meal vs control. CBA - Sensitivity, Outcome 32 Percent weight for age: Sensitivity ICC $=0.05$.

\section{Review: School feeding for improving the physical and psychosocial health of disadvantaged students}

Comparison: II Developing country: School meal vs control. CBA - Sensitivity

Outcome: 32 Percent weight for age: Sensitivity ICC $=0.05$

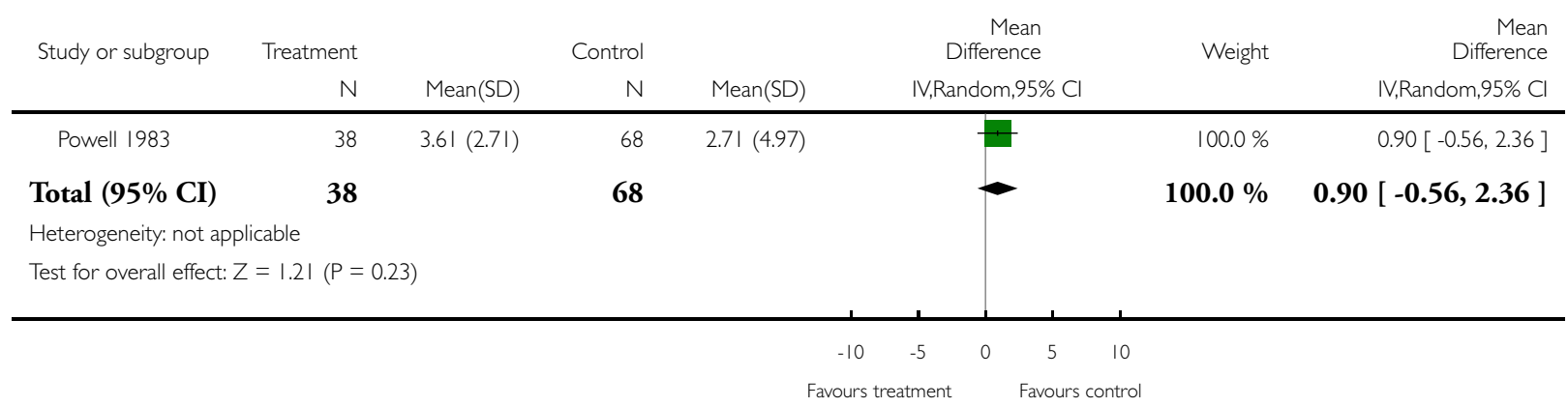


Analysis I I.33. Comparison I I Developing country: School meal vs control. CBA - Sensitivity, Outcome 33 Percent weight for age: Sensitivity ICC $=0.1$.

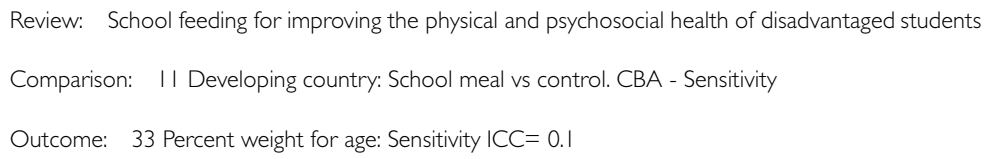

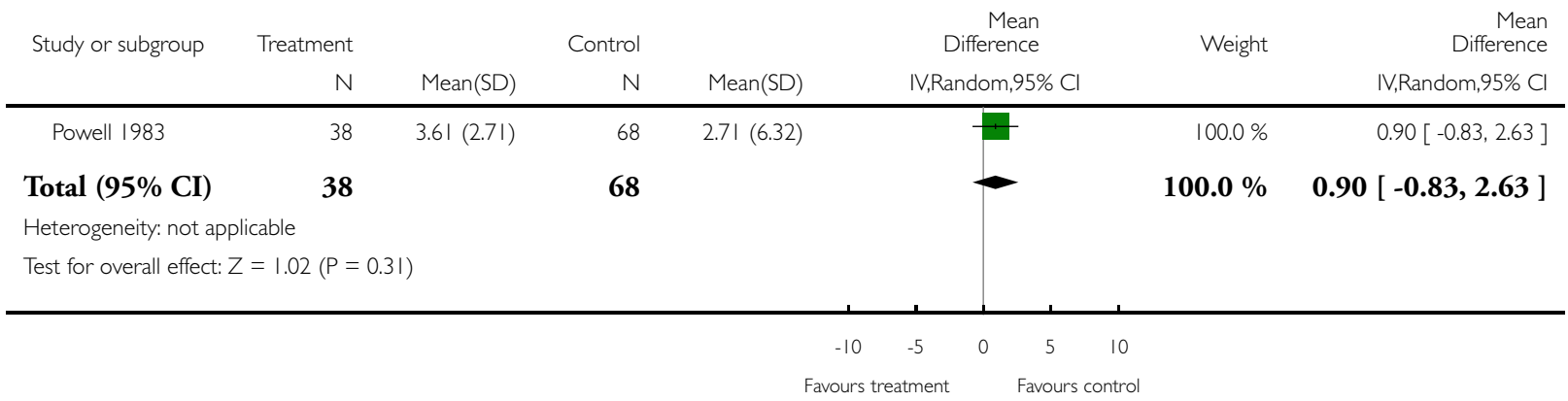

Analysis I I.36. Comparison I I Developing country: School meal vs control. CBA - Sensitivity, Outcome 36 Verbal IQ (total): sensitivity-0.10.

Review: School feeding for improving the physical and psychosocial health of disadvantaged students

Comparison: I I Developing country: School meal vs control. CBA - Sensitivity

Outcome: 36 Verbal IQ (total): sensitivity-0.10

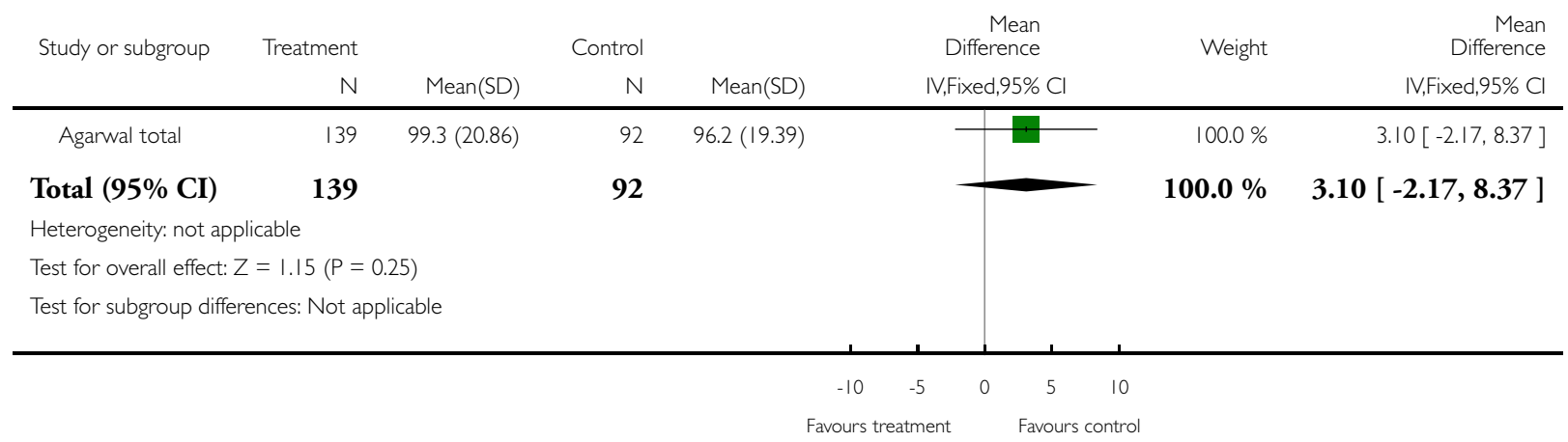




\section{Analysis I I.37. Comparison I I Developing country: School meal vs control. CBA - Sensitivity, Outcome 37 Verbal IQ (total): sensitivity-0.20.}

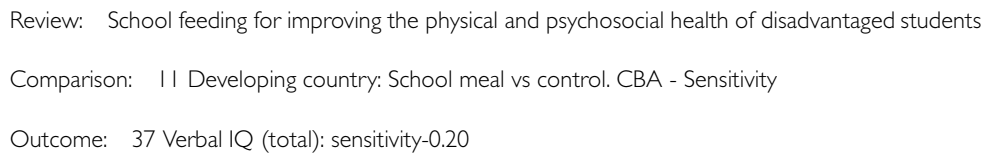

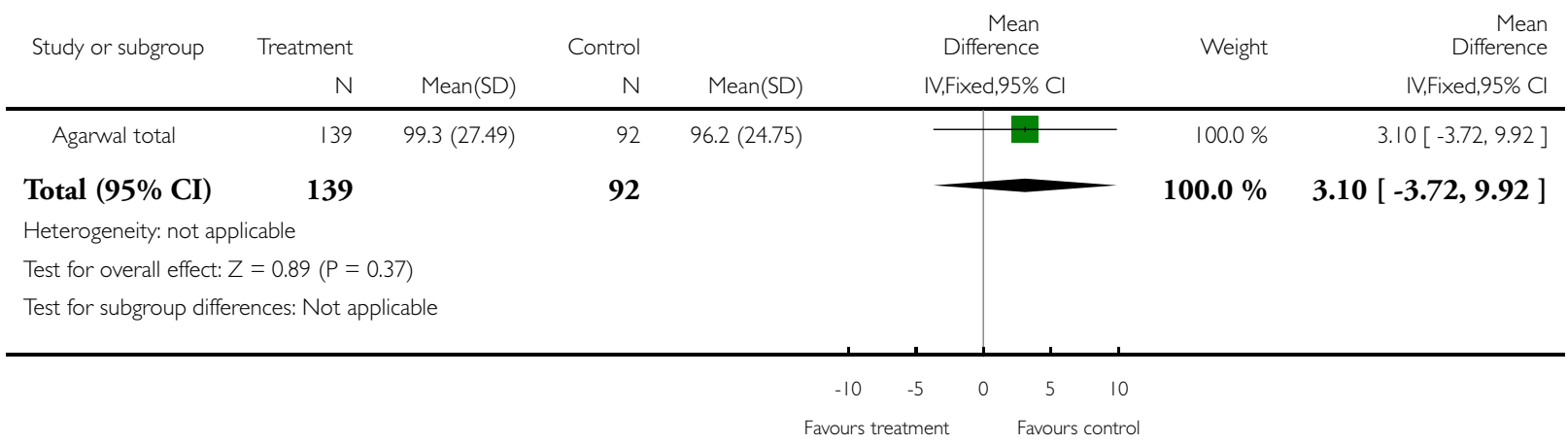

Analysis I I.38. Comparison I I Developing country: School meal vs control. CBA - Sensitivity, Outcome 38 Performance IQ (total): sensitivity-0.10.

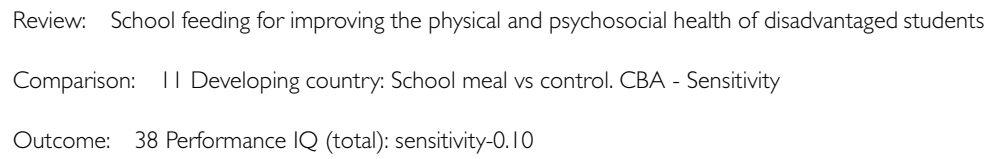

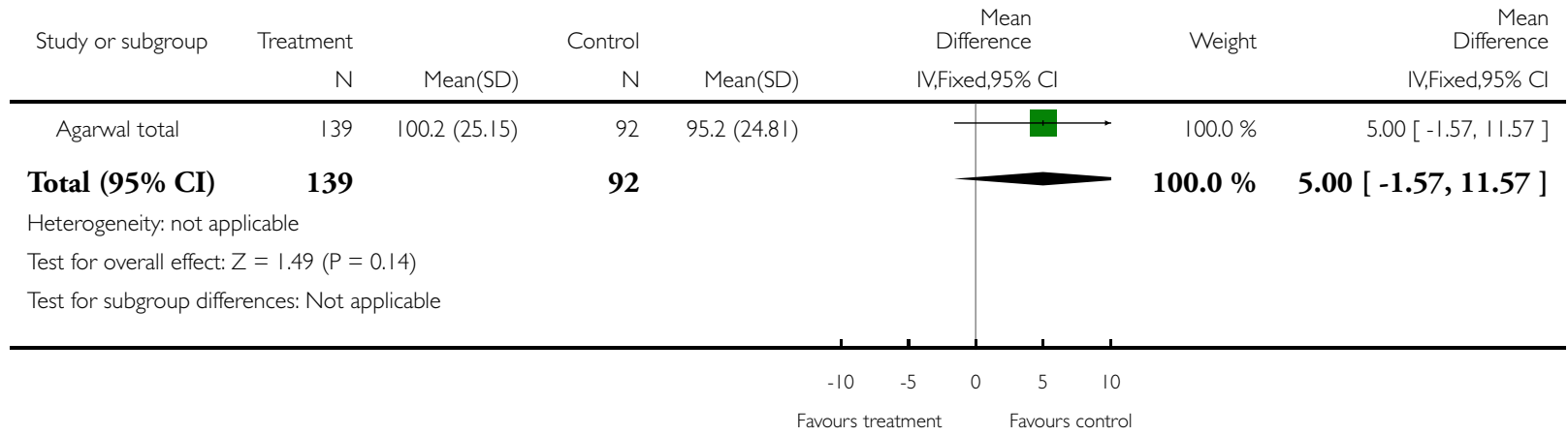


Analysis I I.39. Comparison I I Developing country: School meal vs control. CBA - Sensitivity, Outcome 39 Percentage standard height. Sensitivity $=.0 \mathrm{I}$.

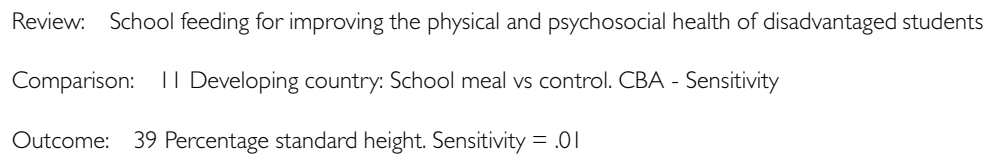

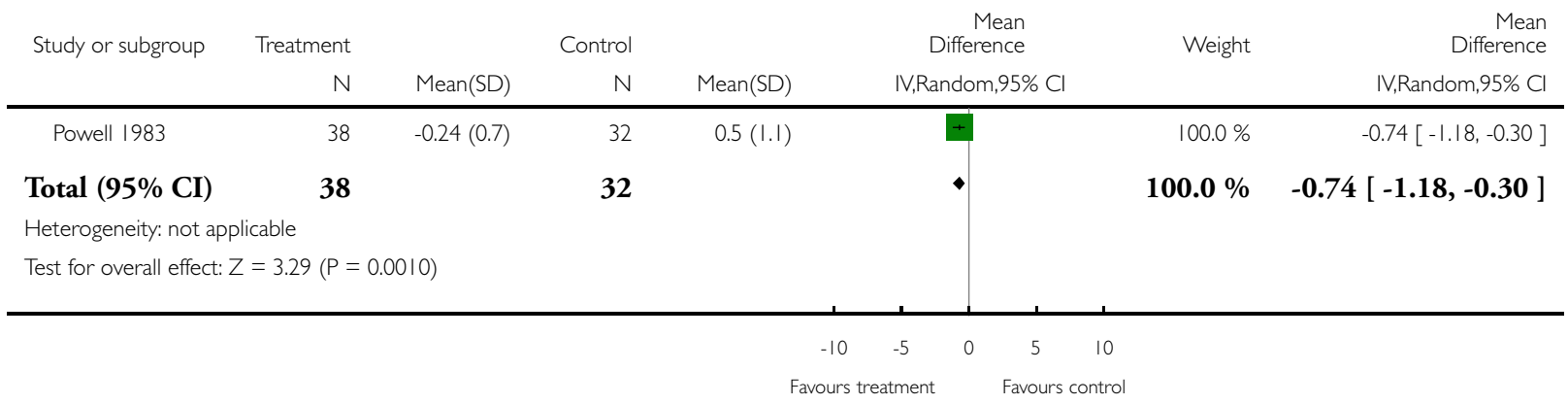

\section{Analysis I I.4I. Comparison I I Developing country: School meal vs control. CBA - Sensitivity, Outcome 4 I} Performance IQ (total): sensitivity-0.20.

Review: School feeding for improving the physical and psychosocial health of disadvantaged students

Comparison: II Developing country: School meal vs control. CBA - Sensitivity

Outcome: 4 I Performance IQ (total): sensitivity-0.20

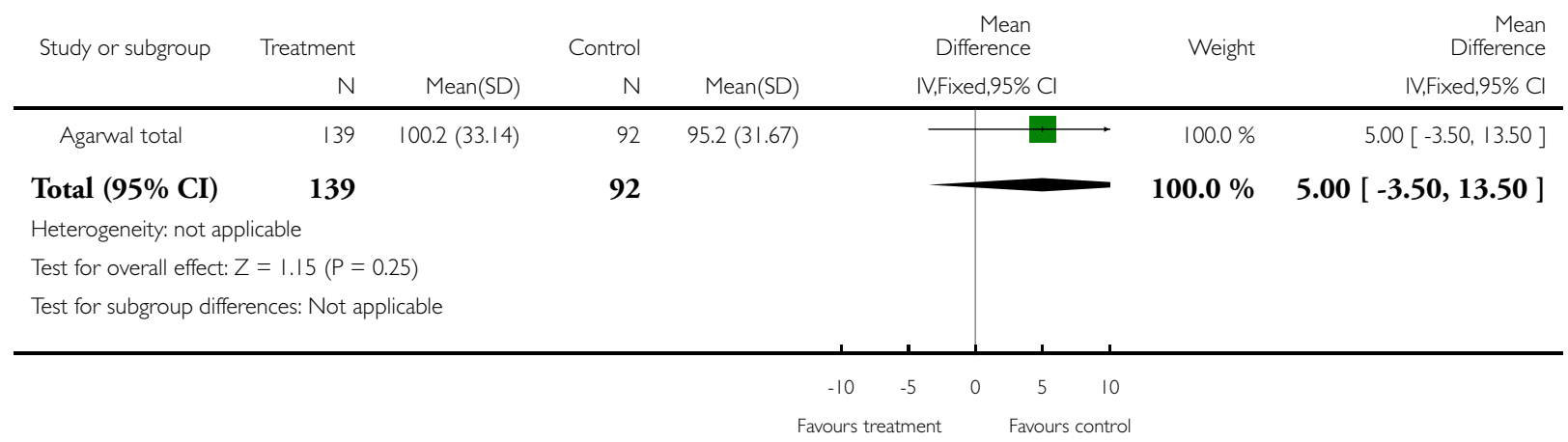


Analysis I I.45. Comparison I I Developing country: School meal vs control. CBA - Sensitivity, Outcome 45 change in reading: sensitivity $I C C=. I$.

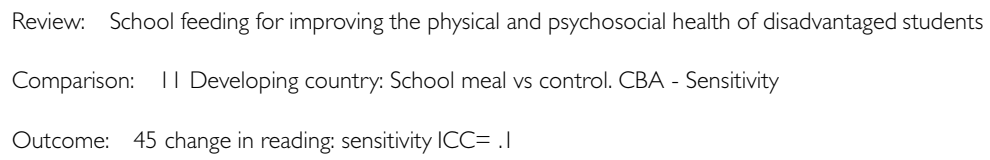

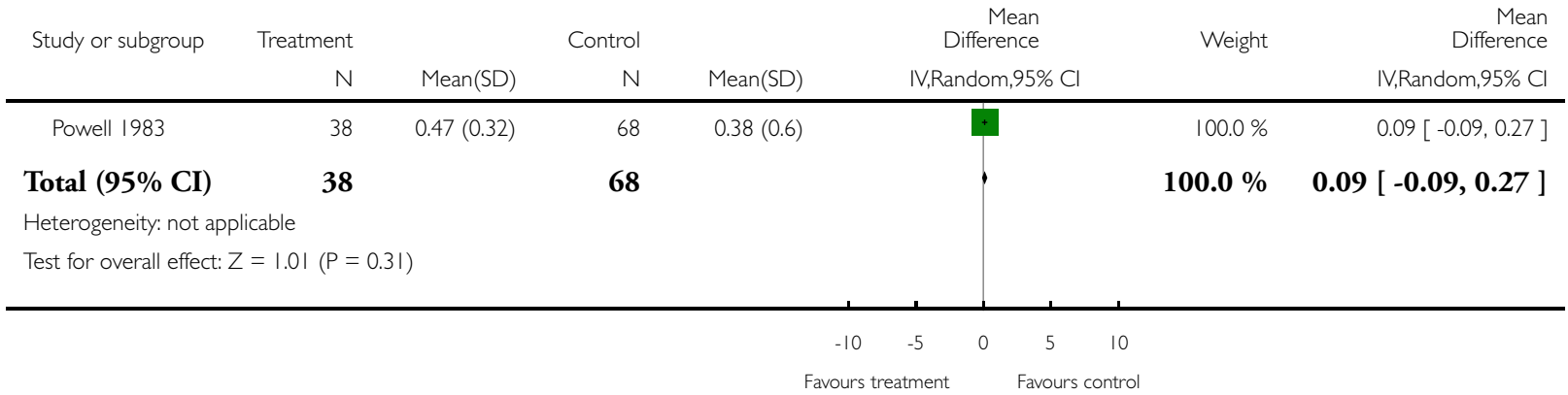

Analysis I I.46. Comparison I I Developing country: School meal vs control. CBA - Sensitivity, Outcome 46 change in reading: sensitivity $I C C=.2$.

Review: School feeding for improving the physical and psychosocial health of disadvantaged students

Comparison: II Developing country: School meal vs control. CBA - Sensitivity

Outcome: 46 change in reading: sensitivity ICC $=.2$

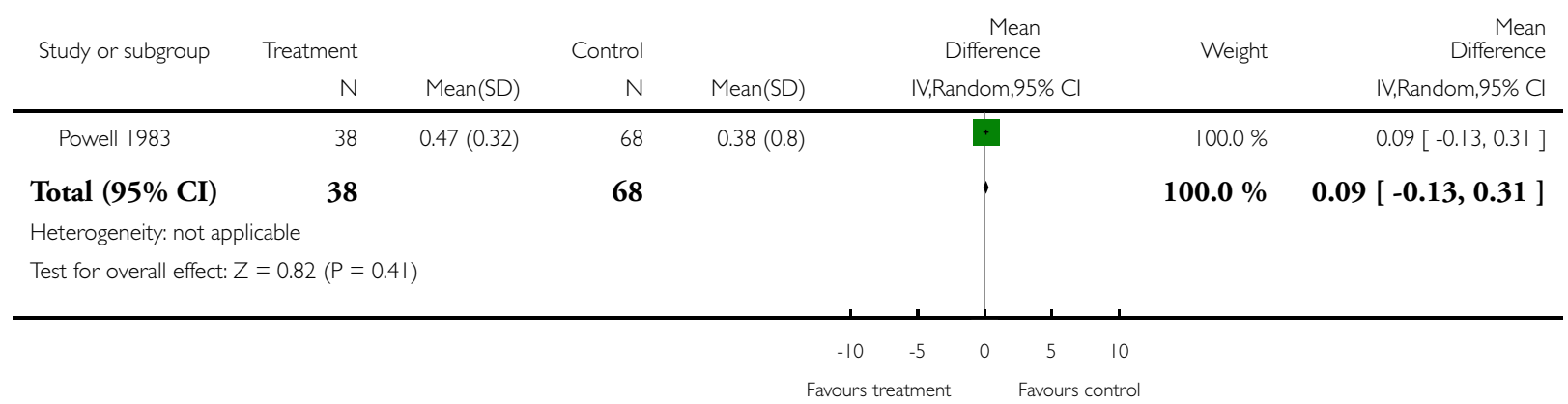


Analysis I I.50. Comparison I I Developing country: School meal vs control. CBA - Sensitivity, Outcome 50 change in spelling: sensitivity ICC $=. \mathrm{I}$.

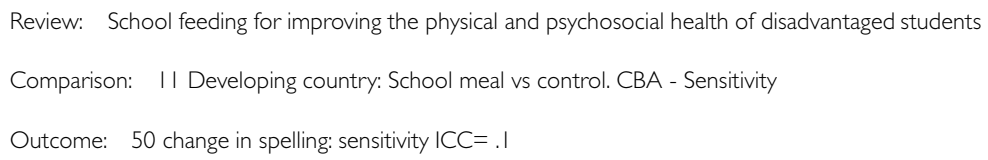

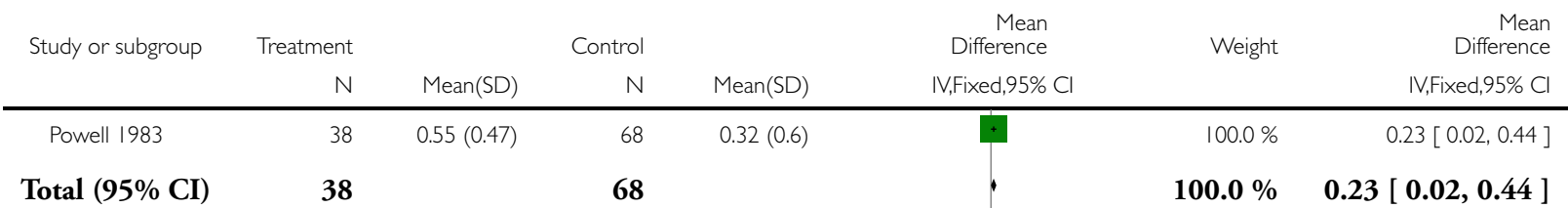

Heterogeneity: not applicable

Analysis I I.52. Comparison I I Developing country: School meal vs control. CBA - Sensitivity, Outcome 52 change in spelling: sensitivity ICC= 0.2 .

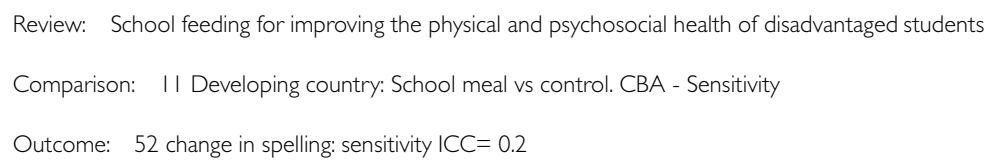

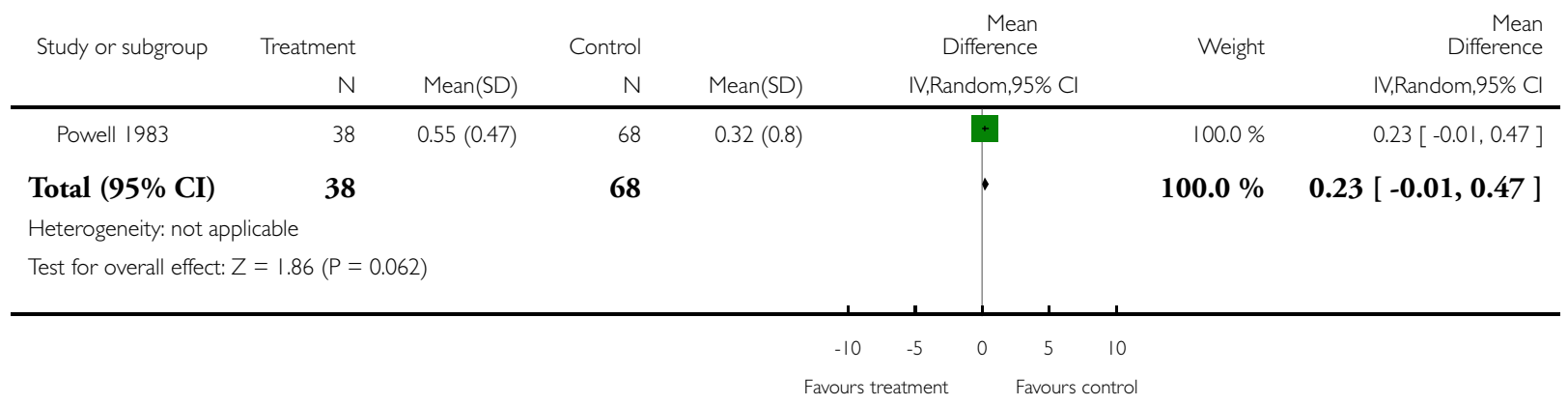


Analysis I I.58. Comparison I I Developing country: School meal vs control. CBA - Sensitivity, Outcome 58 Change in attendance: sensitivity $=.10$.

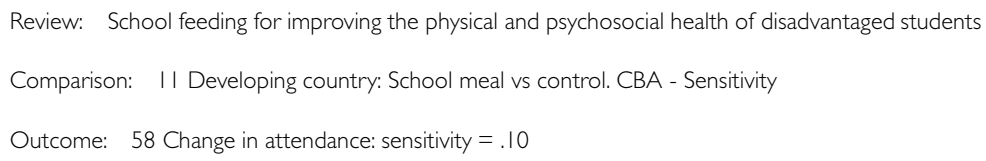

\begin{tabular}{|c|c|c|c|c|c|c|c|}
\hline \multirow[t]{2}{*}{ Study or subgroup } & \multirow{2}{*}{$\begin{array}{r}\text { Treatment } \\
N\end{array}$} & \multicolumn{3}{|c|}{ Control } & \multirow{2}{*}{$\begin{array}{c}\text { Mean } \\
\text { Difference } \\
\text { IV,Fixed,95\% Cl }\end{array}$} & \multirow[t]{2}{*}{ Weight } & \multirow{2}{*}{$\begin{array}{r}\text { Mean } \\
\text { Difference } \\
\text { IV,Fixed,95\% Cl }\end{array}$} \\
\hline & & Mean(SD) & N & Mean(SD) & & & \\
\hline Powell 1983 & 40 & $-2.22(13.93)$ & 68 & $-7.17(26.25)$ & + & $100.0 \%$ & $4.95[-2.64,12.54]$ \\
\hline Total $(95 \% \mathrm{CI})$ & 40 & & 68 & & & $100.0 \%$ & $4.95[-2.64,12.54]$ \\
\hline \multicolumn{8}{|c|}{ Heterogeneity: not applicable } \\
\hline \multicolumn{8}{|c|}{ Test for overall effect: $Z=1.28(P=0.20)$} \\
\hline \multicolumn{8}{|c|}{ Test for subgroup differences: Not applicable } \\
\hline
\end{tabular}

Analysis I I.59. Comparison I I Developing country: School meal vs control. CBA - Sensitivity, Outcome 59 change in attendance: sensitivity $=.20$.

Review: School feeding for improving the physical and psychosocial health of disadvantaged students

Comparison: II Developing country: School meal vs control. CBA - Sensitivity

Outcome: 59 change in attendance: sensitivity $=.20$

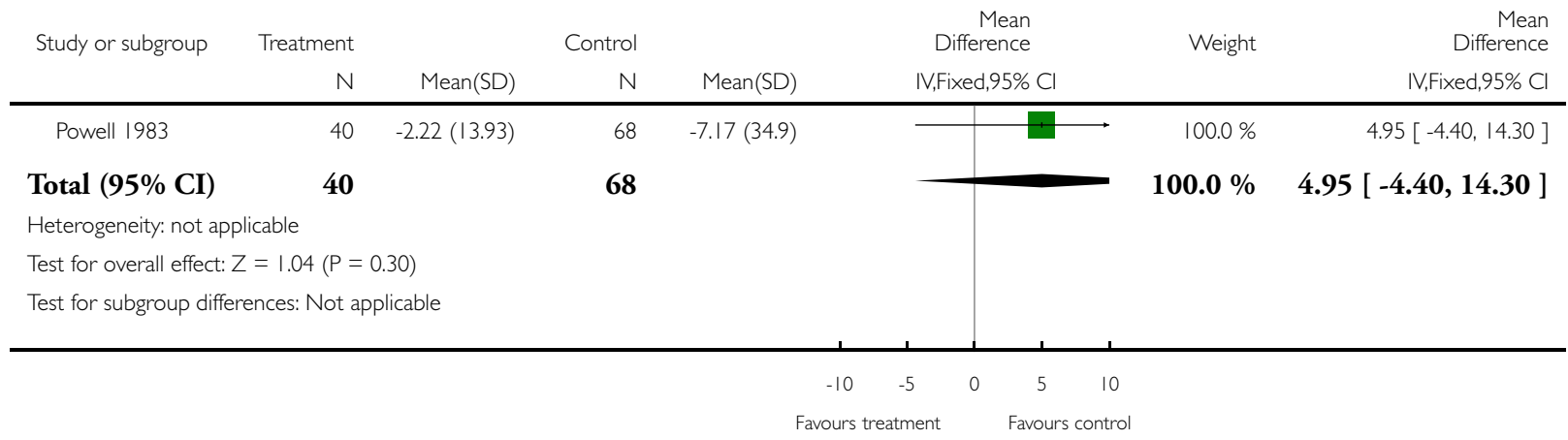


Analysis I I.60. Comparison I I Developing country: School meal vs control. CBA - Sensitivity, Outcome 60 End of study attendance: sensitivity icc $=.10$.

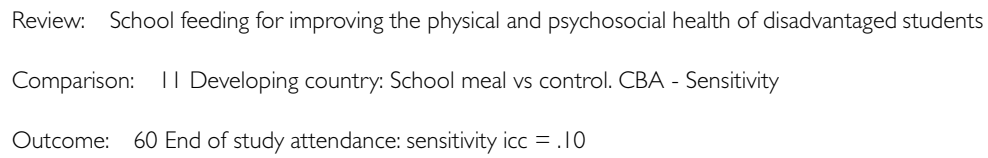

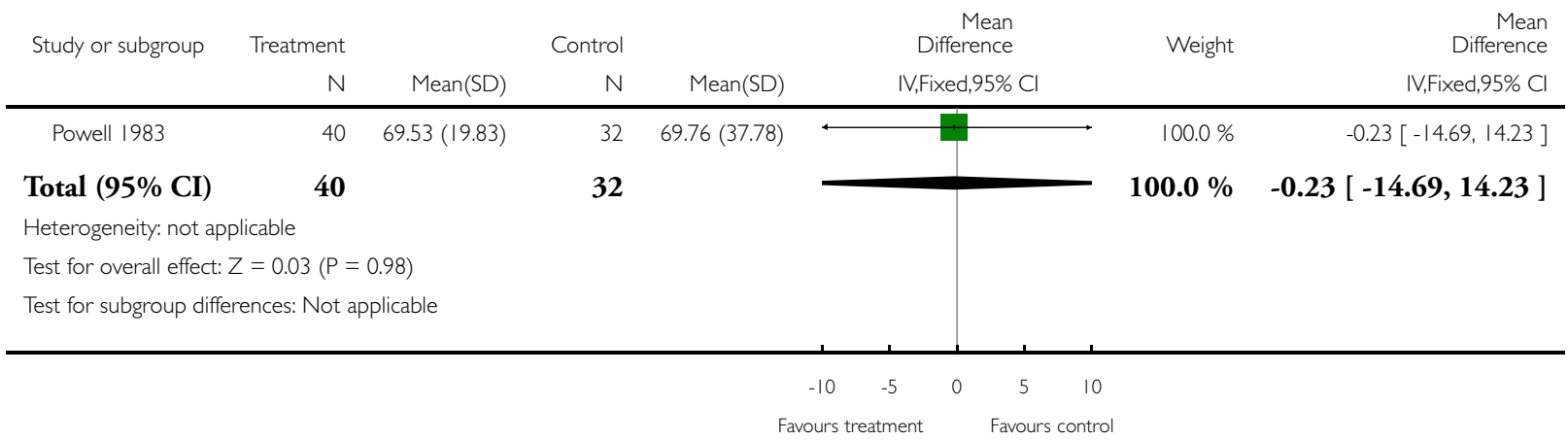

Analysis I I.6I. Comparison I I Developing country: School meal vs control. CBA - Sensitivity, Outcome 6 I End of study attendance: sensitvity icc at .2 .

Review: School feeding for improving the physical and psychosocial health of disadvantaged students

Comparison: II Developing country: School meal vs control. CBA - Sensitivity

Outcome: 61 End of study attendance: sensitvity icc at 2

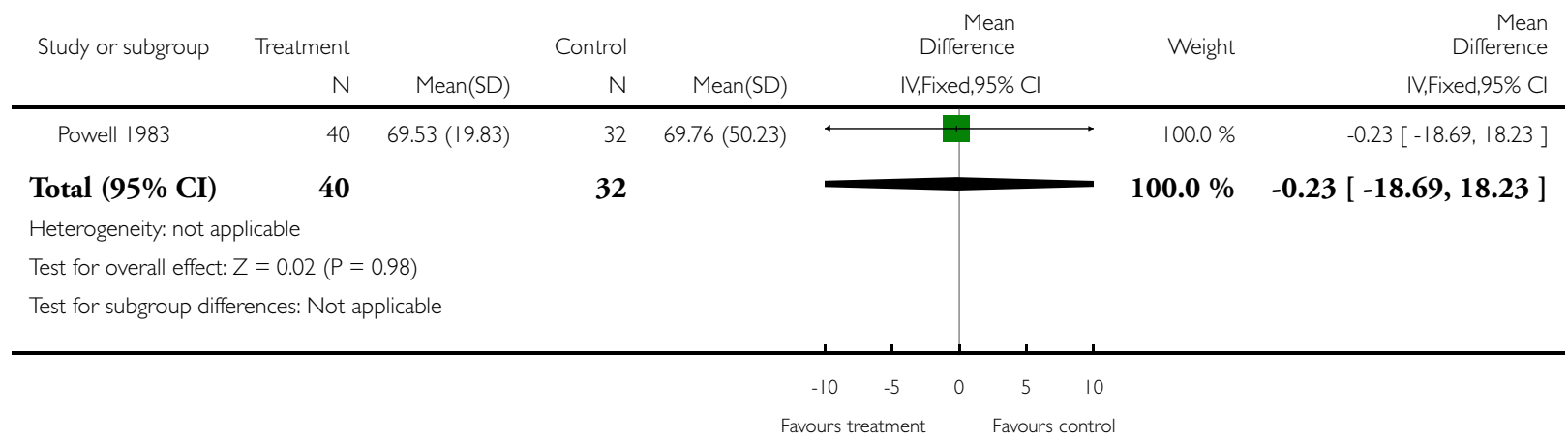




\section{Analysis I I.62. Comparison I I Developing country: School meal vs control. CBA - Sensitivity, Outcome 62 Change in Attendace: Sensitivity $=.05$.}

Review: School feeding for improving the physical and psychosocial health of disadvantaged students

Comparison: II Developing country: School meal vs control. CBA - Sensitivity

Outcome: 62 Change in Attendace: Sensitivity $=.05$

\begin{tabular}{|c|c|c|c|c|c|c|c|}
\hline \multirow[t]{2}{*}{ Study or subgroup } & \multirow{2}{*}{$\begin{array}{r}\text { Treatment } \\
\mathrm{N}\end{array}$} & \multicolumn{3}{|c|}{ Control } & \multirow{2}{*}{$\begin{array}{c}\text { Mean } \\
\text { Difference } \\
\text { IV,Fixed,95\% Cl }\end{array}$} & \multirow[t]{2}{*}{ Weight } & \multirow{2}{*}{$\begin{array}{r}\text { Mean } \\
\text { Difference } \\
\text { IV,Fixed,95\% Cl }\end{array}$} \\
\hline & & Mean(SD) & $\mathrm{N}$ & Mean(SD) & & & \\
\hline Powell 1983 & 38 & $-2.22(13.93)$ & 68 & $-7.17(20.61)$ & + & $100.0 \%$ & $4.95[-1.65,11.55]$ \\
\hline Total (95\% CI) & 38 & & 68 & & & $100.0 \%$ & $4.95[-1.65,11.55]$ \\
\hline \multicolumn{8}{|c|}{ Heterogeneity: not applicable } \\
\hline \multicolumn{8}{|c|}{ Test for overall effect: $Z=1.47(P=0.14)$} \\
\hline Test for subgroup diff & nces: Not ap & licable & & & & & \\
\hline
\end{tabular}

Favours treatment $\quad$ Favours control

Analysis 12.3. Comparison I 2 Developed country: school meal versus control: CBA - Sensitivity, Outcome 3 Weight gain in kg- sensitivity icc=0.0 I. Leighton 1929 used for Orr.

Review: School feeding for improving the physical and psychosocial health of disadvantaged students

Comparison: 12 Developed country: school meal versus control: CBA - Sensitivity

Outcome: 3 Weight gain in $\mathrm{kg}$ - sensitivity icc $=0.01$. Leighton 1929 used for Orr

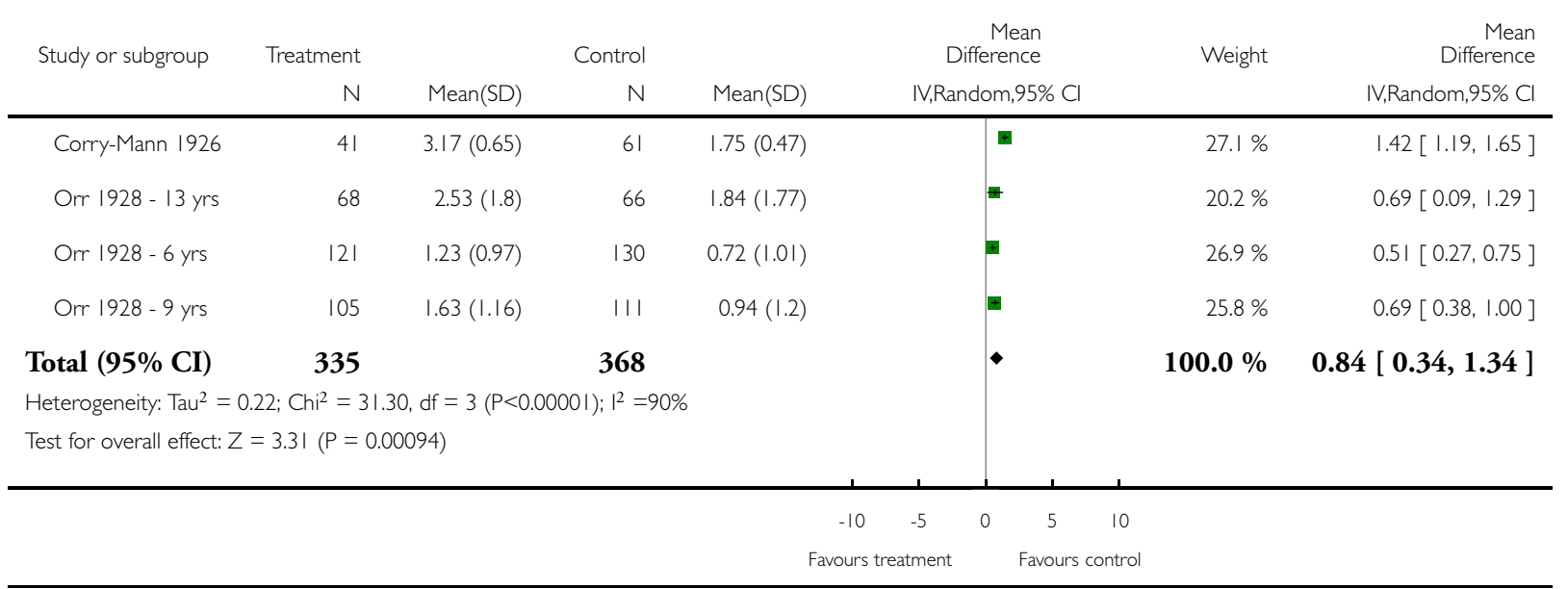

School feeding for improving the physical and psychosocial health of disadvantaged students (Review)

Copyright (c) 2009 The Cochrane Collaboration. Published by John Wiley \& Sons, Ltd. 


\section{Analysis 12.4. Comparison I 2 Developed country: school meal versus control: CBA - Sensitivity, Outcome 4}

Weight gain in kg.- sensitivity icc=0.05. Leighton used for Orr.

Review: School feeding for improving the physical and psychosocial health of disadvantaged students

Comparison: 12 Developed country: school meal versus control: CBA - Sensitivity

Outcome: 4 Weight gain in $\mathrm{kg}$.- sensitivity icc=0.05. Leighton used for Orr

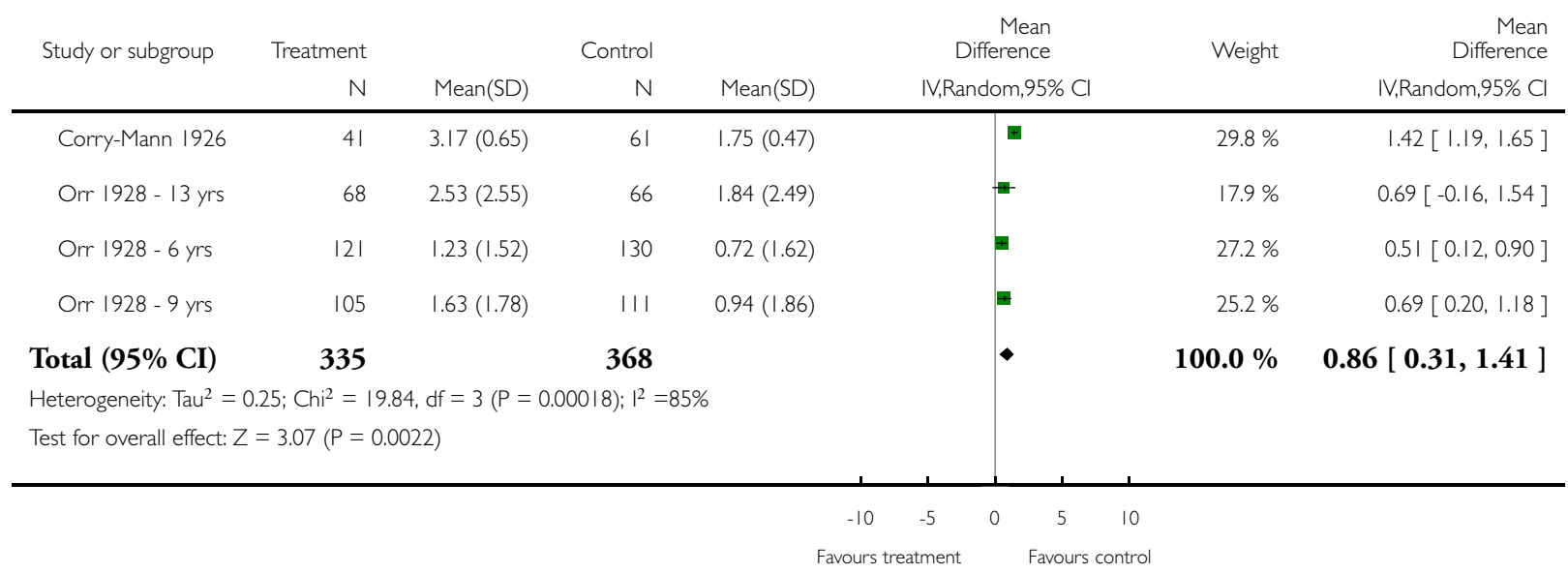


Analysis 12.5. Comparison I Developed country: school meal versus control: CBA - Sensitivity, Outcome 5 Weight gain in $\mathbf{k g}$. - sensitivity ICC=0.I. Leighton used for Orr.

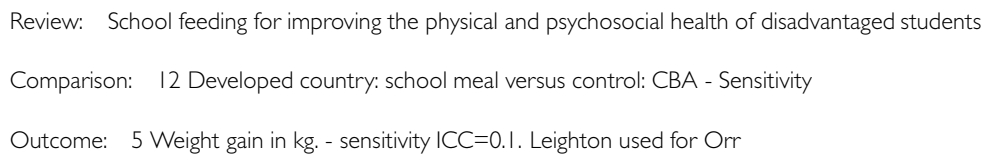

\begin{tabular}{|c|c|c|c|c|c|c|c|c|c|}
\hline \multirow[t]{2}{*}{ Study or subgroup } & \multirow{2}{*}{$\begin{array}{r}\text { Treatment } \\
\mathrm{N}\end{array}$} & \multicolumn{3}{|c|}{ Control } & \multicolumn{3}{|c|}{$\begin{array}{r}\text { Mean } \\
\text { Difference }\end{array}$} & \multirow[t]{2}{*}{ Weight } & \multirow{2}{*}{$\begin{array}{r}\text { Mean } \\
\text { Difference } \\
\text { IV,Random,95\% Cl }\end{array}$} \\
\hline & & Mean(SD) & $N$ & Mean(SD) & & \multicolumn{2}{|c|}{ IV,Random,95\% Cl } & & \\
\hline Corry-Mann 1926 & 41 & $3.17(0.65)$ & 61 & $1.75(0.47)$ & & & + & $32.6 \%$ & $1.42[1.19,1.65]$ \\
\hline Orr $1928-13$ yrs & 68 & $2.53(3.25)$ & 66 & $1.84(3.16)$ & & & $\Psi$ & $15.3 \%$ & $0.69[-0.40,1.78]$ \\
\hline Orr $1928-6$ yrs & 121 & $1.23(2.01)$ & 130 & $0.72(2.01)$ & & & $\$$ & $27.2 \%$ & $0.51[0.01,1.01]$ \\
\hline Orr $1928-9$ yrs & 105 & $1.63(2.33)$ & 111 & $0.94(2.15)$ & & & 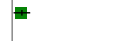 & $24.9 \%$ & $0.69[0.09,1.29]$ \\
\hline Total (95\% CI) & 335 & & 368 & & & & $\bullet$ & $100.0 \%$ & $0.88[0.31,1.45]$ \\
\hline \multicolumn{10}{|c|}{ Heterogeneity: $\operatorname{Tau}^{2}=0.24 ; \mathrm{Chi}^{2}=14.45, \mathrm{df}=3(\mathrm{P}=0.002) ; \mathrm{I}^{2}=79 \%$} \\
\hline \multicolumn{10}{|c|}{ Test for overall effect: $Z=3.03(P=0.0025)$} \\
\hline & & & & & -10 & -5 & 5 & 10 & \\
\hline \multicolumn{10}{|c|}{ Favours treatment $\quad$ Favours control } \\
\hline
\end{tabular}


Analysis 12.7. Comparison I 2 Developed country: school meal versus control: CBA - Sensitivity, Outcome 7 Height gain in $\mathrm{cm}$. adjusted ICC $=0.016$.

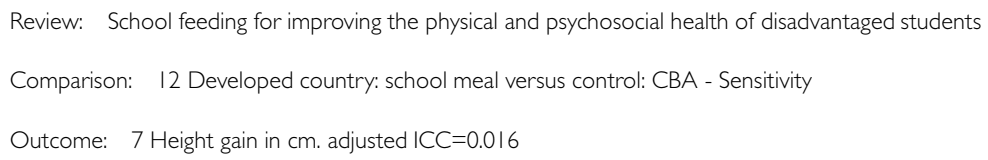

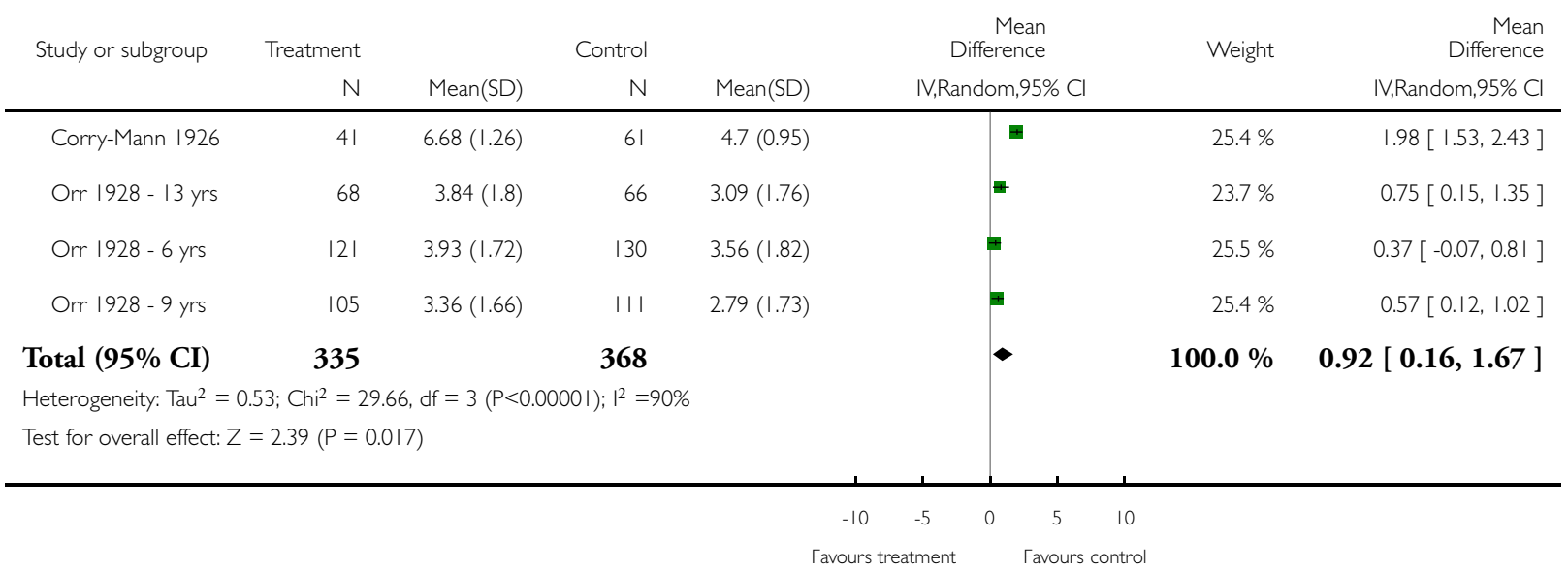


Analysis 12.8. Comparison I Developed country: school meal versus control: CBA - Sensitivity, Outcome 8 Height gain in $\mathrm{cm}$. sensitivity $\mathrm{ICC}=0.01$.

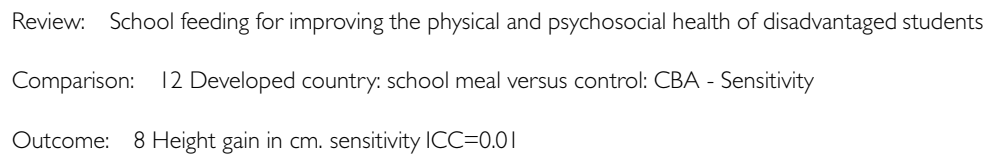

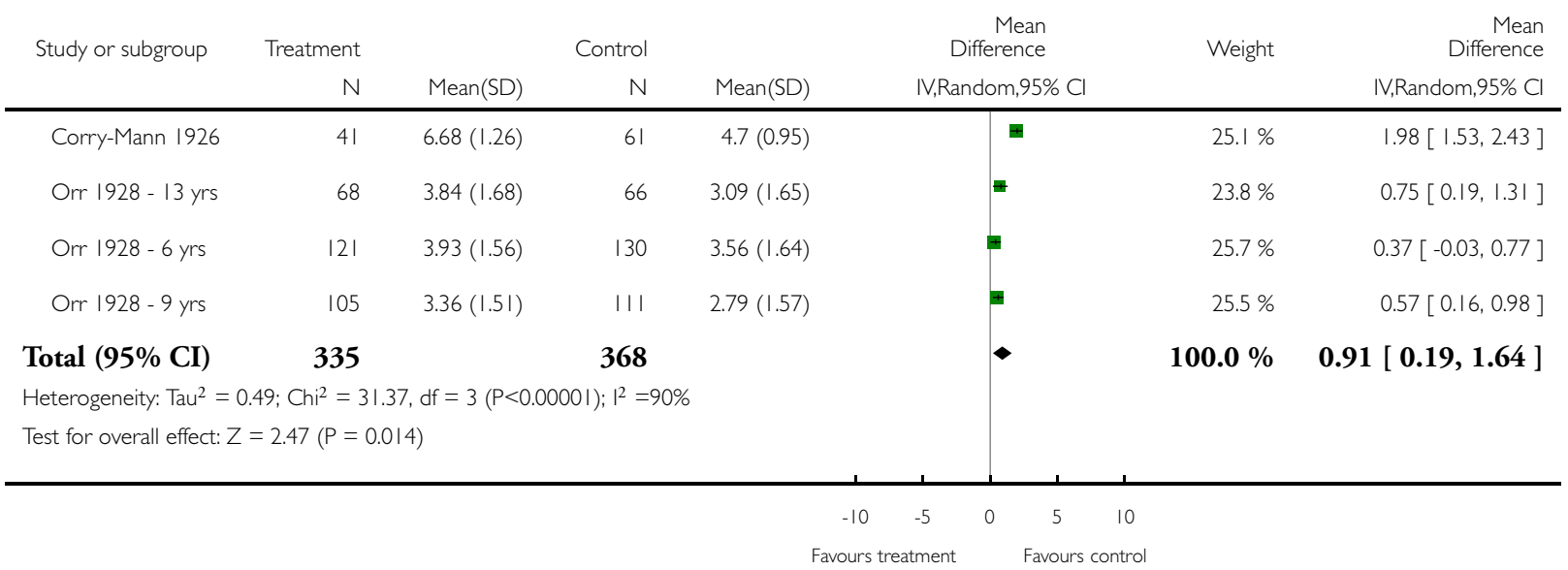


Analysis 12.9. Comparison I 2 Developed country: school meal versus control: CBA - Sensitivity, Outcome 9 Height gain in $\mathrm{cm}$. sensitivity ICC $=0.05$.

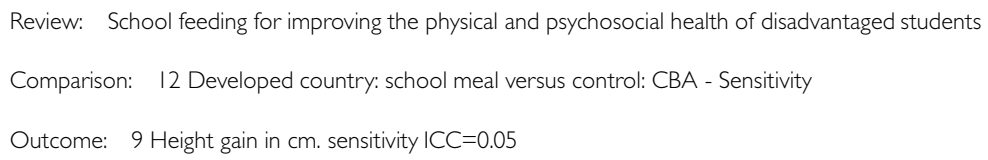

\begin{tabular}{|c|c|c|c|c|c|c|c|c|c|}
\hline \multirow[t]{2}{*}{ Study or subgroup } & \multirow{2}{*}{$\begin{array}{r}\text { Treatment } \\
\mathrm{N}\end{array}$} & \multicolumn{3}{|c|}{ Control } & \multirow{2}{*}{\multicolumn{3}{|c|}{$\begin{array}{c}\text { Mean } \\
\text { Difference } \\
\text { IV,Random,95\% Cl }\end{array}$}} & \multirow[t]{2}{*}{ Weight } & \multirow{2}{*}{$\begin{array}{r}\text { Mean } \\
\text { Difference } \\
\text { IV,Random,95\% Cl }\end{array}$} \\
\hline & & Mean(SD) & $N$ & Mean(SD) & & & & & \\
\hline Corry-Mann 1926 & 41 & $6.68(1.26)$ & 61 & $4.7(0.95)$ & & & $\mathbf{+}$ & $26.8 \%$ & $1.98[1.53,2.43]$ \\
\hline Orr $1928-13$ yrs & 68 & $3.84(2.37)$ & 66 & $3.09(2.31)$ & & & 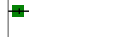 & $23.2 \%$ & $0.75[-0.04,1.54]$ \\
\hline Orr $1928-6$ yrs & 121 & $3.93(2.46)$ & 130 & $3.56(2.62)$ & & & 覀 & $25.0 \%$ & $0.37[-0.26,1.00]$ \\
\hline Orr $1928-9$ yrs & 105 & $3.36(2.32)$ & 111 & $2.79(2.44)$ & & & \# & $25.0 \%$ & $0.57[-0.06,1.20]$ \\
\hline Total $(95 \% \mathrm{CI})$ & 335 & & 368 & & & & 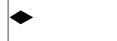 & $100.0 \%$ & $0.94[0.09,1.79]$ \\
\hline \multirow{2}{*}{\multicolumn{10}{|c|}{ Heterogeneity: $\mathrm{Tau}^{2}=0.64 ; \mathrm{Chi}^{2}=22.98, \mathrm{df}=3(\mathrm{P}=0.00004) ; \mathrm{I}^{2}=87 \%$}} \\
\hline \multicolumn{5}{|c|}{ Test for overall effect: $Z=2.17(P=0.030)$} & & & & & \\
\hline & & & & & -10 & -5 & 5 & 10 & \\
\hline
\end{tabular}


Analysis 12.10. Comparison 12 Developed country: school meal versus control: CBA - Sensitivity, Outcome 10 Height gain in $\mathrm{cm}$. sensitivity ICC $=0 . \mathrm{I}$.

Review: School feeding for improving the physical and psychosocial health of disadvantaged students

Comparison: 12 Developed country: school meal versus control: CBA - Sensitivity

Outcome: 10 Height gain in $\mathrm{cm}$. sensitivity ICC $=0.1$

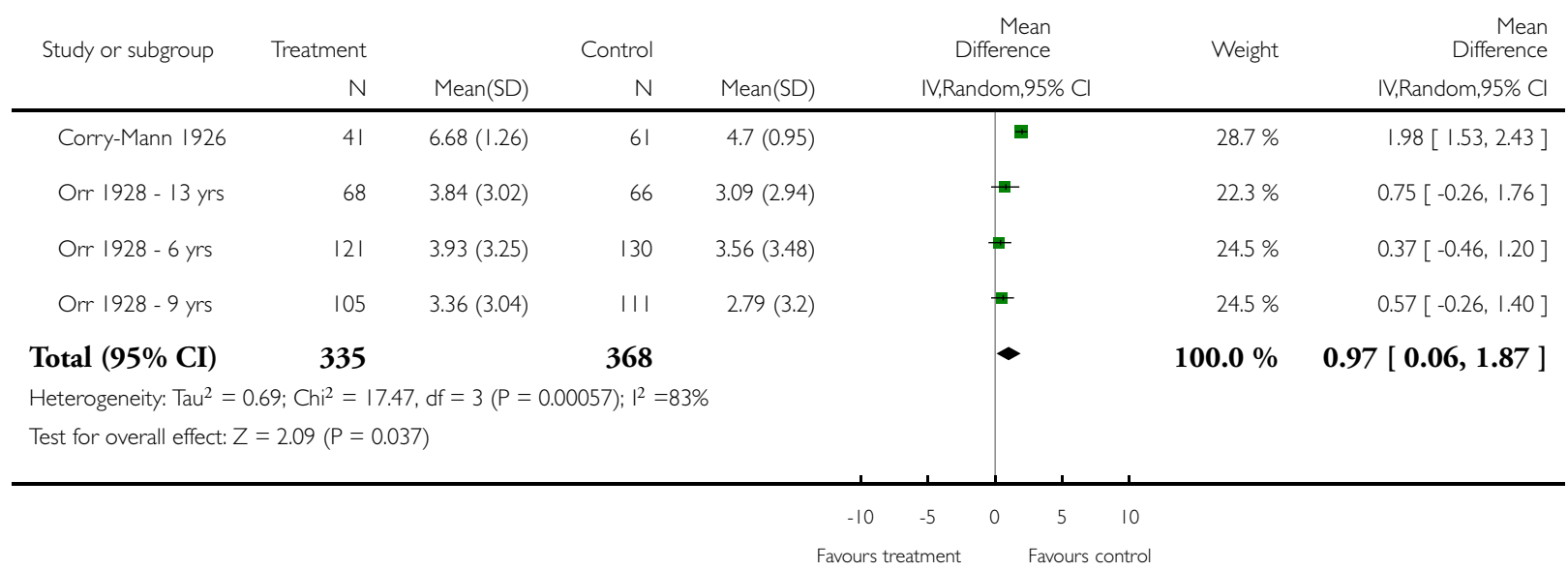


Analysis 12.12. Comparison I2 Developed country: school meal versus control: CBA - Sensitivity, Outcome 12 Height gain in $\mathrm{cm}$. Leighton used for Orr. Sensitivity 0.01 .

Review: School feeding for improving the physical and psychosocial health of disadvantaged students

Comparison: 12 Developed country: school meal versus control: CBA - Sensitivity

Outcome: 12 Height gain in $\mathrm{cm}$. Leighton used for Orr. Sensitivity 0.01

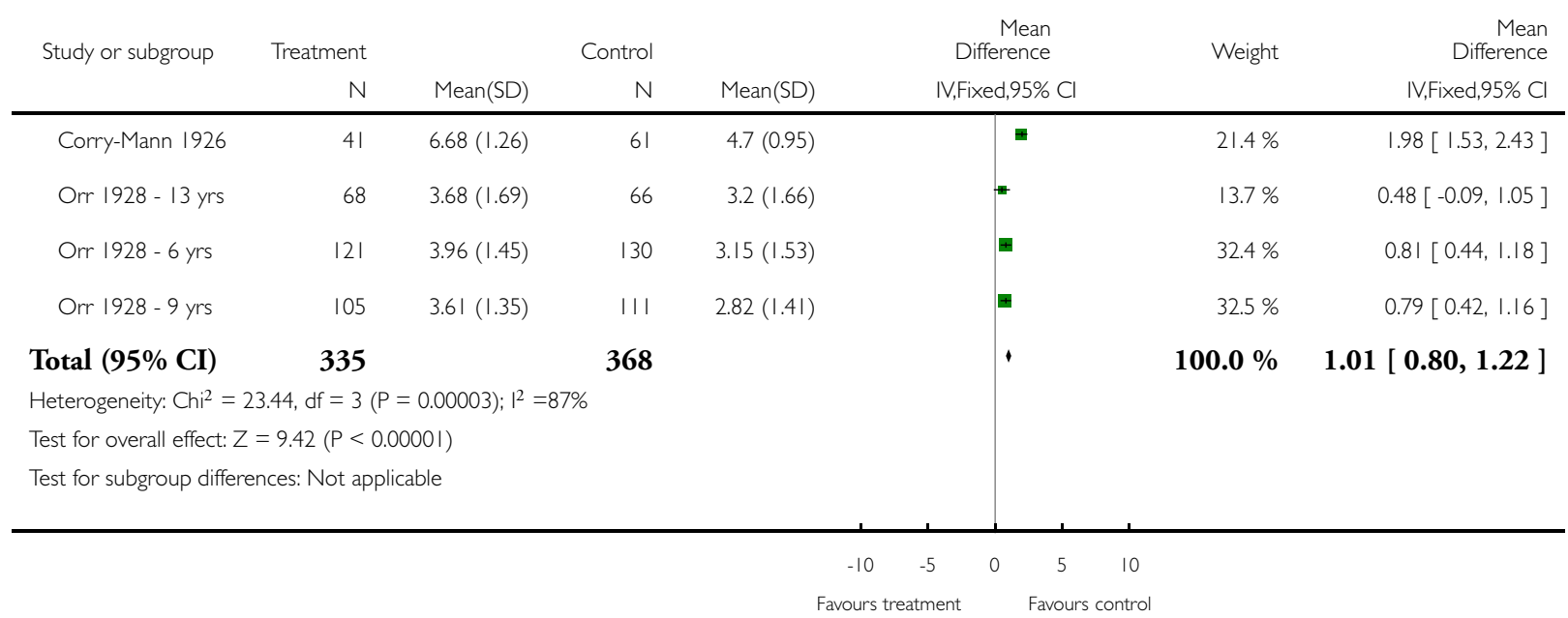


Analysis 12.13. Comparison 12 Developed country: school meal versus control: CBA - Sensitivity, Outcome I 3 Height gain in $\mathrm{cm}$. Sensitivity ICC $=\mathbf{0 . 0 5}$. Leighton used for Orr.

Review: School feeding for improving the physical and psychosocial health of disadvantaged students

Comparison: 12 Developed country: school meal versus control: CBA - Sensitivity

Outcome: 13 Height gain in $\mathrm{cm}$. Sensitivity ICC $=0.05$. Leighton used for Orr

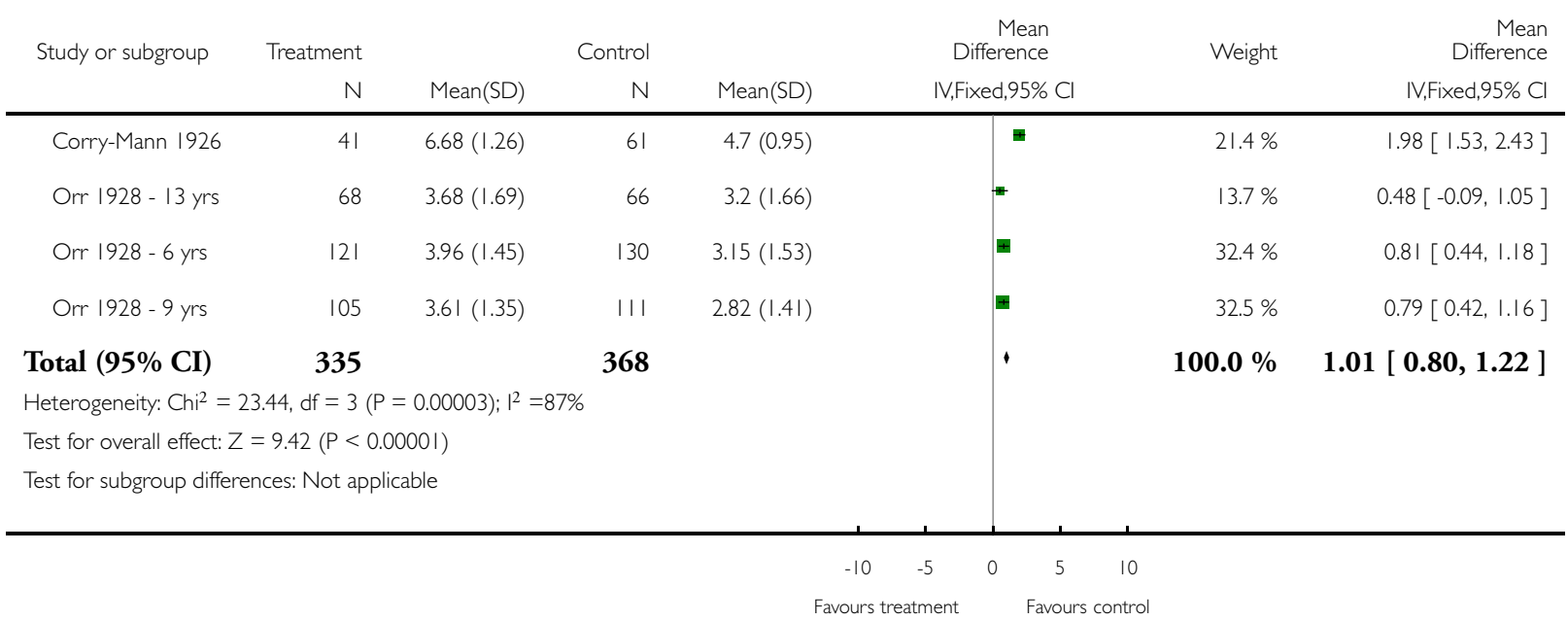




\section{Analysis 12.14. Comparison I2 Developed country: school meal versus control: CBA - Sensitivity, Outcome}

I 4 Height gain in $\mathrm{cm}$. Sensitivity ICC = . I. Leighton used for Orr.

Review: School feeding for improving the physical and psychosocial health of disadvantaged students

Comparison: 12 Developed country: school meal versus control: CBA - Sensitivity

Outcome: 14 Height gain in $\mathrm{cm}$. Sensitivity ICC $=$. I. Leighton used for Orr

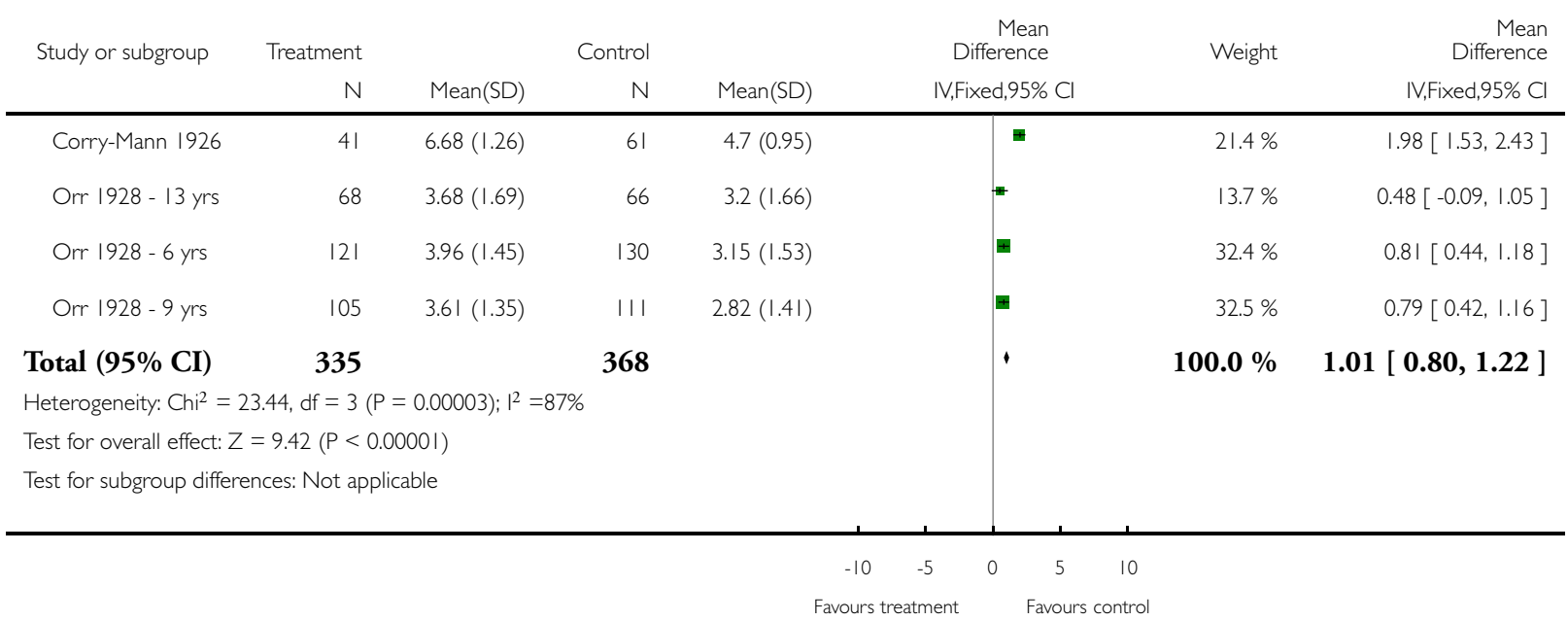

\section{A D D ITIO NAL TABLES}

Table 1. Table 6: LLMIC: Effect size and significance by various study attributes

\begin{tabular}{|c|c|c|c|c|c|c|c|c|c|}
\hline Study ID & Date & $\begin{array}{l}\text { Type of } \\
\text { study }\end{array}$ & Blinding & Energy & Weight & Height & Attendance & $\begin{array}{l}\text { Intelli- } \\
\text { gence }\end{array}$ & Math \\
\hline $\begin{array}{l}\text { Bailey } \\
1962\end{array}$ & 1962 & $\mathrm{CBA}$ & $\mathrm{U}$ & $9 \%$ Low & $.21 \mathrm{~ns}$ & 0.2 & & & \\
\hline $\begin{array}{l}\text { Devadas } \\
1979\end{array}$ & 1979 & CBA & $\mathrm{U}$ & $\begin{array}{l}\text { 18-21\%: } \\
\text { higher }\end{array}$ & $\begin{array}{l}.95, . . .33, . \\
90, \text { sig }\end{array}$ & $\begin{array}{l}2.62,2.75 \\
2.65\end{array}$ & & & \\
\hline $\begin{array}{l}\text { Powell } \\
1983\end{array}$ & 1983 & CBA & A & $\begin{array}{l}\text { 18-21\%: } \\
\text { higher }\end{array}$ & & & $\begin{array}{l}2.8 \text { days per } \\
\text { semester } \\
\text { diff. }\end{array}$ & & Beta $=.15$ \\
\hline $\begin{array}{l}\text { Agarwal } \\
1989\end{array}$ & 1989 & CBA & $\mathrm{U}$ & $\begin{array}{l}25 \%: \\
\text { higher }\end{array}$ & .7 and $.8 s$ & $-.3, .2$ & & $\begin{array}{l}3.92 \mathrm{FS}, 5 . \\
69 \mathrm{P}, 3.3 \mathrm{~V}\end{array}$ & $\begin{array}{l}3.7 \text { points } \\
\text { per year }\end{array}$ \\
\hline $\begin{array}{l}\text { Chandler } \\
1995\end{array}$ & 1995 & RCT & A & $\begin{array}{l}24 \%: \\
\text { higher }\end{array}$ & & & & & \\
\hline
\end{tabular}


Table 1. Table 6: LLMIC: Effect size and significance by various study attributes (Continued)

\begin{tabular}{|c|c|c|c|c|c|c|c|c|}
\hline $\begin{array}{l}\text { Jacoby } \\
1996\end{array}$ & 1996 & RCT & $\mathrm{U}$ & $\begin{array}{l}\text { 26\%: } \\
\text { higher }\end{array}$ & & & $\begin{array}{l}3.5 \% \text { diff. } 6 \\
\text { days a year }\end{array}$ & \\
\hline $\begin{array}{l}\text { Powell } \\
1998\end{array}$ & 1998 & $\mathrm{rCT}$ & A & $\begin{array}{l}32 \%: \\
\text { higher }\end{array}$ & $.47 \mathrm{a}$, sig & $.17 \mathrm{a} \mathrm{ns}$ & $\begin{array}{l}2.3 \% \text { diff. } 4 \\
\text { days a year }\end{array}$ & $\begin{array}{l}.71 \text { points } \\
\text { per year }\end{array}$ \\
\hline $\begin{array}{l}\text { Neumann } \\
2003\end{array}$ & 2003 & RCT & A & 13\%: lower & .28 (N.S) & -0.37 & & $\begin{array}{l}.17 \text { points } \\
\text { per year }\end{array}$ \\
\hline Du 2004 & 2004 & RCT & A & $10 \%$ : lower & 1.5 & $1.20(\mathrm{~S})$ & & \\
\hline
\end{tabular}

Table 2. Table 7: HIC: Effect size and significance by various study attributes

\begin{tabular}{|c|c|c|c|c|c|c|c|c|c|}
\hline Study ID & Date & $\begin{array}{l}\text { Type of } \\
\text { study }\end{array}$ & Blinding & Energy & Weight & Height & Attendance & Intelligence & Math \\
\hline $\begin{array}{l}\text { Correy- } \\
\text { Mann } \\
1926\end{array}$ & 1926 & $\mathrm{CBA}$ & $\mathrm{U}$ & $\begin{array}{l}\text { 19\%: } \\
\text { higher }\end{array}$ & $1.42 \mathrm{~kg}$ & $1.98 \mathrm{~cm}$ & & & \\
\hline Orr 1928 & 1928 & $\mathrm{CBA}$ & $\mathrm{U}$ & $\begin{array}{l}\text { 14-18\%: } \\
\text { higher }\end{array}$ & $.05-.54$ & 0.65 & & & \\
\hline $\begin{array}{l}\text { Tisdall } \\
1951\end{array}$ & 1951 & CBA & $\mathrm{U}$ & $\begin{array}{l}36 \%: \\
\text { higher }\end{array}$ & 0.32 & 0.25 & n.s. & & \\
\hline $\begin{array}{l}\text { Lieberman } \\
1976\end{array}$ & 1976 & $\mathrm{CBA}$ & $\mathrm{U}$ & $14 \%$ : lower & & & $\begin{array}{l}5 \text { days a year, } \\
\text { n.s. }\end{array}$ & & \\
\hline Paige 1976 & 1976 & $\mathrm{CBA}$ & $\mathrm{U}$ & $12 \%$ : lower & .09-.96 & $.2-1.0$ & $\begin{array}{l}2.5 \text { days per } \\
\text { year, .n.s }\end{array}$ & & \\
\hline $\begin{array}{l}\text { Baker } \\
1980\end{array}$ & 1980 & RCT & A & 5\%: higher & $.15 \mathrm{~ns}$ & $0.22 \mathrm{~ns}$ & & & \\
\hline Bro 1994 & 1994 & ITS & I & & & & & & \\
\hline Bro 1996 & 1996 & ITS & I & & & & & & \\
\hline $\begin{array}{l}\text { Shemilt } \\
2004\end{array}$ & 2004 & RCT & $\mathrm{U}$ & & & & & & \\
\hline
\end{tabular}


Table 3. Quality of included studies

\begin{tabular}{|c|c|c|c|c|c|}
\hline Study & Shape intervention & Baseline measure & Reliable outcome & Contamination? & Blinded assessment \\
\hline Agarwal & & A for all & $U$ for 4 & A & $\mathrm{U}$ \\
\hline Bailey & & $\mathrm{U}$ & U A for hemoglobin & $\mathrm{U}$ & $\mathrm{U}$ \\
\hline Baker & & A height $U$ weight & $\mathrm{U}$ & I & A \\
\hline Bro 1994 & I & n.a. & A & n.a. & I \\
\hline Bro 1996 & A & n.a. & I & n.a. & I \\
\hline Chandler, 1995 & & n.a. & A & A & A \\
\hline Corry-Mann & & A & $\mathrm{U}$ & $\mathrm{U}$ & $\mathrm{U}$ \\
\hline Devadas, 1979 & & A & $\begin{array}{l}\text { U for weight, height, } \\
\text { A for hemoglobin }\end{array}$ & $\mathrm{U}$ & $\mathrm{U}$ \\
\hline Du 2004 & & A & $\begin{array}{l}\text { U for weight, height, } \\
\text { A for BMD }\end{array}$ & U & A \\
\hline Jacoby 1996 & & A & A & A & $\begin{array}{l}\text { I for attendanceU for } \\
\text { psychological }\end{array}$ \\
\hline Lieberman, 1976 & & $\mathrm{U}$ & U for all & A & $\mathrm{U}$ \\
\hline Neumann 2003 & & A & $\begin{array}{l}\text { A for weight, height, } \\
\text { A for psychological } \\
\text { tests, U for hemat- } \\
\text { ocrit, hemoglobin }\end{array}$ & A & A \\
\hline Orr 1928 & & $\mathrm{U}$ & U & A & $\mathrm{U}$ \\
\hline Paige 1976 & & A weight, $U$ height & A & A & $\mathrm{U}$ \\
\hline Powell 1983 & & $\begin{array}{l}\text { I for spelling, read- } \\
\text { ing, U for math, A } \\
\text { for height for age, } \\
\text { weight for age }\end{array}$ & $\mathrm{U}$ & A & A \\
\hline Powell 1998 & & A for all 6 & A & A & A \\
\hline Shemilt 2006 & & $\mathrm{U}$ for $3, \mathrm{~A}$ for one & A for $3, \mathrm{U}$ for 1 & I & $\mathrm{U}$ \\
\hline Tisdall, 1953 & & $\mathrm{U}$ & $\mathrm{U}$ & $\mathrm{U}$ & $\mathrm{U}$ \\
\hline
\end{tabular}


Table 3. Quality of included studies

Totals

7 A for all, $5 \mathrm{U}$ for $5 \mathrm{~A}$ for all, $7 \mathrm{u}$ for all, 9A $5 \mathrm{U}, 2 \mathrm{I}, 2 \mathrm{na}$

6A, 9U, 2 I, 1mixed

all, 2 mixed $A$ and $U, 5$ mixed, 1 I

1 mixed $A$ and $I$

Table 4. Absolute and relative differences for subgroup analysis by age: RCTs

\begin{tabular}{|c|c|c|c|c|c|c|c|}
\hline A & B & C & D & $\mathbf{E}$ & $\mathbf{F}$ & G & $\mathbf{H}$ \\
\hline Age group & Outcome & $\begin{array}{l}\text { \# children, \# } \\
\text { studies }\end{array}$ & $\begin{array}{l}\text { Control base- } \\
\text { line }\end{array}$ & $\begin{array}{l}\text { Control } \\
\text { change from } \\
\text { baseline }\end{array}$ & $\begin{array}{l}\text { Abso- } \\
\text { lute difference } \\
\text { in change }\end{array}$ & $\begin{array}{l}\% \text { change rela- } \\
\text { tive to baseline }\end{array}$ & $\begin{array}{l}\% \text { change rel- } \\
\text { ative to rate of } \\
\text { change }\end{array}$ \\
\hline $9-10$ years & Weight (kg) & $\begin{array}{l}1226,2 \text { stud- } \\
\text { ies }\end{array}$ & $21.8 \mathrm{~kg}$ & $1.62 \mathrm{~kg}$ & $0.42 \mathrm{~kg}$ & 1.9 & $26 \%$ \\
\hline $\begin{array}{l}\text { Mixed age, 6- } \\
16 \text { years }\end{array}$ & Weight (kg) & $\begin{array}{l}236 \text { children, } \\
1 \text { study }\end{array}$ & $20.4 \mathrm{~kg}$ & $3.47 \mathrm{~kg}$ & $0.28 \mathrm{~kg}$ & $1.4 \%$ & $8.1 \%$ \\
\hline $9-10$ years & Height $(\mathrm{cm})$ & $\begin{array}{l}1226 \text { children, } \\
2 \text { studies }\end{array}$ & $123.6 \mathrm{~cm}$ & $4.29 \mathrm{~cm}$ & $0.40 \mathrm{~cm}$ & $0.33 \%$ & $9.3 \%$ \\
\hline $\begin{array}{l}\text { Mixed 6-16 } \\
\text { years }\end{array}$ & Height $(\mathrm{cm})$ & $\begin{array}{l}236 \text { children, } \\
1 \text { study }\end{array}$ & $115.5 \mathrm{~cm}$ & $10.04 \mathrm{~cm}$ & $-0.37 \mathrm{~cm}$ & $-0.32 \%$ & $-3.7 \%$ \\
\hline
\end{tabular}

Table 5. Absolute and relative differences for age subgroups: CBAs

\begin{tabular}{|c|c|c|c|c|c|c|c|}
\hline A & B & C & D & $\mathbf{E}$ & $\mathbf{F}$ & G & $\mathbf{H}$ \\
\hline Age group & Outcome & $\begin{array}{l}\text { \# children, \# } \\
\text { studies }\end{array}$ & $\begin{array}{l}\text { Control base- } \\
\text { line }\end{array}$ & $\begin{array}{l}\text { Control } \\
\text { change from } \\
\text { baseline }\end{array}$ & $\begin{array}{l}\text { Abso- } \\
\text { lute difference } \\
\text { in change }\end{array}$ & $\begin{array}{l}\% \text { change rela- } \\
\text { tive to control } \\
\text { baseline }\end{array}$ & $\begin{array}{l}\% \text { change rel- } \\
\text { ative to rate of } \\
\text { change }\end{array}$ \\
\hline $5-6$ years & Weight (kg) & $\begin{array}{l}106 \text { children, } \\
1 \text { study }\end{array}$ & $15.11 \mathrm{~kg}$ & $0.97 \mathrm{~kg}$ & $0.95 \mathrm{~kg}$ & $6.4 \%$ & $98 \%$ \\
\hline $6-8$ years & Weight (kg) & $\begin{array}{l}564 \text { children, } \\
2 \text { studies }\end{array}$ & $18.22 \mathrm{~kg}$ & $1.64 \mathrm{~kg}$ & $0.67 \mathrm{~kg}$ & $3.7 \%$ & $40.8 \%$ \\
\hline $9-10$ years & Weight (kg) & $\begin{array}{l}212 \text { children, } \\
1 \text { study }\end{array}$ & $22.72 \mathrm{~kg}$ & $2.0 \mathrm{~kg}$ & $0.89 \mathrm{~kg}$ & $3.9 \%$ & $44.5 \%$ \\
\hline $\begin{array}{l}\text { Mixed ages, } 7- \\
13 \text { years }\end{array}$ & Weight (kg) & $\begin{array}{l}140 \text { children, } \\
1 \text { study }\end{array}$ & $22.9 \mathrm{~kg}$ & $2.28 \mathrm{~kg}$ & $0.21 \mathrm{~kg}$ & $0.9 \%$ & $0.9 \%$ \\
\hline 5-6 years & Height $(\mathrm{cm})$ & $\begin{array}{l}106 \text { children, } \\
1 \text { study }\end{array}$ & $104.69 \mathrm{~cm}$ & $4.06 \mathrm{~cm}$ & $2.62 \mathrm{~cm}$ & $3.9 \%$ & $65 \%$ \\
\hline
\end{tabular}


Table 5. Absolute and relative differences for age subgroups: CBAs

(Continued)

\begin{tabular}{|c|c|c|c|c|c|c|c|}
\hline 6-8 years & Height $(\mathrm{cm})$ & $\begin{array}{l}564 \text { children, } \\
2 \text { studies }\end{array}$ & $116.6 \mathrm{~cm}$ & $3.8 \mathrm{~cm}$ & $1.25 \mathrm{~cm}$ & $1.1 \%$ & $33 \%$ \\
\hline $9-10$ years & Height $(\mathrm{cm})$ & $\begin{array}{l}212 \text { children, } \\
1 \text { study }\end{array}$ & $124.1 \mathrm{~cm}$ & $5.3 \mathrm{~cm}$ & $-0.21 \mathrm{~cm}$ & $-0.2 \%$ & $-4.0 \%$ \\
\hline $\begin{array}{l}\text { Mixed ages, } 7- \\
13 \text { years }\end{array}$ & Height $(\mathrm{cm})$ & $\begin{array}{l}140 \text { children, } \\
1 \text { study }\end{array}$ & $123.6 \mathrm{~cm}$ & $5.24 \mathrm{~cm}$ & $0.2 \mathrm{~cm}$ & $0.2 \%$ & $3.8 \%$ \\
\hline
\end{tabular}

Table 6. Absolute and relative differences for randomized controlled trials

\begin{tabular}{|c|c|c|c|c|c|c|}
\hline A & B & $\mathrm{C}$ & D & $\mathbf{E}$ & $\mathbf{F}$ & G \\
\hline Outcome & $\begin{array}{l}\text { \# children, \# } \\
\text { studies }\end{array}$ & $\begin{array}{l}\text { Baseline (control } \\
\text { group) }\end{array}$ & $\begin{array}{l}\text { Absolute change } \\
\text { from baseline }\end{array}$ & $\begin{array}{l}\text { Weighted abso- } \\
\text { lute difference in } \\
\text { change }\end{array}$ & $\begin{array}{l}\% \text { change relative } \\
\text { to baseline }\end{array}$ & $\begin{array}{l}\% \text { change relative } \\
\text { to rate of change }\end{array}$ \\
\hline Weight (kg) & $\begin{array}{l}1462 \text { children, } \\
3 \text { studies }\end{array}$ & $29.4 \mathrm{~kg}$ & $2.88 \mathrm{~kg}$ & $0.39 \mathrm{~kg}$ & $1.3 \%$ & $13.5 \%$ \\
\hline Height (cm) & $\begin{array}{l}1462 \text { children, } \\
3 \text { studies }\end{array}$ & $134.5 \mathrm{~cm}$ & $6.34 \mathrm{~cm}$ & $0.38 \mathrm{~cm}$ & $0.3 \%$ & $6 \%$ \\
\hline
\end{tabular}

Table 7. Absolute and relative differences for controlled before after studies

\begin{tabular}{|c|c|c|c|c|c|c|c|}
\hline A & B & $\mathrm{C}$ & D & $\mathbf{E}$ & $\mathbf{F}$ & & G \\
\hline Outcome & $\begin{array}{l}\text { \# children, } \\
\text { \# studies }\end{array}$ & $\begin{array}{l}\text { Baseline (control } \\
\text { group) }\end{array}$ & $\begin{array}{l}\text { Change from } \\
\text { baseline (control } \\
\text { group) }\end{array}$ & $\begin{array}{l}\text { Absolute differ- } \\
\text { ence in change }\end{array}$ & $\begin{array}{l}\text { Relative } \\
\text { change }\end{array}$ & $\%$ & $\begin{array}{l}\% \text { change relative } \\
\text { to rate of change }\end{array}$ \\
\hline Weight (kg) & $\begin{array}{l}991 \text { children, } \\
3 \text { studies }\end{array}$ & $18.22 \mathrm{~kg}$ & $1.62 \mathrm{~kg}$ & $0.71 \mathrm{~kg}$ & $3.9 \%$ & & $44 \%$ \\
\hline Height $(\mathrm{cm})$ & $\begin{array}{l}988 \text { children, } \\
3 \text { studies }\end{array}$ & $116.6 \mathrm{~cm}$ & $4.33 \mathrm{~cm}$ & $1.45 \mathrm{~cm}$ & $1.2 \%$ & & $33 \%$ \\
\hline
\end{tabular}




\section{WHAT'S NEW}

Last assessed as up-to-date: 30 April 2006.

\begin{tabular}{l|l|l}
\hline Date & Event & Description \\
\hline 22 September 2008 & Amended & Converted to new review format. \\
\hline
\end{tabular}

\section{H I S T O R Y}

Protocol first published: Issue 1, 2004

Review first published: Issue 1, 2007

\begin{tabular}{lll}
\hline Date & Event & Description \\
\hline 14 November 2007 & New search has been performed & Minor update: 14/11/07 \\
\hline 14 November 2006 & New citation required and conclusions have changed & Substantive amendment \\
\hline
\end{tabular}

\section{CONTRIBUTIONSOFAUTHORS}

BK had the idea for the review, obtained funding for developing the protocol, wrote the protocol,identified articles to retrieve, looked over all of the articles, decided on inclusion/exclusion of studies, extracted data, performed analyses, rated quality, and wrote the review.

VR helped with writing the protocol, identified articles to retrieve, looked over all of the articles, decided on inclusion/exclusion of studies, performed analyses, extracted data, and edited the review/.

MP provided guidance on many aspects of the review, and edited the review at all stages.

BM helped to decide on inclusion/exclusion of studies, helped to calculate RDA for energy, read each study for clinical impact, gave advice on clinical relevance, and helped to write the review

JK calculated RDA for energy, extracted data for nutritional tables on each study, read each study for clinical impact, gave advice on clinical relevance, and helped to write the review.

TG provided input on classification and inclusion/exclusion of studies, wrote a thorough realist review, and edited the review. Parts of the realist review were incorporated into the dicsussion. It will also be published as a complementary article.

LJ read all included papers with psycho-social outcomes, rated baseline measurement and reliability of outcome measures, identified clinical significance of these outcomes, and wrote sections ot the discussion.

GW was the study statistician and provided statistical advice at all stages of the review.

JM developed the search strategy and performed literature searches.

AF rated baseline measurement and reliability of outcome measures for growhth outcomes.

BS rated quality of included studies.

AM provided advice on certain study designs, inclusion/exclusion of studies, helped with quality ratings, and edited the review.

PT provided advice and guidance, rated the reliability of biochemical outcome measurements and biochemical measurements at baseline, and edited the review.

School feeding for improving the physical and psychosocial health of disadvantaged students (Review)

Copyright @ 2009 The Cochrane Collaboration. Published by John Wiley \& Sons, Ltd. 


\section{DECLARATIONSOF INTEREST}

None known.

\section{SOURCES OF SUPPORT}

\section{Internal sources}

- No sources of support supplied

\section{External sources}

- Cochrane Health Promotion and Public Health Field, Australia.

\section{NOTES}

This review is co-registered within the Campbell Collaboration.

\section{INDEX TERMS}

\section{Medical Subject Headings (MeSH)}

*Child Behavior; *Food Services [standards]; *Growth; *Schools; *Vulnerable Populations; Absenteeism; Body Weight; Child Nutrition Disorders [diet therapy]; Dietary Services [standards]; Educational Status; Energy Intake; Intelligence

\section{MeSH check words}

Child; Humans 